\title{
Product innovations and barriers to entry
}

Citation for published version (APA):

Bunte, F. H. J. (1997). Product innovations and barriers to entry. [Doctoral Thesis, Maastricht University]. Universiteit Maastricht. https://doi.org/10.26481/dis.19970131fb

Document status and date:

Published: 01/01/1997

DOI:

10.26481/dis.19970131fb

Document Version:

Publisher's PDF, also known as Version of record

\section{Please check the document version of this publication:}

- A submitted manuscript is the version of the article upon submission and before peer-review. There can be important differences between the submitted version and the official published version of record.

People interested in the research are advised to contact the author for the final version of the publication, or visit the DOI to the publisher's website.

- The final author version and the galley proof are versions of the publication after peer review.

- The final published version features the final layout of the paper including the volume, issue and page numbers.

Link to publication

\footnotetext{
General rights rights.

- You may freely distribute the URL identifying the publication in the public portal. please follow below link for the End User Agreement:

www.umlib.nl/taverne-license

Take down policy

If you believe that this document breaches copyright please contact us at:

repository@maastrichtuniversity.nl

providing details and we will investigate your claim.
}

Copyright and moral rights for the publications made accessible in the public portal are retained by the authors and/or other copyright owners and it is a condition of accessing publications that users recognise and abide by the legal requirements associated with these

- Users may download and print one copy of any publication from the public portal for the purpose of private study or research.

- You may not further distribute the material or use it for any profit-making activity or commercial gain

If the publication is distributed under the terms of Article $25 \mathrm{fa}$ of the Dutch Copyright Act, indicated by the "Taverne" license above, 
PRODUCT INNOVATIONS

AND

BARRIERS TO ENTRY 


\title{
PRODUCT INNOVATIONS
}

\author{
AND \\ BARRIERS TO ENTRY
}

PROEFSCHRIFT

ter verkrijging van de graad van doctor aan

de Universiteit Maastricht,

op gezag van de Rector Magnificus, Prof. mr M.J. Cohen

volgens het besluit van het College van Decanen,

in het openbaar te verdedigen

op vrijdag 31 januari 1997

om 14.00 uur

door

Franciscus Hermanus Johannes Bunte 


\title{
PRODUCT INNOVATIONS
}

\author{
AND \\ BARRIERS TO ENTRY
}

PROEFSCHRIFT

ter verkrijging van de graad van doctor aan

de Universiteit Maastricht,

op gezag van de Rector Magnificus, Prof. mr M.J. Cohen

volgens het besluit van het College van Decanen,

in het openbaar te verdedigen

op vrijdag 31 januari 1997

om 14.00 uur

door

Franciscus Hermanus Johannes Bunte 


\section{Promotores:}

Prof. dr J.A.H. Maks

Prof. dr A. van Witteloostuijn

\section{Co-promotor:}

Dr. T.H.W. Ziesemer

\section{Beoordelingscommissie:}

Prof. dr J. Muysken (voorzitter)

Prof. dr J. Beath (University of St Andrews, United Kingdom)

Prof. dr H.J.M. Peters

Prof. dr W.E. Steinmueller (University of Sussex, United Kingdom) 


\section{Voorwoord}

Bij het behalen van het doctoraal diploma economie aan deze instelling besefte ik dat mijn kennis van de algemene economie nog te wensen overliet. Dit is één van de redenen geweest waarom ik aan het promotie-onderzoek ben begonnen, waar het onderliggende proefschrift uit voortgekomen is. Ik ben mij weliswaar bewust van diverse onvolkomenheden in het proefschrift, maar ervaar het wel als teken dat ik de afgelopen vier jaren veel bijgeleerd heb.

Dit proefschrift moge dan diverse tekortkomingen bevatten, het zou er nog meer bevat hebben, als ik de afgelopen jaren niet in interactie met allerlei personen verbeteringen had aangebracht. Ten eerste ben ik mijn promotores dankbaar voor hun begeleiding en commentaar: Hans Maks met name voor de procesbegeleiding en zijn nadruk op economische intuïtie, welvaartsanalyses en beleidsimplicaties: Arjen van Witteloostuijn met name voor de opzet van de hoofdstukken 4 en 5 en de vele suggesties voor verwijzingen in het gehele proefschrift. Buiten mijn promotores hebben een drietal personen een belangrijke inbreng op de opzet van de hoofdstukken 2, 3 en 4 gehad: Joan Muysken, Thomas Ziesemer en met name John Beath. De discussies in de werkgroep micro-economie, later gedurende de mima-colloquia, zijn een belangrijke stimulans voor de voortgang van het onderzoek geweest. Dit geldt ook voor het werkoverleg met Arjan Wolters, Maarten-Pieter Schinkel, Marco Haan, Thomas Zwick en onze begeleiders. Dank ben ik in het bijzonder verschuldigd aan Erik de Regt vanwege de grondigheid waarmee hij mijn papers doorgenomen heeft en voorzien heeft van (technisch) commentaar; aan Thomas Ziesemer, Marco Haan en Stuart Dixon voor het natrekken van het rekenwerk; aan de leden van de beoordelingscommissie, in het bijzonder Hans Peters, voor de vele suggesties voor verbeteringen; aan Christophe Boone, Ciska Bosman en Woody van Olffen voor de suggesties ten aanzien van hoofdstuk 5; aan Gavin Reid, John Beath, Fiona, Wendy, Joan, Julia, Wendy en Simon voor het gastvrije onthaal in St Andrews.

Het onderzoek is verder mogelijk gemaakt door de prettige sfeer op de werkvloer waar met name mijn collega-AIO's en de secretaresses micro-economie/EPS - Silvia Beenen, Els van Aernsbergen, Maud Soudant en Francien Schijlen - verantwourdelijk voor zijn geweest. Voor de broodnodige afleiding buiten de werkvloer dank ik mijn ouders, Ingrid en Romiro, mijn peettante, Arjan en Hetty, Dianne, Stefan, de deelnemers aan de Alles is Drama-cursus theatersport in de seizoenen 93/94 en 94/95, Thomas, Ralph en Christine, en de medewerkers en bezoekers van het COC-cafe. 



\section{Contents}

Voorwoord $\ldots \ldots \ldots \ldots \ldots \ldots \ldots \ldots \ldots \ldots \ldots \ldots \ldots \ldots$

Contents $\ldots \ldots \ldots \ldots \ldots \ldots \ldots \ldots \ldots \ldots \ldots \ldots \ldots \ldots \ldots \ldots \ldots \ldots$

List of symbols $\ldots \ldots \ldots \ldots \ldots \ldots \ldots \ldots \ldots \ldots \ldots$ vii

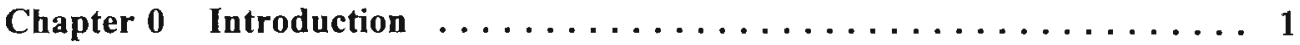

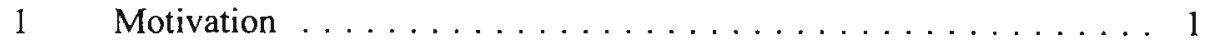

2 Historical background $\ldots \ldots \ldots \ldots \ldots \ldots \ldots \ldots$

3 Social welfare $\ldots \ldots \ldots \ldots \ldots \ldots \ldots \ldots \ldots \ldots$

4 Product differentiation and innovation $\ldots \ldots \ldots \ldots \ldots$

$5 \quad$ Contents . . . . . . . . . . . . . . . . . 7

Chapter 1 On entry and welfare $\ldots \ldots \ldots \ldots \ldots \ldots \ldots \ldots \ldots$

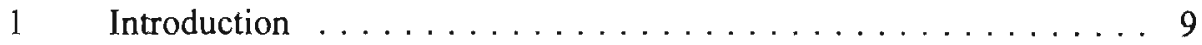

2 Early literature on entry and entry deterrence $\ldots \ldots \ldots \ldots \ldots 11$

2.1 The theory of monopolistic competition $\ldots \ldots \ldots \ldots \ldots 11$

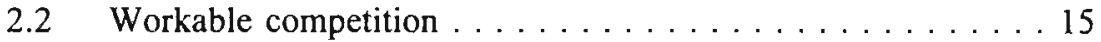

2.3 Limit price theory $\ldots \ldots \ldots \ldots \ldots \ldots \ldots \ldots$

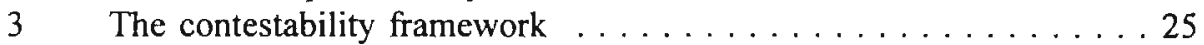

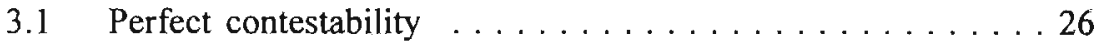

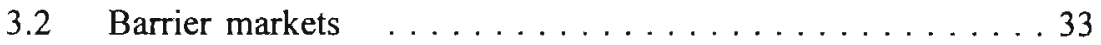

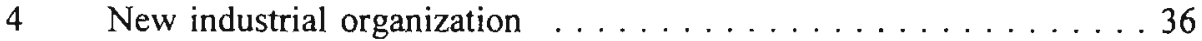

4.1 Rent dissipation . . . . . . . . . . . . . 36

4.2 Limit pricing with imperfect information . . . . . . . 40

$5 \quad$ Discussion . . . . . . . . . . . . . . . . . 42

Appendix to Chapter $1 \ldots \ldots \ldots \ldots \ldots \ldots \ldots \ldots$

A Structure, conduct and performance norms . . . . . . . . 44

Chapter 2 The dynamics of innovation and entry resulting from stochastic

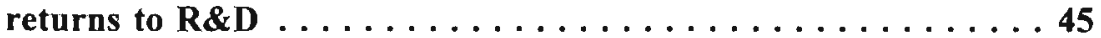

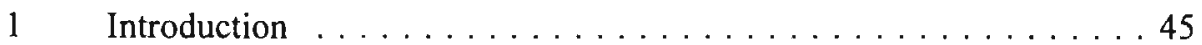

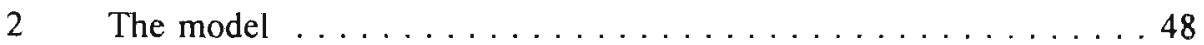

$2.1 \quad$ A general outline . . . . . . . . . . . . 48

2.1.1 The structure of a competition game $\ldots \ldots \ldots \ldots \ldots \ldots$

2.1 .2 The demand system . . . . . . . . . . . . . 49

2.1.3 The cost function . . . . . . . . . . . . . 50

2.1.4 Sunk costs, quality and marginal costs $\ldots \ldots \ldots \ldots \ldots 5$

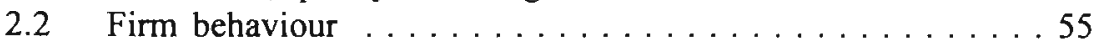

2.2.1 Expectations on rival firm behaviour .......... 55

2.2.2 The firm's price and investment strategies $\ldots \ldots \ldots 56$ 
2.3 Welfare analysis $\ldots \ldots \ldots \ldots \ldots \ldots$

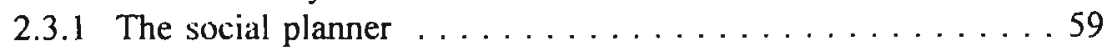

2.3 .2 The monopolist . . . . . . . . . . . . . . . 59

2.3 .3 A comparison . . . . . . . . . . . . . . . . . 60

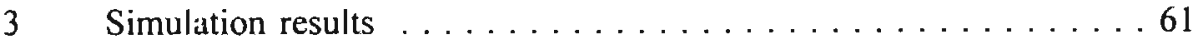

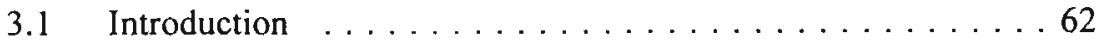

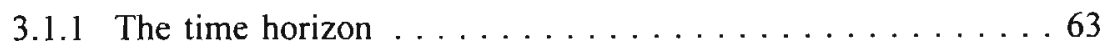

3.1 .2 Spillovers ....................... 64

3.1 .3 Industry dynamics . . . . . . . . . . . . . . . 64

3.1 .4 Methodology ..................... 66

3.1 .5 Expectation mechanisms . . . . . . . . . . . . 67

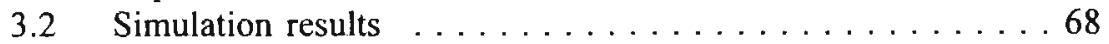

3.2 .1 Outline of the results $\ldots \ldots \ldots \ldots$. . . . . . . 68

3.2 .2 Rational expectations . . . . . . . . . . . . . . . 69

3.2 .3 Firm heterogeneity . . . . . . . . . . . . . . 80

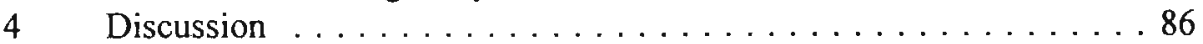

Chapter 3 Variety and quality competition in a horizontal differentiation framework . . . . . . . . . . . . . . . . . . . 89

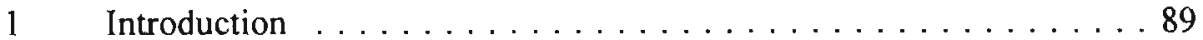

$2 \quad$ A general outline . . . . . . . . . . . . . . . . . . . . . . . . . . . . . .

2.1 The model's structure . . . . . . . . . . . . . . . . . . . 94

2.2 The demand and cost specifications . . . . . . . . . 94

2.2.1 Demand . . . . . . . . . . . . . . . . . . . . . . . 94

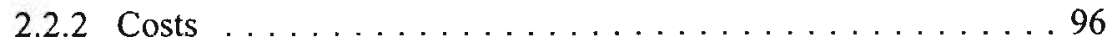

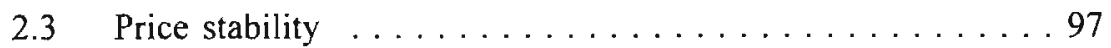

3 The Hotelling scenario . . . . . . . . . . . . . . . . . 102

$3.1 \quad$ Prices . . . . . . . . . . . . . . . . . . . . 103

3.2 Product quality . . . . . . . . . . . . . . . . . 104

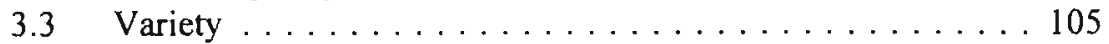

3.4 The R\&D game as a Prisoner's Dilemma . . . . . . . . 106

4 The limit price scenario . . . . . . . . . . . . . . . . . 108

4.1 Price instability ... . . . . . . . . . . . . . 109

$4.2 \quad$ Prices . . . . . . . . . . . . . . . . . . 110

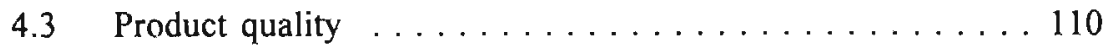

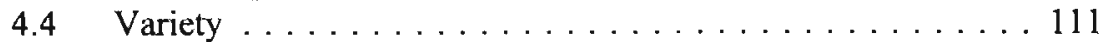

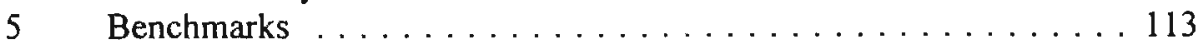

5.1 The social planner .................... 113

5.2 The monopolist ................... 115

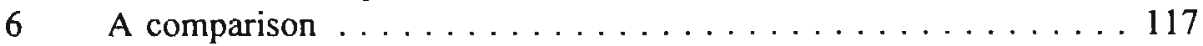

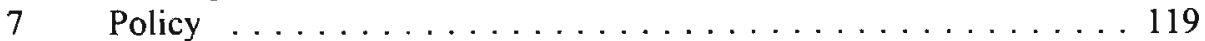

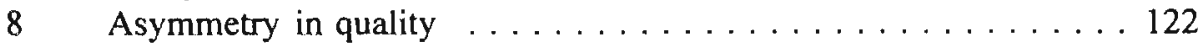

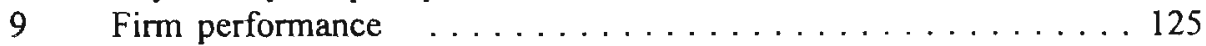

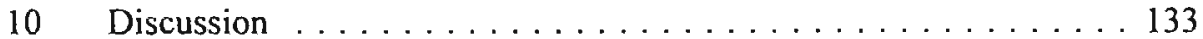




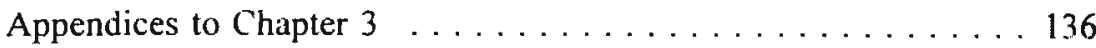

A Consumer demand ................... 136

B Prices in the Hotelling scenario . . . . . . . . . . . . 136

C Product $R \& D$ in the Hotelling scenario $\ldots \ldots \ldots \ldots \ldots \ldots 138$

D The R\&D game as a Prisoner's Dilemma . . . . . . . . . . . . 140

E Product R\&D in the limit price scenario . . . . . . . . . . 140

F Product variety in the limit price scenario . . . . . . . . . 143

G Equilibrium quality and variety under policy . . . . . . . . . . 144

$\mathrm{H} \quad$ Product R\&D and variety under asymmetry . . . . . . . . 146

I Consumer surplus and industry profits in case of asymmetry $\ldots 147$

Chapter 4 Multimarket competition with intrafirm spillovers and capacity constraints . . . . . . . . . . . . . . . . 149

$1 \quad$ Introduction . . . . . . . . . . . . . . . . . . 149

2 A general outline . . . . . . . . . . . . . . . . 153

2.1 The structure of the model $\ldots \ldots \ldots \ldots \ldots \ldots \ldots$

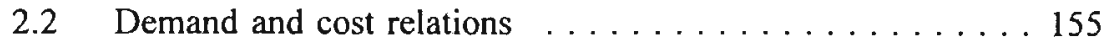

2.2 .1 Demand ...................... 155

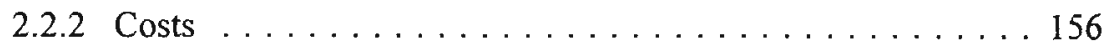

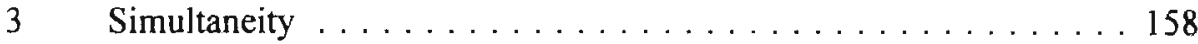

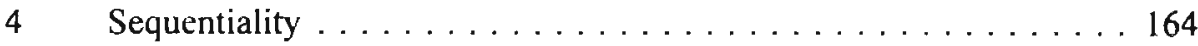

$5 \quad$ Discussion . . . . . . . . . . . . . . . . . 170

Appendices to Chapter $4 \ldots \ldots \ldots \ldots \ldots \ldots \ldots \ldots$

A Equilibrium profits when at least one firm does not invest . . . 173

B Decisions on supply . . . . . . . . . . . . . . . . 174

C The non-existence of Nash-equilibria with both firms accommodating entry (area II) . . . . . . . . . . . . . . . . . . . . . . 179

D Asymmetric Nash-equilibria under simultaneous decisions making . 180

E Proof of Proposition 4.2 . . . . . . . . . . . . . . . 184

Chapter 5 An experimental study of price and investment behaviour . . . 189

1 Introduction . . . . . . . . . . . . . . . . . . . . . . 189

2 The experimental set-up . . . . . . . . . . . . . . . 192

2.1 The relation with Chapter $2 \ldots \ldots \ldots \ldots \ldots \ldots \ldots$

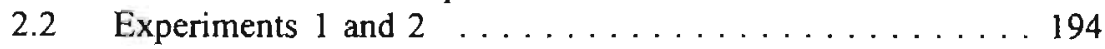

2.2 .1 The price decision $\ldots \ldots \ldots \ldots \ldots \ldots \ldots \ldots \ldots$

2.2.2 The quality decision . . . . . . . . . . . . . . 196

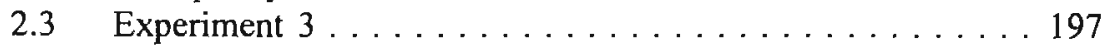

3 Hypotheses . . . . . . . . . . . . . . . . . . . . . . 198

$3.1 \quad$ Experiment specific hypotheses $\ldots \ldots \ldots \ldots \ldots \ldots \ldots$

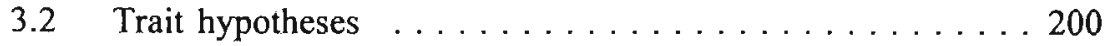

4 Methods . . . . . . . . . . . . . . . . . . . . . . 204

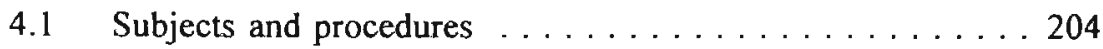

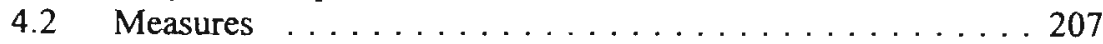


Vi

4.2.1 Measuring quality, price and competitive behaviour . . . . 207 4.2.2 Measuring subjective characteristics . . . . . . . . . 208

$5 \quad$ Results . . . . . . . . . . . . . . . . . . 210

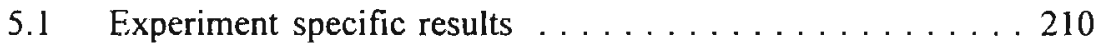

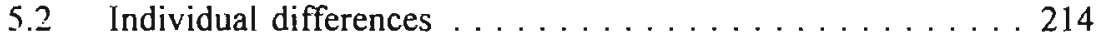

6 Discussion . . . . . . . . . . . . . . . . . . 221

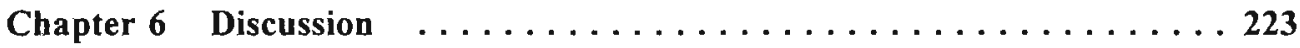

References .......................... . 229

Samenvatting in de Nederlandse taal $\ldots \ldots \ldots \ldots \ldots \ldots$

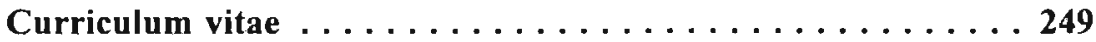




\section{List of symbols}

\begin{tabular}{|c|c|c|}
\hline $\mathrm{ac}$ & $=$ & Average total cost \\
\hline $\mathrm{C}$ & $=$ & Entry accommodation \\
\hline CS & $=$ & Consumer surplus \\
\hline $\mathrm{D}$ & $=$ & Entry deterrence \\
\hline d & $=$ & Distance \\
\hline $\mathrm{E}$ & $=$ & Entry (undercutting) \\
\hline $\mathrm{F}$ & $=$ & Forgoing entry \\
\hline $\mathrm{K}$ & $=$ & Capacity \\
\hline M & $=$ & Number of markets \\
\hline $\mathrm{mc}$ & $=$ & Marginal cost \\
\hline $\mathrm{N}$ & $=$ & Number of consumers (per market) \\
\hline $\mathrm{P}$ & $=$ & Price \\
\hline Q & $=$ & Quality \\
\hline $\mathrm{R}$ & $=$ & R\&D efforts \\
\hline $\mathrm{RC}$ & $=$ & Process R\&D expenses \\
\hline $\mathrm{RQ}$ & $=$ & Product R\&D expenses \\
\hline s & $=$ & Location \\
\hline S & $=$ & Supply \\
\hline $\mathrm{SC}$ & $=$ & Total sunk costs \\
\hline $\mathrm{TC}$ & $=$ & Total costs \\
\hline $\mathbf{u}$ & $=$ & Utility losses (transport costs) \\
\hline $\mathrm{U}$ & $=$ & Utility \\
\hline VC & $=$ & Total variable costs \\
\hline W & $=$ & Consumer income \\
\hline$X$ & $=$ & Demand for product $X$ \\
\hline $\mathrm{Y}$ & $=$ & Demand for product $Y$ \\
\hline $\mathrm{z}$ & $=$ & Marginal consumer \\
\hline $\mathrm{Z}$ & $=$ & Demand for numéraire commodity $Z$ \\
\hline$\beta$ & $=$ & Spillover rate \\
\hline$\Delta Q$ & $=$ & Change in quality \\
\hline$\varepsilon$ & $=$ & Entry cost (per unit) \\
\hline$\kappa$ & $=$ & $\mathrm{K} / \mathrm{N}$ \\
\hline$\pi$ & $=$ & Gross profits \\
\hline$\Pi$ & $=$ & Net profits \\
\hline$\zeta$ & $\begin{array}{l}= \\
=\end{array}$ & Share of R\&D costs not borne by the firm \\
\hline & $=$ & Social welfare \\
\hline
\end{tabular}





\section{Chapter}

0

Introduction

The main part of the thesis concerns a theoretical investigation of conditions under which (potential) competition enforces firms to charge cost prices and to improve upon product quality for the benefit of the consumer. This investigation is motivated by empirical phenomena in two ways. First, in many industries (potential) competition indeed seems to sentence firms to average cost pricing and to an acceleration of the innovation process. Second, in industries in which this is not the case, coordination may be improved by government policy in order to ensure both average cost pricing and an acceptable innovation rate. Market coordination may be improved upon by active government policies such as subsidies and competition policy or by restoring free competition. This study attempts to indicate under what conditions (potential) competition enforces competitive pricing and an acceptable innovation rate. Industries meeting these conditions should be liberalized, at least when competition is not already free. When firms do not behave competitively, active policy measures may be advocated.

Empirical observations indeed indicate that competition induces both average and marginal cost pricing and heavy investments in R\&D. In the market for personal computers ( $\mathrm{PC}$ 's), for instance, price-cutting is very intense: 'profit margins are razor-thin'. Net profits are $1 \%$, if the PC maker has the lowest costs [Wall Street Journal Europe (WSJE): 2-11-95]. 'The only sure winner in this Darwinian battle may be the consumer, as PC makers try to get ahead by loading their machines with technology only dreamed of a few years ago' [op. cit.]. Entrants from related markets, among which Intel and Hewlett-Packard, reduced (gross) profits of traditional PC-makers from $12 \%$ in 1990 to 5-6\% in 1994 and 1995 [Business Week (BW): 21 8-95 and 9-10-95]. This observation also indicates that firms in related markets constitute an important entry threat. Entry from related markets is easy when are there economies of scope in production or marketing (Hewlett-Packard) and when strategic aspects matter (Intel).

Economies of scope are one of the main factors explaining the surge in technological progress and multimarket competition. Both features explain why industries 'which were once cosy havens for making easy profits are now subject to vigorous competition' [Grant (1991: 117)]. The surge in information technology is one of the key factors behind the growing substitutability in production. As a result prices drop faster than ever while at the same time technological progress is more impressive than ever before. Especially industries such as consumer-electronics, computers, chips and telecommunications are affected [BW: 6-3-95]. Since creative destruction is 
fiercer than in the past, 'the whole trick is to get in quickly and run as fast as you can' [op. cit. p. 39]. High technology markets, such as the market for AM-LCD's, quickly change into bulk markets [NRC: 27-10-95]. Price cuts may be tremendous: AM-LCD prices dropped from over $\$ 1000$ to $\$ 700$ within one year.

Vigorous competition does not only refer to price competition, but also to innovation policies. This phenomenon is observed in the PC market - see above - but also in the markets for drugs [WSJE: 24/5-11-95], cosmetics [NRC: 14-2-95], jet-engines [BW: 27-3-95] and cars [BW: 17-4-95]. Patent races for new drugs are very intense and involve billions of dollars [WSJE: 24/5-11-95]. R\&D races in the pharmaceutical industry are particularly intense, because the rents attached to patents are large. However, R\&D competition remains fierce, even though patents become less effective since the surge in information technology facilitates imitation. This feature explains the growing importance of multimarket competition [Van Wegberg (1993)]. Product development is also an important competitive instrument in the market for shampoo and other cosmetics [NRC: 14-2-95]. New products like Procter \& Gambles Pantène and Infasil and Unilever's Organics and Dove gained substantial market share in the Netherlands and the United Kingdom in a short period of time.

Competition is not only vigorous with respect to price or R\&D competition, examples in advertising are famous as well. Johnson \& Johnson - Merch, for instance, recently fought an advertising war in the market for non-prescription heartburn drugs. Marketing outlays amount to 200 million dollars, while sales are only 1 billion dollars [WSJE: 17-10-1995]. The introduction of new shampoos - see previous paragraph - was attended with a rise in spending on television commercials of $150 \%$ in a two years period [NRC: 14-2-95]. The U.S. cigarette industry probably constitutes the most famous example in this respect. Advertising expenses dissipate net profits substantially unless halted by government policy: a ban on television ads in 1970 reduced outlays from $\$ 315$ in 1970 to $\$ 252$ in 1971 while raising profits accordingly [Scherer and Ross (1990: 596)].

\section{Historical background}

The focus on competitive results induced by the entry threat falls in a long tradition of an extensive literature on both price and innovation theories. Adam Smith (1776: 77) already notices that when the return to capital exceeds the natural rate, 'their great profit would tempt so many new rivals to employ their stocks in the same way, that ... the market price would soon be reduced to the natural price'. Walras (1874: 396) similarly states that 'si ... le prix de vente est supérieure à leur prix de revient en services producteurs, les entrepreneurs affluent ou développent leur production, en fait baisser le prix et réduit l'écart' [italics added]. And with respect to innovations Schumpeter (1942: 83) points out that the entry threat 'keeps the capitalist engine in motion' by enforcing firms to introduce new products, new methods of production or transportation, new forms of industrial organization and to enter new markets.

The notion that entry (and exit) play(s) an important role in establishing competitive equilibria, recurs in the economic literature of this century. Chamberlin 
(1933) and Robinson (1933) use this argument in order to establish a long-run competitive equilibrium in their theory of monopolistic competition. Chamberlin (1933) argues and Dixit and Stiglitz (1977) show that the trade-off between variety and price (average cost) is optimal from a social point of view. Bain (1949: 449) similarly notes that 'established sellers forego prices high enough to maximize the industry profit for fear of thereby attracting new entry to the industry and thus reducing the demands for their outputs and their own profits'. Entry deterring prices foregoing short-run profit maximization are referred to as limit prices. Milgrom and Roberts (1982) recently repopularized limit price theory by showing that, in case of asymmetric information, the mere entry threat causes price reductions (and increases in investment [Bagwell and Ramey (1988)]). Prices approach competitive levels unless (1) there are no substitutes in consumption and (2) there are significant economies of scale without any opportunity for technical substitution. When these conditions are satisfied, competition is likely to be workable: prices reflect average and marginal costs while the innovation rate is acceptable [Clark (1940)].

The pervasiveness of the entry threat has been stressed again recently in the literature on rent dissipation [Posner (1975); Fudenberg and Tirole (1987)], in particular in contestability theory [Baumol (1982); Baumol, Panzar and Willig (1982)]. Contestability theory is a formalization of Clark's (1940) theory of workable competition, constructed in order to replace the theory of perfect competition. When there are no exit barriers, i.e. no sunk costs, firms are forced to apply average and marginal cost pricing, no matter which market they are in. ${ }^{(1)}$ The entry threat does not only affect price policy: zero-profit equilibria also arise in other contexts, such as capacity construction [Eaton and Lipsey (1980)] and patent races [Fudenberg and Tirole (1987)].

Maks (1986) and Van Witteloostuijn and Maks (1988) extend contestability theory to a dynamic framework. The extension enables them to derive a benchmark characterized by both average and marginal cost pricing and an optimal innovation rate. This benchmark is referred to as the barrier market concept [Maks (1986)] or quasi-contestability theory [Van Witteloostuijn (1992)]. Maks (1986) and Van Witteloostuijn (1992) provide a normative theory for evaluating price and innovation policies. However, in order to apply barrier market theory as a benchmark, the results must be shown to hold in certain scenarios, i.e. under certain conditions. As argued in the previous section, there is a vast literature in economics obtaining competitive results. However, there are not that many studies yet obtaining competitive outcomes in terms of both prices and innovations, especially with respect to product innovations. Van Witteloostuijn (1990) provides some examples. There are also some examples in New Industrial Organization (NIO), notably Maskin and Tirole (1988), Stahl (1988) and Hartwick (1991). In this thesis further scenarios will be presented in which barrier market results are obtained or approached. In order to keep the thesisproject manageable, attention has been restricted to product innovations.

(1) In a natural monopoly, price equals average costs only. 
The thesis attempts to provide scenarios in which barrier market results are obtained or approached. In due course we therefore present some positive theories supplied with welfare-theoretic evaluations. These theories may be used as points of departure fre policy recommendations. The basis for welfare analysis is social welfare as F ceived by the social planner. According to Bergson (1938) social welfare $\Sigma$ depends on the satisfaction or rather utility $\mathrm{U}$ experienced by all $\mathrm{N}$ individuals in the economy: $\Sigma=\sigma\left(U_{1}, \ldots, U_{N}\right)$. In principle, the social planner may attach different weights to the individuals. The utility experienced by one individual may also depend on the utility experienced by other persons. However, the latter possibility will be neglected in this study. In general, industrial organization (IO) distinguishes two components of social welfare: industry profits $\Pi$ and consumer surplus CS. We will weigh the profits received by each individual to the same degree; we will also do so for the consumer surplus experienced by each individual. This enables us to simplify the social welfare function to: $\Sigma=\lambda . \Pi+$ CS. The constant $\lambda(\geq 0)$ reflects the fact that different weights may be attached to consumer surplus and industry profits. It is quite common to attach equal weights to industry profits and consumer surplus ( $\lambda=$ 1) [Tirole (1988)], because economists are not eager to weigh one individual more than another.

(invernments seem to attach a larger weight to consumer well-being than to industry profits. The U.S. Department of Justice and Federal Trade Commission guidelines indicate that in general private actions, a merger for instance, are challenged when it sorts anti-competitive effects - price increases - even if there is an offsetting rise in industry profits due to cost reductions [Carlton and Perloff (1994)]. This guideline indicates that the effects on consumer well-being rather than social welfare, as defined above, are decisive in U.S. competition policy. The European Commission takes a similar stand. The European Commission allows agreements between firms only if, among other things, consumers obtain a fair share of the benefits obtained by the agreement. Like the U.S. authorities 'the Commission tends to interpret the 'fair share' concepts in terms of lower prices rather than in terms of improved service or other more intangible values' [Van Bael and Bellis (1987: 50)]. In recent years, the European Commission gives consumer well-being primacy over social welfare as guideline for policy evaluations: ${ }^{(2)}$ 'de overheidstaak waarmee de Commissie belast is, te weten het beschermen van de concurrentie en daarmee het beschermen van de consumenten' [EC (1995: 23)]. Both U.S. and European governments tend to give consumer well-being primacy over social welfare in policy evaluations. In terms of the above welfare function, this implies: $\Sigma=\lambda . \Pi+\operatorname{CS}(0 \leq$ $\lambda<1)$ or even $\Sigma=C S(\lambda=0)$. Because of the importance attached to consumer well-being, (developments in) consumer surplus are depicted next to social welfare.

Social welfare may be regarded from two perspectives: a static or a dynamic

(2) In English: 'the government task entrusted to the Commission, namely protecting competition and by so doing protecting consumers'. 
environment. In a static environment consumer preferences and technological relationships are given. In such an environment the social planner is concemed with price policy only: innovations - changes in technology - are ruled out by definition. In a dynamic environment preferences and technology may change. Since we are interested in changes in technology, we take consumer preferences as given. In a dynamic environment the social planner needs to consider both price and innovation policies.

Related to this difference in perspective is the difference between static and dynamic efficiency. In a static environment, the social planner is interested in the price vector maximizing social welfare. This price vector implies static efficiency. In this study partial analysis is applied. When the analysis is restricted to one industry, the following holds. Static efficiency is obtained when price equals marginal costs first-best condition - or, alternatively, average costs - second-best condition. The latter condition is necessary when a zero-profit constraint should be taken into account. In this study, we will assume that this is so. In a dynamic environment, however, both price and innovation policies need to be considered. Dynamic efficiency refers to maximizing social welfare over time. Surpluses in future periods may be increased by investments in technology. Dynamic efficiency is obtained when the marginal loss of surplus in one period - due to investment - is matched by the marginal increase of discounted surpluses in future periods [Nord-haus (1969)]. The trade-off between investment expenses and discounted surpluses is optimal, i.e. efficient. When the trade-off is not efficient, but innovations are realized, we refer to dynamic economies.

\section{Product differentiation and innovation}

In the thesis we pinpoint attention to product innovations. Before defining product innovations we would like to point out that products may differ in two respects. Products are differentiated with respect to horizontal or vertical product characteristics. The distinction between these types of characteristics depends on the way consumers perceive them. Consumers may have different preferences with respect to horizontally differentiated products - when sold at the same price; they do not with respect to vertically differentiated products [Tirole (1988)]. Horizontal diflerentiation will be referred to as differences in variety, vertical differentiation as differences's in quality. Take a simple product like yoghurt. Consumers may differ with respect to the degree of sourness most preferred - a horizontal characteristic; they all are likely to prefer a more durable or a more nutritious brand - a vertical characteristic. Take a car. Consumers may differ with respect to the colour most preferred - a horizontal characteristic. They all are likely to prefer a car which is more economic in petrol or is able to attain a higher speed - a vertical characteristic. Product innovations refor to vertical product characteristics. They may be defined as impro-vements upon one or more vertical characteristics: yoghurt may be come more nutritious or cars more economic in petrol.

The innovations modelled in the thesis refer to and are interpreted in terms of 
product innovations. However, this fact does not preclude any interpretation in terms of process innovations or advertising. Since demand and costs are linear in the models of Chapters 3 and 4 , product innovations are equivalent to process innovations [De Bondt and Veugelers (1991: 347)]. Advertising raises the perceived quality of products. So, when the subjective preferences of (rational) consumers are taken as point of departure for evaluating consumer well-being, product $R \& D$ and advertising campaigns are equivalent. There is, however, one subtlety overlooked in the reference to the subjectivity of preferences. When one (monopolistic) firm advertises, the perceived quality of its product and the utility derived from consuming may indeed rise. However, when two or more firms advertise, the perceived quality and the utility derived may not rise, since the perceived quality may be defined relative to other qualities [Galbraith (1958) and Dixit and Norman (1978)]. In that case, advertising outlays only dissipate social surplus.

Table 0.1

A comparison of Chapters 2 to 4

$\begin{array}{lll}\text { Analytical } & \text { Model features } \\ \text { techniques } & \end{array}$

2 Game theory Average total costs constant Simulations Representative consumer

No capacity constraints Geographically separated markets

3 Microeconomics Game theory

Average variable costs constant Differentiated consumers No capacity constraints One (segmented) market

4 Game theory Average variable costs constant Representative consumer Capacity constraints Two markets with substitutes in production

Prices approach marginal cost when entry costs fall Optimal investment in R\&D Duplications of efforts Industries are monopolized when entry costs are low

Prices approach marginal cost when there is less desire for variety

Underinvestment in R\&D All surplus from innovations accrues to consumers Product differentiation is optimal in case of hit-and-run entry; otherwise it is not

Prices approach marginal cost when spillovers and capacity rise

Firms do not invest in R\&D when spillovers are high 


\section{Contents}

The thesis is constructed as follows. Chapter 1 reviews the literature on entry threats and competitive pricing and innovation behaviour in order to embed the thesis in the extensive literature on this topic. Chapters 2 to 4 all present a theoretical scenario obtaining or approaching barrier market results. The three theoretical chapters are compared in Table 0.1. Chapter 2 gives the results of simulation analyses based on one competition game. Chapters 3 and 4 are based on standard micro-economic and game-theoretical techniques and thus fall within New Industrial Organization (NIO) [Davies and Lyons (1991)]. Chapters 2 to 4 all refer to multi-market competition. In the thesis, multimarket competition is defined as competition between producers in horizontally differentiated markets. The differentiation is based on a subdivision in either geographic markets [Chapter 2] or product markets [Chapter 4]. Chapter 3 is not based on a multimarket model, but on a related model. In this chapter, the differentiation is based on a subdivision in consumer markets.

Chapter 2 argues that average and marginal cost pricing and investment in R\&D may be combined when average total costs instead of average variable costs are constant. Empirical studies suggest that average total costs are constant in some industries [Scherer and Ross (1990: 106-7)]. This observation is also used in contestability theory in order to introduce flat-bottomed average total costs curves [Baumol (1982)]. Simulation analysis shows that when the returns to R\&D are stochastic, an industry may be monopolized when entry costs are low. This result is due to the fact that rival firms go bankrupt or face a large quality or cost disadvantage and abstain from further investments in R\&D.

Chapter 3 illustrates that firms may charge a higher mark-up over marginal costs when the consumer's desire for variety rises. Part of the mark-up over marginal cost is needed to cover product $R \& D$ expenses. Since market demand is fixed, product innovations influence market share only. A general rise in quality does not affect the market price. For this reason the duopolists face a Prisoner's Dilemma game in terms of product R\&D: all surplus created by innovations is passed through to the consumers. When price competition is soft, the firms minimize product variety in order to gain market share; when price competition is fierce, the firms differentiate products to some degree in order to soften price competition.

Chapter 4 illustrates the importance of the assumption made in Chapters 2 and 3 with respect to (the absence of) capacity constraints. When excess capacity is small, the entry threat is less effective as a result of which the mark-up over marginal costs is likely to increase. Marginal cost pricing only occurs when excess capacity is sufficiently high. Chapter 4 also stresses the importance of general knowledge for multimarket competition: when knowledge is easily transferable from one industry to another - intrafirm spillover are high - mark-ups are lower since rival firms are able to offer products with similar qualities. However, because prices approach marginal costs when spillovers are high, the mark-up needed to cover $R \& D$ expenses may become too small. In this case, firms may abstain from investment in R\&D.

Chapter 5 describes how Chapter 2's competition game may be transformed for experimental analysis. The preliminary results indicate that mark-ups exceed marginal 
costs substantially, but tend to decline through time. This result is primarily due to two factors facilitating coordination between players. The subjects play an unknown number of rounds. This time structure is equivalent to an infinite time horizon which fosters cooperation. The players play a simplified version of the competition game first. This version fosters cooperation as well. This enables the players to reach a degree of mutual understanding. This feeling of mutual understanding may carry over to more complex versions of the competition game. Chapter 6 will end with a discussion. 


\section{Chapter}

1

\section{On entry and welfare}

\section{Introduction}

The importance of entry for the establishment of a competitive equilibrium has been recognized ever since economics developed into a full-fledged science, and even before that moment. Adam Smith (1776) argues that resources are shifted from one industry into another when the market price in the former sector exceeds the natural (or cost) price. When the market price is above the natural price, at least one factor of production must earn an above average return. When the return to capital exceeds the natural rate, 'their great profit would tempt so many new rivals to employ their stocks in the same way, that ... the market price would soon be reduced to the natural price' [Smith (1776: 77)]. And with respect to labour: '[I]f in the same neighbourhood there was any employment evidently either more or less advantageous than the rest, so many people would crowd into it in the one case, and so many would desert it in the other, that its advantages would soon return to the level of other employments' [Smith (1776: 116)]. Smith thus concludes that market prices equal natural (or cost) prices in the long run. This view on the working of the market mechanism can also be found in the work of neo-classical economists as Walras (1874): 'Si, dans certaines entreprises, le prix de vente des produits est supérieure à leur prix de revient en services producteurs, d'où resulte un bénéfice, les entrepreneurs affluent ou développent leur production, en fait baisser le prix et réduit l'écart; et si, dans certaines entreprises, le prix de revient des produits en services producteurs est supérieur à leur prix de vente, d'où resulte une perte, les entrepreneurs se détournent ou restreignent leur production, ce qui diminue la quantité des produits, en fait hausser le prix et réduit encore l'écart' [Walras (1874: 396); italics added].

The entry threat does not only discipline price behaviour, it also 'keeps the capitalist engine in motion' by enforcing firms to introduce new products, new methods of production or transportation, new forms of industrial organization and to enter new markets [Schumpeter (1942: 83)]. 'It is hardly necessary to point out that competition of the kind we now have in mind acts not only when it is merely an ever-present threat. It disciplines before it attacks. The businessman feels himself to be in a competitive situation even if he is alone in his field or if, though not alone, he holds a position such that investigating government experts fail to see any effective competition between him and any other firms in the same or a neighbouring field and in consequence conclude that his talk, under examination, about his competitive sorrows is all make-believe. In many cases, though not in all, this will in the long run enforce behavior very similar to the perfectly competitive pattern' [op. cit.: $85]$. 
The notion that entry (and exit) play(s) an important role in establishing competitive equilibria, recurs in the economic literature of this century. Chamberlin (1933) uses this argument in order to establish a long-run competitive equilibrium in his theory of monopolistic competition. The mechanism of entry and exit does not only explain why profits are eroded in the long run, but also why the trade-oft between variety and price (average cost) is optimal [Dixit and Stiglitz (1977)]. Competitive equilibria are not only attained by processes of entry and exit, but also by the mere threat of entry. The equilibrium-enforcing nature of the entry threat has been stressed by Bain (1949) in his limit price theory. Long-run equilibria are attained if profitable entry is no longer possible. At that moment there is no (credible) entry threat any more. In the long run, prices consequently approach the competitive levels unless (1) there are no substitutes in consumption and (2) there are significant economies of scale without any opportunity for technical substitution in related industries. It is unlikely that both conditions hold in the long run: Clark (1940) argues that long-term elasticities in both demand and supply tend to be high. Entry into industries is one of the major determinants of long-run elasticities and thus of competitive equilibria. Entry (or even the mere threat of entry) thus enforces 'workable' outcomes. Clark refers to this competitive equilibrium as workable competition. In contrast to perfect competition this concept incorporates dynamic clements, but it is less well defined than perfect competition. In the tradition of Adam Smith, Clark emphasizes the importance of processes towards equilibria and the dynamic economies that occur outside the perfectly competitive world.

The importance of the entry threat for the establishment of competitive equilibria, and consequently for welfare comparisons, has been stressed again recently in contestability theory [Baumol, Panzar and Willig (1982)]. This theory is a formalization of the theory of workable competition, constructed in order to derive a more precise benchmark that may replace the theory of perfect competition. In contrast to the theory of workable competition, contestability theory focuses on a static framework. In order to encompass dynamic economies in a contestability framework the barrier market concept has been developed [Maks (1986) and Van Witteloostuijn and Maks (1988)]. The concept looks for conditions in which competitive pricing may be combined with (optimal) investments in innovations. The importance of the entry threat in eroding profits also recurs in other branches of new industrial organization than contestability theory. The erosion of profits is the prime characteristic of the literature on rent dissipation [Posner (1975)]. The literature on patent races is one of the most widespread applications in this field [Fudenberg and Tirole (1987)]. The entry threat is also one of the most important factors explaining price reductions and increases in investment in limit price theory under asymmetric information [Milgrom and Roberts (1982)].

As already indicated in the introduction, the main purpose of this thesis is the search for scenarios in which both static and dynamic efficiency are enforced by entry or the mere threat to enter. These scenarios are referred to as barrier market scenarios. The above review shows that the view on the market mechanism as laid down in barrier market theory is not strange to economic theory. This chapter reviews the main contributions of this century attaining barrier market results, in 
particular the theories of monopolistic competition and workable competition, limit price theory, contestability theory and new industrial organization. The review is not thorough, but merely presents the major contributions in industrial organization reaching competitive results.

As stated in the introduction, barrier market theory as laid down by Maks (1986) and Van Witteloostuijn (1990) is mainly normative in nature. Normative theory is developed in order to provide benchmarks. However, in order to apply normative theory, one must show that there are scenarios in which the benchmarks results indeed are obtained. The latter is the task of positive economics. The search for barrier market scenarios is an attempt to enlarge the applicability of barrier market theory. We will do so in Chapters 2 to 4 . With respect to the theories reviewed in this chapter the following classification can be made. The theory of monopolistic competition, limit price theory and new industrial organization are mainly positive. the theory of workable competition and contestability theory mainly normative. The latter theories are discussed in order to show that our normative perception of the world does not fall from heaven. The former theories explain the development of the above theories and provide a starting point for the scenarios developed in Chapters 2 to 4 . Since we develop theoretical scenarios in the next three chapters, we confine our attention in this chapter to theoretical contributions to industrial organization. Empirical studies, in particular those on limit pricing, are neglected.

In this chapter, the literature relating entry (threats) and competitive pricing will be reviewed. We will class the relevant contributions to the most important theories on this tradition: The theory of monopolistic competition, the theory of workable competition, limit price theory, the contestability framework and new industrial organization and discuss the theories in chronological order. Section 2 discusses early literature on entry and entry deterrence: The theory of monopolistic competition, the theory of workable competition, and limit price theory. Contestability theory and the barrier market concept are presented in Section 3. Section 4 discusses (recent) literature in the field of new industrial organization with competitive outcomes. Section 5 concludes this chapter, and addresses some attention to the linkage of this review with the rest of the book.

Early literature on entry and entry deterrence

\subsection{The theory of monopolistic competition}

The theory of monopolistic competition was set out in 1933 by Edward H. Chamberlin in The Theory of Monopolistic Competition and by Joan Robinson in The Economics of Imperfect Competition. The outline given below is primarily based on Chamberlin's theory.

Pure monopoly is characterized by control over supply [Chamberlin (1933: 65)]. Control over supply may limit competition at the supply side. This limitation is not necessarily sufficient to extract monopoly profits from consumer markets. Demand needs to be price inelastic to some degree. Monopolistic competition is characterized 
by product heterogeneity. Product heterogeneity provides some control over supply [Demsetz (1982: 49-52)]. Demand curves consequently are downward sloping. This enables producers to actually set prices. Demand is subject to change, however, because rival enterprises producing substitute products may enter or exit the industry. Demand is also subject to change because rival firms may alter prices, qualities and advertising outlays. These changes increase or decrease the elasticity of demand, and hercby cause an approximate equalization of price and average cost. In contrast with the theory of pure monopoly, the theory of monopolistic competition is concerned with industry (group) equilibrium. An industry is in equilibrium when entry and exit, and changes in price, quality or selling expenses do not occur any longer. In the long run, industry prices approximately equal average costs, although they are not necessarily equal to average costs [Chamberlin (1933: 110-113) and (1951: 353)]. ${ }^{(1)}$ The number of available substitute products may be small, even in the long run. The available substitutes may be substitutable in a limited degree. This may be due to patents or trade marks granted, control over supply, transportation costs, etc. The number of (potential) enterprises in a monopolistic industry may be either large or small. In the literature, usually a large-number assumption is made with respect to monopolistic competition [Scherer and Ross (1990)]. The small-number assumption is elaborated in the literature on oligopoly. The large-number case will be elaborated below.

An individual firm's position can be explained with Figure 1.1. A firm is assumed to have a U-shaped average cost curve ac and a corresponding marginal cost curve $\mathrm{mc}$. The demand curve $\mathrm{X}$ and the marginal return curve $\mathrm{mr}$ are downward sloping. Profits are maximized (or losses minimized) by equilibrating marginal returns and marginal costs. Equilibrium is found at $O$. In the short run, producers may earn positive or negative profits. Profits are positive in $O$. When profits are positive, entry occurs. As a consequence the demand of all firms in the industry goes down. ${ }^{(2)}$ Demand falls from $X$ to $X$. When profits are negative, some firms exit implying that the demand of all remaining firms increases. Entry occurs as long as firms make positive profits; exit takes place as long as enterprises suffer losses. In the long term, profits whether positive or negative are dissipated by the process of entry and exit. Long-run equilibrium is established at $\mathrm{O}^{\prime}$.

(1) In a recent paper, Pascoa (1994) stresses this point. In a generalization of Hart's (1985) model, he finds that profits generally are larger than zero in a Chamberlinian framework.

(2) Chamberlin assumes that strategic interaction is absent in monopolistic markets. A firm does not suffer from the behaviour of another firm, when it has many competitors. A firm's behaviour has consequences for all other firms in about the same degree. Strategic interaction is absent in oligopolistic market structures, as the Cournot behavourial assumption is postulated [Friedman (1979: 55) and (1983: 64-71)]. In a 1951 article Chamberlin (1951: 346n) loosens the above assumption. He introduces the notion of a chain market in his work. This notion resembles Hotelling's (1929) horizontal differentiation framework. 


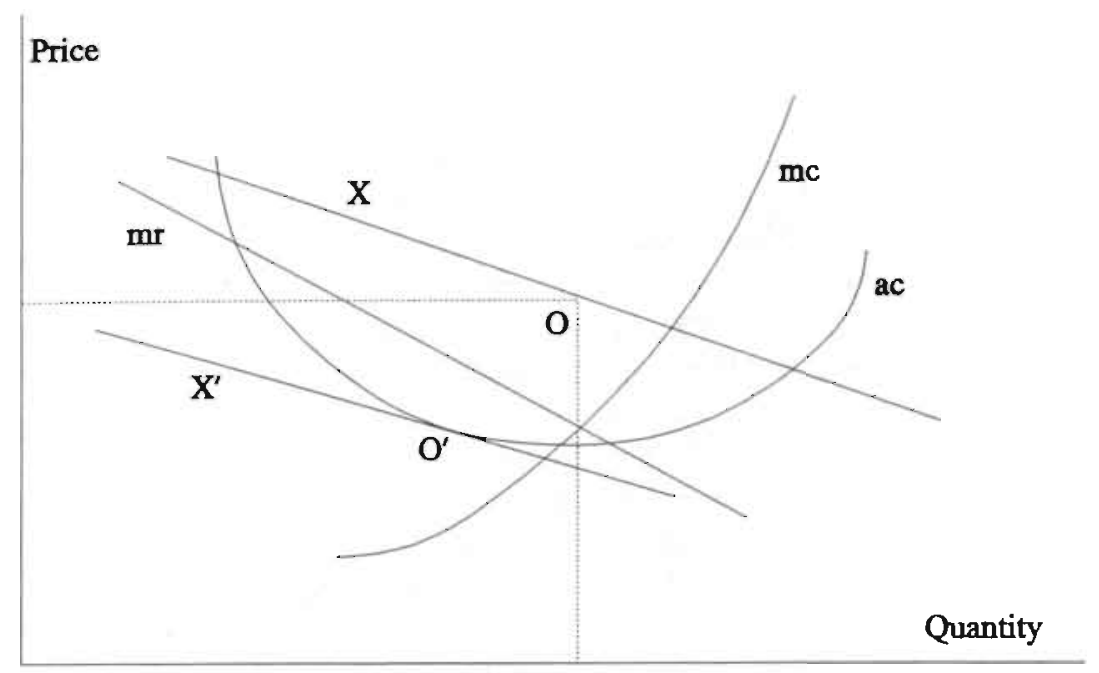

Figure 1.1: Monopolistic competition and entry

Chamberlin distinguishes a second equilibrating process. This process is given by Figure 1.2. When an individual firm reduces its price, rivals do not notice the reduction since they are all affected to the same small degree. Rival firms consequently do not react upon a price reduction by an individual firm. The demand curve faced by individual firms thus is very elastic. This curve is given by $\mathrm{x}$ in Figure 1.2. Because price elasticity is high, each individual firm reduces its price as this is profitable at first sight. However, although firms may not react on individual price reductions, they act as if they do. Because all firms reduce their prices, their market shares stay about the same. An individual firm's demand can be represented by a second demand curve $X$, which incorporates the behaviour of other firms. Firms lower their prices since their demand curves are given by $\mathrm{x}$, but actual demand increases according to $\mathrm{X}$. From $\mathrm{O}$ a process starts during which the demand curve $\mathrm{x}$ shifts downwards along $\mathrm{X}$ towards $\mathrm{O}^{\prime}$. In $\mathrm{O}^{\prime}$, profits again are zero. Cham-berlin distinguishes two other decision variables than price: Product quality and selling expenses. With respect to these variables a similar analysis is possible. In the long-run equilibrium, changes in quality or selling expenses are no longer profitable.

Chamberlin provides economic analysis with the axiom that a zero-profit condition is valid from a long-term perspective. The zero-profit condition is (primarily) caused by processes of entry and exit. In the theory of monopolistic competition profits are about zero in the long term, just as in the case of perfect competition. In contrast to perfect competition, price does not equal marginal cost in a monopolistic competitive setting. This is due to the assumption that products are heterogenous so that individual producers face downward-sloping demand curves. The demand curve 


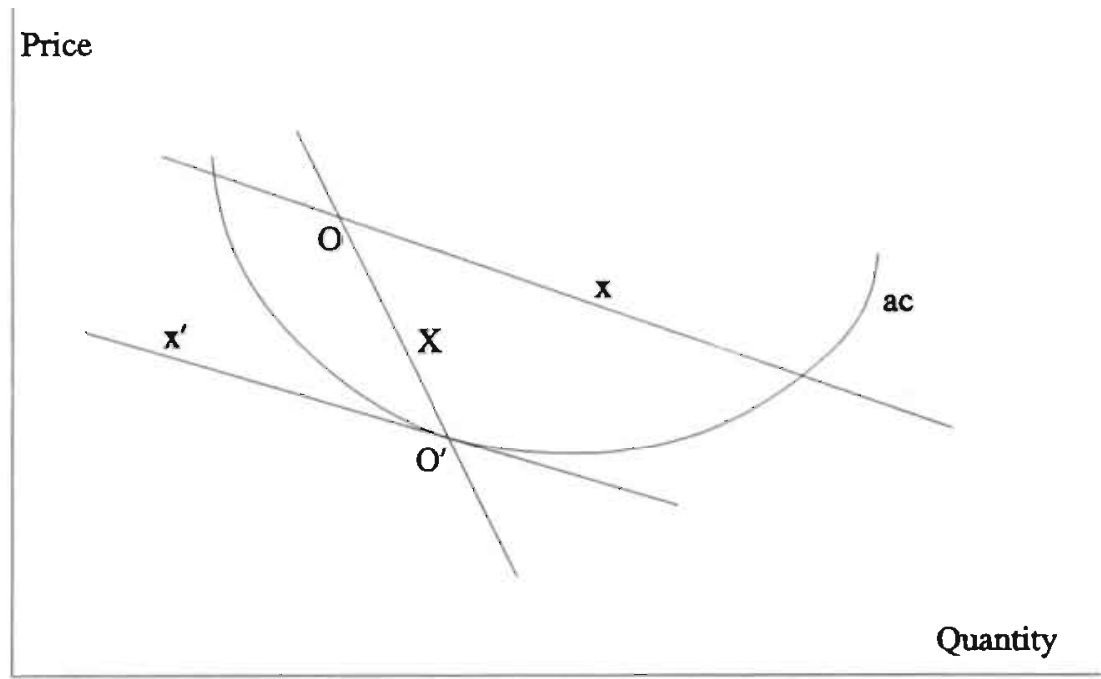

Figure 1.2: Monopolistic competition and myopia

consequently is tangent to the U-shaped average cost curve in the interval in which the average cost curve is downward sloping. In the long-run equilibrium. average cost is not minimized. This result is known as the excess capacity argument, and is seen as an inefficiency: Prices are higher than they would be in the perfectly competitive equilibrium. Quality levels likewise are lower than could be attained under perfect competition [Chamberlin (1933: 100)]. This result, however, is heavily debated.

Chamberlin's long-run equilibrium concept is criticised by Demsetz (1959). According to Demsetz (1959: 28-29), production at minimum average costs is the only sustainable production level. Demsetz argues that changes in quantity are attended with changes in advertising (or quality): Each quantity has its own optimal level of advertising. As a consequence, advertising outlays are different for each quantity. Demsetz further argues that average returns depend on advertising as well and have an inverted $U$-shape. In equilibrium average return equals minimum average cost. If it would not, firms would either merge or split. Demsetz' argument is attacked by Barzel (1970). Barzel shows that average return (demand) must be a decreasing function of the quantity sold, when changes in preferences due to changes in advertising are accounted for. This fact in combination with the zero-profit condition suffices to establish a long-run equilibrium at the downward sloping part of the cost curve. Demsetz (1972) accepts Barzel's criticism on methodological grounds, but nevertheless keeps arguing that the concept of monopolistic competition is not consistent and that production levels other than those corresponding with the minimum cost level cannot be sustainable.

Demsetz' (1959) arguments find support in more recent contributions to the 
literature on monopolistic competition. Tirole (1988: 288), for instance, argues that the reasoning behind the notion of excess capacity is flawed. If a product is unique, its introduction can be justified even if economies of scale are not exhausted. If there is one competitor selling exactly the same product, the demand curve is horizontal at the competitor's price. As a consequence, price equals minimum average cost. ${ }^{(3)}$ With respect to monopolistic competition it is common to assume that each producer sells a unique product. When this is so, there is excess capacity in the sense that in the long-run equilibrium there must be increasing returns to scale [Krouse (1990: 131-132)]. But if no other firm produces exactly the same good, the level of capacity is not the decisive factor in deciding whether the allocation of resources is optimal or not. Average cost (price) must be weighed against the desire for variety. Dixit and Stiglitz (1977) show, using a CES-utility function, that in the long run both firm output and the number of varieties are optimal subject to a zero-profit constraint. When this constraint is not imposed, output per firm is lower while the number of varieties is higher. This result contradicts the myth of excessive brand proliferation often found in the literature. Besanko et al. (1990), employing a logit demand model, reach similar conclusions as Dixit and Stiglitz do: Product variety is optimal when lump-sum subsidies are not allowed for; otherwise, it is lower instead of higher. However, when more general CES-utility functions are used [Hart (1985); Yang and Heijdra (1993); and for a remark on the latter paper Dixit and Stiglitz (1993)], the number of varieties may either be too small or too large and output per lirm either too large or too small. But these contributions do show that the long-run equilibrium in monopolistic competition is likely to be more or less ideal [Chamberlin (1933)]. Variety and price (average cost) are traded off almost perfectly from the perspective of consumer utility. ${ }^{(4)}$ Dynamic efficiency is approached while net profits are zero. There is no static efficiency since price exceeds marginal cost, but prices are about optimal when the zero-profit constraint is taken into account (second-best optimality).

\subsection{Workable competition}

The concept of workable competition is developed as a critical reaction to the concept of perfect competition [Clark (1940)]. Neo-classical analysis provided economic theory with perfect competition as a welfare-theoretic benchmark for

(3) There is a flaw in Tirole's (1988: 288) analysis as well. In the equilibrium described by Tirole both firms sell the quantity at which average costs are minimum at a price equal to average cost. Now, suppose that one firm raises its price infinitesimally. Its demand falls to zero while its rival's demand doubles. However, because costs are U-shaped, the rival firm is not willing to meet the rise in demand. As a consequence, all consumers buying at the firm which raises its price are forced to pay the higher price.

(4) In spatial differentiation models, there is likely to be excessive brand proliferation: price competition is less fierce because of strategic interdependence. Profits and entry thus are higher than under Chamberlinian competition [Deneckere and Rothschild (1992)]. 
evaluating industry performance. Under perfect competition the three Paretian optimality conditions are met: (1) The marginal rate of substitution between any pair of goods is the same for each consumer; (2) the marginal rate of technical substitution for any pair of production factors is equal for every good; and (3) the marginal rate of transformation for every pair of goods is equal to the marginal rate of substitution for that pair. The first condition guarantees that consumers cannot improve utility by voluntary exchange. The second condition says that production cannot be increased by a shift in the factors of production. The third condition implies that consumers cannot be made better off by raising production of one good at the detriment of another. The three conditions are satisfied under perfect competition since the market mechanism guarantees that a Walrasian general equilibrium ${ }^{(5)}$ is established. This implies that price and marginal cost are equal in every market. In order to restore general equilibrium and Pareto optimality the first-best rule, price equals marginal cost, may be applied. This policy recommendation guarantees static efficiency.

However, perfect competition is a poor measuring rod for evaluating industry performance. Industry structure and conduct, as observed in reality, do not accord with the assumptions underlying perfect competition. This default limits the possibility to draw conclusions from the theory of perfect competition and certainly to translate these conclusions into policy. In the theory of perfect competition, no account is heing made of aspects like increasing returns to scale, external effects, product differentiation and product and process innovations. The theory consequently is not able to weigh the costs and benefits these aspects create against static efficiency. It is unclear on this ground alone whether it is desirable to achieve equality of price and marginal cost. For a critique on perfect competition see Sche-rer and Ross (1990: 29n). One may also question the first-best Pareto-conditions on welfare-theoretic grounds. Second-best theory shows that an approach to perfect competition in one market does not necessarily improve social welfare [Lipsey and Lancaster (1956); see Mishan (1981) for an overview]. Suppose that social welfare may be given by $\Sigma(\mathbf{x})$ and feasibility constraint $\Phi(\mathbf{x})$, where $\mathbf{x}=\left[\mathrm{x}_{1}, \ldots, \mathrm{x}_{\mathrm{n}}\right]^{\prime}$ is a vector representing all goods. The first-best rule is given by $\Sigma_{i} / \Sigma_{j}=\Phi_{i} / \Phi_{j}(i \neq j)$. In a second-best world, there are some restrictions inhibiting the application of the firstbest rule - price equals marginal cost - to all markets. When it is necessary to satisfy a zero profit constraint, for instance, marginal cost pricing can no longer be applied in industries exhibiting economies of scale. Second-best theory argues that social welfare may be maximized subject to these constraints. Now, suppose that the industry exhibiting economies of scale applies average cost pricing. As a result price no longer equals marginal cost in this sector: $\Sigma_{x} / \Sigma_{y}=\lambda_{x y} \Phi_{x} / \Phi_{y}(\lambda \neq 1)$. Given this constraint, the second-best rules can now be given by $\Sigma_{i} / \Sigma_{j}=\lambda_{i j} \Phi_{i} / \Phi_{j}$, where in general $\lambda_{i j}$ $\neq 1$. The first-best Pareto conditions are no longer optimal. In principle, one could apply the second-best requirements implied by the $\lambda_{\mathrm{ij}}$ 's. However, the information

(5) A Walrasian general equilibrium is reached when notional demand equals notional supply in each market. 
requirements needed to apply the second-best conditions are enormous. These requirements give a blow to the possibility to pursue industrial policy. A way out of this blow is offered by third-best theory [Ng (1983)]. We will follow a slightly different way and will suppose, as is common in Industrial Organization, that it is legitimate to apply partial analysis.

The concept of workable competition is developed as a critique to perfect competition. The concept takes account of aspects of market structure like increasing returns to scale and dynamic economies in order to obtain a more comprising benchmark. Workable competition is described by the state of an industry which may be considered as the most desirable from society's point of view. This state is the benchmark for evaluating the business. Sosnick (1958) gives an alternative definition of workability. An industry may be considered to be workable if government policy is not able to improve social welfare by any industry policy. Von Weiszäcker (1980) discusses barriers to entry from a similar point of view. From a welfare-theoretic point of view the simple fact that entrants bear costs that incumbents do not bear is not relevant. ${ }^{(6)}$ This only becomes relevant if a cost asymmetry is attended with a distortion in the allocation of resources. ${ }^{(7)}$ When there is no such distortion, one should not make a big fuss about the cost asymmetry. Von Weiszäcker illustrates his argument with a discussion of Coumot-competition. Suppose that costs are given by a constant returns-to-scale technology and set-up costs SC. It would be optimal from a social point of view if one firm would produce up to the point where price equals average cost. (We assume that there is a zero-profit constraint.) Set-up costs are incurred only once. In the zero-profit Cour-not-equilibrium, however, many firms would produce a smaller overall amount, since all firms need to cover set-up costs. Price is higher and there is unnecessary duplication of set-up costs. So, given the fact that there is too much entry from a social point of view [op. cit. p. 405], entry deterrence would not be so bad after all.

Industry performance depends on industry structure and the behaviour of enterprises in the industry. The influence of structure and conduct on performance can be scheduled in a structure-conduct-performance (SCP) diagram as given by Figure 1.3. The influence is shown by the solid lines. Industries are more complex than the solid lines in Figure 1.3 suggest. Conduct determines structure, and performance both structure and conduct. This influence is depicted through the interrupted lines. Structure, conduct and performance influence each other reciprocally. This explains why criteria for performance do not suffice to determine the workability of an industry. Criteria for structure and conduct are needed as well [Sosnick (1958: 385n)].

(6) This comes down to Stigler's (1968) definition of barriers to entry. There is a barrier to entry according to Stigler if an entrant needs to bear costs an incumbent does not have to bear.

(7) This comes down to Von Weizsäcker's (1980a) definition of barriers to entry. There is a barrier to entry according to Von Weizsäcker if entrants bear costs incumbents do not have to bear and if this fact is detrimental to social welfare. This detinition accords with the barrier market concept [Sub-section 1.3.2]. 


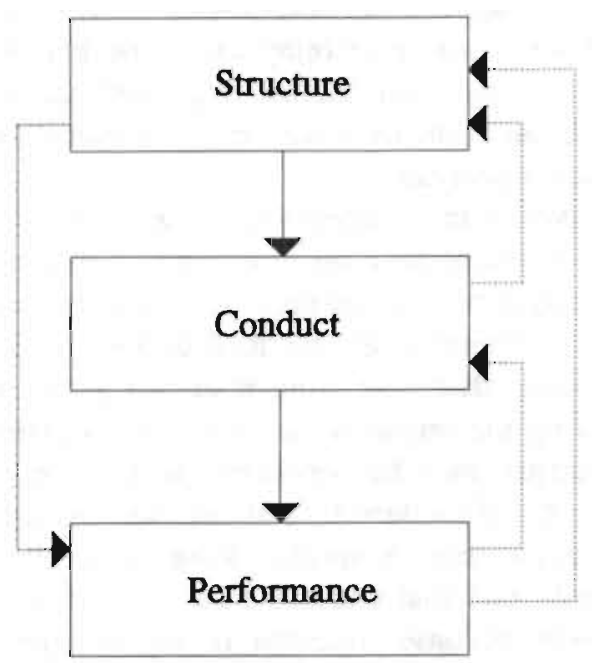

Figure 1.3: Structure-Conduct-Performance Diagram (I)

On the basis of the first definition mentioned above several norms have been developed for market structure, firm behaviour and industry performance. Sosnick (1958: 389-401) mentions 7 norms for structure, 6 for conduct and 13 for performance, Scherer and Ross (1990: Chapter 2) mention 3, 6 and 7 norms, respectively. Most of the norms mentioned by Scherer and Ross are reproduced in Appendix A to give an impression of the norms formulated by authors on workable competition. The norms have been criticized on the following grounds. (1) The first two criteria mentioned in the Appendix are similar to the assumptions of perfect competition and most of the other criteria mentioned follow from these two. (2) It is difficult to implement the criteria since they are not well defined and may conflict with each other. (3) The importance of the criteria is dependent on the situation prevailing in a particular market. In order to establish more precise policy recommendations Reid (1987: 124) proposes to define structure, conduct, and performance characteristics $\left(\mathbf{V}_{\mathrm{s}}, \mathbf{V}_{\mathrm{s}}\right.$ and $\mathbf{V}_{\mathrm{p}}$, respectively) and to make these characteristics the arguments of the social welfare function $\Sigma=\Sigma\left(\mathbf{V}_{s}, \mathbf{V}_{\mathrm{c}}, \mathbf{V}_{\mathrm{p}}\right)$. The welfare function may be defined by the legislature. The causal relationships given by Figure 1.3 make up the constraint $\Phi$ $=\Phi\left(\mathbf{V}_{\mathrm{s}}, \mathbf{V}_{\mathrm{c}}, \mathbf{V}_{\mathrm{p}}\right)$ under which the optimization problem has to be solved. Other constraints, for instance legal ones, could be added. In practice, the legislature is likely to compare a few policy options, for instance $\mathbf{V}^{1}=\left(\mathbf{V}_{\mathrm{s}}^{1}, \mathbf{V}_{\mathrm{c}}{ }^{1}, \mathbf{V}_{\mathrm{p}}{ }^{1}\right)$ and $\mathbf{V}^{2}=$ $\left(\mathbf{V}_{\mathrm{s}}^{2}, \mathbf{V}_{\mathrm{v}}{ }^{2}, \mathbf{V}_{\mathrm{p}}{ }^{2}\right)$. Now when $\Sigma\left(\mathbf{V}^{1}\right)>\Sigma\left(\mathbf{V}^{2}\right), \mathbf{V}^{1}$ should be preferred. Reid (1987: 130n) gives some examples of implementing these recommendations. He shows, for instance, that output subsidies in combination with lump-sum taxes may be used to appropriate the deadweight loss caused by monopolistic price setting. In the examples, Reid applies partial analysis and does not eschew making simplifying assumptions if necessary to arrive at policy recommendations. Criticism may be 
launched from the perspective of second-best theory, but Reid (1987: 122) argues that the blow second-best theory gives to policy recommendations may not be that serious. Not all potential difficulties are important in specific contexts [Guesnerie (1980)]. As already stated above, we will follow a similar line below and apply partial analysis as well.

We may conclude that workable competition is developed as a benchmark comprising both marginal cost pricing (static efficiency) and process and product innovations (dynamic economies). However, the criteria for evaluating industry performance are not well defined and may conflict with each other. The trade-off between static and dynamic efficiency is balanced out optimally from a social point of view, since dynamic economies are rewarded such that investments are just induced [Appendix A]. Reid (1987) suggests that formalization of the concept may be possible. Contestability theory and the barrier market concept [Section 3] give other examples of the way in which the concept of workable competition may be formalized ${ }^{(8)}$ While contestability theory remains static in nature, the barrier market concept explicitly incorporates dynamic features into the analysis.

Clark (1940) pays some attention to the plausibility of workable competition. According to Clark (1940: 246-249) firms face (potential) severe competition from firms offering the same product or close substitutes. Long-run demand of individual firms thus is very elastic as a consequence of which the possibility to exploit monopoly power is limited. Competition enforces workable outcomes since the degree of substitutability between goods is sufficiently high. This view on the market mechanism resembles the classical view on competition [Smith (1776)] and that of Chamberlin (1933) [Sub-section 2.1].

\subsection{Limit price theory}

The first foundations of limit price theory were formulated in the 1940s and further developed in the 1950s. Bain (1949) was the first to acknowledge the entry-deterring effect of limit prices. Bain (1956) provided empirical support for these notions. Other important contributions are Sylos Labini (1957) and Modigliani (1958), and more recently Gaskins (1971). In the literature on limit pricing, a distinction is made between small-scale and large-scale entry. ${ }^{(9)}$ After an introduction in limit price theory we will discuss small and large-scale entry respectively. Thereupon we will criticize one of the main assumptions made in the early large-scale entry models: The Sylos' postulate. At the end of this section we will discuss papers assimilating this criticism.

(8) Theories of pricing under asymmetric information also obtain workable outcomes in the limit [Stiglitz (1989: 797) and Bester (1988: 210)], i.e. when the number of firms goes to infinity.

(9) An entrant is considered to be small if its entry does not affect the market price. 
Bain (1956: 1) stresses the importance of potential competition for industry performance. Incumbent enterprises are not only disciplined by mutual competition, but also by potential entry. Industries reach a stable long-term equilibrium when the process of entry (and exit) comes to a standstill. Profitable entry is then no longer possible (Sylos Labini, 1957: $5 \mathrm{ln}$ ). Incumbent enterprises in concentrated industries consequently do not necessarily have substantial monopoly power. If they exploit their monopoly power, the long-run equilibrium is broken and entry induced as a consequence of which the incumbents' long-run profits are reduced [Bain (1949: 451)]. The entry threat narrows the zone of discretion in which enterprises may set prices. The (limit) price thus approaches the average cost level. The degree in which potential competition disciplines incumbents, finds expression in the condition of entry, commonly referred to in the literature as the barrier to entry [Scherer and Ross (1990)]. An entry barrier may be defined as 'the advantage of established sellers ... over potential entrant sellers, these advantages being reflected in the extent to which established sellers can persistently raise their prices above a competitive level without attracting new firms to enter the industry [Bain (1956: 3)]. ${ }^{(10)}$ Entry can be deterred, even if incumbent enterprises make (substantial) profits, when (1) economies of scale are not negligible, (2) incumbent enterprises have product differentiation advantages or (3) absolute cost advantages. When economies of scale are significant, entry adds substantial output to industry output. This addition causes a decline in price. The expected post-entry price may be low enough to deter entry. Large-scale entry is discussed below. Established enterprises have a product differentiation advantage when consumers are not perfectly informed about the characteristics of the products of potential entrants [Bain (1956: 114-120) and Sylos Labini (1957: 53-56)]. Potential entrants have to overcome consumer ignorance by spending (relatively) large expenses on advertising outlays. Bain (1956: 18) supposes that the determinants of barriers to entry are not subject to large changes.

\section{Small-scale entry}

In the case of small-scale entry the dominant firms in a particular industry have to consider the so-called competitive fringe. This fringe consists of a large number of small-scale potential entrants which enter the industry if price exceeds their minimum average cost level. The limit price, which is defined as the highest price which may be set without attracting entry, thus equals the average cost level of rival producers. Dominant firms earn positive profits when they set the limit price and also have a cost advantage over the potential entrants. If the potential entrants' reaction period is sufficiently small, their cost level may indeed put an upper limit to the price incumbent firms may set without inducing entry. If their reaction period is sufficiently long, incumbent firms face a trade-off. Incumbents earn larger profits in

(10) Several alternatives are proposed. The most important are by Stigler (1968) and Von Weiszäcker (1980) [footnote 6 and 7]. 
the short run when they set a price above the limit price. ${ }^{(1)}$ Long-term profits fall, however, as rivals enter the market. The price set depends on the speed of entry and the discount rate. Gaskins (1971) models the speed of entry V as a linear function of the difference between the market price $P_{m}$ and the limit price $P_{1}$

$\mathrm{V}=\mathrm{v}\left(\mathrm{P}_{\mathrm{m}}-\mathrm{P}_{1}\right)$

where $v$ is a constant indicating the entry speed. ${ }^{(12)}$ The difference $\left(P_{m}-P_{l}\right)$ may also be negative: It may be profitable for an incumbent enterprise to reduce the output of established fringe firms by inducing their exit. In that case the incumbent gives up current profits in exchange for higher future profits. Gaskins' main contribution to limit price theory is the introduction of a continuous price set from which the incumbent may choose. The incumbent does not necessarily choose between the short-run profit-maximizing and the limit price. The incumbent maximizes discounted profits by weighing short-run versus long-run profits. He may set a price (1) above the limit price in order to gain large short-run profits (at the detriment of market share) or (2) below the limit price in order to gain market share and high profits in the long run. ${ }^{(13)}$ In the latter case the incumbent raises the price in a later stage when rival output has been reduced sufficiently.

\section{Large-scale entry}

According to Sylos Labini (1957: 43), incumbent firms do not curtail output in case of large-scale entry in order to deter entry and in order to hold the average cost level down. (This assumption is referred to in the literature as the Sylos postulate.) Potential entrants acknowledge that large-scale entry reduces market price: They are concerned with market price ex post. The fact that entry reduces price, enables incumbents to set prices above minimum average cost, even if they do not have cost advantages in relation to potential entrants. This result is outlined by Modigliani (1958: 218-220). The analysis will be sketched briefly. Suppose incumbent firms sell quantity $S$ at price $P$ [Figure 1.4]. Entrants may be supposed to enter at the minimum optimal scale (MOS): The scale at which average costs are minimum. After entry, market output equals $S^{\prime}$. Price falls from $P$ to $P$ ', the minimum average cost level MAC. $P$ thus deters entry as entrants do not make positive profits after entry. However, an entrant may also enter at a lower scale than the MOS. Since incumbents

(II) We presuppose that the short-run profit-maximizing price level exceeds the limit price. If it does not, the incumbent enterprises do not face a trade-off.

(12) The behaviour of fringe firms and thus the entry speed are postulated rather than derived from profit maximization. It is plausible to assume that the entry speed depends on the difference between the market price and the limit price, id est the cost level of fringe firms.

(13) The price set may, of course, also equal the limit price. 


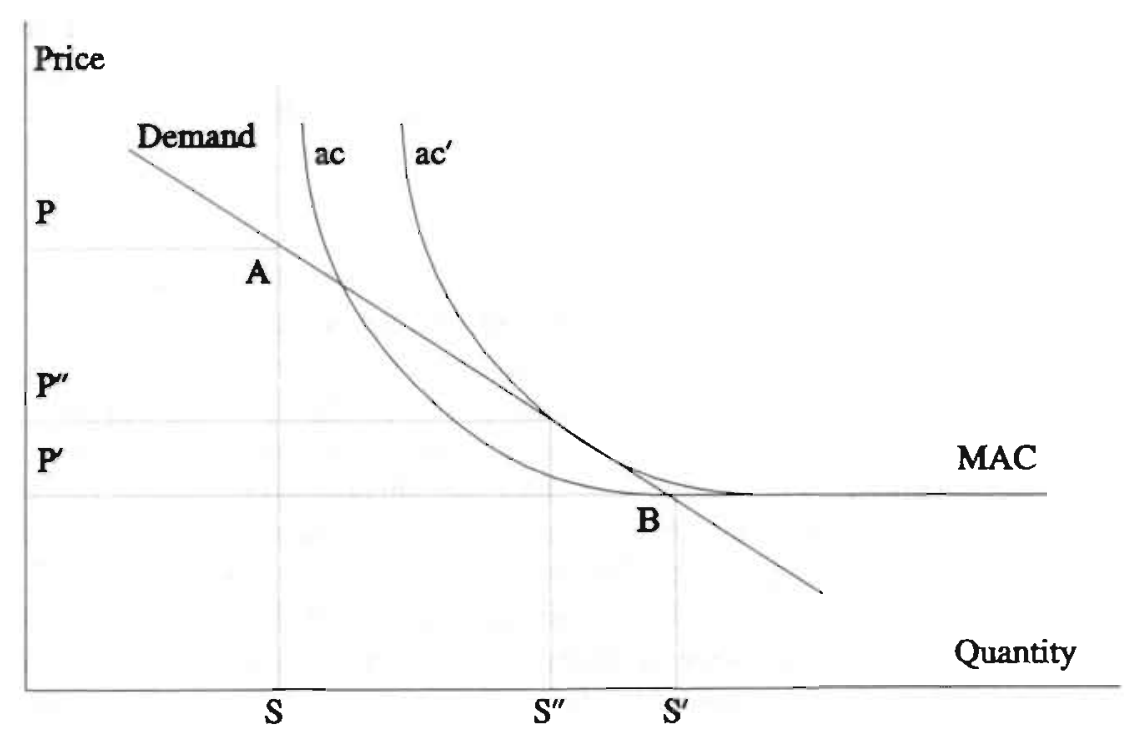

Figure 1.4: Deterrence of large scale entry

produce $\mathrm{S}, \mathrm{AB}$ can be considered to be the entrant's demand curve. The entrant's average cost curve ac is drawn beginning in $S$. Then it is profitable to enter at a lower scale than MOS, because the cost curve is below the demand curve to the left of B. The entry-deterring output and price levels can be found by shifting the cost curve horizontally to the right until it is tangent to the demand curve. The cost curve (ac') will then no longer be below the demand curve. The entry-deterring output level equals S", and the entry deterring price level P".

We may thus conclude that static efficiency is not met, but may be approached. The degree to which the limit price approaches marginal and average cost depends on market size, elasticity of demand and economies of scale. The limit price falls when market size or elasticity of demand increases. The limit price rises when economies of scale become more important. The latter occurs when the minimum optimum scale increases or when the curvature of the average cost curve at lower levels of output increases. In the long run, demand elasticities tend to be high. At the global scale, scale economies are not important. In general, the market power of firms seems limited.

\section{Credible threats}

The Sylos' postulate is criticized on the following ground. It may be profitable for incumbent enterprises to restrict output when entry has occurred. The knowledge that - after entry - output restriction is the more profitable strategy for incumbent enterprises, invalidates the Sylos' postulate. Entry is more profitable when the Sylos' 
postulate is not valid and an output restriction may be expected. It is argued that incumbent firms may nevertheless threaten not to restrict output in order to deter entry. Others argue that this threat is empty, since it is not rational, i.e. profit maximizing. ${ }^{(14)}$ Subsequently, attempts have been made to formulate non-empty threats. A threat is non-empty when a commitment to uphold the threat after entry (ex post) has been made. According to Scherer and Ross (1990: 381), commitments involve investments in durable and irreversible assets. Threats and commitments have been analyzed by Schelling (1960), Spence $(1977,1979)$ and Dixit $(1979,1980)$. The literature on threats and commitments is reviewed by Gilbert (1989), Lyons (1991) and Van Wegberg (1993). Commitments may relate to unit costs and capacity, as they do in the literature mentioned above, but they do not have to. They may also relate to patents [Gilbert and Newbery (1982)] or product differentiation [Schmalensee (1978)], in particular plant location [Hotelling (1929), Hay (1976) and Prescott and Visscher (1977)]. Two commitment models will be treated below: One on capacity and unit costs following Dixit (1980), and the other on product innovation following Prescott and Visscher (1977).

\section{Capacity}

The importance of commitments for the credibility of a threat was first recognised by Schelling (1960). Schelling analyzed games involving threats (and commitments) in his analysis of international conflicts. Spence (1977) recognized the importance of commitments for threats by incumbent firms against potential entrants. The models Spence presented do not really involve commitments. Dixit (1980), however, presents a model which does involve a commitment. He formulates a Coumot model with one incumbent firm and one potential entrant. The incumbent enterprise has the opportunity to install capacity upfront and by so doing reduce marginal costs over some interval. The reduction in marginal costs increases the gross margin. The investment makes an increase in production more profitable if compared with the zero investment case, whether entry occurs or not. The potential entrant realizes this, and consequently knows that capacity investment reduces residual demand and limits entry opportunities. Dixit does not predict that incumbents invest in capacity in order to bar entry. They may find it profitable to invest in order to bar entry or in order to influence the duopoly outcome, if accommodation of entry is the more profitable strategy. Dixit (1979: 29) points out that it is easier to deter entry when goods are substitutes, but that - after entry - profits are higher when goods are not very good substitutes. Basu and Singh (1990: 66-7) show that a distinction between sunk entry and production costs reduces the credibility of the entry threat and increases the opportunity to earn monopoly profits. The timing structure is such that the incumbent

(14) Bain (1949: 452) was already aware of this fact: 'At the extreme, it could even be argued that a potential entrant to an oligopoly should pay little regard to price or profit received by established firms, especially if he thought price was being held down in order to "bluff" him away from the industry.' 
has the opportunity to deter entry if necessary. The incumbent acts as Stackelbergleader. The distinction between sunk entry and production costs gives credibility to the incumbent's leadership because part of the follower's reaction function is eliminated. The necessity to deter will thus never materialize.

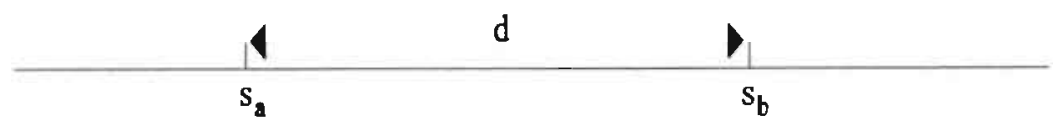

Figure 1.5: Entry deterrence in case of horizontal differentiation

\section{Product differentiation}

Hotelling (1929) analyzed product differentiation by modelling geographic distance using a one-dimensional line. ${ }^{(15)}$ This model can also be used to analyze other product characteristics than distance. Prescott and Visscher (1977) present a model of entry deterrence based on Hotelling. Their paper presents a few models with the following characteristics. Firms enter sequentially. A firm which enters, invests irreversibly in location. The sunk nature of the investment guarantees that firms will not relocate. A firm has to earn enough money in order to recover the investment expenses. Consequently, a firm only enters if it is able to serve an area that is sufficiently large. The sequential nature of the entry process enables first movers to choose their location strategically. As a result. they are able to guarantee areas which are larger than necessary to cover the investment expenses and which still are not large enough to induce further entry. This can be illustrated using a simple example. Suppose the area is one dimensional and that the customers are uniformly distributed along the line given in Figure 1.5. Firm $A$ is located at $s_{a}$ and firm $B$ at $s_{b}$. There is one potential entrant, firm C. All firms are supposed to charge the same price. The area between $A$ and $B$ is equal to $d$. The distance necessary to cover the investment outlays is equal to $(\mathrm{d} / 2)$. Wherever firm $\mathrm{C}$ locates between $\mathrm{A}$ and $\mathrm{B}$, it will only secure an interval with a length of $(d / 2)$. It is not worthwhile for firm $C$ to invest in a location between $A$ and $B$ as it only recovers its investment expenses. If the line is long enough, firm A and firm B are able to guarantee an interval with a length of (d/2) on both sides of their locations. The length of the total interval they thus serve equals $d$, which is twice the amount needed to recover the investment outlays. The power of potential entry is limited, according to Prescott and Visscher. This result is due to the assumption that investments in location are associated with sunk costs. The location decision is irreversible. When this assumption is dropped, net profits are zero

(15) Because competition in product characteristics is explicitly modelled in Hotelling's framework, firms are able to invest strategically. Strategic interaction is not considered in Chamberlin's theory of monopolistic competition [sub-section 2.1]. This justifies the zero profit constraint in the latter theory, but not in Hoteling's framework. 
in equilibrium [Salop (1979)].

Prescott and Visscher (1977) assume that enterprises locate only one firm in an industry. Judd (1985) and Bhatt (1987) both argue that this assumption is not that unlikely. In both models an incumbent with more than one outlet is more vulnerable to entry than an incumbent with one outlet. Judd (1985) considers the entry threat for a firm incumbent in two related markets, the market for oranges and the one for apples. Judd shows that brand proliferation is not credible when markets are related. When the entrant decides to enter the market for oranges, for instance, Bertrand competition implies a loss for the entrant, but a larger loss for the incumbent since the market for apples is affected as well. This forces the incumbent to withdraw from the market for oranges rather than the entrant. In Bhatt (1987) the incumbent also prefers one outlet over more, since a disproportionate share of the burden to curtail output falls on the larger firm.

\section{Concluding remarks}

Limit price theory shows that the threat of potential entry limits the discretion of incumbent enterprises to elevate prices in order to extract monopoly profits. Industries reach a long-term equilibrium when profitable entry is no longer possible. Entry may be deterred by limit pricing since this strategy reduces the profitability of entry. The strategy is associated with a reduction in profits and an increase in consumer surplus. However, limit prices are only credible when a commitment is involved. The Sylos' postulate as such, for instance, is difficult to uphold. Scherer and Ross (1990) argue that commitments involve investments. In Dixit (1980), incumbent enterprises invest in capacity in order to reduce marginal costs. The investment can be seen as a process innovation. Investments may lead to process and product innovations and thus increase social welfare.

What does the discussion on credibility imply for the debate on static versus dynamic efficiency? The entry threat does not inhibit monopoly pricing, since limit pricing as such is not credible. However, the threat induces firms to make irreversible investments. The investments may be associated with process and product innovations, i.e. lower costs and prices and higher qualities. Limit price theory thus predicts that markets do not necessarily perform very well in terms of static efficiency and probably quite well in terms of dynamic efficiency. Note, however, that the latter is not guaranteed by the need to make commitments.

\section{The contestability framework}

The entry threat is nowhere so pervasive as in the contestability framework. This framework may be subdivided into two different concepts: (1) Perfect contestability introduced by Baumol, Panzar and Willig (1982); and (2) the barrier market concept developed by Maks (1986) and Van Witteloostuijn and Maks (1987 and 1988) as an extension of perfect contestability to a dynamic framework. Baumol et al. argue that when there are no sunk costs, price equals marginal costs in no matter what market 
structure (when average costs are constant over a sufficiently long range). In order to introduce dynamic economies sunk costs are allowed for in the barrier market concept. In this concept both static and dynamic efficiency is met. This section is constructed as follow: Sub-section 3.1 treats contestability theory; Sub-section 3.2 deals with the barrier market concept.

\subsection{Perfect contestability}

The basic assumption underlying contestability is that there are no exit costs related to entry. So entry is absolutely costless, and potential entry thus becomes a pervasive threat for incumbent firms. Potential entrants are able to prey upon incumbent firms making positive profits by so-called hit-and-run entry. Incumbent firms are forced to apply marginal cost pricing as a consequence of which static efficiency is enforced regardless of market structure. This general introduction into contestability theory is elaborated below. The assumptions and definitions are given first. Thereupon we consider the performance of a perfectly contestable market. Before we discuss the criticism made we insert a pause to discuss intertemporal allocation and efficiency. We end with a discussion of criticism launched against perfect contestability and some concluding remarks.

\section{Assumptions}

The assumptions presented below are necessary in order to make a benchmark out of the concept of perfect contestability. They underlie the normative part of Baumol $e t$ al.'s analysis. The following assumptions are made [Baumol et al. (1982: 4-7)]..$^{(16)}$

(1) Potential entrants are able to deliver the same products against the same costs as incumbents do. So, potential entrants do not suffer disadvantages relative to incumbents due to differences in production techniques or in the consu-mers' perception of the products offered.

(2) There are no sunk costs and, by implication, no exit costs. Sunk costs are the value of capital that cannot be recouped by selling the capital. Exit costs are the sunk costs that have not yet been amortized. So, entry is perfectly reversible.

(3) Potential entrants evaluate profit opportunities on the basis of incumbent firms' pre-entry prices. This assumption can be defended with reference to, for instance, antitrust policy, Bertrand-Nash expectations or costless entry and exit [Baumol et al. (1982: 11)].

(16) Van Witteloostuijn (1990: 53-56) presents an exhaustive list of assumptions. The list includes some assumptions which presumably are implicit in Baumol et al. (1982). 


\section{Definitions}

The definitions given below characterize cost functions and equilibrium conditions. They describe a positive theory of market structure and may thus be used for other purposes than grounding perfect contestability. The following definitions are made by Baumol et al. (1982: 16-29).

(1) An industry configuration is feasible if $\Sigma S_{i}=X(P)$ and $P . S_{i}-T C\left(S_{i}\right) \geq 0$ for all $i=1, \ldots, m$. The subscript $i \in\{1, \ldots, m\}$ and represents a firm, $S_{i}$ denotes firm i's output, $X$ industry demand, $P$ industry price and TC a firm's total costs.

(2) A feasible industry configuration is sustainable if $\mathrm{P}_{\mathrm{e}} \mathrm{S}_{\mathrm{e}} \leq \mathrm{TC}\left(\mathrm{S}_{\mathrm{e}}\right)$ for all $\mathrm{P}_{\mathrm{e}} \leq \mathrm{P}$ and $S_{e} \leq X\left(P_{e}\right) .{ }^{(17)}$ The subscript e refers to the potential entrant.

(3) An industry is a natural monopoly if the cost function is subadditive over the relevant range of outputs. A cost function is subadditive if $\mathrm{TC}(\mathrm{S})<\Sigma \mathrm{TC}\left(\mathrm{S}_{\mathrm{i}}\right)$, where $\Sigma \mathrm{S}_{\mathrm{i}}=\mathrm{S}$.

\section{Performance}

The price vector that yields zero profits is the only vector that guarantees the sustainability of a contestable market configuration. So $\left(P-a c\left(S_{1}\right)\right) S_{i}=0$ for all $i=1$, ..., $\mathrm{m}$; ac denotes average costs. This result is conditional on the above assumptions. The result is illustrated by the payoff scheme denoted in Table 1.1 [Van Witteloostuijn (1990: 61)]. Note that the table represents an extensive form game. There is one incumbent and one potential entrant. The incumbent has two alternatives: $P>$ ac $\left(S_{i}\right)$ $\left(a_{1}\right)$ and $P=a c\left(S_{i}\right)\left(a_{2}\right)$. The entrant also has two alternatives: $P_{e}<P\left(a_{3}\right)$ and nonentry $\left(a_{4}\right)$. The payoffs of the players are depicted in the table. The dominating strategies are underlined.

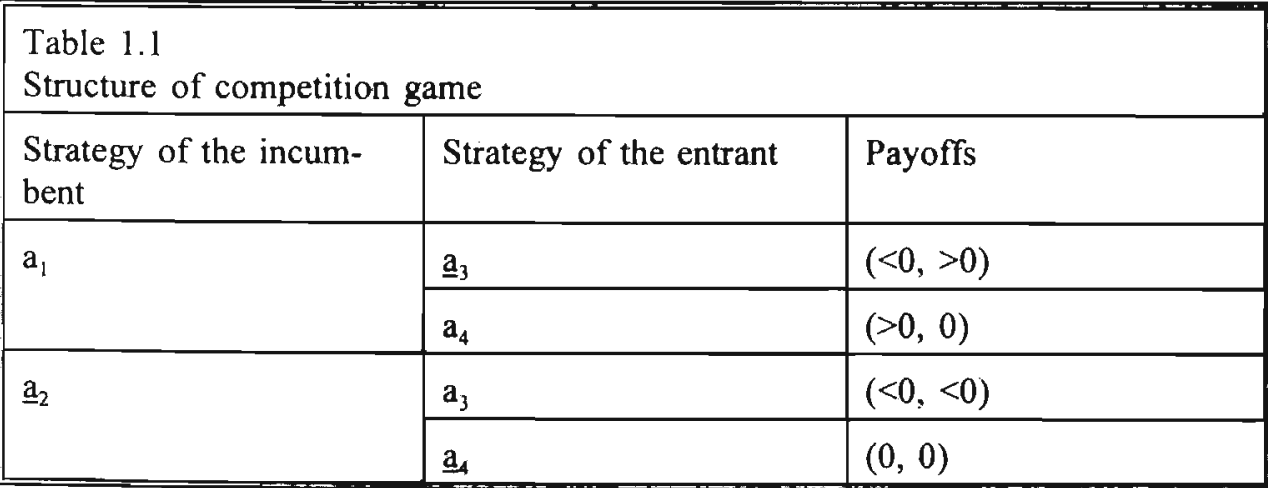

(17) This definition refers to temporal sustainability. A market configuration is intertemporarily sustainable, if the entry threat in period $t$ does not influence current prices and planned future prices [Baumol et al. (1982: 372)]. 
Expelled firms are supposed to incur a (small) loss, although this contradicts the very definition of contestability theory. This assumptions implies that the incumbent faces exit costs while the entrant does not [Van Witteloostuijn (1990: 60)]. The combination $\left(a_{2}, a_{4}\right)$ is a unique Nash-equilibrium, because the entrant will choose $a_{3}$ given $a_{1}$ and $a_{4}$ given $a_{2}$. Given these strategies, $a_{2}$ is the better strategy for the incumbent. (If the incumbent does not suffer a loss when being undercut, $a_{1}$ would weakly dominate $a_{2}$.)

The performance of contestable markets can now be summarized. The results presented hold, because an argument similar to the one given by Table 1.1 applies [Baumol et al. (1982: 347-360)]. Summarizing we have the following results:

(1) Firms produce against minimal costs.

(2) Market structure is optimal. There is no industry configuration which produces total output at lower cost. Marginal costs are equal over firms in the industry.

(3) Cross subsidies are not possible. ${ }^{(18)}$

(4) Prices equal average costs and even marginal costs if there are two or more firms in the industry.

(5) Product variation is optimal. This result only holds, when the fixed costs associated with product differentiation are not sunk.

(6) Intertemporal allocation is optimal. Under some circumstances this result is not applicable to a monopoly [Baumol (1982: 12-14)]. For this reason (the sustainability of) intertemporal allocation will be discussed below.

If incumbents do not act according to the above results, potential entrants are able to expel them. A rigorous proof can be found in Baumol et al. (1982: 347-360).

\section{Intertemporal allocation}

As said, intertemporal allocation may not be optimal under a monopoly. Intertemporal allocation is not optimal when it is unsustainable. Intertemporal allocation is not sustainable whenever there is no path of Ramsey prices deterring entry. When entry cannot be deterred, wasteful duplication of resources may occur [Ramsey (1929)]. An allocation is Ramsey optimal when social welfare (or consumer surplus) is maximized subject to a zero budget constraint [Boiteux (1956); Baumol et al. (1982: Chapter 13) give a description of Ramsey optimal investment paths]. In the next chapter the issue of intertemporal unsus-tainability is addressed again. This justifies an elaboration of the issue at this point.

Baumol (1982: 12-14) shows that intertemporal allocation is not sustainable if capital costs are sunk and capital construction reveals increasing returns while

(18) They may be possible in case of two-part pricing [Heywood and Pal (1993)]. However, two-part pricing hardly occurs. 
demand increases through time. ${ }^{(19)}$ In this case it is not possible to invest optimally and to set Ramsey prices without provoking entry. This can be shown using a simple two-periods example. Production is supposed to depend on capacity only. Production costs TC thus are

$\mathrm{TC}\left(\mathrm{X}_{1}, \mathrm{X}_{2}\right)=\mathrm{SC}\left(\mathrm{X}_{1}\right)+\mathrm{SC}\left(\mathrm{X}_{2}-\mathrm{X}_{1}\right)$

where $X_{1}$ and $X_{2}$ denote demand in period 1 and period 2, respectively, and $\mathrm{SC}(\mathrm{X})$ the sunk costs needed to generate capacity $X$. By assumption, $X_{2}>X_{1}$. A configuration is sustainable if (1) $\mathrm{P}_{1} \mathrm{X}_{1}+\mathrm{P}_{2} \mathrm{X}_{2} \geq \mathrm{TC}\left(\mathrm{X}_{1}, \mathrm{X}_{2}\right)$ and (2) $\left(\mathrm{P}_{1}, \mathrm{P}_{2}\right)$ is not dominated, where $P_{1}$ and $P_{2}$ denote prices in the respective periods. Entry in period 1 is not profitable whenever

$\mathrm{P}_{1} \mathrm{X}_{1}+\mathrm{P}_{2} \mathrm{X}_{1} \leq \mathrm{SC}\left(\mathrm{X}_{1}\right)$

Equation (2) and condition (1) define the set of equilibrium prices. Combining these two gives

$\mathrm{P}_{2} \geq \mathrm{SC}\left(\mathrm{X}_{2}-\mathrm{X}_{1}\right) /\left(\mathrm{X}_{2}-\mathrm{X}_{1}\right)$

Because of the assumption of increasing returns in construction costs

$\operatorname{SC}\left(X_{2}-X_{1}\right) /\left(X_{2}-X_{1}\right)>\operatorname{SC}\left(X_{2}\right) / X_{2}$

Comparing equation (3) and (4) gives

$\mathrm{P}_{2}>\mathrm{SC}\left(\mathrm{X}_{2}\right) / \mathrm{X}_{2}$

A potential entrant enters in the second period if $\mathrm{P}_{2} \mathrm{X}_{2}-\mathrm{SC}\left(\mathrm{X}_{2}\right) \geq 0$. Equation (5) shows that entry indeed is profitable. This implies that there is no sustainable configuration, as average costs are lower for the entrant than for the incumbent. If the incumbent would set a second-period price $\mathrm{P}_{2} \leq \mathrm{SC}\left(\mathrm{X}_{2}\right) / \mathrm{X}_{2}$ in order to prevent entry, he would either make a loss or be expelled from the market in period 1 . Baumol (1982) concludes that markets face great difficulties in coping with intertemporal allocation. The unsustainability of market configurations is a severe social problem, as costly duplication of capacity occurs. Note that Baumol again assumes that the incumbent sets its price only once. When this is so, the incumbent cannot break even and deter entry. When the incumbent is allowed to react upon the entrant, entry may become unprofitable and may be deterred. The instability problem may

(19) Two points are worth remarking. First, when discussing intertemporal allocation, Baumol et al. drop the assumption of zero sunk costs. Second, demand may be constant or decreasing: as long as capacity deteriorates (to a larger extent), the argument still is applicable. 
also not arise when there is an asymmetry in favour of the incumbent or competition is Coumot instead of Bertrand [Baumol et al. (1982: 425-429) and Reid (1987: 165)].

\section{Criticism}

Perfect contestability is criticized ever since Baumol launched his 'uprising in the theory of industrial organization'. The concept is not so much criticized for internal inconsistency, but more for its presumed lack of robustness ${ }^{(20)}$ with respect to (some of) its assumptions. Since perfect contestability is designed as a benchmark, this criticism is only partly justified. A lack of robustness does not make perfect contestability a less valuable benchmark for evaluating industry performance right away. Policy recommendations, however, are more difficult to make when the assumptions made are implausible from an empirical point of view and the lack of robustness with respect to these assumptions is serious. Since criticism is pinpointed to the presumed lack of robustness, the assumptions made are heavily attacked, particularly because the assumptions are considered to be implausible from an empirical point of view [see, for instance, Stiglitz (1987)]. Let us consider some of the assumptions made.

(1) Contestability theory more or less presumes the presence of potential entrants holding excess capacity. The question arises what kind of firms are likely to hold excess capacity. New firms probably need time to invest and to sink costs. This invalidates some of the assumptions of barrier market theory as a consequence of which new firms are not likely to be an effective entry threat. This threat may also come from firms incumbent in related markets [Hines (1957)]. However, there are two qualifications to be made with respect to the threat exercised by firms incumbent in related markets. (1) When excess capacity is not sufficiently high, the assumption of zero opportunity costs is likely to be invalidated, because entry has repercussions for the entrants' home markets. (2) When spare capacity is sufficiently high, entrants are inclined to dump. (21) However, Cairns and Mahabir (1988) argue that it is not an equilibrium strategy to hold excess capacity in a (perfectly) s.ontestable world since excess capacity implies that costs are not minimized. However, when there are constant returns to scale over some interval [Baumol (1982)], holding excess capacity may be sustainable. Moreover, there is equipment which may be shifted about instantaneously from one market to another. The most men-

(20) A theory is robust with respect to a particular assumption if a (minor) change in this assumption leads to a minor change in the results [Schwartz (1986: 43)]. For example, contestability theory is robust with respect to the zero-sunk-costs-assumption if the introduction of a small sunk cost leads to a tiny price increase.

(21) Entrants are likely to dump when the entry threat is one-sided. When it is not, a nodumping equilibrium may arise. In this equilibrium profits are not necessarily equal to zero. 
tioned market in this respect is, of course, the airline industry. ${ }^{(22)}$ But other service industries are likely to be contestable as well [Spence (1983)].

Stiglitz (1987) argues that sunk costs are an essential element in industrial organization and should be included into the analysis. He shows that when sunk costs are introduced in a contestable framework, the following results may occur.

(i) Profits do not attract entry. 'Even a negligible entry cost can fully cushion the incumbent against encroachment' [Stiglitz (1987: 891)]. The incumbent's price may equal the monopoly price (p. 892). When competition after entry is Bertrand, any sunk cost level prevents entry, no matter how high the pre-entry price level is. This may be illustrated as follows. When there are constant returns to scale in production, total costs $\mathrm{TC}$ are as follows: $\mathrm{TC}=\mathrm{SC}+\phi . \mathrm{S}$ where SC denotes sunk costs, $\mathrm{S}$ output and $\phi$ constant average production costs. Homogeneity of goods and Ber-trand competition suffice to enforce marginal cost pricing when there are two or more producers (with sufficient capacity). In this case all firms in the industry suffer a loss equal to SC. This argument explains why a second firm never enters the industry and a monopolist is able to reap monopoly profits. Any level of sunk costs suffices to deter entry.

(ii) The entrant expels the incumbent and behaves as a common monopolist afterwards.

(iii) The incumbent colludes with the entrant.

Stiglitz' arguments indicate a possible lack of robustness. However, Baumol et al. (1983: 494) and Schwartz (1986: 43) indicate that contestable results may be obtained as limit values. In both papers, price approaches marginal costs, when sunk costs go to zero. These results show that contestability is more robust with respect to zero-sunk-costs assumption than sometimes suggested.

(3) Schwartz and Reynolds (1983) argue that the results depend on the assumption that entrants are able to enter instantaneously (while incumbents are not able to react immediately). When one of these assumptions is dropped, the results may no longer hold. Like any other theory in IO, contestability theory indeed depends on the specific game-theoretic set-up employed [Saloner (1991)].

(22) Bailey et al. (1983) argue that the airline industry is contestable without rigorously proving it. They mention features indicating contestability, like substantial shifts in market share. Several studies question the contestability of airline markets. Peteraf (1995) does not find any relation between sunk costs and the mark-up over marginal cost. However, the reputation of potential entrants has a pervasive influence on the incumbents' pricing behaviour. Sinclair (1995) questions Bailey et al.'s result by showing that economies of scope related to hub-and-spoke systems determine entry and exit decisions. This result only indicates that airline companies need to have similar starting positions. Evans and Kessides (1994) show that contestability is undermined by multimarket contact. 
However, this may imply that contestable results are obtained much more frequently than Schwartz and Reynolds (1983) and Shepherd (1984) suggest. Brock (1983), for instance, gives several examples in which contestable results are achieved. Moreover, the time-structure employed in contestability theory is not implausible from an empirical point of view. Empirical evidence indicates that the reaction speed of incumbents tends to be low: Prices are rigid in reality [Carlton (1986)].

(4) One may also argue that the results may not be achieved when competition is Cournot instead of Bertrand [Brock (1983: 1061). ${ }^{(23)}$ This criticism may indeed indicate a lack of robustness. The choice between Cournot and Bertrand competition depends on the fierceness of price competition assumed by the modeller. Soft price competition is captured by the Cournot postulate, tough price competition by the Bertrand postulate [Sutton (1991: 6)]. In new industrial organization. both choices are considered to be legitimate. Given the purpose of the thesis - the search for benchmark scenarios within the contestability framework [Chapter 0] - the choice for the Bertrand postulate is obvious and legitimate.

\section{Concluding remarks}

Perfect contestability shows that static efficiency may be obtained in every market structure when there are no exit costs, i.e. sunk costs. This makes perfect contestability a far more comprising theory than perfect competition. Since sunk costs are zero by assumption, dynamic economies and efficiency are not considered. In this sense perfect contestability is less comprising than workable competition. However, in contrast to the latter theory, perfect contestability is formalized and gives welldefined criteria for evaluating industry performance. In this sense, perfect contestability puts a great step forward. Summarizing, as a benchmark perfect contestability may be considered as an improvement relative to both perfect and workable competition. Whether perfect contestability may be used for policy recommendations depends on the plausibility of the assumptions made and on the theory's robustness with respect to these assumptions. The above criticism indicates that one should be careful before advocating free competition without any reservation. However, the theory may have some metaphorical value for explaining long-term developments, especially with respect to industry structure, as indicated by Baumol (1982: 8): '[W]hile the industry structures which emerge in reality are not always those which minimize costs, they will constitute reasonable approximations to the efficient structures'. In Sub-section 3.2 and in Section 4 sunk costs are introduced in contestability-like frameworks. This allows one to test the robustness of the results with respect to the zero-sunk-costs assumption.

(23) Calem (1988) studies potential entry in a Cournot setting. When the entry threat is one sided, market equilibrium resembles the contestable result. 


\subsection{Barrier markets}

A barrier market can be defined as a market in which incumbent tirms adopt a policy of average cost pricing as well as investment in innovation [Van Witteloos-tuijn (1990: Chapter 10)]. The barrier market concept thus allows an analysis of both static and dynamic aspects of efficiency, as is intended. Although the definition does not give a guide line for the magnitude of investments in innovation, Maks (1986) and Van Witteloostuijn and Maks (1988) have dynamic efficiency in the back of their minds. Van Witteloostuijn (1990: 126) makes a distinction between the perfect and the imperfect barrier market concept. In a perfect barrier market, market price equals (minimum) average cost. ${ }^{(24)}$ In an imperfect barrier market price is somewhere between the average cost level and the limit price defined in Sub-section 2.2. This distinction may be extended as follows. In a perfect barrier market, average cost pricing is combined with socially optimal investments in $R \& D$; in a imperfect barrier market, prices and investments deviate slightly from these levels. The contestability assumptions are adjusted in the following way in order to make innovations possible.

(1) Investment is associated with positive sunk cost and thus with positive exit cost.

(2) Incumbent firms nevertheless fear the entrance of potential competitors despite the necessity to sink costs.

Sunk costs incurred ex ante do not raise entry barriers ex post. There are by assumption some so-called superior potential entrants (SPEs) around that introduced sunk costs ex ante as well. Their marginal cost levels equal the incumbents'. Marginal costs are higher for so called inferior potential entrants.

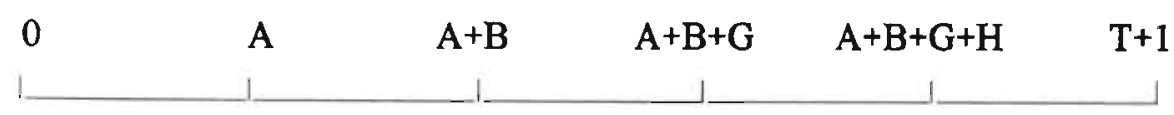

Figure 1.6: The time structure of a barrier market game

A barrier market can be modelled as follows [Figure 1.6]. Suppose there are a number of periods $\mathrm{t}\{\mathrm{t} \in T \mid 0 \leq \mathrm{t} \leq \mathrm{T}\}$. Transactions take place once in every period t. An innovation opportunity is available from date $t=0$ onwards and the innovation is outdated at date $t=(T+1)$. The incumbent initiates the investment in $R \& D$ in period $A_{i}$ and the entrant in $A_{e}$. By assumption (2) $A_{i}=A_{e}$. It takes both entrepreneurs $B$ periods to undertake the investment. The incumbent markets the new product in period $\mathrm{A}+\mathrm{B}$. The potential entrant may enter $\mathrm{G}$ periods later. Retaliation

(24) Van Witteloostuijn and Maks (1988: 118-9) model constant average costs over some range of output as Baumol (1982: 9) does. (Average cost is of course not minimum in a natural monopoly.) 
takes the incumbent $H$ periods after entry. Competition in barrier markets can be modelled using two-periods games. Therefore it is assumed that $A_{1}=A_{e}=0, B=1$, $\mathrm{G}=0, \mathrm{H}=1$ and $T=1$. The subgame perfect equilibrium concept defines the equilibrium outcome. In equilibrium, investment, price and quality levels are such that investment costs are just covered, price is minimal and consumer utility maximal. If incumbents do not stick to these levels, then potential entrants enter their home markets. If they do not invest optimally, they will be expelled by potential entrants. If they set prices above average costs, they will be expelled as well. The argument for optimal behaviour is similar to the argument for average cost pricing given in contestability theory [Sub-section 3.1]. Because the performance of a perfect barrier market is optimal, the market is a suitable benchmark for analysing both static and dynamic competition, as in the theory of workable competition [Sub-section 2.3]. The barrier market concept thus comprises the most essential results of two theories: Average cost pricing borrowed from contestability theory [Sub-section 3.1] and investment in sunk costs (for the benefit of innovations) borrowed from limit price theory [Sub-section 2.2].

\section{Criticism}

In barrier markets sunk costs are made. This allows one to evaluate dynamic economies and efficiency besides static efficiency. The barrier market concept thus meets one of the main criticisms made against perfect contestability. The primary purpose of the concept is to give a benchmark for evaluating static and dynamic efficiency. As such it does not matter that much whether the assumptions made are plausible or not. However, in order to see whether the concept may be used for policy recommendations, the robustness of the results with respect to the assumptions made is discussed below. In Chapter 2 to 4 we investigate whether there are scenarios in which barrier market results may be obtained.

(1) A critical assumption of barrier market theory is that there is always at least one potential entrant around exercising an effective entry threat. The potential entrant should have (1) sufficient excess capacity and (2) have the same technology as the incumbent does. The first requirement is already mentioned in the sub-section on contestability [page 30]. With respect to the second requirement, Stiglitz (1987: 926) argues that technologies by their very nature are associated with sunk and subadditive costs. The sunk nature of costs enables incumbent firms to pre-empt potential entrants in technology competition. This makes 'potential competition particularly ineffective in those sectors of the economy where R\&D is important' [Stiglitz (1987: 932)]. The literature on R\&D competition indeed seems to suggest that incumbency is a first-mover advantage inhibiting R\&D by rival firms [Tirole (1988: 399) and Encoua, Geroski and Jaquemin (1986)]. This result is partially due to the winner-takes-all nature of the patent races studied. However, patents are not always very effective. First-mover advantages may thus be less important than Tirole and Encoua et al. argue. In Chapters 2 to 4 we will show that R\&D 
competition is not necessarily precluded.

(2) In the perfect barrier market outcome incumbent firms are awarded for their innovative activities with a zero protit [Van Witteloostuijn (1990: Chapter 12)]. Therefore, the question arises why incumbent firms invest at all. Van Witteloostuijn proposes some solutions to this problem.

(i) There may be a distinction between ex ante profit expectations and ex post results. Expected profits may be positive, while realized profits may be not.

(ii) In an imperfect barrier market framework positive profit expectations are likely, because they do in fact result.

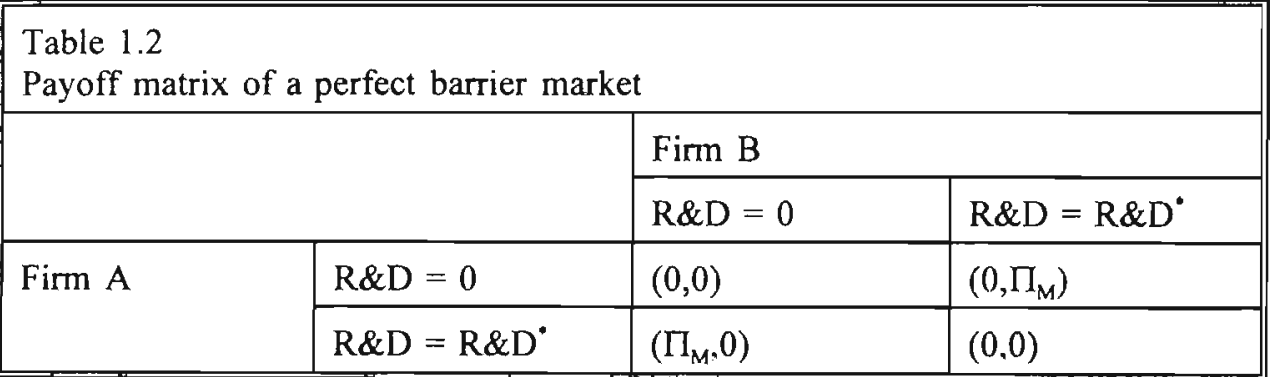

(iii) Investing in $R \& D$ weakly dominates not investing under the following circumstances. When firm $A(B)$ invests in $R \& D$ and firm $B(A)$ does not, firm A (B) may expel the rival firm and obtain positive net profits. The rival firm makes profits nor losses. When both firms do not invest, the market is contestable and net returns are zero. When both firms invest, the barrier market scenario applies and net profits are zero again. The above is summarized in Table 1.2. $\Pi_{M}$ represents monopoly profits and $R \& D^{*}$ the optimal investment level. The table clearly shows that investing weakly dominates not investing. In Chapter 5 we show how this table may be derived using the demand and cost specifications exposed in Chapter 2.

\section{Concluding remarks}

Barrier market theory offers a benchmark comprising both static and dynamic efficiency and in this respect outperforms perfect contestability. Workable competition also deals with static and dynamic efficiency, but fails to obtain well-defined criteria for evaluating industry performance. Summarizing, we may thus conclude that barrier market theory offers the most definite benchmark developed up until now. With respect to the robustness of the assumptions made, the assumption that there is an effective entry threat from a firm with the same technological abilities as the incumbent, needs closer attention in future research. This is particularly important since first-mover advantages such as incumbency seem to lead to asymmetric equilibria [Tirole (1988: 399)]. This would invalidate the barrier market concept. 
Whether symmetric R\&D equilibria are possible and barrier market scenarios may be derived. is the key research question of Chapters 2 to 4 . In the next section we will investigate whether new industrial organization already provides such scenarios. Some examples are already provided by Van Witteloostuijn (1990).

\section{New industrial organization}

New industrial organization studies a wide range of aspects with an extremely dispersed array of results. New industrial organization is not so much characterized by the issues treated or the results achieved, but by the methods applied. The mode of analysis is the mathematical tool box supplemented by game theory. Market structure and industry performance are derived from a set of initial conditions and assumptions made with respect to conduct as laid down in the equilibrium concept employed. The causal relationships are given by Figure 1.7, which is borrowed from Davies and Lyons (1991). Figure 1.7 is nothing more than another version of the SCP-diagram [Sub-section 2.2]. The most popular equilibrium concept is the Nashequilibrium. This concept is combined with the behavioural postulates given by Cournot (1838), Bertrand (1883), Hotelling (1929), Chamberlin (1933) or Von Stackelberg (1943).

There are two strands in new industrial organization which deserve more scrutinous attention: (1) The literature on rent dissipation obtains results similar to the results of contestability theory. (One may consider contestability theory to be a part of the rent dissipation literature [Fudenberg and Tirole (1987)].) In the literature on rent dissipation, the competitive threat (due to potential entry) completely dissipates the monopoly. However, this rent is not always dissipated in a socially valuable way. The theory on rent dissipation is analyzed in Sub-section 4.1. (2) The limit pricing model is formalized in a context of incomplete information by Mil-grom and Roberts (1982). Limit price theory has already been discussed in Sub-section 2.2. The current state of limit price theory will be discussed in Sub-section 4.2.

\subsection{Rent dissipation}

One of the most well-known contributions on rent dissipation is Eaton and Lipsey (1980). Their model will be sketched briefly. On basis of this sketch a more general discussion will follow.

Eaton and Lipsey (1980) study the decision to install capacity when there is an entry threat. In their model, capital has to be installed in order to make production at marginal cost mc possible. The installation of capital can be achieved at a sunk cost $\mathrm{SC}$ per unit of time. Capital is worn out after $\mathrm{H}$ periods. If one firm operates, it earns gross profits $\pi_{\mathrm{m}} \in[\mathrm{SC}, 2 \mathrm{SC}]$. If two (or more) firms operate, they all receive zero 


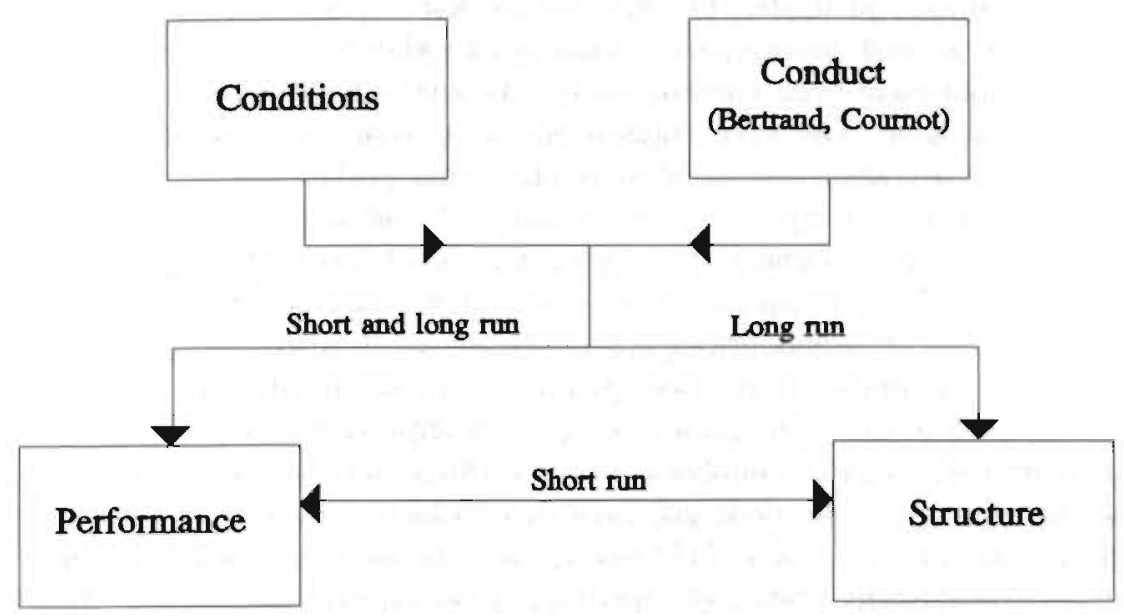

Figure 1.7: Structure-Conduct-Performance Diagram (II)

profits due to Bertrand competition. ${ }^{(25)}$ In equilibrium one firm will produce and sell at the monopoly price. However, incumbency may change. This is where the entry threat comes in. Suppose that the incumbent plans to reinvest at the moment at which the old capital wears out. The entrant has an incentive to pre-empt the incumbent by investing $\omega$ time earlier. When the entrant does so, the incumbent abstains from reinvesting and exits the industry. In order to prevent pre-emption by the entrant, the incumbent pre-empts the entrant by investing $2 \omega$ time before capital wears out. The entrant may invest another $\omega$ time earlier, etc. In equilibrium, the incumbent invests $\Delta$ time before capital wears out, where $\Delta$ is so long that the entrant is just indifferent between investing and not investing. Since the incumbent has twice the capacity needed $\Delta$ time before capital turns into scrap, social wasteful duplication of capital occurs.

The entry threat dissipates all rent, since the incumbent is also indifferent between investing and not investing. This result is in line with contestability theory. The dissipation occurs in a completely wasteful way: Capacity is available in duplicate $\mathrm{V} H$ percent of the time. Consumers pay the monopoly price all the time, and consequently do not benefit at all from the entry threat. The first result is known as

(25) This is the assumption made by Eaton and Lipsey. This assumption is not necessary, however. Gross profits for both firms only have to be smaller than gross profits under monopoly. 
the rent-dissipation postulate, the second as the wastefulness postulate [Posner (1975) $]^{(26)}$ The second result is due to the set-up chosen. When a socially valuable investment would have been chosen, consumers would have gained from the excessive investments made. The advantages would be passed on partially (or maybe even completely) to the consumers. In Maskin and Tirole (1988). entry is not deterred by early reinvestment, but by a larger capacity. If the capacity is large and fully employed, output may approach the contestable output level. The capacity installed is higher, the lower the discount rate is, i.e. the higher future profits are weighted. Stahl (1988) argues that Bertrand prices are likely to result when firms fight a winnertakes-all game in inputs in the first period of the competition game and that the capacity acquired in the input game does not put any constraint on the price game in the second period. These assumptions are very crucial and extremely stringent.

The rent-dissipation result is achieved in two kinds of models: Wars of attrition and patent races [Tirole (1989: 311) and Fudenberg and Tirole (1987)]. In a war of attrition, two incumbent firms fight for the hegemony over an industry. The hegemony over an industry has a value $V_{m}$ for the firm concerned. During the fight gross profits are zero due to Bertrand pricing. One of the firms consequently is bound to leave the industry. During the fight prices are competitive, after the fight the remaining firm charges the monopoly price. During the war there may be technological inefficiency due to excess capacity. Expected profits are zero during the war. Expected monopoly profits exactly match the losses during the war. This does not imply that price equals average cost on average: The allocation is not constrained optimal [Fudenberg and Tirole (1987: 178)]. Consumers consequently benefit during the war and suffer afterwards.

A patent also has a value $V_{m}$ to the appropriating firm, since a legal monopoly is granted. Firms thus compete in order to obtain a patent. When firms start from symmetric positions, they are likely to speed up $R \& D$ spending in order to obtain the patent. The private value of the patent is likely to be completely dissipated in the $R \& D$ race. Society may benefit from the race, however, since the introduction date of a new technology may be accelerated. When firms start from asymmetric positions, the race may not take place, since the firm expected to lose may not even start. ${ }^{(27)}$ This phenomenon is called $\varepsilon$-pre-emption: A firm which is $\varepsilon$ ahead in the race, wins the race, because the lagging firms know that they can not beat the leading firm and drop out of the race. The asymmetry may be between an incumbent and an entrant firm [Gilbert and Newbery (1982) and Leininger (1991)], between a leading and a

(26) Wenders (1987) shows that the costs associated with rent dissipation may even be larger than the monopoly rent earned by the winning firm. This result is due to the fact that consumers may make costs in order to prevent rents being earned. In the limit the costs are twice as high.

(27) This result rests on the assumptions that $R \& D$ has a cumulative nature and that the R\&D process is specified in a deterministic way. When information is not cumulative and innovations are drastic, the entrant spends more on R\&D than the incumbent and consequently is more likely to win [Reinganum (1985)]. 
lagging firm [Vickers (1986) and Beath et al. (1987)] or may be due to differences in the valuation of the patent and the future (discount rate) or to differences in $R \& D$ efficiency [Harris and Vickers (1985)]. An advantage of $\varepsilon$-pre-emption is the fact that socially wasteful duplication of efforts does not occur, but consumers do not gain more from the innovation than they already would. However, leapfrogging is possible in more fancy patent races: Fudenberg et al. (1983) show that $\varepsilon$-pre-emption does not occur when there are information lags or when there is a multi-stage patent race. Leininger (1991) shows that entrants may beat incumbents when they have a first-mover advantage and a larger R\&D budget (a bigger purse).

This discussion shows that monopolies are likely to persist, at least under Bertrand competition. This result is connected with the Bertrand paradox: Competition is so severe that duopolists are not able to recover R\&D expenses. There are two effects influencing the R\&D decision: (1) The efficiency effect and (2) the replacement effect. The firm which spends more on $R \& D$ wins the rent race. The efficiency effect gives the difference in profits between winning and not winning. The incumbent receives the difference between monopoly $\Pi_{m}{ }^{i}$ and duopoly profits $\Pi_{d}{ }^{i}$, the entrant the difference between duopoly profits $\Pi_{d}{ }^{e}$ and his opportunity profits $\Pi_{0}{ }^{e}$. This effect is more favourable for the incumbent, since total duopoly profits never are larger than monopoly profits:

$\Pi_{\mathrm{m}}{ }^{\mathrm{i}}-\Pi_{\mathrm{d}}{ }^{\mathrm{i}} \geq \Pi_{\mathrm{d}}{ }^{\mathrm{e}}-\Pi_{\mathrm{o}}{ }^{\mathrm{e}}(=0) \Leftrightarrow \Pi_{\mathrm{m}}{ }^{\mathrm{i}} \geq \Pi_{\mathrm{d}}{ }^{\mathrm{i}}+\Pi_{\mathrm{d}}{ }^{\mathrm{c}}$.

The replacement effect represents the loss in profits for the incumbent firm when the old technology is replaced. This effect is always negative for the incumbent, and does not exist for the entrant. The efficiency effect favours the incumbent, the replacement effect the entrant. When the innovation is drastic, i.e. the innovator is able to set the monopoly price $\left(\Pi_{d}{ }^{e}=\Pi_{m}{ }^{i}\right.$ and $\left.\Pi_{d}{ }^{i}=0\right)$, the entrant wins the race, since the efficiency effect is the same for both firms [Reinganum (1985)]. When the innovation is not drastic and the incumbent is concerned with replacement by the entrant, the incumbent is likely to pre-empt [Gilbert and Newbery (1982)]. In most models developed in new industrial organization until now, the incumbent has a larger incentive to innovate than the entrant [Tirole (1988: 399)]. A necessary condition for pre-emption (by the incumbent) to occur, is that the entrant has no opportunity to disturb the equilibrium. Pre-emption therefore needs to be effective: Competition should be impossible (patent) or unprofitable (Bertrand competition). Pre-emption by the incumbent firm does not necessarily happen under Cournot competition [Vickers (1986), for instance]. Pre-emption should also be deterministic.

Rent dissipation also occurs in other types of technology races: In a competition game with learning effects [Fudenberg and Tirole (1987: 18n)] and in a technology adoption race [Tirole (1988: 402n)]. The presence of learning effects stimulates firms to increase output. When there is an entry threat, the process of technology adoption is accelerated. Both effects benefit consumers. The Prescott-Visscher (1977) model on product differentiation also is akin to the rent dissipation model [page 24]. 


\section{Concluding remarks}

Whenever there is a rent to be earned, whether it is created by the market or the government (patent), there is competition for it. Firms incur costs in order to obtain the rent. The rent may be completely dissipated, or even more than fully [Baye et al. (1994)]. In this respect the rent-dissipation literature resembles the literature on Bertrand pricing and contestability theory [Mills (1988)]. However, this does not imply static efficiency. When a war of attrition is over or a patent is won, monopoly prices are set. ${ }^{(28)}$ The costs made in order to obtain the rent usually involve dynamic economies as is most clear in the case of patents. However, Posner (1975) argues and Eaton and Lipsey (1980) show that rent dissipation may be socially wasteful. On the other hand, Maskin and Tirole (1988), Stahl (1988) and Hartwick (1991) show that rent dissipation may be associated with socially valuable expenses. Maskin and Tirole (1988) and Stahl (1988) even show that contestable results may be obtained. Dynamic economies may be obtained, but dynamic efficiency is not guaranteed. One may thus only conclude that the welfare effects of rent races still are ambiguous which is a typical conclusion for a review on (new) industrial organization.

\subsection{Limit pricing with imperfect information}

One of the problems of the limit pricing model is the very fact that a low price as such does not have any commitment value. A low price may have a commitment value when incumbent and entrant firms have asymmetric information, for instance when the entrant does not know the incumbent's cost level. The price is then used as a signal. Milgrom and Roberts (1982) discuss the incumbent's pricing behaviour when the entrant is uncertain with respect to the incumbent's cost. In their model, the incumbent is either low cost or high cost. Entry is profitable when the incumbent is high cost, but not when it is low cost. The incumbent may use the price to signal its cost technology in order to deter entry. The Milgrom-Roberts model is a special type of limit price theory, since the possibility to signal causes a price decrease. The exposition below follows Milgrom and Roberts (1982) closely. Mil-grom and Roberts (1986) discuss quality signalling in a comparable setting. Equilibrium strategies have to fulfil three conditions.

(1) The incumbent's strategies need to be profit maximizing.

(2) The entrant's strategies need to be profit maximizing; the entrant thus only enters when expected profits are positive.

(3) The strategies have to be Bayes consistent: When the strategy of the low-cost

(28) During a war of attrition expected profits are zero. The losses during the war equal the profits after the war times the chance that the war is won. The winner makes positive profits on net, the loser losses. 
producer is likely to differ from that of the high-cost producer, the posterior entry probabilities will be either 0 or 1 ; when the strategies are likely to be the same, the posterior entry probabilities are determined by prior expeclations. ${ }^{(29)}$

There are two types of equilibria, separating and pooling. There is a separating equilibrium when the strategies of the high cost firm are likely to differ from those of the low-cost firm. There is a pooling equilibrium when they are likely to be the same. There is a separating equilibrium when the following two conditions are fulfilled.

(1) It is not profitable for the high-cost firm to pretend being low cost

$$
\Pi_{L}{ }^{H}+\delta \Pi_{M}{ }^{H}<\Pi_{M}{ }^{H}+\delta \Pi_{D}{ }^{H} \text {. }
$$

The left-hand side represents the profits $\Pi$ of the high-cost firm (superscript $H$ ) when it sets a limit price (subscript L) in the first period and deters entry in the second period. It consequently earns monopoly profits (subscript $M$ ) in the second period. The right-hand side denotes profits when entry is not deterred. The first term at the right-hand side represents profits in the first period at the monopoly price (subscript $\mathrm{M}$ ). The second term denotes duopoly profits in the second period (subscript $\mathrm{D}$ ). Of course, $\delta$ is the discount rate.

(2) It is not profitable for the low-cost firm to pretend it is high cost

$$
\Pi_{L}{ }^{L}+\delta \Pi_{M}{ }^{L}<\Pi_{M}{ }^{L}+\delta \Pi_{D}{ }^{L} \text {. }
$$

The left-hand side represents the profits $\Pi$ of the low-cost firm (superscript L) when it sets a limit price (subscript L) in the first period and deters entry in the second period. It consequently earns monopoly profits (subscript $\mathrm{M}$ ) in the second period. The right-hand side denotes profits when entry is not deterred. The first term at the right-hand side represents profits in the first period at the monopoly price (subscript $\mathrm{M}$ ). The second term denotes duopoly profits in the second period (subscript D).

Generally, there exist several separating equilibria. However, it is possible to eliminate dominated strategies [Bagwell and Ramey (1988: 64)]. There is one condition for the mere existence of a separating equilibrium: The low-cost incumbent should gain more from entry deterrence than the high-cost incumbent [page 65]. Martin (1995) shows that pooling equilibria are less sustainable when there are two incumbents producing strategic complements (instead of substitutes). This result is due to

(29) When $\rho$ is the chance that the incumbent is high cost, entry is profitable with chance $\rho$ and it is not profitable with chance $(1-\rho)$. 
the fact that high-cost firms want to reveal their cost to a cooperative incumbent rival, i.e. in the case of complementarity, but not to a competitive one, i.e. in the case of substitutability. In LeBlanc (1992), firms choose between a predatory versus a limit pricing strategy. LeBlanc shows that strong incumbents ${ }^{(30)}$ pursue the former strategy and weak incumbents the latter. Strong firms thus are likely to be able to sustain monopoly prices, weak firms are not. Bagwell and Ramey (1988) extend the Milgrom-Roberts model with a second instrument, advertising. They reveal that prices decrease and advertising outlays are spurred by the entry threat under uncertainty. Salonen (1994) discusses buying strategies in a limit pricing context. Firms buy at high prices in order to signal high costs and to deter entry. In equilibrium entry is deterred at buy and sell prices above competitive prices: Consumers definitely are worse off.

Bagwell (1993), Srinivasan (1991) and Dixon (1994) extend the above framework to a multimarket setting. Srinivasan (1991) argues that a firm which is incumbent in more than one market faces weaker incentive compatibility constraints, in particular the first one just given. This enables the firm to lower its signalling costs and to raise its prices. Dixon (1994) shows that the possibility to enter in more than one market raises the profitability and consequently the likelihood of entry. This raises signalling costs, which implies that the entry-deterring cost level needs to be lower. Bagwell (1993) discusses a model in which one entrant decides which of $n$ markets to enter. The incumbent firms may invest in order to lower production costs. A low price is supposed to signal low costs. The market of the firm with the highest price is entered. A symmetric pooling equilibrium results. The entry threat lowers prices and increases investment in process R\&D.

Summarizing we may conclude that the entry threat induces incumbent firms to set lower prices [Milgrom and Roberts (1982)] and to invest more in R\&D [Bag-well and Ramey (1988) and Bagwell (1993)]. Limit pricing thus enhances static efficiency and promotes dynamic economies, but not necessarily dynamic effi-ciency.

\section{$5 \quad$ Discussion}

At the beginning of this century the neo-classical paradigm dominated economics. This paradigm provided economic theory and policy with perfect competition as a welfare-theoretic benchmark. Perfect competition refers to a static framework stripped of all dynamic elements of competition as envisaged by classical economists. The concept does not cope with a small number of firms, product heterogeneity and technological change. In the course of this century several alternative bench-marks and theories have been proposed. This century thus exhibits a development in which more and more dynamic elements of competition are brought to the fore. These elements have been incorporated gradually in new welfare-theoretic devices incorporating both static and dynamic efficiency.

(30) Strong firms have a cost advantage in Bain's (1956) sense. 


\begin{tabular}{|c|c|c|c|}
\hline Theory & $\begin{array}{l}\text { Static } \\
\text { efficiency }\end{array}$ & $\begin{array}{l}\text { Dynamic } \\
\text { economies }\end{array}$ & Qualifications \\
\hline $\begin{array}{l}\text { Perfect competition } \\
\text { Monopolistic competition } \\
\text { Workable competition } \\
\text { Limit price theory } \\
\text { Perfect contestability } \\
\text { Barrier market theory } \\
\text { Rent dissipation literature }\end{array}$ & $\begin{array}{l}\text { yes } \\
\text { zero profits } \\
\text { yes } \\
\text { no } \\
\text { yes } \\
\text { yes } \\
\text { zero discounted } \\
\text { profits }\end{array}$ & $\begin{array}{l}\text { no } \\
\text { yes } \\
\text { yes (efficiency) } \\
\text { yes } \\
\text { no } \\
\text { yes (efficiency) } \\
\text { yes }\end{array}$ & $\begin{array}{l}\text { Large-number assumption } \\
\text { Large-number assumption } \\
\text { Not well-defined criteria } \\
- \\
\text { Equal rivals (no sunk costs) } \\
\text { Equal rivals after investment } \\
-\end{array}$ \\
\hline
\end{tabular}

Table 1.3 summarizes the performance of the theories reviewed in this chapter in terms of static efficiency and dynamic economies or efficiency. The table also qualifies the theories. Static efficiency is achieved by perfect competition, perfect contestability and the barrier market concept. Note that profits are zero in case of monopolistic competition and that this may be considered optimal from a second-best point of view [Dixit and Stiglitz (1977)]. A first-best solution requires an ingenuous lump-sum tax regime. Discounted profits are also zero under rent dissipation. However, rent dissipation remains associated with periodic monopoly profits. Monopolistic competition, workable competition, limit price theory, the barrier market concept and new industrial organization all study dynamic economics. However, dynamic efficiency is only implied by barrier market theory. Workable competition implies dynamic efficiency, but does not know how to define it properly. Dynamic efficiency seems to be approached by monopolistic competition quite often [Dixit and Stiglitz (1977)]. Table 1.3 shows several theories attaining static efficiency and/or dynamic economies or efficiency. The results of perfect competition are thus extended and shown to hold for more general cases. We now know that static efficiency does not depend on the large-number assumption and may be combined with dynamic economies (or efficiency). The barrier market concept is the most welldefined benchmark developed until now. It is the only benchmark implying both static and dynamic efficiency. For this reason the barrier market concept will be used as reference point in the following chapters. Barrier market results only hold, when there is an effective entry threat. This threat induces static and dynamic efficiency if two similar producers both invest in R\&D and obtain the same technological opportunities. Whether there are scenarios in which these results are obtained is the research objective of Chapters 2 to 4 . 


\section{Appendix to Chapter 1}
A Structure, conduct and performance norms

\section{Structural norms}

(1) There should be as many organizations as scale economies permit.

(2) There should be no government imposed barriers to entry.

(3) Quality differentials should be moderate and price-sensitive.

\section{Conduct norms}

(4) There should be uncertainty concerning the reactions of competitors to business policy.

(5) Firms should not collude.

(6) Tactics should not be unfair, exclusionary, predatory, or coercive.

(7) Inefficient organizations should not be sheltered.

(8) Promotion should be informative.

(9) Price discrimination should not occur.

\section{Performance norms}

(10) The operation of an organization should be efficient.

(11) Output and quality should accord to consumer demand.

(12) Profits should reward innovation and investment at a level just sufficient to make innovation and investment worthwhile to undertake.

(Scherer and Ross, 1990, Ch. 2) 


\section{Chapter}

\section{The dynamics of innovation and entry resulting from stochastic returns to $R \& D$}

\section{Introduction}

In Chapter 1, Sub-section 3.1, we showed that it is almost impossible to reconcile contestability with sunk costs due to the Bertrand paradox. However, in this chapter we will argue that contestability may be reconciled with the sinking of costs and that such a reconciliation even is plausible from an empirical point of view. Consider the Bertrand paradox again. When there are two firms selling a homogeneous product with a constant returns to scale technology, Bertrand competition in combination with any level of sunk costs suffices to make the entry threat incredible and thus ineffective [Stiglitz (1987: 890n) or Dasgupta and Stiglitz (1988: 261)]. Because the entry threat is ineffective, the incumbent firm may reap monopoly profits. The argument can be illustrated briefly. When there are constant returns to scale in production, total costs TC are as follows: TC $=S C+\phi . S$, where SC denotes sunk costs, $S$ output and $\phi$ constant average production costs. Homogeneity of goods and Bertrand competition suffice to enforce marginal cost pricing when there are two or more producers (with sufficient capacity). In this case all firms in the industry suffer a loss equal to SC. This argument explains why a second (or a third, etc.) firm never enters the industry and the monopolist is able to reap monopoly profits. Since it is necessary to sink costs in order to perform research and development (R\&D), R\&D and Bertrand competition do not seem to be reconcilable. Bertrand competition eliminates the ability of firms to appropriate part of the surplus created by innovations and thus reduces the incentive to innovate to zero [Katz (1986: 529)].

Stiglitz' result depends on the assumption of constant retums to scale in production. However, empirical observations suggest that average total costs are roughly constant over a range of output for many industries despite the presence of sunk costs [Scherer and Ross (1990: 106-7)]. ${ }^{(1)}$ These observations have been the starting point

(1) Average total costs are especially likely to be constant in industries producing more or less homogeneous products, like chemicals, aluminium and cement [Johnston (1960), Levin (1977), Moore (1959) and Walters (1963)]. The range over which they are constant may be considerable: average total costs are roughly constant for sulfuric acid over a range from 100.000 tons per year to $1,000,000$ tons per year [Levin (1977: 213)]. This, of course, does not imply that there is excess capacity over this range: [Johnston (1960)]. The survey by Walters (1963) indicates that constant returns to scale may refer to production costs only. As a result, average total costs are more likely to be decreasing for heterogeneous products [Morrison (1990)], since sunk (R\&D and adverti- 
for the cost relation modelled below. ${ }^{(2)}$ In the model outlined below average total costs are constant despite the presence of sunk costs. The fall in average sunk costs is exactly matched by the rise in average variable costs, at least over the relevant range of output. When these cost relations are taken as a starting point for an analysis, Bertrand competition and (optimal) investments in R\&D can be shown to be reconcilable. This can be illustrated briefly, again. Total costs TC are a linear function of output: $\mathrm{TC}=\phi . \mathrm{S}$ (over some range of output). Sunk costs equal SC and variable costs $\mathrm{VC}$ are $\mathrm{VC}=\phi . \mathrm{S}-\mathrm{SC}$. Marginal costs consequently are $\phi$ as well. When Bertrand prices are set, prices equal both average total and marginal costs. So when average total costs are (about) constant, Bertrand competition and R\&D may be reconciled. As a result, barrier market outcomes may be obtained, at least when excess capacity is sufficiently high. These two conditions, constant average total costs and excess capacity. explain why barrier market results are obtained in the first scenario considered [Table 2.1]. The cost function also allows several firms to coexist in equilibrium. In this respect the chapter differs from the literature on patent races which are won by one and only one firm [Tirole (1989: 394n)]. This result makes our model more attractive than patent models, since not all R\&D games have necessarily a winner-takes-all nature.

The chapter thus provides a way to incorporate the entry threat as laid down in contestability theory [Baumol, Panzar and Willig (1988)] into a dynamic framework. The chapter hereby gives an example of a barrier market scenario [Van Witteloostuijn and Maks (1988)]. Barrier market theory comprises competitive pricing with dynamic economies. Barrier market equilibria are characterized by zero profits, even under monopoly and oligopoly, and also by optimal investments in $\mathrm{R} \& \mathrm{D}$, since the entry threat is the force 'behind the introduction of dynamic economies of market behaviour' [op. cit.: 117].

The model presented below analyzes competition with respect to price and product quality. Both product quality and production cost are subject to R\&D. In the second section a two-period game is studied in order to establish the result that contestability and sunk costs are reconcilable. In the third section the results of sequences of competition games are analyzed using simulation techniques in order to study stochastic R\&D outcomes. This allows one to study dynamic elements like entry, exit, bankruptcy and quality and cost leadership and thus to endogenize market structure. The simulation studies offer the opportunity to investigate whether markets are likely to be monopolized or whether the entry threat is likely to prevail. As long the entry threat prevails, it exerts competitive pressure on the market. As a consequence resources move to the most valuable uses, the market power of incumbent firms is limited, costs are minimized and new products and processes are introduced, inter alia by actual entry [Evans and Siegfried (1992)]. Entry and exit are likely to

sing) outlays are higher for heterogeneous products.

(2) Note that an equivalent observation has been used in contestability theory to defend constant returns to scale [Baumol (1982: 9)]. 
Table 2.1

A comparison of Chapters 2 to 4

Analytical $\quad$ Model features
techniques

2 Game theory Simulations

3 Microeconomics Game theory
Average total costs constant Representative consumer No capacity constraints Geographically separated markets

Average variable costs constant Differentiated consumers No capacity constraints One (segmented) market
Prices approach marginal cost when entry costs fall Optimal investment in R\&D Duplications of efforts Industries are monopolized when entry costs are low

Prices approach marginal cost when there is less desire for variety Underinvestment in R\&D All surplus from innovations accrues to consumers Product differentiation is optimal in case of hit-andrun entry; otherwise it is not

Prices approach marginal cost when spillovers and capacity rise Firms do not invest in R\&D when spillovers are high

be related: The exit of a lethargic incumbent may be caused by an alert entrant. The first stylized fact distinguished by Geroski (1991: 11) confirms this hypothesis: The correlation between entry and exit rates is high [see Evans and Siegfried (1992) for the US, Geroski (1991) for the UK, Kleijweg and Lever (1995) for the Netherlands, and Siegfried and Fvans (1994) for an overview]. Entry and exit are related because. among other things, barriers to entry and barriers to exit are. Because entry and exit are related to barriers to entry and exit, these processes vary across industries (and over time). This is the second stylized fact of entry [Geroski (1991)]. Both observations are also obtained by the simulation studies. The model thus provides a good starting point for future extensions.

The chapter is organized as follows. Section 2 presents the model developed. Sub-section 2.1 gives a general outline and the model specification, Sub-section 2.2 analyses firm behaviour and Sub-section 2.3 presents the benchmarks used and gives the analytical results. In Section 3 the results of simulations are presented. Subsection 3.1 discusses some stylized facts on entry and introduces the structure of the simulations. Sub-section 3.2 gives the results. Section 4 discusses the results of Sections 2 and 3 and refers to the following chapters. 


\section{The model}

This section discusses the competition game developed in order to analyze quality and price competition under the threat of potential entry. This section outlines the model employed and gives the analytical results. Sub-section 2.1 gives a general outline and presents the demand and cost relations. Sub-section 2.2 discusses the R\&D and price decisions taken by the firms. Sub-section 2.3 presents two benchmarks in order to subject the market's results to a welfare analysis.

\subsection{A general outline}

\subsection{The structure of a competition game}

In the model outlined below there are $\mathrm{M}$ markets. We model $\mathrm{M}$ markets in order to endow each firm (and thus each potential entrant) with a home market. The entrants thus do not hang in the wings [Cairns and Mahabir (1988)]. Each market is occupied by one firm. In each market there are $\mathrm{N}$ consumers with identical preferences. The firms are able to enter each other's markets at an entry cost $\varepsilon$ per product. There are several explanations for these entry costs: (1) Transportation costs, (2) product adaptation costs or (3) differences in preferences. There are no differences in entry costs across markets or producers. Each firm is incumbent in its home market and a potential entrant into all the other markets. The entry threat thus refers to all (M-1) markets in which the firm is not incumbent. Note that the entry threat is reciprocal rather than one-sided. The threat is especially important, because the firms do not face a capacity or any other resource constraint. This characteristic is closely bound up with the cost function chosen.

\begin{tabular}{|l|l|l||}
\hline \hline \multicolumn{3}{|l||}{$\begin{array}{l}\text { Table } 2.2 \\
\text { Structure of the competition game }\end{array}$} \\
\hline Period & Stage & Enterprises' decisions \\
\hline 1 & 1 & Investment decisions \\
\hline 2 & 1 & Price decisions \\
\cline { 2 - 4 } & 2 & Market transactions \\
\hline
\end{tabular}

Competition is modelled by a two-period game [Table 2.2]. Firms decide on investment in $R \& D$ and price in order to maximize profits in each game. In the first period enterprises simultaneously decide on product and process R\&D in order to improve the quality of the product offered for sale in the second period and to lower the costs of producing it. A firms's quality and cost levels in period two depend on its quality and cost levels in period one and on its R\&D investments in that period. The firms know each other's quality and cost levels in period one. However, they do 
not observe each other's $R \& D$ investments. Moreover, the returns to $R \& D$ are stochastic. R\&D output differs per firm, either because the returns are firm specific or because the firms make other inferences on the distribution of the random variables and invest differently. Information on quality and cost remains private for at least one period: There are no spillovers within a game. As a consequence, firms have a quality-cost advantage or disadvantage in period two.

In period two the firms decide on price simultaneously. They observe each other's quality and cost levels before they do so: There is perfect information in period two. When the firms determined their prices, the consumers decide which product to buy. They choose the consumer surplus maximizing price-quality offer. When the firms decide on either product $R \& D$, process $R \& D$ or price, they acknowledge that the product they offer for sale is only bought when it provides a higher surplus than the product of rival firms (or at least not a lower surplus). So, firms try to forestall (successful) entry of rival firms in their home market and also try to outperform their rivals in the latters' home markets.

\subsubsection{The demand system ${ }^{(3)}$}

In Sub-section 2.1.1 we already indicated that there are $M$ firms. Each firm $j$ offers one variety $\mathrm{j}$ of the good under consideration $[\mathrm{j} \in\{1, \ldots, \mathrm{M}\}]$. In principle, cach firm may offer a different variety, i.e. a different price-quality combination. ${ }^{(4)}$ Consumers buy one of the varieties, the variety offering the highest level of consumer surplus. Consumers derive utility from the amount $X_{j}$ consumed of the variety maximizing consumer surplus and the amount $Z$ consumed of the numeraire. Utility $U$ is modelled by the following quasi-linear quadratic utility function

$$
U\left(X_{j}, Z\right)=Q_{j} X_{j}-\gamma X_{j}^{2}+Z,
$$

where $X_{j}$ denotes the quantity consumed of the good offered by firm $j, Q_{j}(>0)$ gives the quality of the good consumed and $\gamma(>0)$ is a parameter. The subscript $\mathrm{j}$ refers to a particular firm $j$. Note that utility differs per firm if the quality level $Q_{j}$ is different over firms. The budget constraint equals

$$
P_{j} X_{j}+Z=W
$$

(3) The model is a special version of the one employed by Dixit (1980: 4): the case of perfect substitutes. In the stochastic version of the model, however, imperfect substitutes are offered for sale. In contrast with Dixit only one of these substitutes is bought in this model in order to incorporate total entry. A simple general equilibrium version of the demand system is given by Horstmann and Markusen (1992).

(4)

Since qualities may differ, the varieties are not necessarily homogeneous. 
where $P_{j}$ is the price of $X_{j}, W$ is income and the price of $Z$ is 1 . The budget constraint is assumed not to be binding for the consumption of any variety $\mathrm{j}$. This implies that the consumption of the numeraire commodity is positive. Substituting for $Z$ into equation (1) and differentiating to $X_{j}$, the following individual demand function results ${ }^{(5)}$

$$
\begin{array}{ll}
X_{j}=\left[Q_{j}-P_{j}\right] / 2 \gamma & \text { if } Q_{j}-P_{j}>Q_{k}-P_{k} \geq 0 \text { for all } k \neq j \text { and } \\
X_{j}=0 & \text { if } Q_{k}-P_{k}>Q_{j}-P_{j} \geq 0 \text { for some } k \neq j .
\end{array}
$$

In this way individual demand is modelled as a function of price and quality and not as a function of income. Since we assume that consumers have identical preferences, market demand can be derived by multiplying $\mathrm{X}_{\mathrm{j}}$ by the number of customers $\mathrm{N}$.

\subsubsection{The cost function}

Technological progress requires the sinking of $R \& D$ expenses. Sunk costs do not change as a result of a change in output. Average sunk costs thus decrease with output. Empirical studies nevertheless suggest that output is produced 'at more or less constant total costs per unit' [Scherer and Ross (1990: 106-7); italics added] over the relevant range of output. In order for average total costs to be constant, the fall in average sunk costs must be roughly matched by a rise in average variable costs. These costs thus are not constant as Stiglitz (1987) assumes. This observation has been the starting point of the cost functions defined. In the model exposed right now, average total costs are assumed to be a linear function of output. The condition of constant average total costs also guarantees that marginal costs are constant and identical to average total costs [page 46]. Total costs TC may thus be defined as follows

$\mathrm{TC}_{\mathrm{j}}=\mathrm{ac}_{\mathrm{j}} \mathrm{S}_{\mathrm{j}}$

where ac denotes average total cost and $S(\geq S C / a c)$ output. The subscript $j$ refers to one of the $\mathrm{M}$ firms. For the moment we assume that any firm's capacity is large enough to cover any demand. The constancy of average total and marginal costs enables us to define relations between these cost levels and R\&D expenses on both product and process innovations. The next sub-section will be devoted to the derivation of these relations. Before we do so, we pay further attention to some of the features of the above cost function.

As already illustrated in the introduction [page 46], average total costs equal mar-

(s) When $Q_{j}-P_{j}=Q_{k}-P_{k}$ for some $k \neq j$ and $Q_{j}-P_{j}>Q_{k}-P_{k}$ for all other $k \neq j$, firm $j$ shares the market with all firms $\mathrm{k}$ for which the equality holds. 
ginal costs. ${ }^{(6)}$ As a result, marginal cost pricing and average cost pricing do not bite. This also implies that dumping is not profitable. Dumping is only profitable when average total costs (price) exceed marginal costs. The variable cost function implied by equation (4): $\mathrm{VC}=$ ac.S-SC imposes a restriction on the relevant range of supply. When $\mathrm{S}$ is small $(\mathrm{S}<\mathrm{SC} / \mathrm{ac}$ ), variable costs are negative. Since (variable) costs cannot be negative, this range should be excluded from the analysis. Amortization of sunk costs usually complicates the entry deterrence game, because a mark-up over marginal costs needs to be charged [Baumol et al. (1982)]. However, because average total costs equal marginal costs, one does not need a mark-up over marginal costs to cover sunk costs in this model. The amortization problem is ruled out.

\subsubsection{Sunk costs, quality and marginal costs}

The relation between R\&D expenses and the induced quality and costs improvements is presumably characterized by decreasing returns to investment [Kamien and Schwartz (1982)]. ${ }^{(7)}$ This holds for investment in quality improvement as well as for investment in cost reduction. First, attention will be addressed to the relation between product $R \& D$ expenses, $R Q$, and quality improvement and subsequently to the relation between process R\&D expenses, RC, and cost reduction. Sunk costs SC consist of the sum of these two components only.

At each moment in time there is a set of possibilities for quality improvement. The exploration of these possibilities requires resources. Because of decreasing retums to investment, some of the possibilities do not require much efforts (resources) in relation to the induced quality improvements, but others do. Enterprises are likely to deal with the possibilities which do not require many resources in relation to the induced improvements first. The quality improvement resulting from spending the first guilder on product R\&D expenses consequently is higher than the quality improvement resulting from spending the second, the tenth or the hundredth guilder on product $R \& D$. The relation between product $R \& D R Q$ and quality improvement is modelled as follows

$$
Q_{j, 2}-Q_{j, 1}=\mu_{j, 1} \sqrt{R Q_{j, 1}},
$$

where the subscript 1 refers to period 1 and the subscript 2 to period 2 . The relation between product $R \& D$ and the change of quality is depicted in Figure 2.1.

In a certain competition game R\&D performance may differ from firm to firm. A company may simply be more lucky than its rivals in raising quality. R\&D performance may also differ from one period to another. That is why quality improve-

(6) Total costs TC = ac.S may subdivided in sunk costs $\mathrm{SC}$ and variable costs $\mathrm{VC}=$ ac.SSC. Marginal costs are $\mathrm{dVC} / \mathrm{dS}=\mathrm{ac}$.

(7) See Scherer (1965), Mansfield et al. (1971) and Dasgupta (1986) as well. 


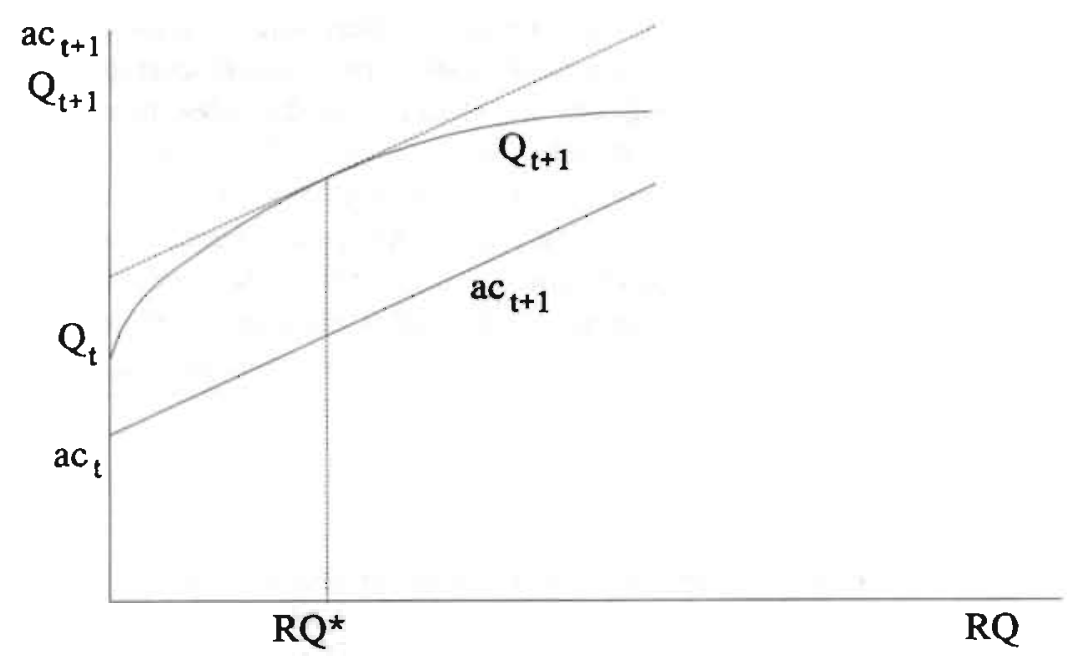

Figure 2.1: RQ, quality and cost

ments depend, among other things, on random variable $\mu$. The random variable is based on a normal distribution with mean $\rho_{\mu}\left(\rho_{\mu}>0\right)$ and variance $\sigma_{\mu}{ }^{2}$. The distribution is, however, truncated at 0 and $2 \rho_{\mu}$. The distribution is truncated at 0 in order to exclude the possibility of negative quality improvements. The distribution is also truncated at $2 \rho_{\mu}$ in order to keep it symmetric around the mean. The distribution of the random variable is the same for all firms. The stochastic nature of the R\&D process creates quality and cost differences in the simulations performed, because the drawings from the distribution differ per firm or because the firms have different expectations with respect to the random variable. In the former case all firms are assumed to know $\mu$ 's distribution and to employ rational expectations. In Sub-section 3.1.5 we discuss the expectation mechanisms employed as well as the reason for modelling differences in expectation formation. Other types of firm heterogeneity could be studied as well. The distribution of the random variable, i.e. R\&D efficiency, may differ per firm, for instance.

Equation (5) enables us to rewrite equation (3a) into

$$
X_{j, 2}=\left[Q_{j, 1}+\mu_{j, 1} \sqrt{R Q_{j, 1}}-P_{j, 2}\right] / 2 \gamma .
$$

Average total and marginal costs are likely to rise when quality is improved upon. Because returns to investment are decreasing, average total costs rise at an increasing rate as a function of the quality improvement. For this reason the relation between 
quality improvements and costs is modelled as follows ${ }^{(s)}$

$a c_{j, 2}=m c_{j, 2}=m c_{j, 1}+n\left(Q_{j, 2}-Q_{j, 1}\right)^{2}$

In order to simplify the analysis below, we assume that $\eta=\theta /\left(\mu_{\mathrm{j}, 1}\right)^{2}$, where $\theta$ is an arbitrary constant larger than zero. Equation (6a) endogenizes average total and marginal cost. The relation between product R\&D expenses and costs can be found by substituting equation (5) into equation (6a)

$\mathrm{ac}_{\mathrm{j}, 2}=m c_{\mathrm{j}, 2}=\mathrm{mc}_{\mathrm{j}, 1}+\theta \mathrm{RQ}_{\mathrm{j}, 1}$

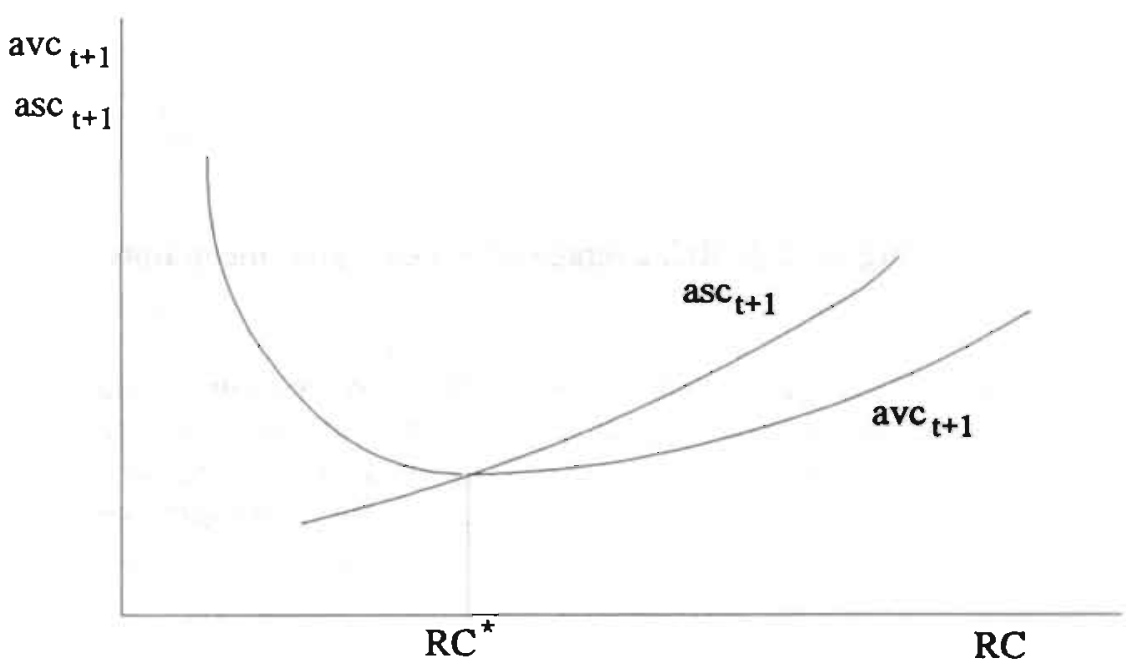

Figure 2.2: RC, average sunk and average variable costs

The relation between product R\&D expenses and average total and marginal costs is depicted in Figure 2.1. The relations given by equations (4) and (6b) suffice to guarantee a unique solution to the decisions on investment in product R\&D, because the function given by (4) is strictly concave while that given by (6b) is convex. ${ }^{(9)}$

Like quality improvement, cost reduction is attended with decreasing retums to

(8) This specification is similar to the specification of sunk costs in the R\&D literature [D'Aspremont and Jaquemin (1988)]. It also justices the principle of local search used in evolutionary economics [Nelson and Winter (1982)].

(9) Consumer surplus depends positively on the difference between quality and price. Since the competition game is won by the firm offering the highest level of consumer surplus, firms maximize the difference between quality and average (and marginal) cost - the lower bound on price - when deciding on product R\&D. 


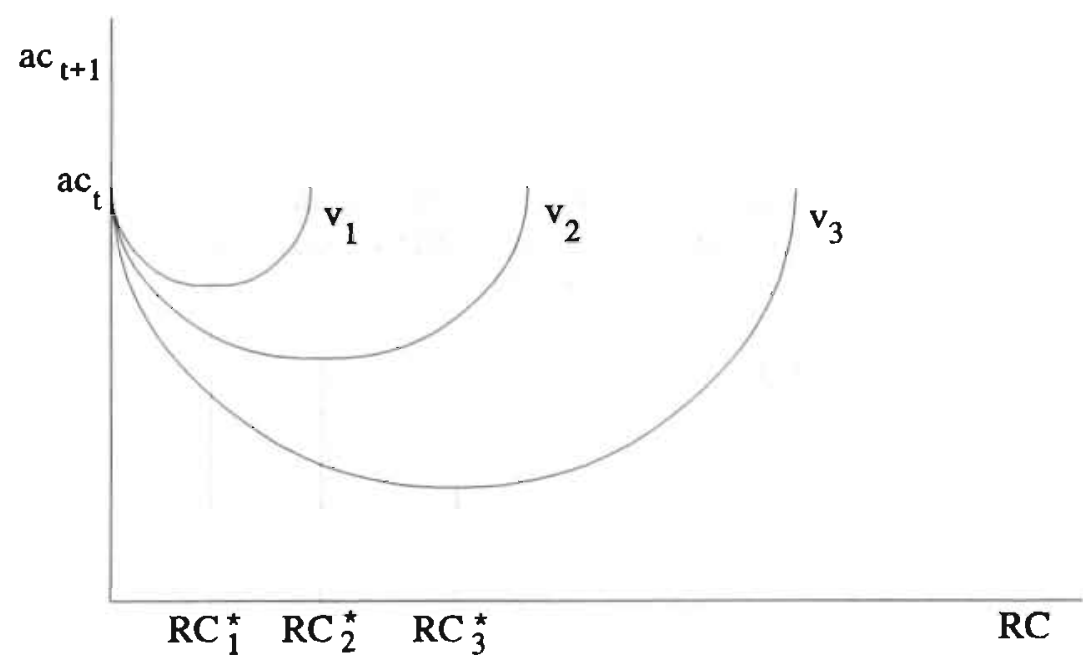

Figure 2.3: RC, average total costs and uncertainty

R\&D. Process R\&D expenses RC influence both average sunk costs and average variable costs. Because returns to investment decrease, average sunk costs increase an increasing rate as a function of process R\&D expenses RC. For the same reason average variable costs decrease at a decreasing rate and may even increase (at an increasing rate) when $\mathrm{RC}$ reaches a critical point. This may happen when the difference between the old and the new technique becomes too large. When the difference between techniques becomes too large, employees have to be trained, production may run down, etc. Figure 2.2 gives average sunk and average variable costs as a function of $\mathrm{RC}$. When average sunk and average variable costs run as in Figure 2.2, average total and marginal costs decrease at a decreasing rate until $\mathrm{RC}$ reaches $\mathrm{RC}^{*}$ and increases at an increasing rate thereafter. This is shown in Figure 2.3. The relation between process R\&D expenses and costs is modelled as follows ${ }^{(10)}$

$$
\begin{aligned}
& a c_{j, 2}=m c_{j, 2}=\left(m c_{j, 1}+\theta R Q_{j, 1}\right)\left(1-v_{j, 1}^{2}+\left(R C_{j, 1}-v_{j, 1}\right)^{2}\right) \text { or } \\
& a c_{12}=m c_{j, 2}=\left(m c_{j, 1}+\theta R Q_{j, 1}\right)\left(1+R C_{j, 1}^{2}-2 v_{j, 1} R C_{j, 1}\right) .
\end{aligned}
$$

In a certain competition game R\&D performance may differ from firm to firm. A company may simply be more lucky than his rivals in lowering costs. R\&D performance may also differ from one period to another. For this reason the opportunity to decrease costs is modelled using random variable $v$. The random variable $v$ is

(11) The function $\mathrm{ac}(\mathrm{RC})$ is constructed such that $\mathrm{ac},(0)=\mathrm{ac}+\theta \mathrm{RQ} \mathrm{Q}_{1}$, lim $\mathrm{Rc} \downarrow 0 \mathrm{ac} \mathrm{c}_{2}=$ $\mathrm{ac}_{1}+\theta R Q_{1}, \mathrm{ac}^{\prime}(0)<0$ and $\mathrm{a}^{\prime \prime}(\mathrm{RC})>0$ for $\mathrm{RC} \geq 0$. 
based on a normal distribution with mean $\rho_{v}\left(\rho_{v}>0\right)$ and variance $\sigma_{v}{ }^{2}$. The distribution is truncated at 0 (and $2 p_{v}$ ) in order to exclude the possibility of cost increases (and to keep the distribution symmetric around the mean). By assumption the distribution is uncorrelated with $\mu$ 's distribution. The drawings differ per lirm. The relation between $\mathrm{RC}$ and costs is depicted in Figure 2.3 for three value of $v\left(v_{1}<v_{2}\right.$ $<v_{3}$ ). Optimal investment $R C^{*}$ is an increasing function of $v$.

\subsection{Firm behaviour}

\subsubsection{Expectations on rival firm behaviour}

All $M$ firms compete for the favour of customers. Only firms offering the most favourable price-quality combination obtain positive demand. Firms acknowledge that they have to match the level of consumer surplus offered by rival firms in order to obtain positive demand (and gross profits). In the tradition of contestability theory, they play a winner-takes-all price game. We therefore discuss expectations on rival firm behaviour first. Since we look for a sub-game perfect equilibrium, the price decision is studied first. Because price competition is Bertrand, firms know that rival firms will apply marginal cost pricing when they need to do so in order to ensure positive demand. Marginal cost pricing maximizes consumer surplus under the constraint that marginal costs (including entry costs) are covered. Marginal costs and quality determine the maximum level of consumer surplus rival firms are willing to offer. Each rival firm $\mathrm{e}$ is willing to offer the following level of consumer surplus in market $\mathrm{m}^{(11)}$

$\mathrm{CS}_{\mathrm{e}, 2}^{\mathrm{m}}=\frac{\left(\mathrm{Q}_{\mathrm{e}, 2}-\mathrm{mc}_{\mathrm{e}, 2}-\delta_{\mathrm{e}}^{\mathrm{m}} \varepsilon\right)^{2}}{4 \gamma}$.

Subscript e refers to rival firm e $[\mathrm{e} \in\{1, \ldots, \mathrm{M}\}]$; superscript $\mathrm{m}$ denotes market $\mathrm{m}$ $[\mathrm{m} \in\{1, \ldots, \mathrm{M}\}] ; \delta_{\mathrm{e}}^{\mathrm{m}}=0$ if $\mathrm{m}=\mathrm{e}$ and 1 otherwise. The term $\delta_{\mathrm{e}}{ }^{\mathrm{m}} \varepsilon$ indicates that entry costs have to be borne in entry markets. When the firms decide on price, they take the restrictions implied by equation (8) into account. In the next sub-section, we will assume that the R\&D decision does not depend on the consumer surplus rival firms are expected to offer. The derivation of rival R\&D is therefore skipped. Since rival firms are profit-maximizing enterprises themselves, they are supposed to employ the same $R \& D$ rules.

The right-hand side of equation (8) represents consumer surplus C.S. Demand $X$ is linear and equals $\mathrm{X}=(\mathrm{Q}-\mathrm{P}) / 2 \gamma$ [equation (3a)], price equals $\mathrm{P}$ and demand is zero for any $\mathrm{P}$ larger than $Q$. 


\subsubsection{The firm's price and investment strategies}

Knowing the maximum level of consumer surplus each rival firm e may offer. the firm (incumbent) may turn to its own decisions. The firm maximizes profits under the constraint that it is able to offer a level of consumer surplus which is at least as high as the level rival firms may offer. The price set by firm $i[i \equiv\{1, \ldots, M\}]$ in market $m[m \in\{1, \ldots, M\}]$ thus has to meet the following constraints

$$
\frac{\left(Q_{i, 2}-P_{i, 2}^{m}\right)^{2}}{4 \gamma} \geq \mathrm{CS}_{e, 2}^{m}
$$

for each rival firm $e[e \in\{1, \ldots, M\}$ and $e \neq i]$. Solving for $\mathrm{P}_{i}^{\mathrm{m}}$ gives

$$
\mathrm{mc}_{\mathrm{i}, 2}+\delta_{i}^{\mathrm{m}} \varepsilon \leq \mathrm{P}_{\mathrm{i}, 2}^{\mathrm{m}}=\mathrm{Q}_{\mathrm{i}, 2}-2 \sqrt{\beta C S_{\mathrm{e}, 2}^{\mathrm{m}}}=\mathrm{Q}_{\mathrm{i}, 2}-\left(\mathrm{Q}_{\mathrm{e}, 2}-\mathrm{mc}_{\mathrm{i}, 2}-\delta_{\mathrm{e}}^{\mathrm{m}} \varepsilon\right)
$$

where $\delta_{\mathrm{e}}{ }^{\mathrm{m}} \varepsilon$ and $\delta_{i}^{\mathrm{m}} \varepsilon$ indicate firm e's and firm i's entry costs in market $\mathrm{m}$, respectively. As before, firm e's entry costs are zero if $\mathrm{e}=\mathrm{m}$ and $\varepsilon$ otherwise. Likewise, firm i's entry costs are zero if $i=m$ and $\varepsilon$ otherwise. The equality in equation (10a) only holds when the resulting price is not lower than marginal costs (including entry costs) and does not exceed the monopoly level. ${ }^{(12)}$ Note that there may be a difference between home market and entry market surplus and thus between the home market and the entry market price due to the presence of entry costs.

When firms decide on R\&D in the first period of each two-period competition game, they take account of the constraints imposed by equation (10a) on the price decisions to be taken in the second period of the game. In the first period, the firms also have to deal with the uncertainty surrounding the R\&D process. The returns to R\&D are stochastic and may be firm specific. This implies that three scenarios may arise. (1) The firm in question has the most favourable quality-cost relation. If this is so, the firm makes positive profits in its home market and possibly in some of its entry markets. (2) The firm in question does not have the most favourable qualitycost relation. If entry costs are sufficiently high, the firm is able to retain its home market at positive gross profits. (3) If entry costs are not, the firm is expelled from its home market and makes a net loss equal to its R\&D expenses.

The maximization problem based on these possibilities involves intricate expectation formation and optimization procedures which are analytically hard and probably even impossible to handle. For this reason, we applied two simplifications. (1)

(12) There is only one firm able to set a price above marginal costs. Since if $m c_{i}+\delta_{i}{ }^{m} \varepsilon<P_{i} m$ $=Q_{1}-\left(Q_{e}-m c_{e}-\delta_{c}{ }^{m} \varepsilon\right)$, then $m c_{i}+\delta_{c}{ }^{m} \varepsilon>\left(P_{t}{ }^{m}=\right) Q_{e}-\left(Q_{i}-m c_{i}-\delta_{1}^{m} \varepsilon\right)$. This implies that each rival firm e can do no better than marginal cost pricing. So. firm i can only elevate its price above marginal costs if all its rivals are not able to expel it from market $m$, even when marginal cost pricing. This argument explains why we postulate marginal cost pricing for all rival firms in Sub-section 2.2.1. 
When firms are risk averse, they may neglect the possibility to obtain extra profits in their entry markets. When firms do so, they weigh R\&D expenses against expected gross profits in their home markets. (2) In principle, any firm may obtain the best quality-cost relation in the second period of the competition game. However, the firm with the most favourable quality-cost relation in the first period of the game is most likcly to have the most favourable relation in the second period as well. For this reason. the firm with the most favourable quality-cost relation in the first period is taken as a reference point for decision making. But even when these simplifications are incorporated in the maximization problem, the expectation and optimization procedures remain intricate. For this reason the second simplification is translated into the following rule of thumb. Home market demand is expected to be positive when

$$
\mathrm{E}\left[\overrightarrow{\mathrm{m}}_{\mathrm{i}, 2}\right] \leq \mathrm{E}\left[\mathrm{P}_{\mathrm{i}, 2}^{\mathrm{i}}\right]=\mathrm{E}\left[\mathrm{Q}_{\mathrm{i}, 2}\right]-\left(\mathrm{E}\left[\mathrm{Q}_{\mathrm{c}, 2}\right]-\mathrm{E}\left[\mathrm{mc}_{\mathrm{c}, 2}\right]-\varepsilon\right),
$$

where the superscript $i$ refers to firm i's home market and the subscript $e$ to the entrant with the most favourable quality-cost relation in period 1 .

The maximization procedure followed in the simulation analyses of Section 3 now is as follows. All firms maximize home market profits with respect to product and process R\&D. This enables them to determine their own expected quality and cost levels and those of the most favoured rival. When the expected quality and cost levels are such that the expected price exceeds expected average total (and marginal) costs [equation (10b)], the firms invest in $R \& D$; otherwise, they refrain from doing so. The maximization problem is defined as follows ${ }^{(13)}$

$\max E\left[\Pi_{i, 2}\left(\mathrm{RQ}_{i, 1}, \mathrm{RC}_{\mathrm{i}, 1}\right)\right]=\mathrm{E}\left[\mathrm{NX} X_{i, 2}^{\mathrm{i}}\left(\mathrm{P}_{\mathrm{i}, 2}^{\mathrm{i}}-\mathrm{ac}_{\mathrm{i}, 2}\right)\right]$

where subscript $\mathrm{i}$ refers to firm $\mathrm{i}[\mathrm{i} \in\{1, \ldots, \mathrm{M}\}]$ and superscript $\mathrm{i}$ to its home market. Demand $X_{i}$ is given by equation (3a), quality $Q$, by equation (5), price $P_{i}$ by equation (10a) and average cost $\mathrm{ac}_{i}$ by equation (7). $\mathrm{N}$ denotes the number of

(13) Profits are maximized assuming certainty equivalence. This implies that we neglect the expectation formation problem for the moment. Equations (3a) and (10a) may be used to rewrite equation (11) as follows:

$$
\begin{aligned}
& \mathrm{E}\left[\mathrm{NX}_{\mathrm{i}, 2}\left(\mathrm{P}_{\mathrm{i}, 2}-\mathrm{ac}_{\mathrm{i}, 2}\right)\right]= \\
& E\left[(N / 2 \gamma)\left(Q_{i, 2}-P_{i, 2}\right)\left(P_{i, 2}-a c_{i, 2}\right)\right]= \\
& \mathrm{E}\left[(\mathrm{N} / 2 \gamma)\left(\mathrm{Q}_{\mathrm{c}, 2}-\mathrm{ac}_{\mathrm{e}, 2}-\varepsilon\right)\left(\mathrm{Q}_{\mathrm{i}, 2}-\mathrm{Q}_{\mathrm{e}, 2}+\mathrm{ac}_{\mathrm{e}, 2}+\varepsilon-\mathrm{ac}_{\mathrm{i}, 2}\right)\right]= \\
& \mathrm{E}\left[(\mathrm{N} / 2 \gamma)\left(\mathrm{Q}_{\mathrm{e}, 2}\left(\mu_{\mathrm{e}, \mathrm{1}}\right)-\mathrm{ac}_{\mathrm{e}, 2}\left(v_{\mathrm{e}, 2}\right)-\varepsilon\right)\left(\mathrm{Q}_{\mathrm{i}, 2}\left(\mu_{\mathrm{i}, 2}\right)-\mathrm{Q}_{\mathrm{e}, 2}\left(\mu_{\mathrm{e}, 2}\right)+\mathrm{ac}_{\mathrm{c} .2 .}\left(v_{\mathrm{e}, 2}\right)+\varepsilon-\mathrm{ac}_{\mathrm{t}, 2}\left(v_{\mathrm{t}, 2}\right)\right)\right]
\end{aligned}
$$

Recall that $Q$ is a linear function of $\mu$, and ac a linear function of $v$. The following multiplicative terms: $\mu_{e}{ }^{2}, v_{e}{ }^{2}, \mu_{e} v_{e}, \mu_{e} \mu_{i}, v_{e} \mu_{i}, \mu_{e} v_{i}$ and $v_{e} v_{i}$, enter equation (11). Since $\mu_{e}, \mu_{1}, v_{e}$ and $v_{1}$ are drawn independently, the last five terms do not complicate the expectation formation problem. However, the first two terms do. 
consumers per market. Substituting for $X_{i}, Q_{i}, P_{i}$ and $a_{i}$ and differentiating with respect to $R Q_{i}$ and $R C_{i}$, respectively, gives the following levels of product and process R\&D

$$
\begin{aligned}
& \mathrm{RQ}_{i, 1}=\frac{\mathrm{E}\left[\mu_{i, 1}\right]^{2}}{4 \theta^{2}\left(1+\mathrm{RC}_{i, 1}^{2}-2 \mathrm{E}\left[\mathrm{v}_{\mathrm{i}, \mathrm{l}}\right] \mathrm{RC}_{\mathrm{i}, \mathrm{l}}\right)^{2}} \text { and } \\
& \mathrm{RC}_{\mathrm{i}, 1}=\mathrm{E}\left[\mathrm{v}_{\mathrm{i}, \mathrm{l}}\right] .
\end{aligned}
$$

After substituting for $\mathrm{RC}, \mathrm{RQ}$ can be reduced to

$$
R Q_{i, 1}=\frac{E\left[\mu_{i, 1}\right]^{2}}{4 \theta^{2}\left(1-E\left[v_{i, 1}\right]^{2}\right)^{2}} .
$$

Profit maximizing rival firms, of course, apply the same R\&D rules. However, when expected profits are negative according to equation (10b), the firm does not invest in product and process $R \& D$. The maximization problem followed is simplified to a large extent. However, note that the equilibrium levels of $R \& D$ are more or less implied by the technical relations given by equations (5) to (7), when one abstracts from the uncertainty and randomness involved in the model. Equations (12b) and (13) define R\&D investment as a function of the expected values of the random variables only. As stated above, rival firms are expected to employ the same R\&D rules. Expenses on product R\&D RQ are an increasing function of the expected cost decrease induced by process $R \& D$ expenses, $E[v]^{2}$. These expenses thus are complementary to expenses on product $R \& D$.

Equations (1) to (13) determine the enterprises' equilibrium outcomes. Consider the two-period game given by Table 2.2 again and assume that the returns to investment in R\&D are not stochastic. Randomness is studied in the next section where a dynamic analysis of the competition process described above is performed. When firms start with the same quality and cost levels in period $1\left(Q_{1}\right.$ and $\left.m c_{1}\right)$, they all invest according to equations (12b) and (13). Since the returns to $R \& D$ investment are not stochastic, they all end up with the same quality and cost levels in period 2 $\left(\mathrm{Q}_{2}\right.$ and $\left.\mathrm{mc}_{2}\right)$. When $\varepsilon>0$, each firm is able to deter entry at a price just below $\left(\mathrm{mc}_{2}+\varepsilon\right)$ and earn a net profit approximately equal to $\varepsilon X$. When $\varepsilon \downarrow 0$, net profits approach zero. When $\varepsilon=0$, firms may enter their rivals' markets. But in order to do so, they must apply marginal and average cost pricing. Gross prolits just cover R\&D expenses, whether firms enter their rivals' home markets or not. So, when average total costs are constant over the relevant range of output Bertrand pricing and sunk costs may be reconciled. This result contradicts Stiglitz' (1987: 890) result.

\subsection{Welfare analysis}

In order to carry out a welfare analysis of the above results, two benchmarks are con- 
structed: These of the social planner and of the monopolist. In both henchmarks there is a plant in each market. Entry costs do not have to be incurred. R\&D expenses have to be incurred only once: The knowledge acquired may be fully employed in all $\mathrm{M}$ markets.

\subsubsection{The social planner}

Social welfare $\Sigma$, as maximized by the social planner, is defined as the sum of consumer surplus and the planner's profits. Second-best considerations are left aside as well as distributive aspects: Consumer surplus and industry profits are given equal weights. The social planner has perfect foresight over the two-period game. The maximization problem can be defined as follows

$\max E\left[\Sigma_{s}\left(\mathrm{RQ}_{s, 1}, \mathrm{RC}_{s, 1}, \mathrm{P}_{\mathrm{s}, 2}\right)\right]=\mathrm{E}\left[\mathrm{MN} \frac{\left[\mathrm{Q}_{\mathrm{s}, 2}-\mathrm{P}_{\mathrm{s}, 2}\right]^{2}}{4 \gamma}+\mathrm{MN} \frac{\left[\mathrm{Q}_{\mathrm{s}, 2}-\mathrm{P}_{\mathrm{s}, 2}\right]}{2 \gamma}\left[\mathrm{P}_{\mathrm{s}, 2}-\mathrm{ac}_{\mathrm{s}, 2}\right]\right]$.

The subscript $\mathrm{s}$ is added to the variables in order to distinguish them from the variables derived elsewhere. The first part of the right-hand side denotes consumer surplus; the second part of the right-hand side denotes industry profits. The following levels of product and process $\mathrm{R} \& \mathrm{D}$ and price can be derived

$$
\begin{aligned}
& \mathrm{RQ}_{\mathrm{s}, 1}=\frac{\mathrm{E}\left[\mu_{\mathrm{s}, 1}\right]^{2}}{4 \theta^{2}\left(1-\mathrm{E}\left[v_{s, 1}\right]^{2}\right)^{2}}, \\
& \mathrm{RC}_{\mathrm{s}, 1}=\mathrm{E}\left[v_{\mathrm{s}, 1}\right] \text { and } \\
& \mathrm{P}_{s, 2}=\mathrm{mc}_{\mathrm{s}, 2}=\mathrm{ac}_{\mathrm{s}, 2} .
\end{aligned}
$$

Social welfare can be determined using (15), (16) and (17). A social planner may prescribe (15), (16) and (17) in order to maximize social welfare. Notice that equations (15) and (16) are equal to equations (12b) and (13). The investments performed by firms subject to competition are optimal. Remember, however, that when more than one firm invests, duplication of R\&D efforts occurs.

\subsubsection{The monopolist}

The performance of the market process will also be compared with the performance of a monopolist who is not subject to an entry threat. In the second period of each game the monopolist decides on price, while the quality level is fixed. The following function shows the monopolist's gross profits as a function of price 
$\max \pi_{\mathrm{m}}\left(\mathrm{P}_{\mathrm{m}, 2}\right)=\mathrm{MN} \frac{\left[\mathrm{Q}_{\mathrm{m}, 2}-\mathrm{P}_{\mathrm{m}, 2}\right]}{2 \gamma}\left[\mathrm{P}_{\mathrm{m}, 2}-\mathrm{mc}_{\mathrm{m}, 2}\right]$.

Taking the first-order derivative with respect to $P_{m, 2}$ gives the following solution

$$
P_{m 2}=\frac{1}{2}\left(Q_{m, 2}+m_{m, 2}\right) \text {. }
$$

'The first period's optimization problem can now be determined by substituting equation (19) into equation (18)

$\max E\left[\Pi_{m}\left(R Q_{m, 1}, R C_{m, 1}\right)\right]=E\left[M N \frac{\left(Q_{m, 2}-a_{m, 2}\right)^{2}}{8 \gamma}\right]$

where $Q_{m, 2}$ is given by equation (5) and $a c_{m, 2}$ by equation (7). The solution of the maximization problem towards $\mathrm{RC}$ is

$\mathrm{RC}_{\mathrm{m}, \mathrm{l}}=\mathrm{E}\left[\mathrm{v}_{\mathrm{m}, 1}\right]$

The solution of the maximization problem towards RQ under the assumption of certainty equivalence equals

$$
R Q_{m, 1}=\frac{E\left[\mu_{m, 1}\right]^{2}}{4 \theta^{2}\left(1-E\left[v_{m, 1}\right]^{2}\right)^{2}} .
$$

To distinguish the monopolist $R \& D$ and price levels from the other $R \& D$ and price levels the subscript $\mathrm{m}$ is added to the variables. Social welfare can be determined on the basis of equations (19), (21) and (22).

\subsubsection{A comparison}

Now all investment and price decisions have been determined, both for the firms subject to competition and for the benchmarks constructed, they may be compared. The following (in)equalities hold when the returns to $R \& D$ are not stochastic

$$
\begin{aligned}
& \mathrm{RQ}_{s}=\mathrm{RQ}_{\mathrm{c}}=\mathrm{RQ}_{\mathrm{i}}=\mathrm{RQ}_{\mathrm{m}}, \\
& \mathrm{RC}_{\mathrm{s}}=\mathrm{RC} \mathrm{C}_{\mathrm{c}}=\mathrm{RC}_{\mathrm{i}}=\mathrm{RC}_{\mathrm{m}} \text { and } \\
& \mathrm{P}_{\mathrm{s}}=\mathrm{mc} \leq \mathrm{P}_{\mathrm{i}} \leq \mathrm{P}_{\mathrm{e}}=\mathrm{mc}+\varepsilon \leq \mathrm{P}_{\mathrm{m}},
\end{aligned}
$$

at least when $\varepsilon$ is small enough for the last inequality to hold. Equations (23) to (25) 
comprise the most essential analytical results. All firms invest optimally. This result is not surprising because (1) average total and marginal costs are a constant function. of output and (2) the equilibrium levels of R\&D are more or less imposed by in the technical relations between $R \& D$, quality and costs given in Sub-section 2.1.4. The profit margin of incumbent firms is approximately equal to the entry cost faced by potential entrants. When $\varepsilon \downarrow 0$, the incumbent's price level approaches marginal cost. The monopolist, of course, sets a sub-optimal price, i.e. above marginal (and average) cost.

Process $R \& D$ is a positive function of $E[v]$ only. This is not surprising, since the maximum cost decrease equals $\mathrm{E}[\mathrm{v}]^{2}$ for $\mathrm{RC}=\mathrm{E}[\mathrm{v}]$ [equation (7)]. Product $\mathrm{R} \& \mathrm{D}$ depends positively on $E[\mu]$ and $E[v]$, and negatively on $\theta$. A guilder spent on product R\&D causes a larger rise in quality the larger $\mu$ is [equation (5)]. A rise in quality gives rise to a larger increase in cost the larger $\theta$ is; the cost rise is a decreasing function of $v$, as explained above [equation (7)]. In the next section uncertainty and, more importantly, randomness are explicitly allowed for. These features determine processes of entry, exit, bankruptey, and quality and cost leadership, so endogenizing the development of market structure. Let us turn to an analysis of industry dynamics.

\section{Simulation results}

This section analyses simulations of a sequence of the competition game set out in the previous section. This is done in order to obtain an insight in the development of market structure under various parameter configurations. Uncertainty and randomness play an important role in the determination of this development. The results of the simulations are analyzed in Sub-section 3.2. Before the results are analyzed, the structure of a sequence of competition games is discussed in Sub-section 3.1. But first some observations on entry are given in order to see whether our model corresponds with the facts of life.

Geroski (1991: 11) distinguishes two facts on entry. According to Geroski (1) the entry rate varies largely over time and across industries, and (2) entry and exit rates are highly correlated with each other. ${ }^{(14)}$ The latter observation is incorporated in our model by the nature of hit-and-run entry: Bertrand competition in combination with the absence of capacity constraints. The first observation is done some justice by the parameter $\varepsilon$. The ease of entry differs in our model depending on the value of $\varepsilon$. This parameter may reflect (1) transportation costs, (2) product adaptation costs, (3) differences in preferences or anything else. Since industries differ in these respects, the ease of entry differs accordingly. During a sequence of games, i.e. through time, firms may acquire strategic advantages in terms of quality or cost. When a firm has acquired a strategic advantage, it is more difficult to enter its home market. Our model consequently is also able to explain differences in the entry rate through time.

(14) Kleijweg and Lever (1995) make similar observations for the Netherlands, and Evans and Siegfried (1992) for the US. See Siegfried and Evans (1994) for an overview. 
By modelling a set of related markets our model also does justice to the fact that firms incumbent in related markets are the only type of firms likely to enter at a hitand-run basis [Geroski (1991: 40n)]. With respect to hit-and-run entry it is also noteworthy to remark that $50 \%$ of all large entrants ( $\geq 500$ employees) in the UK exited a market rather quickly after a short period (5 years) of making relatively large sales in the market entered [Geroski (1991: 29n)].

\begin{tabular}{|c|c|c|c|c|}
\hline \multicolumn{5}{|c|}{$\begin{array}{l}\text { Table } 2.3 \\
\text { Structure of a sequence of games }\end{array}$} \\
\hline \multirow[t]{2}{*}{ Period } & \multicolumn{4}{|c|}{ Competition game } \\
\hline & 1 & 2 & 3 & 4 \\
\hline 1 & $\begin{array}{l}\text { R\&D } \\
\text { decision }\end{array}$ & & & \\
\hline \multirow[t]{3}{*}{2} & $\begin{array}{l}\text { Price } \\
\text { decision }\end{array}$ & & & \\
\hline & Spillovers & & & \\
\hline & & $\begin{array}{l}\text { R\&D } \\
\text { decision }\end{array}$ & & \\
\hline \multirow[t]{3}{*}{3} & & $\begin{array}{l}\text { Price } \\
\text { decision }\end{array}$ & & \\
\hline & & Spillovers & & \\
\hline & & & $\begin{array}{l}\text { R\&D } \\
\text { decision }\end{array}$ & \\
\hline \multirow[t]{3}{*}{4} & & & $\ldots$ & \\
\hline & & & $\ldots$ & \\
\hline & & & & $\ldots$ \\
\hline
\end{tabular}

\subsection{Introduction}

In this section sequences of competition games are analyzed. Table 2.3 gives the structure of a sequence. The table shows that firms decide on R\&D without taking spillovers to future periods into account. We will argue why firms do so in Subsection 3.1.1. The table also reveals that there are interfirm spillovers between competition games. The spillover rule will be discussed in Sub-section 3.1.2. The twoperiod time horizon does not make history unimportant. Since the results of R\&D efforts differ per firm, firms may acquire a quality or cost advantage through time. 
The process through which this advantage is obtained is discussed in Sub-section 3.1.3. Before we turn to the results of the analyses we discuss the simulation set-up in Sub-section 3.1.4 and the expectation mechanisms in Sub-section 3.1.5.

\subsubsection{The time horizon}

When firms decide on $R \& D$ investment in a particular game, they do not take account of the spillovers to later games. A short time horizon is modelled in order to simplify the analysis. A two-period time horizon is simply the most convenient time horizon from an analytical point of view. An extension of the time horizon is likely to inflate the R\&D investments without effecting the qualitative results obtained, at least when investments are amortized properly. ${ }^{(15)}$ However, some stronger arguments may be put forward for a short time horizon. Later games do not have to be taken into account when firms value current profits more than they value future profits. This valuation may be expressed by a high discount factor $\mathrm{r}$. Firms may value current profits more than they value future profits because they are risk averse. Suppose that profits $\Pi$ over $\mathrm{n}$ games are given by

$$
\Pi=\sum_{\tau=1}^{\mathrm{n}}\left(\Pi_{\tau} /(1+r)^{r-1}\right)
$$

When $r \rightarrow \infty$, the above equation is reduced to $\Pi=\Pi_{1}$. A strong preference for short-term profits may be related to the organization of the capital market. Short-run profits may be the prime determinant for valuing shares. When this is so, firms especially strive for short-run profits. This holds especially for Anglo-Saxon countries [De Jong (1995)]. There is another good reason to restrict the time horizon to one game. When a longer time horizon would be taken into account, for instance three periods, it would be optimal to spend more on product $R \& D$ in the first period of the game. A higher level of product $R \& D$ in the first period produces a more favourable quality-cost relation in the third period. However, the quality-cost relation in the second period will deteriorate in comparison with the above result. This fact may thus give rise to intertemporal unsustainability as analyzed by Bau-mol et al. (1988: Ch. 14) with the following difference. In a three-period model based on the above demand and cost relations entrants would enter in period 2, while they enter in period 3 in Baumol et al. This difference is due to the fact that Baumol et al. assume that there are increasing returns to investment, while there are decreasing returns in the above models. The very fact that firms which invest more in product $R \& D$ than is optimal from a two-period perspective, are likely to be expelled from the market and to suffer losses, may withhold them from doing so.

(15) When R\&D investments are not amortized properly, the analysis of $R \& D$ and price decisions may become messy [Baumol et al. (1988): Ch. 13 and 14]. Amortization may not evoke substantial problems in this model, given the cost function chosen [page 51]. 


\subsubsection{Spillovers}

Table 2.3 shows that there are interfirm spillovers between competition games. Therefore, some attention has to be addressed to the spillover mechanism. In a world of free competition it is not likely that firms are able to uphold strategic advantages in terms of quality and cost, because 'information about what other firms are doing spreads quite quickly' [Dosi (1988: 1131)]. Mansfield (1985) reports that information on new products is known to at least one rival firm within one year for 83 percent of all firms investigated. Information on new products disperses quickly in industries like electrical equipment, instruments and stone, clay, and glass; it disperses slowly in industries like chemicals and petroleum. Information on new processes is known to at least one rival firm within 18 months for 61 percent of all firms investigated. Information disperses quickly in industries like petroleum, primary metals, transportation equipment and instruments; it disperses slowly in industries like chemicals. pharmaceuticals, electrical equipment, machinery and stone, clay. and glass. Information is received through movement of personnel, networks among engineers and scientists, input suppliers, customers and patents. In order to cope with the phenomenon of spillovers a spillover mechanism has to be defined.

Because spillovers are allowed for, the quality and cost levels available to a company do not depend on the quality and cost levels the company attained itself only, but also on the quality and cost levels obtained elsewhere in the industry. More specifically, the quality-cost relation after game $t$ depends on the most favourable quality-cost relation obtained elsewhere in the market $\left(\mathrm{Q}_{t}^{*}, \mathrm{mc}_{i}\right)^{\left({ }^{(16)}\right.}$ The qualitycost relation available at the beginning of game $t$ is as follows

$$
\left.\left(Q_{j, t+1}, m c_{j, t+1}\right)=\left((1-\beta) Q_{j, t}+\beta Q_{t}\right),(1-\beta) m c_{j, t}+\beta m c_{t}\right)
$$

where $\beta \in[0,1]$. There are full spillovers when $\beta=1$. There are no spillovers when $\beta=0$.

\subsubsection{Industry dynamics}

Before the results of the simulations are analyzed we better pause in order to explain the mechanisms generating these results. Each firm starts a simulation with a certain level of wealth, i.e. a certain level of money. This money may be used to pay R\&D expenses. In Sub-section 2.2 .2 the R\&D decisions of the firms are outlined. The R\&D rules employed [equations (12) and (13)] are the same for all firms. However,

(16) Nelson and Winter (1982) employ a similar procedure for imitation strategies. However, they argue that imitation is more likely to be based on the most dispersed technology rather than the most favourable one. The latter would be more in line with diffusion theories [Dosi (1988)]. In contrast with Nelson and Winter (1982) spillovers are costless in this chapter. 
in the simulations R\&D performance differs per firm. We will consider two causes for these differences. (1) The drawings of the random variables from their distributions are firm specific. One firm is simply more lucky in performing R\&D than another. All firms know the distribution of the random variables and employ rational expectations. R\&D investments thus are equal. (2) The firms do not know the distribution of the random variables and employ different expectation mechanisms. As a result, R\&D investments and performance differ per firm, although the drawings from the distributions are the same for all firms. In both analyses one firms will performs better than its rivals in terms of product or process R\&D. When a firm performs better than all its rivals, it may expel them from their hone markets provided that entry costs are small enough. When the rival firms are expelled, they do not cover their R\&D expenses and make a loss, i.e. their wealth is reduced. When a firm makes too many losses in a short time period, it goes bankrupt and drops out of the $R \& D$ race. Bankruptcy due to bad $R \& D$ performance is one of the main mechanisms driving the results presented below. However, there is another. When a firm performs bad in terms of $R \& D$ in competition game (t) and interfirm spillovers are low, the firm faces a competitive disadvantage at the beginning of competition game $(t+1)$. Because the firm has a lower quality or higher costs relative to rival lirms. expected profits are negative unless entry costs are high enough to compensate for the competitive disadvantage. When expected profits are negative, the firm does not invest. When a firm does not invest any more, the quality or cost lag is likely to become bigger and bigger. A competitive advantage may become larger through time when lagging firms are deterred from investing. This is the second mechanism explaining the results in the following sub-section. One firm may thus monopolize the set of markets because (1) rival firms go bankrupt or (2) they stop investing in R\&D.

In the next section we again compare the market's performance with the performance by the social planner and the monopolist. In order to compare the mar-ket's results with those obtained by the social planner and the monopolist the latter two are assumed to employ a two-period time horizon as well. ${ }^{(17)}$ The firms subject to competition and the monopolist employ rational expectations, while the social planner has perfect foresight over the two-period time horizon. This difference explains one of the results presented below. Another difference influencing the results is the following: The social planner and the monopolist do not suffer from duplication of R\&D efforts, while the market in principle does. However, this difference may be compensated to some extent by the fact that the market participants benefit from interfirm spillovers, while the social planner and the monopolist do not.

(17) The assumption that the social planner has a two-period time horizon has been criticized quite often. According to some economists social planners have the disposal over an. infinite time horizon by definition. However, such social planners do not exist. Governments do, but they tend to be myopic. (They in fact do not even have the: disposal over (limited) perfect foresight.) 


\subsubsection{Methodology}

In order to obtain a better understanding of the simulation results, this sub-section sketches the course of the simulations. Table 2.4 presents the stages walked through during one competition game. At the start of each game the model determines the values of the random variables. These values are made public in the beginning of period two together with all quality and cost levels. Firms therefore estimate the values of the random variables before they decide on $R \& D$. When they have rational expectations, the estimate is simply the mean of the random variables. When they have to make inferences on basis of drawings in the past, we take care that there are enough drawings before competition starts. The estimates enable the firms to determine their own and their rivals' optimal investments. When firms estimate rival investment, they either suppose that rival firms have the same expectation mechanism as they do or they do not know any better mechanism than their own to determine rival investments. The firms subsequently calculate expected qualities and costs. Thereupon the firms compare their own quality-cost combination with the most favourable rival quality-cost combination (including entry costs). When expected profits are positive according to equation (10b), the firm invests; otherwise it abstains from investment. When the firm does not have enough money to pay its $R \& D$ expenses, the firm simply shares its wealth proportionally between product and process $R \& I$ ) expenses.

Table 2.4

The course of a game in the simulations

$\begin{array}{ll}\text { Period } & \text { Decisions } \\ 1 & \text { Drawing the random variables } \\ & \text { Estimating the random variables } \\ & \text { Determination of preferred R\&D investments } \\ & \text { Comparison with rival firms } \\ & \text { R\&D decisions } \\ & \text { Realization of quality and cost levels } \\ & \text { Market allocition } \\ & \text { Determination of demand and profits } \\ & \text { Spillovers }\end{array}$

At the beginning of period two the quality and cost levels are determined and made public. The model subsequently investigates per market which firm has the most favourable quality-cost combination (including possible entry costs). Demand is allocated to this firm. This firm sets a price deterring entry of the 'second-best' firm. When the monopoly price is lower than this level, the monopoly price is set. Subsequently, demand and profits are determined. At the end of the game spillovers are determined according to equation (27). Note that they do not influence the already concluded competition game. 


\subsubsection{Expectation mechanisms}

R\&D performance depends, among other things, on the investments made. These investments are a function of the expected values of the random variables [equations (12b) and (13)]. Firms do not necessarily know the distribution of these variables. If this is so, they need to estimate the expected values in one way or another. Since firms have different perceptions of their environment, they also have different expectations. Management teams have different perceptions of the environment because of differences in: (1) Functional diversity, homogeneity or tenure of management teams [Sutcliffe (1994) and Waller et al. (1995)]; (2) in organizational scanning or performance monitoring [Sutcliffe (1994) and Thomas et al. (1993)]; (3) the degree of centralization [Sutcliffe (1994)]; (4) nationality [Schneider et al. (1991)]; (5) familiarity with the industry (incumbents versus entrants). Some perceptions will accord better with the actual environment than others. The greater the match between managerial perceptions of environmental characteristics and the actual environment, the better an organization is likely to perform [Miller and Cardinal (1994) and Sutclifte (1994)]. The performance of firms influences industry evolution. Firms with a better match are likely to survive the competition process. As in early population ecology literature [Kelly and Amburgey (1991)], the evolution of organizations in the simulations performed is primarily influenced through (foundings and) failures. Since firms do not learn (yet) in the simulations, external selection processes determine the ultinate type of incumbents. Future research will address internal selection processes as well.

\section{Table 2.5}

Expectation mechanisms

(A) Rational Expectations (RATEX)

$\mathrm{E}_{\mathrm{i}}\left[\mu_{\mathrm{i}, \mathrm{t}}\right]=\rho_{\mu}$

$\operatorname{Var}\left(\mathrm{E}_{\mathrm{i}}\left[\mu_{\mathrm{i}, \mathrm{i}}\right]\right)=\sigma_{\mu}^{2}$

(C) Backward Looking 2 (BL 2)

$\mathrm{E}_{\mathrm{i}}\left[\mu_{\mathrm{i}, \mathrm{l}}\right]=\mu_{\mathrm{i},-2-2} / 2+\mu_{\mathrm{i}, \mathrm{t}-\mathrm{l}} / 2$

$\operatorname{Var}\left(\mathrm{E}_{\mathrm{i}}\left[\mu_{\mathrm{i}, \mathrm{l}}\right]\right)=(3 / 2) \sigma_{\mu}^{2}$

(E) Adaptive Expectations (AE)

$E_{i}\left[\mu_{i, 1}\right]=E_{i}\left[\mu_{i, t-1}\right]+0.5\left[\mu_{i, t,-1}-E_{i}\left[\mu_{i, k-1}\right]\right.$

$\operatorname{Var}\left(\mathrm{E}_{i}\left[\mu_{i, 1}\right]\right)=(4 / 3) \sigma_{\mu}^{2}$
(B) Backward Looking 1 (BL 1)

$\mathrm{E}_{\mathrm{i}}\left[\mu_{\mathrm{i}, \mathrm{I}}\right]=\mu_{\mathrm{i}, 1-1}$

$\operatorname{Var}\left(\mathrm{E}_{\mathrm{i}}\left[\mu_{\mathrm{i}, \mathrm{J}}\right]\right)=2 \sigma_{\mathrm{ij}}^{2}$

(D) Backward Looking 3 (BL. 3)

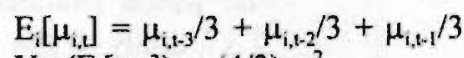

$\operatorname{Var}\left(\mathrm{E}_{i}\left[\mu_{i, 1}\right]\right)=(4 / 3) \sigma_{\mu}^{2}$

The expectation mechanisms employed in the simulations are given by Table 2.5 . The table refers to $\mu$, but applies to $v$ as well. We distinguish rational, backward- 
looking and adaptive expectations. ${ }^{(18)}$ The variance between the realized and the expected values of the random variable is given as well. ${ }^{(19)}$ The variance of the estimator indicates the preciseness of the estimations. RATEX estimates more precise than BL III and AE, the latter two more precise than BL. II, and BL II better than BL I. As argued above, more precise estimators are more likely to survive. We expect an evolution to better informed organizations through the process of failures (external selection).

\subsection{Simulation results}

\subsubsection{Outline of the results}

In the remaining part of this section the results of simulation analyses are discussed. Table 2.6 gives the basis parameter values employed, while Table 2.7 lists the analyses performed. The analyses generate processes of entry, exit, bankruptcy, monopolization, quality and cost leadership, because the random nature of the R\&D process creates differences in qualities and costs. We performed the simulations for two sources for these differences. (1) R\&D performance is firm specific. Firms invest the same amount in $R \& D$, have rational expectations and draw from the same distribution, but simply are lucky or unlucky in performing R\&D. (2) The returns to $R \& D$ are not firm specific, but the firms have different expectation mechanisms. As a result, investments and performance differ. Simulations A to E [Table 2.7] refer to the analysis of luck, simulations $\mathrm{F}$ and $\mathrm{G}$ to the analysis of expectation mechanisms. Table 2.7 also indicates whether other parameter values than the basis values are used and the number of replications.

Table 2.6

Basis parameter values

$$
\begin{array}{ll}
\gamma=0.5 & \rho_{\mu}=0.2 \\
\theta=1 & \sigma_{\mu}{ }^{2}=0.02 \\
\beta=1 & \rho_{\mathrm{v}}=0.15 \\
\varepsilon=0 & \sigma_{\mathrm{v}}{ }^{2}=0.15 \\
\mathrm{Q}_{\mathrm{i}}=1 & \mathrm{M}=3 \\
\mathrm{mc}_{1}=0.75 & \mathrm{~N}=5
\end{array}
$$

Initial wealth $=0.5$
Figures 2.4 to 2.8 present the results of one simulation. This simulation is in no way representative for other simulations, but gives an insight in the course of simulations. Figures 2.9 to 2.11 pay somewhat more attention to the development of quality and marginal cost through time. The sensitivity of the results is studied with respect to three crucial parameters: Entry costs, the spillover rate and the initial number of firms and markets. Figures 2.12 to 2.17 analyze the sensitivity of the results with respect to the entry cost $\varepsilon$. Figures 2.12 and 2.13 do so for full spillovers $(\beta=1)$, Figures 2.14 to 2.17 for less than full spillovers $(\beta=0.6)$. Figure 2.16 and 2.17 also reveal the sensitivity of the results with respect to the number of firms and markets modelled. Analysis $F$ and $G$ repeat

(18) An overview of expectation mechanisms is given by De Jong (1988).

(19) The variance between the realized and the expected values of the random variables is defined as follows: $\operatorname{var}\left(\mathrm{E}_{\mathrm{i}}\left[\mu_{\mathrm{i}, \mathrm{J}}\right]\right)=\left(\mu_{\mathrm{i}, \mathrm{t}}-\mathrm{E}_{\mathrm{i}}\left[\mu_{\mathrm{i}, \mathrm{t}}\right]\right)^{2}$. 
analysis $C$ and $D$ for firm heterogeneity with respect to expectation mechanisms. Note that the firms start from symmetrical positions [Table 2.6]: Initial quality, cost and wealth are the same for all firms. (The subscript 1 denotes the initial value of $Q$ and $\mathrm{mc}$.)

Table 2.7

Overview of simulation analyses

$\begin{array}{llll}\begin{array}{l}\text { Analysis } \\ \text { (\# repl.) }\end{array} & \text { Figure } & \text { Variable } & \begin{array}{l}\text { Parameter } \\ \text { values }\end{array} \\ \text { A (1) } & 4 & \text { Quality } & - \\ & 5 & \text { Marginal cost } & \text { Consumer surplus } \\ & 6 & \text { Industry profits } & - \\ & 7 & \text { Social welfare } & - \\ \text { B (250) } & 8 & \text { Quality } & - \\ & 9 & \text { Marginal cost } & - \\ \text { C }(250-\varepsilon) & 12 & \text { Marginal cost } & - \\ & 11 & \text { Bankruptcy and monopolization } & \varepsilon \in\{0,0.1\} \\ \text { D }(250-\varepsilon) & 14 & \text { Social welfare } & \varepsilon \in\{0,0.1\} \\ & 15 & \text { Bankruptcy and monopolization } & \beta=0.6 / \varepsilon \in\{0,0.1\} \\ \text { E }(250-\varepsilon) & 16 & \text { Social welfare } & \beta=0.6 / \varepsilon \in\{0,0.1\} \\ & 17 & \text { Monopolization } & M=\{2,4\} \\ \text { F }(250-\varepsilon) & 18 & \text { Social welfare } & M=\{2,4\} \\ & 19 & \text { Bankruptcy and monopolization } & \varepsilon \in\{0,0.1\} \\ & 20 & \text { Bankruptcy per firm } & \varepsilon \in\{0,0.1\} \\ \text { G }(250-\varepsilon) & 21 & \text { Social welfare } & \varepsilon \in\{0,0.1\} \\ & 22 & \text { Bankruptcy and monopolization } & \beta=0.6 / \varepsilon \in\{0,0.1\} \\ & 23 & \text { Bankruptcy per firm } & \beta=0.6 / \varepsilon \in\{0,0.1\} \\ & & \text { Social welfare } & \beta=0.6 / \varepsilon \in\{0,0.1\}\end{array}$

\subsubsection{Rational expectations}

Analyses $A$ to $C$ [Table 2.7] all refer to a scenario with full spillovers. This implies that these analyses have relevance for industries where information on product and process innovations disperses immediately. i.e. for industries like electrical equipment and instruments [Mansfield (1985)]. Figures 2.4 to 2.8 [Analysis A] present the results of one particular simulation. These results are in no way representative for other simulations, but give an insight in the course of the replications per-formed. The market's results refer to the companies which are incumbent in that particular period. The market's quality and cost levels are averaged over the three markets. The results refer to 100 periods, the first of which is the starting period. Interpretation of the results is straightforward. In this example the industry happens to be monopolized 
Figure 2.4: Qual ity

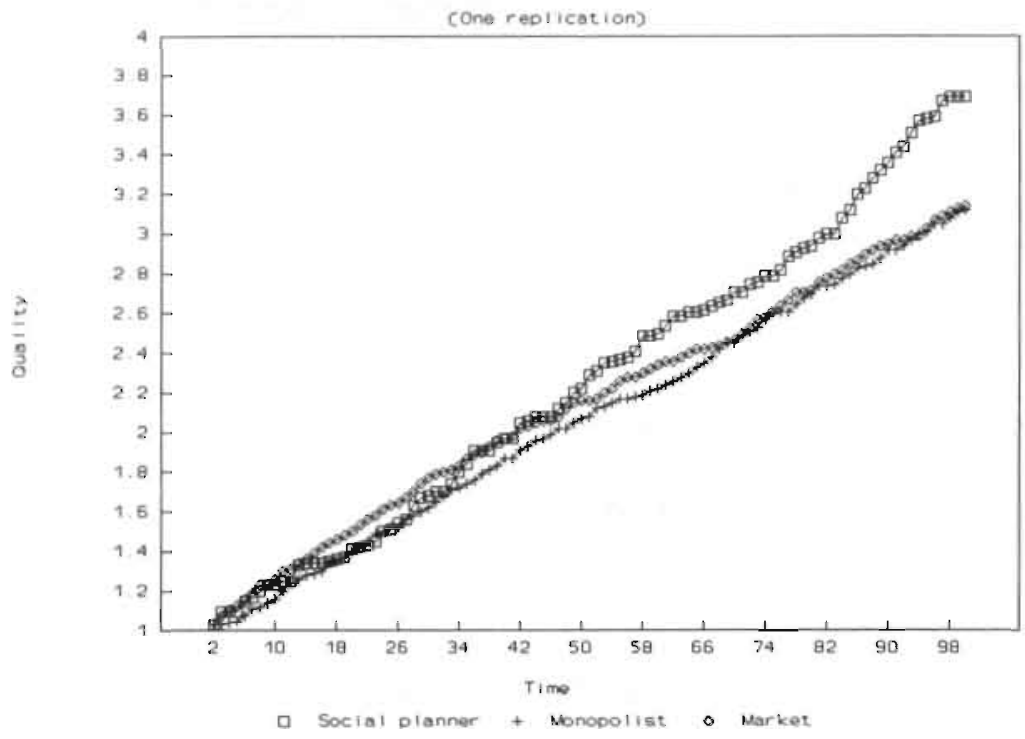

Figure 2.5: Marginal cost

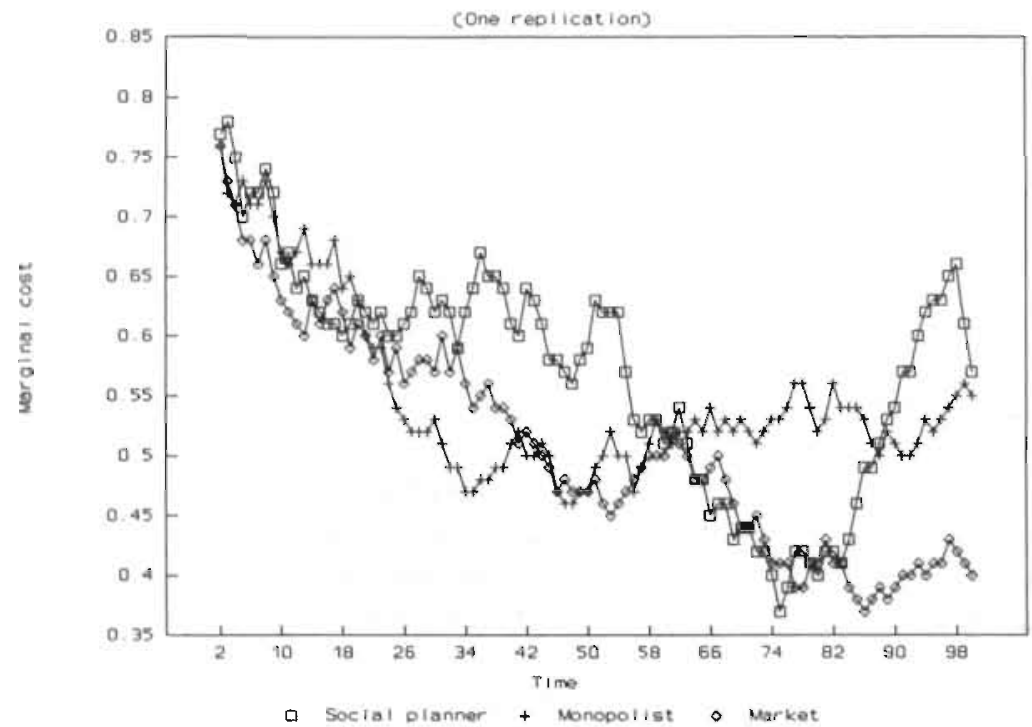


DYNAMICS OF INNOVATION AND ENTRY

71

Figure 2.6: Consumer surplus (one replication)

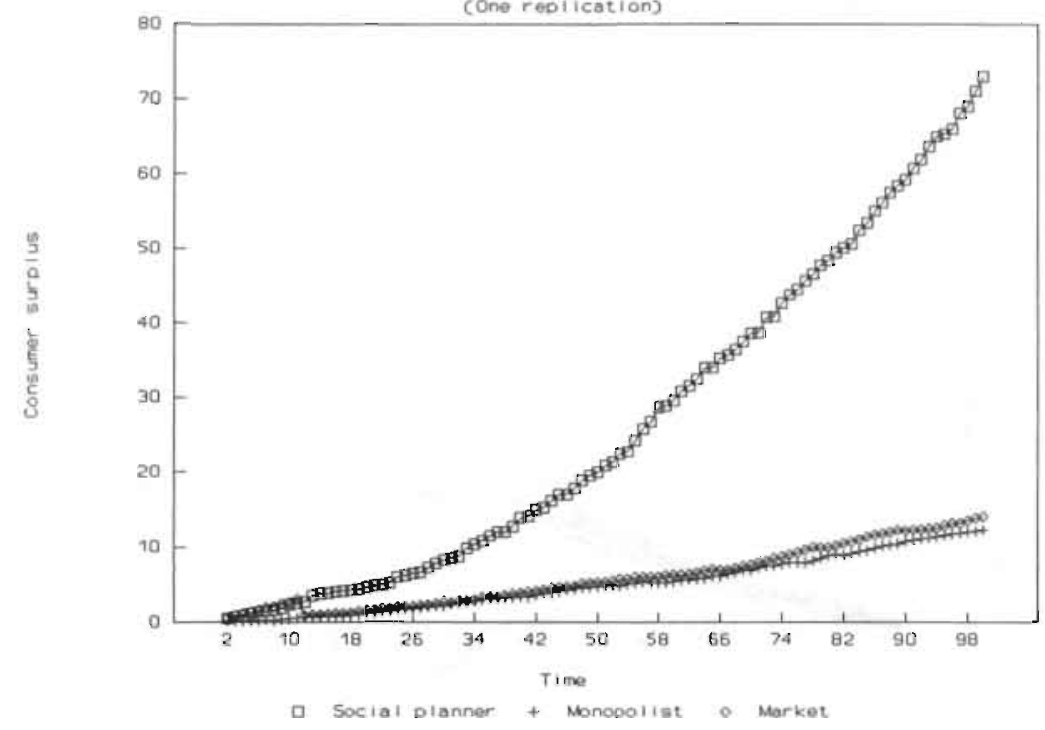

Figure 2.7: Industry profits

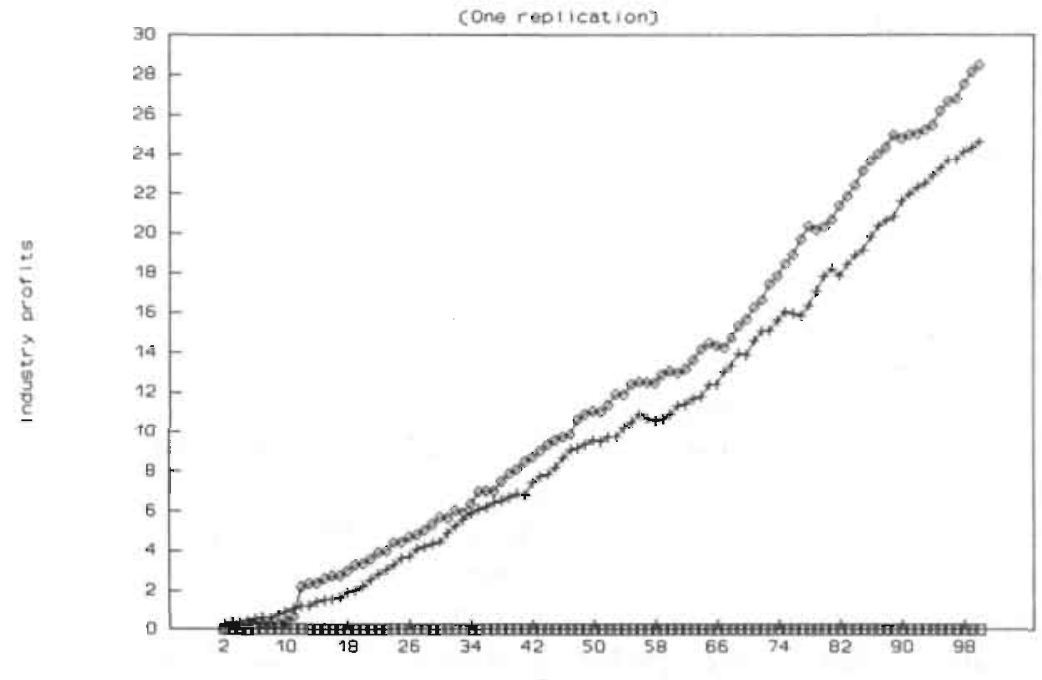

- Social planner + Monopolist o Market 


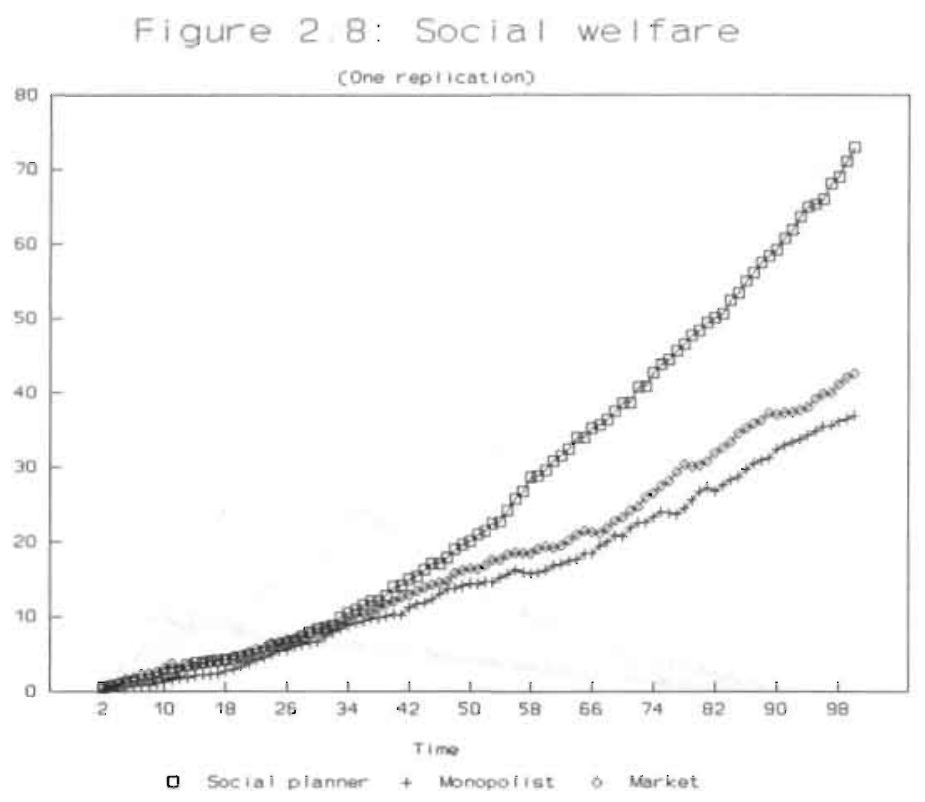

in period 11: Two of the three firms are bankrupt from period 11 onwards. Bcciuse of Bertrand pricing the market's levels of consumer surplus. profits and social welfare more or less correspond with those of the social planner until period 11. In later periods these levels accord with those of the monopolist. It is difficult to notice in the figures, but consumer surplus drops with $70 \%$ between period 11 and 12 , profits rise with $234 \%$ and social welfare goes down with $17 \%$. Figure 2.5 shows that marginal cost is very volatile, while quality develops more steadily [Figure 2.4]. Quality can only rise since $\mu$ is larger than 0 [equation (5)]. Marginal cost, however, may both decrease or increase. Marginal cost decreases when $v$ is large relative to $\theta$, and vice versa [equation (7)].

In order to have a more accurate picture of the development of quality and marginal cost through time, Analysis B averages their development over 250 replications. Figures 2.9 to 2.11 reveal that both the market's and the monopolist's quality development are in line with the social planner's quality development. This results accords with equation (23). The difference in performance is due to the randomness of the model. The social planner's performance in terms of quality outstands the market's and the monopolist's performances because of its superior expectations (perfect foresight). The market performs somewhat better than the monopolist because the firms subject to competition benefit from (full) spillovers. The market's cost level is substantially lower than the social planner's cost level (as well as the monopolist's level): This phenomenon is due to the assumption of full spillovers. The comparison is not fair in a certain sense: The social planner competes against the performance of the union of three firms. The social planner's cost level falls more 
quickly in Figure 2.10 than the monopolist's cost level does. Its costs rise more quickly in Figure 2.11, but do not end up as high as the monopolist's cost level. This difference must be due to the difference in expectation formation (perfect foresight versus rational expectations): The social planner's costs converge more quickly and end at somewhat lower cost levels.

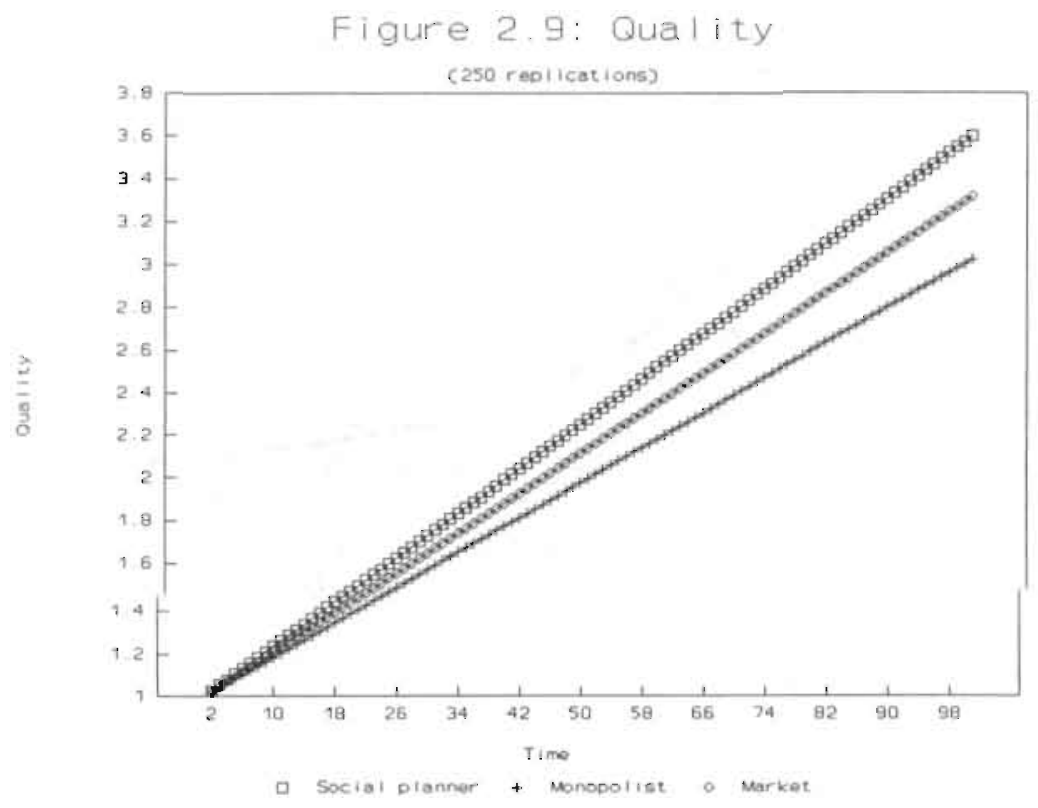

From mere inspection of Figures 2.9 to 2.11 one gets the impression that quality rises linearly and marginal costs approach an asymptote. Analysis of the above equations confirms these observations. Manipulation of equations (5) and (12b) [or (15) or (22)] shows that

$Q_{t} \quad Q_{1}+\frac{E[\mu]^{2}(t-1)}{2\left(1-E[v]^{2}\right)}$

where the subscript $\mathrm{j}$ refers to the agent making expectations (incumbent, potential entrant, social planner or monopolist) and the subscript $t$ to time. Quality is a linear function of time. Equations (7), (12b) [or (15) or (22)] and (13) [or (17) or (21)] enable us to derive

$m c_{1}=m c_{1}\left(1-E[v]^{2}\right)^{t-1}+\frac{E[\mu]^{2}}{4 \theta\left(1-E[v]^{2}\right)^{2}} \sum_{\tau=1}^{1-1}\left(1-E[v]^{2}\right)^{t-\tau}$,

where $0<v<1$, or after taking the limit, 
74

Chapter 2

Figure 2.10: Marginal I cost

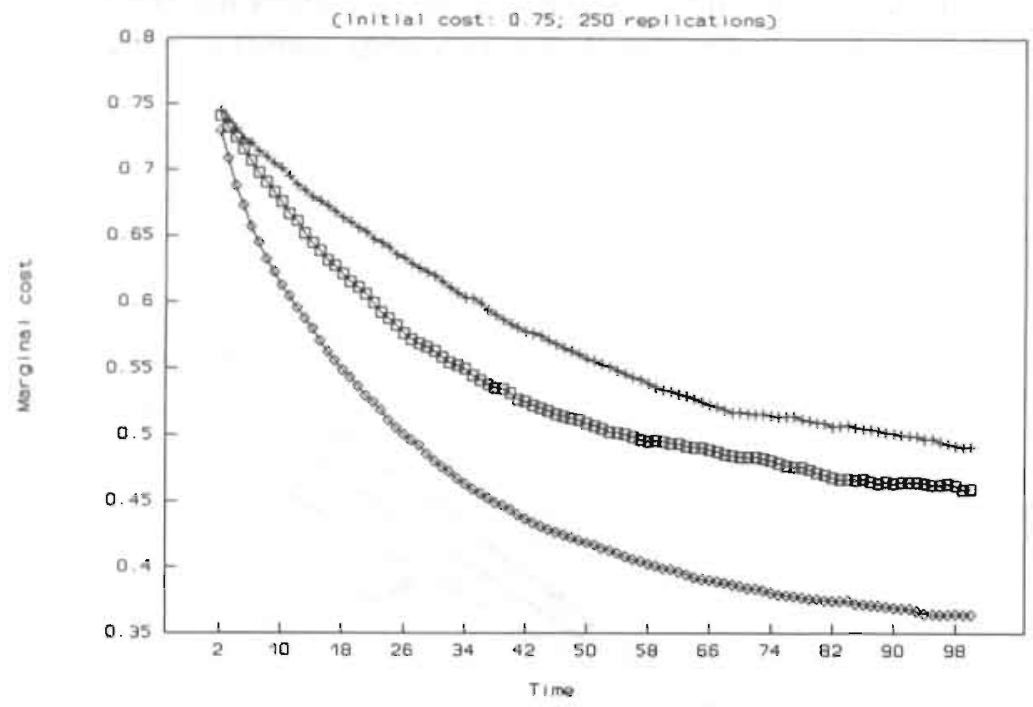

口 Social planner + Monopolist o Market

Figure 2.11: Marginal cost (initial cost 025,250 replications)

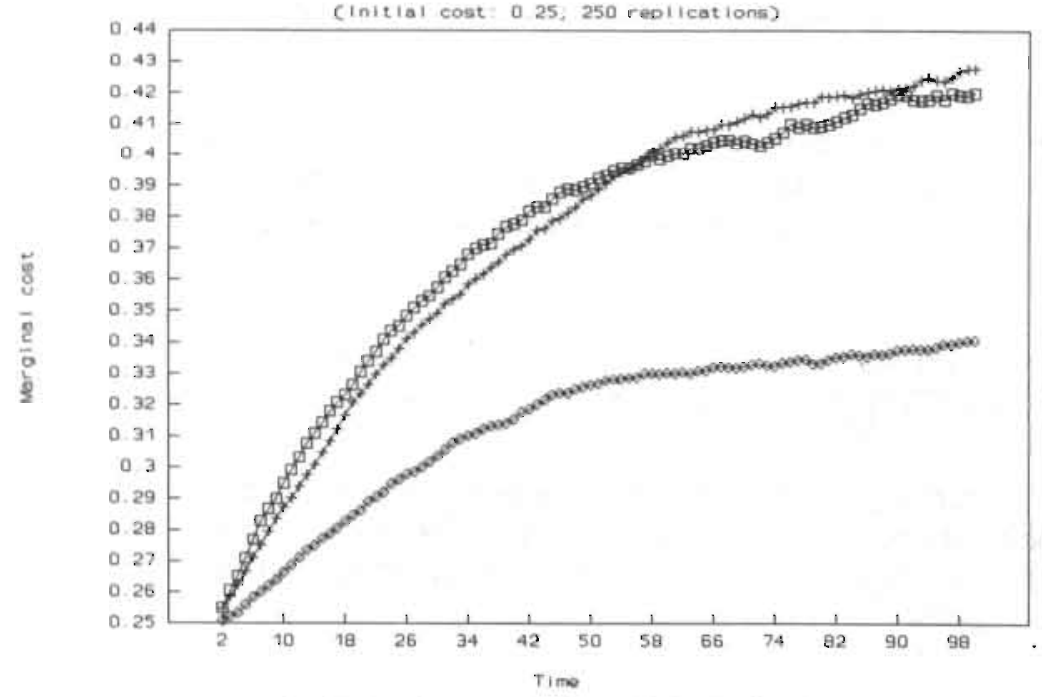

- Soclaiplanner + Monopolist o Market 


$$
\lim _{t \rightarrow \infty} m c_{1}=\frac{E[\mu]^{2}}{4 \theta E[v]^{2}\left(1-E[v]^{2}\right)} .
$$

Marginal costs indeed approach an asymptote. The value of the asymptote equals approximately 0.45 when one substitutes for the mean values of the random variables. When the initial value is higher than the limit value, marginal costs tend to drop; when the value is lower, marginal costs tend to rise. When the asymptotic value is reached, the cost increase induced by the product innovation is exactly matched by the cost decrease induced by the process innovation. The market is likely to approach a somewhat lower asymptote, since its cost performance is influenced by interfirm spillovers.

Analysis $\mathrm{A}$ indicates that the set of $\mathrm{M}$ markets may be monopolized, because all firms but one go bankrupt. Because there are full spillovers between competition games, all firms start each new competition game with the same quality and cost levels. Equation (10b) subsequently guarantees that all firms invest in R\&D (as long as they have not become bankrupt). But because the firms end up with different quality and cost levels in period two of each competition game, the firm with the most favourable quality-cost relation is the only one attracting demand and gross profits. All its competitors are not able to recoup their R\&D expenses. Since firms frequently incur losses, monopolization of the industry is not unlikely. This result would be due to the absence of entry costs. Small entry costs would give firms with less advantageous quality-costs relations some leeway to deter more efficient rivals. Bankruptcies and monopolization would become less likely, as a consequence of which the entry threat would be preserved. Analysis C performs 250 replications for several values of $\varepsilon$ in order to find out how whether the entry threat is preserved at low values of $\varepsilon$. Competition lasts 100 periods (and thus refers to 99 competition games).

Figures 2.12 and 2.13 present the results of analysis C. Since consumer surplus and profits on one side and social welfare on the other side are each other's mirror images. attention is restricted to social welfare. Entry cost $\varepsilon$ is given as a percentage of the initial cost level. Bankruptcy rates and monopolization rates are given in percentages of the maximum possible outcomes. ${ }^{(20)}$ At low values of $\varepsilon$ entry costs are so low that they do not give the firms much shelter against more successful innovators. Firms consequently are more likely to be unable to cover their sunk R\&D outlays at low values of $\varepsilon$ and to go bankrupt. Figure 2.12 indeed shows that bankruptcies are high at low values of $\varepsilon$. At values of $\varepsilon$ close to 0 bankruptcy rates attain $60 \%$ of the maximum level. This leads to monopolization of the set of markets in $20 \%$ to $30 \%$ of the replications performed. The market's level of social welfare

(20) In the figures, monopolization refers to the case in which there is one firm left in the set of markets. There are three firms per replication and 250 replications per value of $\varepsilon$. Since at least one firm will survive the competition process (replication), the maximum number of bankruptcies equals $(3-1) * 250$ or 500 . The maximum number of replications in which a monopoly is established, is, of course, 250 . 
Figure 2.12: Bankruptcy/Monopolization

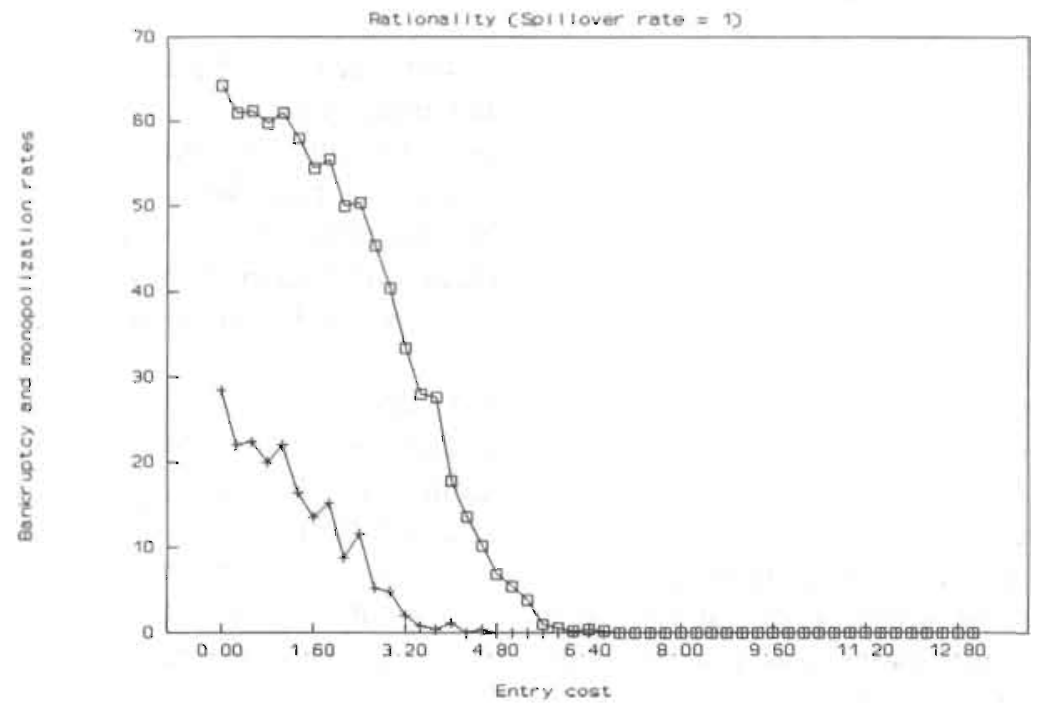

a Bankriptcies + Monopolization

Figure 2.13: Social welfare

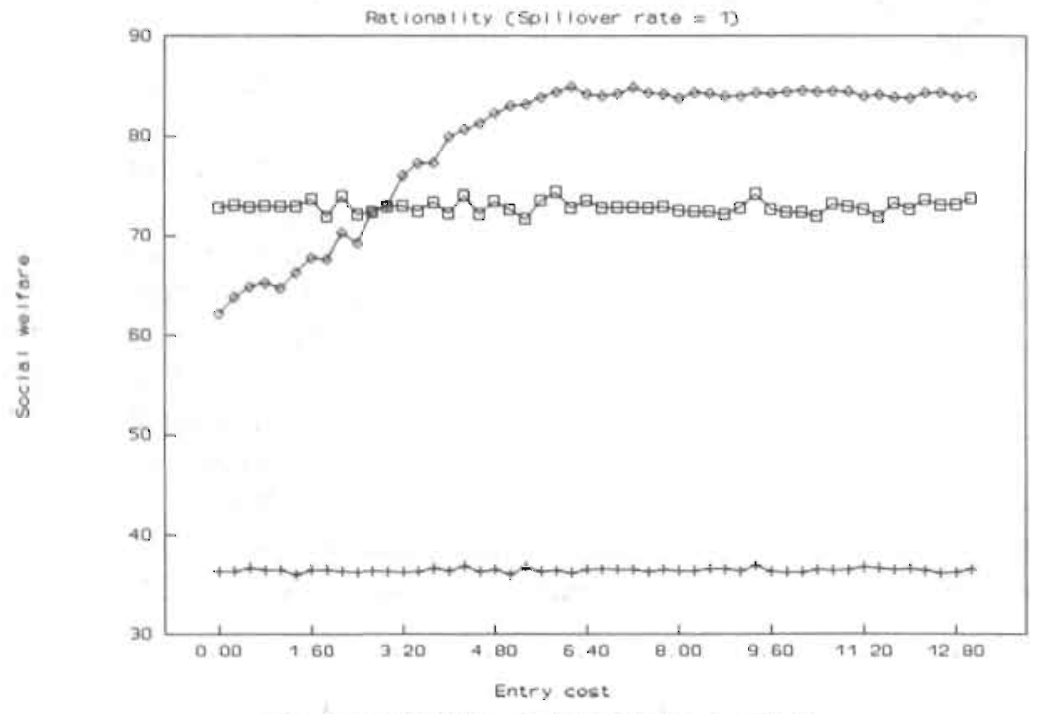

a Social. Dianner + Monopolist o Market. 
consequently is low on average at these values of $\varepsilon$. At high values of $\varepsilon$ the market outperforms the social planner, because the entry threat is preserved and the market's cost performance is better. Preservation of the entry threat seems far more important for social welfare than the shelter given by entry costs. Small entry barriers seem necessary to obtain socially desirable outcomes.

Firms keep investing, when there are full spillovers between competition games. They either expect to retain their home market or they expect potential profits to match R\&D expenses when equation (10b) holds. However, when there are less than full spillovers, firms only invest when entry costs are high enough to overcome the quality or cost disadvantage. As a result, there again is the threat that one firm builds market power, although the source differs in one respect from the one above. Since the random nature of the R\&D process automatically generates quality and cost differences, the starting positions in terms of quality and costs are only the same in the first game. In all subsequent games the starting positions differ, since information does not spillover completely. Consequently, lagging firms do not invest in subsequent periods, unless the entry cost is large enough to overcome the lag in quality or cost. This result is due to the Bertrand paradox. When all lagging firms refrain from investing after a certain period, the leading firm may increase its lead and steadily increase its market power. The model presented above, hereby, gives an example of increasing dominance. This phenomenon is outlined in theoretical IO [Vickers (1986)] and obtained in empirical IO [Dasgupta (1986)].

Analysis $\mathrm{D}$ therefore repeats the above analysis for a spillover rate smaller than 1 $(\beta=0.6)$. This value corresponds with the average value found by Mansfield (1985) [p. 64 above]. The analysis presented now thus has more relevance for markets in which information disperses more slowly, such as the chemical industry. The results of the analysis are shown in Figure 2.14 and 2.15. Bankruptcy rates now are high at intermediate levels of $\varepsilon$. At (very) low levels of $\varepsilon$, a lagging firm thinks that it is unable to catch up with the leading firm and thus refrains from investing. If the lagging firm does not invest, it can not go bankrupt, since it does not sink any costs. The leading firm nevertheless builds market power, because it is able to increase its lead gradually every period with the resulting detrimental effect for social welfare. At intermediate values of $\varepsilon$, the entry cost is high enough to persuade lagging firms to invest. However, because they invest, they (or the leading firm) may go bankrupt. This explains why bankruptcy and monopolization rates are high at intermediate values of $\varepsilon$. When entry costs are high, the entry threat is again preserved. The market performs about as good as the social planner: Barrier market results are obtained. Low entry barriers again seem necessary to obtain barrier market results. Comparing Figures 2.13 and 2.15 indicates that social welfare is higher when spillovers are. As far as patent and trademark policies reduce spillovers and other possibilities for imitation, they do not seem desirable from a social point of view. Note, by the way, that the market's level of social welfare now is lower over the entire range compared with the social planner's level. This is due to the fact that spillovers are lower.

Analyses C and D were performed for three firms (and markets). However, the initial number of firms (and markets) is likely to influence the bankruptcy and mon- 
Figure 2.14: Bankruptcy/Monopolizat ion

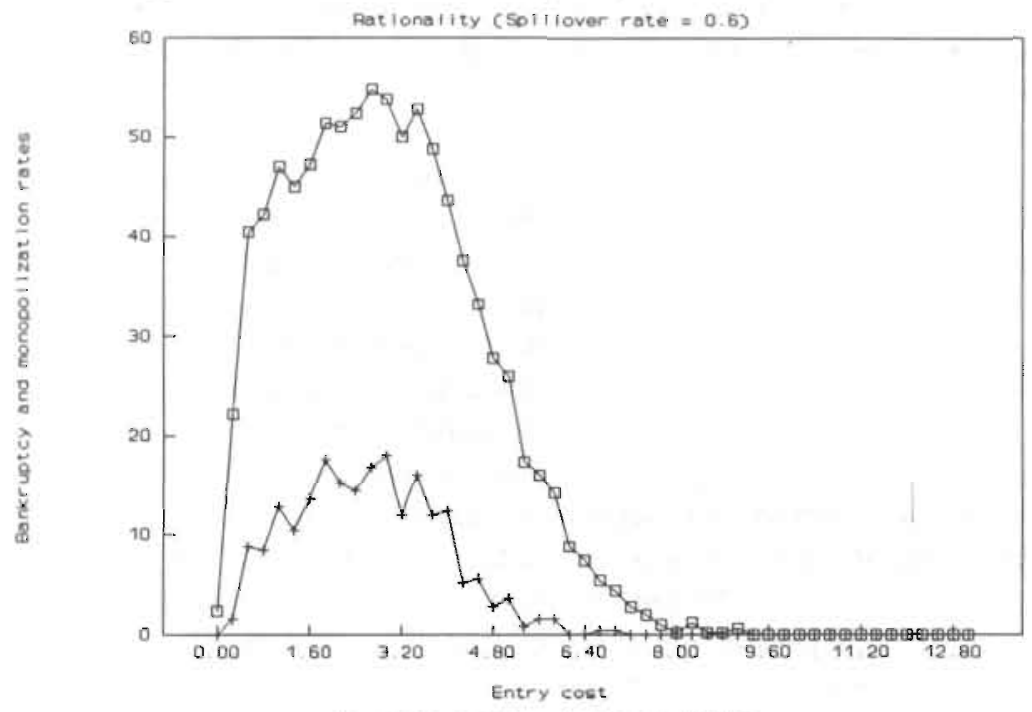

d Bankruptcies + Monopolization

Figure 2.15: Social welfare

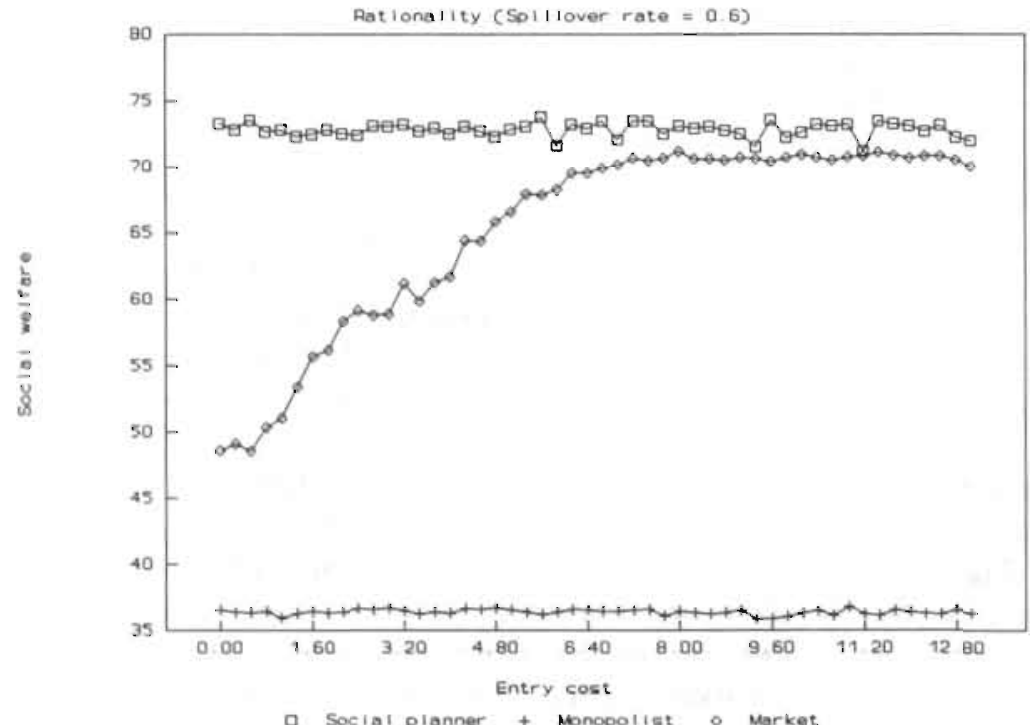

- Social planner + Monopolist o Market. 
Figure 2.16: Monopal izat ion

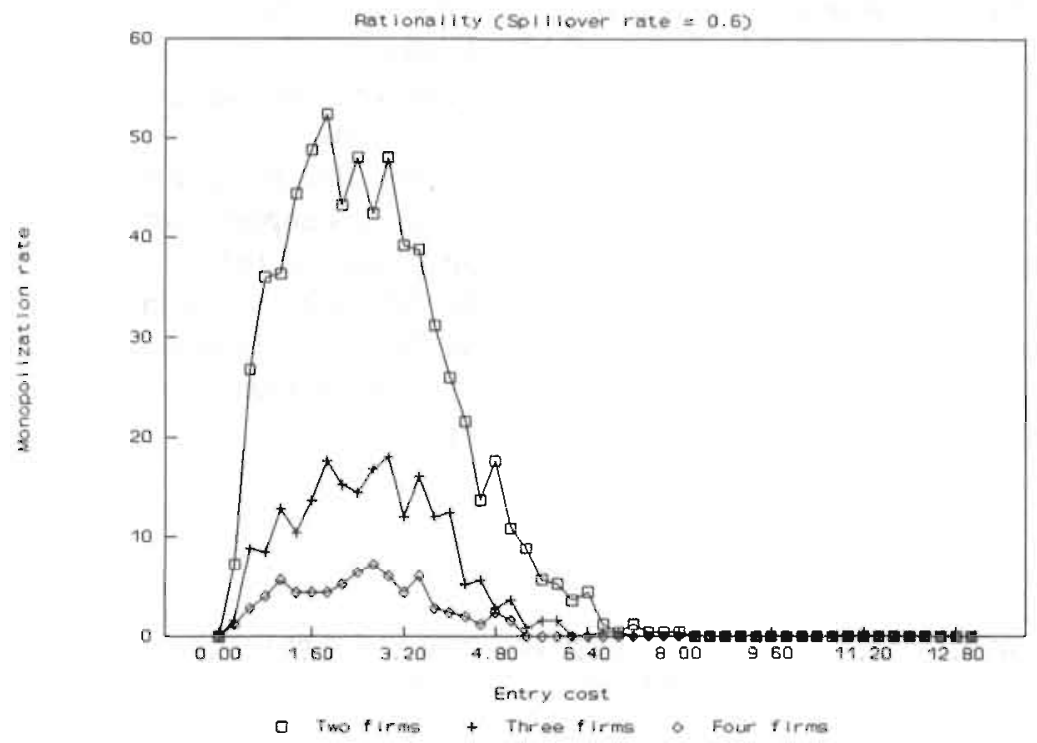

Figure 2.17: Social welfare

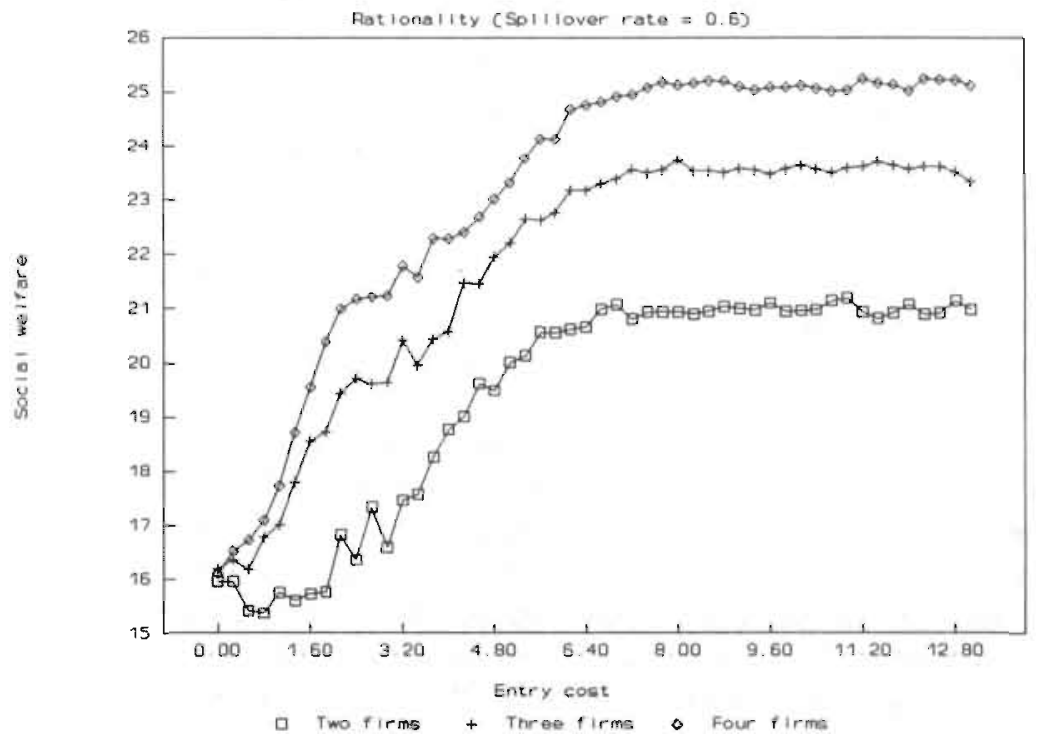


opolization rates. When there are more competitors, entry deterrence is less successful and profit rates are lower, on average. Individual firms are thus more likely to become bankrupt. However, monopolization of the set of $\mathrm{M}$ markets may become less likely, just because there are more rivals. Analysis E [Figures 2.16 and 2.17] is performed to discover the net effect of these opposing tendencies. Because profit margins decrease with the number of firms, bankruptcies rise more than proportionally with an increase in the number of firms. But, because bankruptcy rates increase just somewhat more than proportionally, the monopolization rates decrease dramatically when the number of firms goes up [Figure 2.16]. This is due to the result that the chance that there is one competitor left increases with the number of firms. Because the entry threat is preserved more times and because there are more spillovers when there are more firms, social welfare per market on average is higher when the number of firms increases [Figure 2.17].

\subsubsection{Firm heterogeneity}

Analysis $F$ and $G$ repeat analysis $C$ and $D$ for firm heterogeneity with respect to expectation formation. Figures 2.18 to 2.23 refer to competition between a firm employing BL 2, a firm employing BL 3 and a firm employing RATEX. Similar results are obtained for other combinations of firms. Comparing Figures 2.18 to 2.23 with Figures 2.12 to 2.15 , one sees the same qualitative results. When there are full spillovers, the set of markets may be monopolized through bankruptcy of rival firms. When there are less than full spillovers, the set of markets may be monopolized through either a quality-cost leadership - low entry costs - or bankruptcy of rival firms - intermediate entry costs. However, the figures clearly show that the monopolization threat is more important than the previous section suggested. The introduction of heterogeneous and inferior expectation mechanisms into the model, raises the monopolization threat. Figures 2.20 and 2.23 also show that social welfare on average is lower than it is in Figures 2.13 and 2.15. Rationality refers to the results of analysis $C$ and $D$, heterogeneity to the results of analysis $F$ and $G$. Performance is better under rationality because rational expectations are a superior estimation technique. As a consequence, quality and marginal cost are more favourable when firms have rational expectations.

Figures 2.19 and 2.22 show that firms with more precise information perform better than their more imprecise rivals. This result is confirmed by the results of Table 2.8 and 2.9. These tables are calculated on basis of 1,000 replications using the parameter values given by Table 2.6 (except for the number of firms). As before, competition lasts 99 games. Firm employing precise estimators perform better than their more inaccurate counterparts. Table 2.8 shows that RATEX performs better than $\mathrm{AE}$ and $\mathrm{BL}$ III. The latter perform equally well and perform better than $\mathrm{BL}$ II and BL I. The last mechanism is outperformed by BL II as well. Table 2.9 confirms this view, but also shows that $\mathrm{AE}$ performs relatively bad in combination with more than two rivals. Firm performance may not only depend on the preciseness of estimator used, but also on the number and type of rival firms. The tables also show that the 
Figure 2.18: Bankruptcy/Monopolization

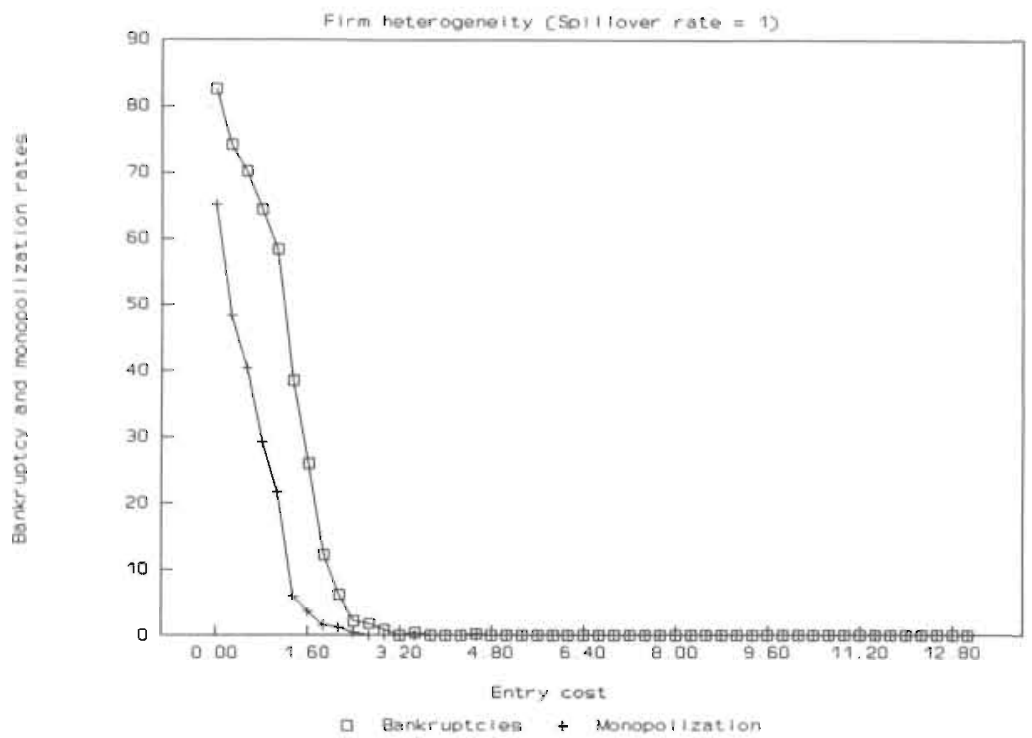

Figure 2.19: Bänkr uptcy per firm

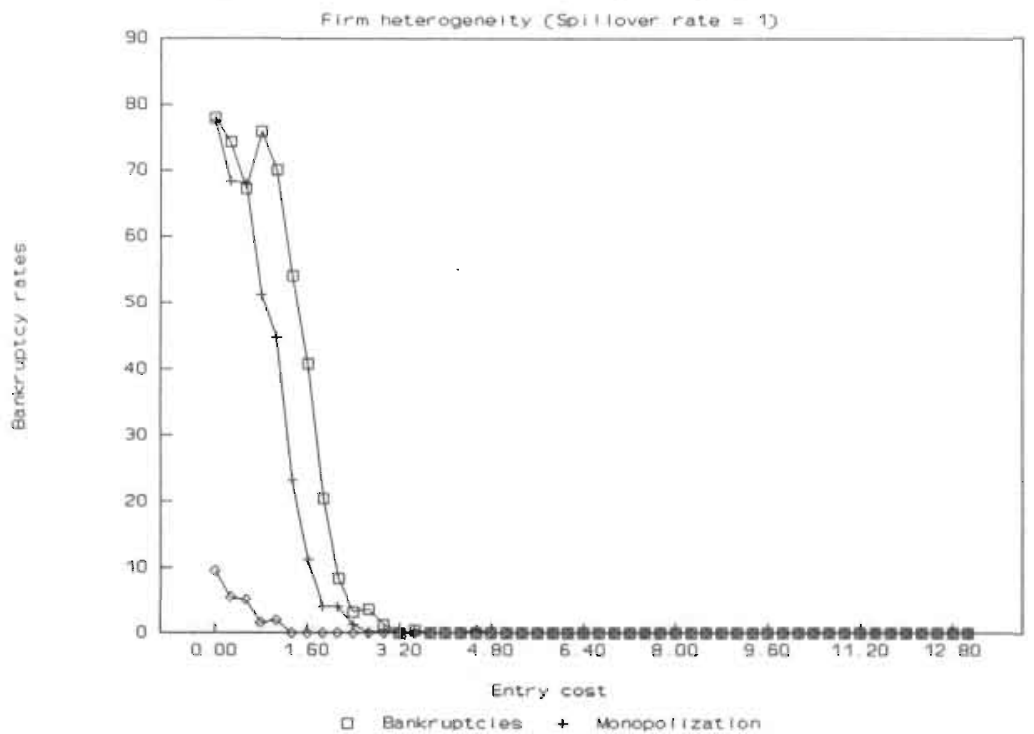


Figure 2.20: Socia! welfare

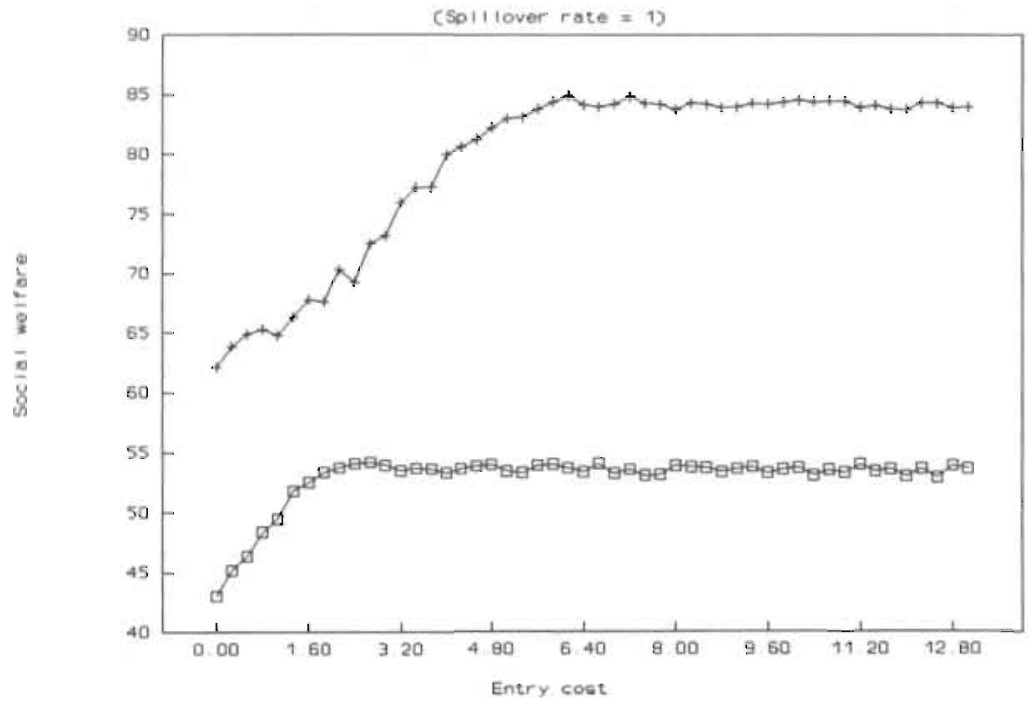

a Rationa!ity + Heterogeneity

Figure 2.21: Bankruptcy/Monopol ization

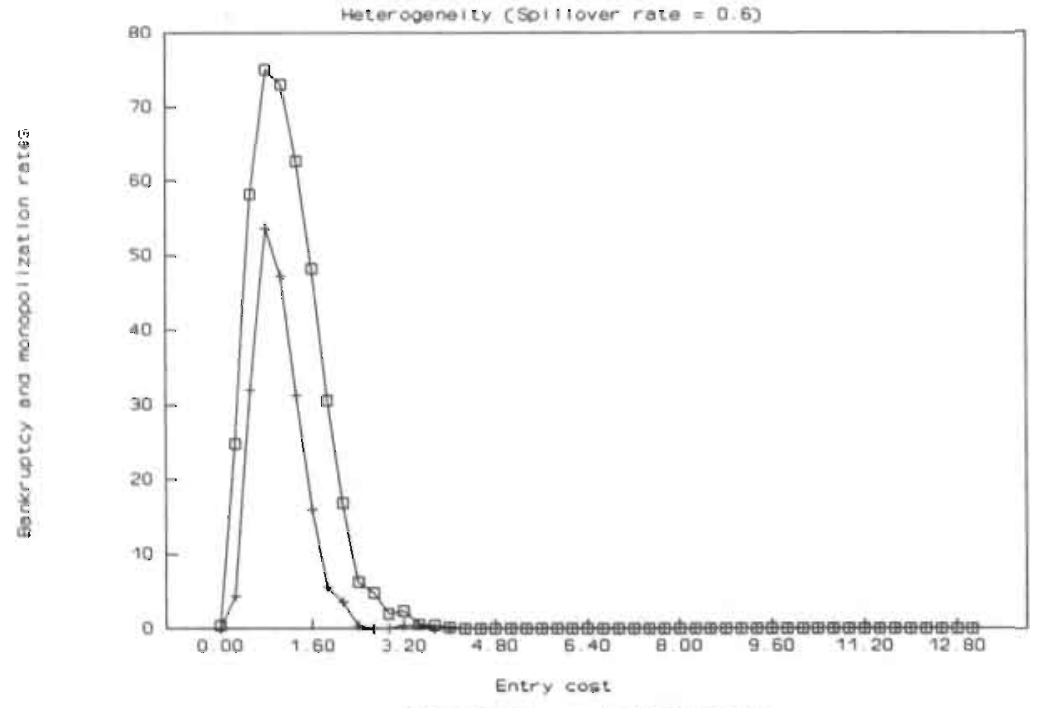

口 Bankruptcies + Monopolization 
Figure 2.22: Bankruptcy per firm

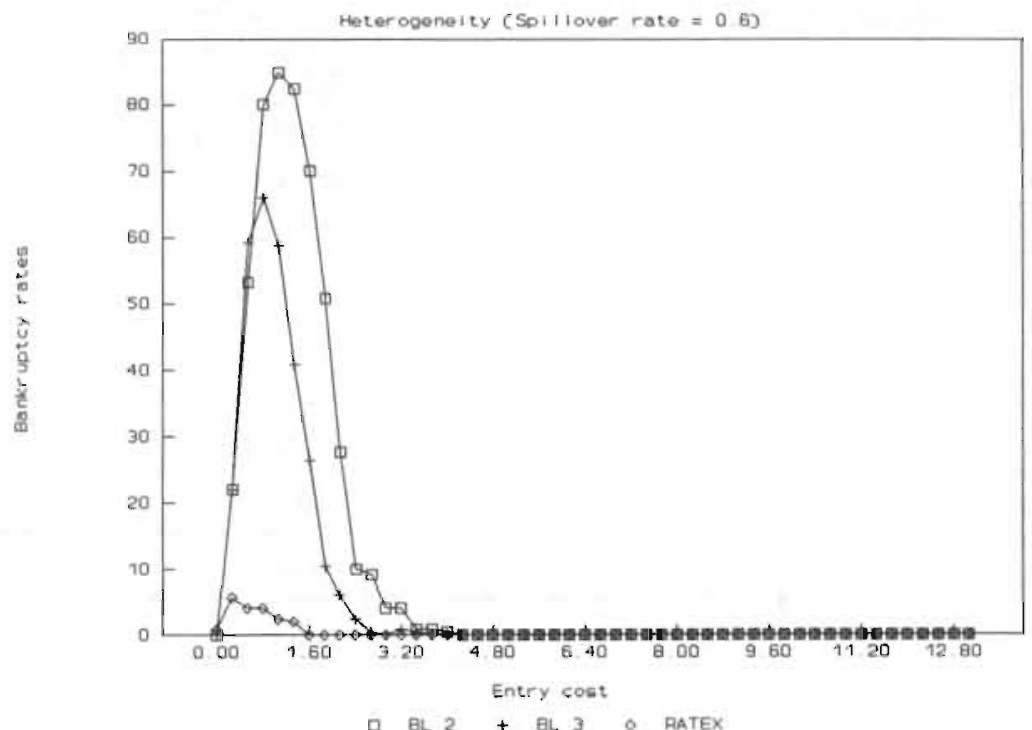

Figure 2.23: Social welfare

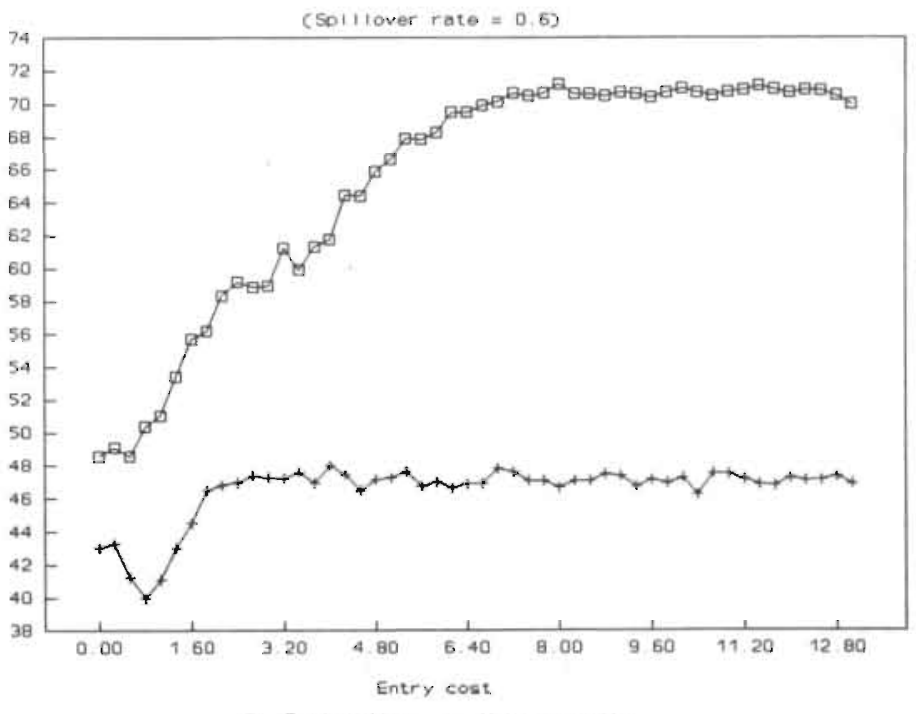

D Rationality * Heterogeneity 
entry threat is preserved more often when the number of firms (and markets) is larger. In general, these outcomes confirm the hypothesis and previously reached result that 'the greater the match between managerial perceptions of environmental characteristics and actual environmental characteristics, the better an organization performs' [Sutcliffe (1994: 1360)]. Strategic planning affects profitability, especially in turbulent environments - when entry costs are low [Miller and Cardinal (1994)]. Because of failures the population of firms evolves from a heterogeneous one to a population of rational firms.

\begin{tabular}{|l|l|l||}
\hline $\begin{array}{l}|l| \mid \\
\text { Table 2.8 } \\
\text { Failure rates }\end{array}$ & Bankruptcy rate & Monopolization rate \\
\hline Firms & $84.4-15.4$ & 99.8 \\
\hline BL 1 - BL 2 & $89.8-10.1$ & 99.9 \\
\hline BL 1 - BL 3 & $93.1-6.9$ & 100.0 \\
\hline BL 1 - AE & $95.1-4.9$ & 100.0 \\
\hline BL 1 - RATEX & $65.8-33.7$ & 99.5 \\
\hline BL 2 - BL 3 & $76.0-24.0$ & 100.0 \\
\hline BL 2 - AE & $89.5-10.4$ & 99.9 \\
\hline BL 2 - RATEX & $47.2-52.7$ & 99.9 \\
\hline BL 3 - AE & $83.8-16.2$ & 100.0 \\
\hline BL 3 - RATEX & $85.8-13.9$ & 99.7 \\
\hline AE - RATEX & & \\
\hline \hline
\end{tabular}




\begin{tabular}{||l|l|l|l|l|l|l||}
\hline \hline \multicolumn{7}{|l|}{$\begin{array}{l}\text { Table 2.9 } \\
\text { Failure rates }\end{array}$} \\
\hline Number of firms & BL 1 & BL 2 & BL 3 & AE & RATEX & MON \\
\hline 3 & 80.2 & 57.5 & 27.9 & - & - & 65.6 \\
\hline 3 & 87.2 & 60.2 & - & 28.5 & - & 75.9 \\
\hline 3 & 91.6 & 73.4 & - & - & 10.5 & 75.5 \\
\hline 3 & 85.2 & - & 27.9 & 57.8 & - & 70.9 \\
\hline 3 & 90.4 & - & 66.6 & - & 12.9 & 66.9 \\
\hline 3 & 94.2 & - & - & 73.6 & 7.9 & 75.7 \\
\hline 3 & - & 67.7 & 38.7 & 52.7 & - & 59.1 \\
\hline 3 & - & 77.6 & 71.8 & - & 12.9 & 62.3 \\
\hline 3 & - & 81.7 & - & 78.0 & 7.4 & 67.1 \\
\hline 3 & - & - & 74.6 & 76.9 & 10.5 & 62.0 \\
\hline 4 & 71.0 & 63.1 & 31.0 & 69.1 & - & 34.7 \\
\hline 4 & 79.1 & 73.7 & 66.2 & - & 14.7 & 34.2 \\
\hline 4 & 80.6 & 71.7 & - & 78.2 & 12.3 & 43.1 \\
\hline 4 & 80.9 & - & 63.1 & 79.9 & 13.0 & 37.0 \\
\hline 4 & - & 73.2 & 71.2 & 76.2 & 10.8 & 31.5 \\
\hline 5 & 76.0 & 74.0 & 66.5 & 87.4 & 13.3 & 21.2 \\
\hline \hline
\end{tabular}


According to established IO literature the Bertrand paradox explains why pervasive price competition reduces or even eliminates R\&D competition [Stiglitz (1987: 890) or alternatively Dasgupta and Stiglitz (1988: 261), Katz (1986: 529) or Sutton (1991: 32)]. In this chapter we saw that this result depends on the assumption of constant economies to scale in production. However, empirical observations seem to suggest that average total costs are constant [Scherer and Ross (1990)]. On the basis of these observations a cost function exhibiting constant average total costs is modelled, despite the presence of sunk costs. This cost function reconciles Bertrand and R\&D competition, and solves the Bertrand paradox. The cost function also allows several firms to co-exist in equilibrium. In this respect the chapter differs from the literature on patent races which are won by one and only one firm [Tirole (1989: 394n)]. This result makes our model more attractive than patent models, since winner-take-all games are hardly observed in practice. The chapter thus provides a way to incorporate the entry threat as laid down in contestability theory in a dynamic framework. The chapter hereby gives an example of a barrier market scenario [Van Wittelonstuijn and Maks (1988)]. Barrier market theory comprises competitive pricing with dynamic economies. Barrier market equilibria are characterized by zero profits, even under monopoly and oligopoly, and also by optimal investments in $R \& D$, since the entry threat is the force 'behind the introduction of dynamic economies of market behaviour' [op. cit.: 117].

Table 2.10

Scenarios

Spillover rate Entry costs

$$
\text { Low }
$$

Low

High
Market power via leadership Monopolization via bankruptcies
Intermediate

Monopolization via bankruptcies

Imperfect

barrier market
High
Imperfect
barrier market
Imperfect
barrier market

The simulations based on the competition game laid down in Section 2 do justice to two stylized facts of entry [Geroski (1991: 11): (1) The entry rate differs across industries and over time and (2) entry and exit rates are correlated. The simulations show under what circumstances the entry threat remains effective. The entry threat fades away either because (1) rival firms go bankrupt or (2) rival firms abstain from investing when they acquire a too large lag in quality or cost. The latter argument is important when entry costs are very small. When entry costs are zero, any lag suffices to withhold lagging rivals from investments in $R \& D$, unless there are full spillovers. This result is in line with the Bertrand paradox. The former argument is important at intermediate levels of entry costs, since at these levels the entry cost is high enough to induce firms to invest, but not high enough to protect them from too 
large differences in terms of $R \& D$ performance. The entry threat is thus only sustained when entry costs are sufficiently high. The analysis in Section 3 shows that the preservation of the entry threat is far more important for the development of social welfare than the presence of entry costs. The competitive pressure enforced by the entry threat outweighs the loss induced by entry costs by far. Barrier market results are most likely when entry barriers are sufficiently high. When price competition is tough, low entry barriers are desirable. Table 2.10 summarizes the outcomes. The simulations indicate that interfirm spillovers generate large quality increases and cost decreases through time. Since spillovers are favourable for the development of social welfare, patent and trademark policies must be eschewed. The spillovers following from independent $R \& D$ processes seem far more important than the duplication of efforts caused. Social planners may have difficulties in copying this element of industry dynamics, unless they set up several independent furms.

The chapter provides one solution to the Bertrand paradox. In order to establish this solution strict assumptions had to be made with respect to costs. In the next two chapters this assumption will be dropped. Chapter 3 analyses competition between differentiated goods. There average production costs are again constant, while average total costs decrease because of the presence of sunk costs. This assumption indeed seems reasonable for differentiated goods [Morrison (1990)]. Chapter 4 has more in common with Chapter 2. In Chapter 4 a model is presented in which two incumbents produce two technically related goods. The incumbents may enter each other's markets just like they do in Chapter 2. In Chapter 4 their products are no substitutes in consumption. In this chapter the firms have capacity constraints and face imperfect interproduct spillovers. In Chapter 5 the Bertrand assumption is tested in three experimental settings. The experiments presented are constructed on basis of Chapter 2.1 



\section{Chapter}

\section{Variety and quality competition in a horizontal differentiation framework}

\section{Introduction}

In the previous chapter we argued that average costs tend to be constant for more or less homogeneous goods over a certain interval. When average total costs (including sunk costs) are constant, Bertrand and R\&D competition can be combined. The previous chapter hereby provides a solution to the Bertrand paradox and gives an example of a barrier market scenario. The model in Chapter 2 seems especially applicable to industries with more or less homogeneous goods. However, most goods are heterogeneous instead of homogeneous. For this reason, this chapter addresses attention to competition between differentiated products. Differences in consumer preferences compel firms to decide on aspects of variety besides aspects of quality. This chapter therefore incorporates differences in consumer preferences, and analyses decisions on variety and quality on basis of these differences. As we already indicated in Chapter 2, scale economies are important for differentiated products [Morrison (1990)]. For this reason, the (rather strict) assumption of constant average total costs is dropped in this chapter. This chapter differs in another respect from the previous one: Competition is between two incumbents in one market and not between $M$ firms incumbent in $M$ different markets. However, this does not imply that there is no such thing as an entry threat in the analysis of this chapter. The firms modelled serve two different segments of the market which are vulnerable to total entry. Because this chapter introduces another complication, horizontal differentiation, the multimarket context has to be simplified in order to keep the analysis tractable. The basic differences and similarities between Chapters 2 and 3 are summarized by Table 3.1 .

This chapter analyses variety and quality competition in Hotelling's (1929) horizontal differentiation framework. We use this framework since it (1) models product differentiation well from a metaphorical point of view, (2) is convenient from an analytical perspective and (3) is one of the most important reference points on product differentiation. In Hotelling's model consumers incur transport costs when they go shopping. When two firms sell the same good at the same price, consumers prefer the closest shop. In Hotelling's model consumers live along a street as depicted by Figure 3.1. When firm $B$ is located at $s_{b}$, firm A maximizes demand (and 
profits) by locating just to the left of $s_{b}{ }^{(1)}$ All consumers to the left of $s_{a}$ will prefer firm A's product over firm B's. But when firm A locates at $s_{a}$, firm B prefers a location to the left of $\mathrm{s}_{\mathrm{a}}$, et cetera. In the end both firms locate in the centre of the market. This argument explains Hotelling's principle of minimum differentiation.

Table 3.1

A comparison of Chapters 2 to 4

Analytical Model features Results techniques

2 Game theory Average total costs constant Simulations Representative consumer No capacity constraints Geographically separated markets

Prices approach marginal cost when entry costs fall Optimal investment in R\&D Duplications of efforts Industries are monopolized when entry costs are low

3 Microeconomics Game theory

Average variable costs constant Differentiated consumers No capacity constraints One (segmented) market
Prices approach marginal cost when there is less desire for variety Underinvestment in R\&D All surplus from innovations accrues to consumers Product differentiation is optimal in case of hit-andrun entry; otherwise it is not

Prices approach marginal cost when spillovers and capacity rise Firms do not invest in R\&D when spillovers are high

4 Game theory

Average variable costs constant
Representative consumer
Capacity constraints
Two markets with substitutes
in production

D'Aspremont, Gabszewicz and Thisse (1979) discovered a flaw in Hotelling's analysis: There is no Nash equilibrium in prices. The resulting instability is due to a discontinuity in demand and price strategies. Consider Figure 3.1 and suppose that firm $A$ undercuts firm $B$ at $s_{b}$ : The consumer at $s_{b}$ prefers firm A's product over firm $B$ 's. Now when transport costs are linear, all consumers to the right of $s_{b}$ must prefer firm A's product as well. Undercutting firm $B$ at $s_{b}$ not only suffices to capture the consumer at $s_{b}$, but also all consumers on the interval $\left[\mathrm{s}_{\mathrm{b}}, 1\right]$. This explains the

(1) Hotelling assumes that consumers are uniformly located along the street. All consumers buy one product (or none). When this is so, demand to the left of $s_{\mathrm{b}}$ is larger than demand to the right. 
discontinuity in demand. The duopolists may follow two price strategies. When the competitor's price is high, it is profitable to capture all demand (when the rival firm is located close-by). The loss in profits due to the price reduction is outweighed by the increase in demand. When the rival's price is low, this is no longer so. In that case, firms do better by exploiting their market power by raising prices and profit margins somewhat. This explains the discontinuity in price strategies, i.e. reaction functions. As a result, there is no pair of prices that constitutes a Nash equilibrium. At least one of the firms always has an incentive to either raise or lower its price.

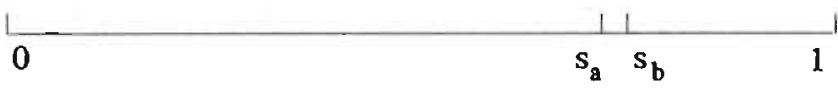

Figure 3.1: Hotelling's Main Street

In order to restore price stability D'Aspremont, Gabszewicz and Thisse (1979) change the demand relations proposed by Hotelling (1929). There is a Nash equilibrium in prices when consumer transport costs are quadratic instead of linear. This change has a dramatic influence on Hotelling's result: Product differentiation is maximum rather than minimum. In this chapter another way is followed in order to tackle the problem. The chapter proposes two solutions which are plausible from an economic point of view. The first solution is Hotelling's original solution and may be defended as follows. Firms are likely to acknowledge their mutual interdependence and hence to respect each other's market segments to a certain extent [Lerner and Singer (1937), Eaton (1972) and Novshek (1980)]. This solution is referred to as the Hotelling scenario [Section 3]. In general, the Hotelling scenario is applicable when price competition is soft. Price competition is soft when: (1) Firms respect each other's market shares [U.S. cigarette industry until 1945; U.S. breakfast cereal industry; turbogenerators; gasoline]; (2) they do not have excess capacity [U.S. steel industry until 1960 and U.S. automobile industry until 1975]; (3) when they do not compete with respect to price [political parties and broadcasting corporations]; (4) when products are sufficiently and irreversibly differentiated.

The second price rule is based on arguments forwarded in the literature on limit pricing and contestability, but has not been proposed up until now. ${ }^{(2)}$ Prices are set such that the price equilibrium is sustainable. This scenario is plausible when hit-andrun entry is an important phenomenon. This solution is referred to as the limit price scenario [Section 4]. Because the firms incur sunk costs, this scenario may provide an example of a barrier market scenario. Hit-and-run entry is an important phenomenon when: (1) Firms have excess capacity [automobile and steel industries since 1970s]; (2) there is mutual distrust or management teams behave competitively [Bic versus Gillette in razor blades and lighters]; (3) product differentiation is not feasible because consumers do not have a large desire for variety or market demand

(2) Poddar (1995) uses a similar solution in a multimarket context. 
is concentrated. Table 3.2 compares the three solutions to the price instability problem.

Table 3.2

A comparison of horizontal differentiation models

$\begin{array}{llll}\text { Reference } & \begin{array}{l}\text { Utility } \\ \text { losses }\end{array} & \begin{array}{l}\text { Solution for } \\ \text { instability }\end{array} & \begin{array}{l}\text { Degree of } \\ \text { differentiation }\end{array} \\ \text { ACi\&T (1979) } & \text { Quadratic } & \text { No instability } & \begin{array}{l}\text { Maximum } \\ \mathrm{s}_{\mathrm{a}}=0 ; \mathrm{s}_{\mathrm{b}}=1\end{array} \\ \text { Hotelling (1929) } & \text { Linear } & \begin{array}{l}\text { Recognition of } \\ \text { nutual dependence }\end{array} & \begin{array}{l}\text { Minimum } \\ \mathrm{s}_{\mathrm{a}}=\mathrm{s}_{\mathrm{b}}=0.5\end{array} \\ \begin{array}{l}\text { Bunte (1997) } \\ \text { Limit price scenario }\end{array} & \text { Linear } & \text { Limit pricing } & \begin{array}{l}\text { Intermediate } \\ \mathrm{s}_{\mathrm{a}}=0.25 ; \mathrm{s}_{\mathrm{b}}=0.75\end{array}\end{array}$

On basis of both price solutions the decisions on quality and variety are derived. In the Hotelling scenario the minimum differentiation result is obtained: There is no horizontal product differentiation. The varieties offered are equal. Firms have an incentive to make similar varieties in order to gain market share as has already been argued above. This result is not surprising since Hotelling's original model is employed. It is surprising that Economides $(1989)^{(3)}$ obtains the opposite result maximum differentiation - although he employs the same model and performs the same analysis. However, Economides does not impose a stability condition on the $R \& D$ decision. When this is done, there are no parameter values left for which there is maximum differentiation [Sorenson (1995)]. The Hotelling scenario supports the minimum differentiation result only. The decisions on variety consequently are not efficient in the Hotelling scenario. Similar varieties do not take account of the consumers' preference for variety. In technical terms, utility losses are not minimised. In the limit price scenario the two forces of maximum and minimum differentiation balance each other out. Varieties are chosen such that in equilibrium there is no price instability, i.e. no incentive for hit-and-run entry. There is neither maximum nor minimum product differentiation. The variety decisions turn out to be efficient from a social point of view, unless it is efficient to have one variety only.

In both scenarios firms underinvest in quality improvements, since all surplus created by innovations is dissipated in the price competition process. The firms are involved in a Prisoner's Dilemma with respect to product innovations. They would be better off if they both would not innovate. In equilibrium both demand and gross profits are not effected by the R\&D investments, as $R \& D$ costs are already sunk.

(3) Economides (1989) normalizes other variables than we do, but in essence the models are the same. 
Product quality is raised at the expense of net profits. This result is familiar from the literature on advertising [Galbraith (1958), Dixit and Norman (1978) and Schmalensee (1986)]. A good example in this respect is the advertising war between Johnson \& Johnson-Merck and Smith-Kline on the market for non-prescription heartburn drugs. Marketing outlays amount to 200 million dollars, while sales are only 1 billion dollars [WSJE: 17-10-95]. This phenomenon may also be observed in many other consumer markets. The model thus shows that competition turns out to be efficient, in the sense that it forces firms to pursue quality improvements and to pass all surplus created through to the consumers. However, since firms underinvest in R\&D they perform less well in terms of social welfare than the benchmark social planner and monopolist do [Sections 5 and 6]. In terms of consumer surplus they outperform the monopolist, while they are outperformed by the social planner. In Section 7 we analyse whether public or private policies, such as subsidies or research joint ventures, may repair the tendency to underinvest. This section employs the policy options listed by D'Aspremont and Jaquemin (1988) and Kamien, Muller and Zang (1992). However, this analysis has not been performed before with horizontal differentiation models. Sections 8 and 9 discuss whether asymmetries in terms of initial qualities and available information repair the incentive to invest in product R\&D. The impact of asymmetries in initial qualities in a horizontal differentiation framework is already discussed by Sorenson (1995). In this chapter his analysis is extended with a welfare analysis and thorough comparative statics.

In equilibrium the prices set in both scenarios are equal. The firms have some market power which enables them to raise price above marginal cost. This power depends positively on the consumers' desire for variety. When the desire for variety diminishes. prices approach marginal costs - the Bertrand result. The firms make positive net profits, but again we find that net profits decrease, when the desire for variety diminishes and the products become more homogeneous from the consumers' perspective. The scenarios thus obtain barrier market results as limit results.

The chapter is organized as follows. Section 2 gives a general outline, the demand and cost specifications and discusses the stability problem. In Section 3 equilibrium prices, qualities and varieties are derived for the Hotelling scenario and in Section 4 for the limit price scenario. Section 5 discusses the decisions taken by the benchmark social planner and monopolist. In Section 6 all decisions are compared. Section 7 investigates what policy measures may be taken to overcome the tendency to underinvest in quality improvements. Sections 8 and 9 analyse the implications of asymmetries and uncertainty for the Hotelling scenario. Section 8 discusses the implications of an asymmetry in initial qualities. Section 9 depicts the implications of uncertainty and firm heterogeneity with respect to available information for firm performance. Section 10 concludes with a discussion.

This section gives a general outline on the model analysed below. Sub-section 2.1 gives the structure of the competition process. Sub-section 2.2 delineates the demand 
and cost specifications. Sub-section 3 discusses price instability in spatial differentiation models, such as the one elaborated below, and presents the solutions chosen to circumvent the instability.

\section{Table 3.3}

Structure of the competition game

\begin{tabular}{||l|l|l|l||}
\hline Period & Stage & Firm A & Firm B \\
\hline \multirow{3}{*}{1} & 1 & Variety decision \\
\cline { 2 - 4 } & 2 & R\&D or quality decision \\
\hline 2 & 1 & Price decision \\
\cline { 2 - 3 } & 2 & Market transactions \\
\hline
\end{tabular}

\subsection{The model's structure}

This sub-section provides a general outline of the model presented below. The model is analysed as a two-period competition game. Each period is subdivided into two stages. We will analyse the decisions taken by two incumbent firms. The firms take the following decisions simultaneously. In the first period's first stage the firms decide on the variety of the product to be sold. In the second stage they decide on the variety's quality. In the second period's first stage firms set prices. When prices have been set, transactions take place in the second stage. Table $3.3^{(4)}$ summarises the above outline. The model has a game-theoretic set up and will thus be solved by the principles of backward induction and subgame perfection.

\subsection{The demand and cost specifications}

\subsubsection{Demand}

In the model outlined below consumer utility depends on a horizontal characteristic and a vertical characteristic. Consumers may have different preferences with respect to horizontal characteristics; they do not with respect to vertical characteristics. Horizontal differentiation will be referred to as differences in variety; vertical differentiation as differences in quality. Take a simple product like yoghurt. Consumers may differ with respect to the degree of sourness most preferred - a horizontal characteristic; they all are likely to prefer a more durable brand - a vertical

(4) The decision order given by Table 3.3 suggests that prices cannot be altered any more, once they have been set. This assumption is rather strict, since prices in general can be adjusted very quickly. We will revert to this argument below. 
characteristic. Take a car. Consumers may differ with respect to the colour most preferred - a horizontal characteristic. They all are likely to prefer a car which is more economic in petrol or is able to attain a higher speed - a vertical characteristic. In the model below the consumers buy one unit of the good under consideration, or none. We will ignore the latter possibility.

Consumer utility $U$ depends on the quality and the variety of the product consumed. The relation between utility $U$ and quality $Q$ is straightforward. Gross surplus equals the (perceived) quality of the product consumed. The relation between utility and variety is somewhat more complicated. When the variety consumed is not equal to the variety most desired, the consumers experience a utility loss. This loss is given by the product of the distance $d$ between the variety consumed and the variety most desired, and the utility loss u per unit distance. Following Hotelling (1929) the preferences for variety may be given by a line running from 0 to 1 [Figure 3.2]. Consumers are uniformly distributed along the line with density 1 . This implies that all consumers prefer a different variety. The firms are located on the line as well, for instance at $s_{a}$ and $s_{b}$. Consumer utility also has to be corrected for the price paid. The price $\mathrm{P}$ gives the opportunity cost incurred by foregoing the consumption of some numéraire commodity. The above may be summarised as follows

$\mathrm{U}=\mathrm{Q}-\mathrm{P}-\mathrm{ud}$.

Both firms offer a product with quality $Q_{j}$ at a price $P_{j}(j \in\{a, b\})$. Consumers buy only one good. Company demand depends on the location of the so-called marginal consumer. The marginal consumer located at $\mathrm{z}$ is indifferent between the two producers. Consumer surplus is equal whether (s)he goes to firm A or firm B. For the consumer at $\mathrm{z}$ the following equality holds ${ }^{(5)}$

$Q_{a}-P_{a}-u\left|s_{a}-z\right|=Q_{b}-P_{b}-u\left|s_{b}-z\right|$.

The subscripts denote the producer: a refers to producer $\mathrm{A}$ and $\mathrm{b}$ to producer $\mathrm{B}$. Consumers located between $s_{a}$ and $z$ strictly prefer producer $A$ 's good, because the utility lost by consuming A's variety is lower than it is at $z$, while the opposite holds for consuming B's. The demand for producer's A variety is proportional to the distance $\mathrm{z}$, while firm B's demand is proportional to $(1-\mathrm{z}){ }^{(6)}$ One may vary market demand by varying the (uniform) density on the line. Equation (2) may be used to

(s) We assume that the whole market is covered. This condition is fulfilled for every combination of $\mathrm{s}_{\mathrm{a}}$ and $\mathrm{s}_{\mathrm{b}}$ when $\left(\mathrm{Q}_{1}-\mathrm{mc}\right) \geq 2 \mathrm{u}$, where subscript 1 refers to period 1. This condition also guarantees that the social planner and the monopolist cover the whole market.

(6) The consumer at $\mathbf{z}$ may be neglected when market demand is large enough. We assume this to be so. 
derive firm A's and firm B's demand by solving for $z^{(7)}$ [Appendix A]

$$
\begin{aligned}
& X_{a}=\frac{1}{2 u}\left(Q_{a}-Q_{b}+P_{b}-P_{a}+u\left(s_{a}+s_{b}\right)\right) \text { and } \\
& X_{b}=\frac{1}{2 u}\left(Q_{b}-Q_{a}+P_{a}-P_{b}-u\left(s_{a}+s_{b}\right)+2 u\right)
\end{aligned}
$$

Now consumer choice has been outlined, some attention has to be addressed to the cost relations.

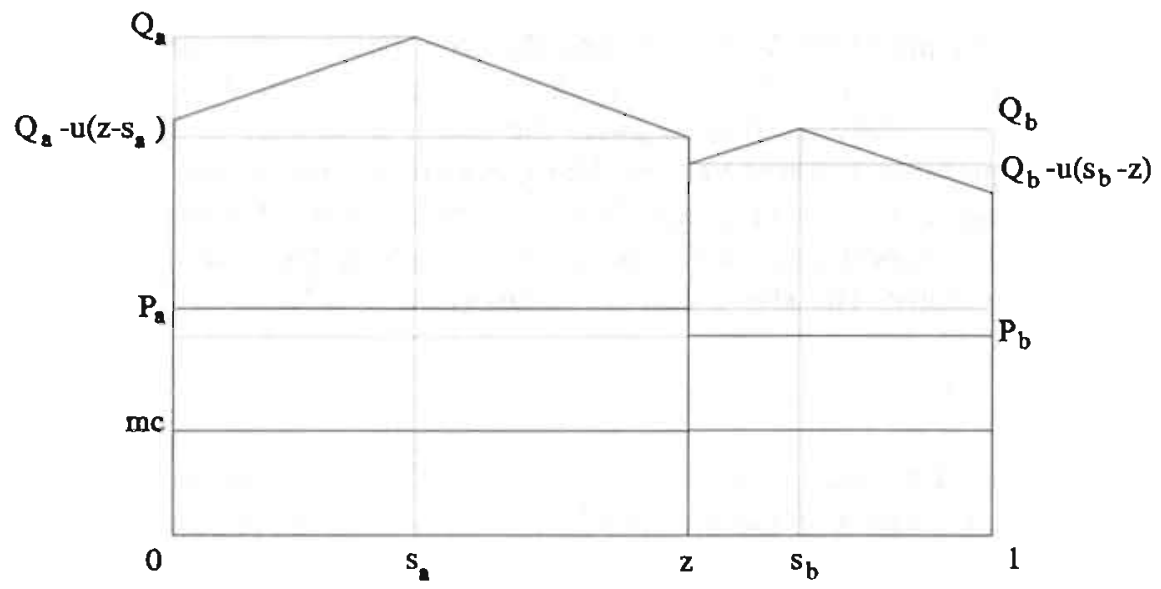

Figure 3.2: Surplusses along Main Street

\subsubsection{Costs}

A distinction is made between two cost components: Sunk costs SC and variable (and marginal) costs VC. Marginal cost mc is constant per unit of production. Sunk costs are made up of product $R \& D$ expenses. These expenses depend on the quality rise $\Delta Q$. The above description may be summarised as follows. Firm j's $(j \in\{a, b\})$ variable costs are defined as

(7) Gabszewicz and Thisse (1986) show that there are three price regimes for the above utility function besides 0 and 1 . We confine our analysis to one of them. To be more specific, we will argue below why each firm is able to provide its own hinterland in the symmetric equilibria we will derive. This rules out two of the three price regimes. We will come back to this issue in Sub-section 2.3. 
$V c_{j}=m c \cdot X_{j}$,

while its sunk costs equal

$S C_{j}=\mu\left(\Delta Q_{j}\right)^{2}$,

where $\mu$ is a parameter denoting R\&D costs. This parameter may be thought of as a symbol comprising $R \& D$ costs and consumer density, i.e. market size. The parameter $\mu$ increases when $R \& D$ costs rise or when market size falls. For reasons of simplicity, we assume that marginal cost does not depend on the quality level. Now demand and costs are defined, it is time to turn to the price decision. Before we do so, we discuss the stability problem.

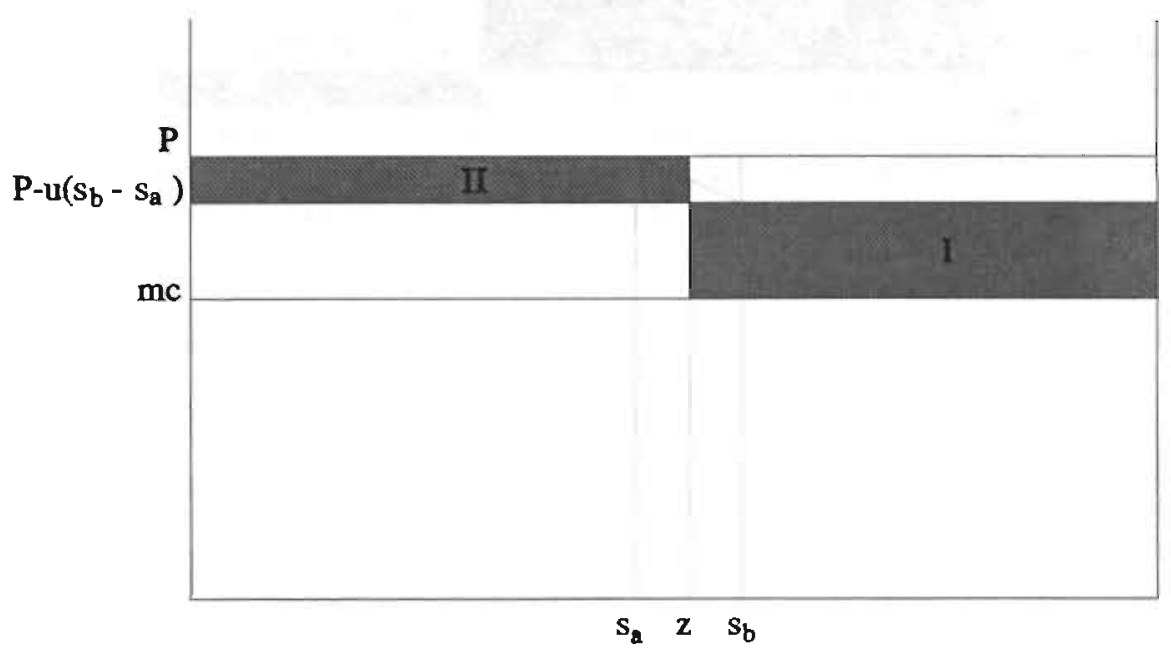

Figure 3.3A: The profitability of undercutting

\subsection{Price stability}

D'Aspremont, Gabszewicz and Thisse (1979) demonstrate that there was a fundamental flaw in Hotelling's (1929) analysis. From the latter analysis we know that firms have a tendency to locate close to each other in order to gain market share. However, when firms are located close together, firms have an incentive to undercut each other. This incentive is related to a discontinuity in demand. The discontinuity is a consequence of the linearity of the utility losses. Consider Figure 3.3A. Suppose that the firms are located at $s_{a}$ and $s_{b}$. The firms offer the same quality and charge the same price. When firm $A$ undercuts firm $B$ at $s_{b}$, all the consumers to the right of $s_{b}$ prefer firm A over firm B, since utility losses are linear. In order to undercut firm B at $s_{b}$, firm $A$ has to lower its price such that the consumers at and to the right of $s_{b}$ 
are willing to incur the additional utility losses. Firm A incurs a benefit and a loss when it undercuts firm B. The gain is equal to gross profits on additional demand [area $I$ in Figure 3.3A]. The cost is equal to the loss in gross profits on previous demand [area II in Figure 3.3A]. When the products are more differentiated than in Figure $3.3 \mathrm{~A}$, the price reduction needed to induce consumers at and to the right of $s_{b}$ to buy firm A's good becomes larger. The benefits of undercutting become smaller and the costs larger. Ultimately, when locations are differentiated enough, there is no incentive to undercut any more [Figure 3.3B].

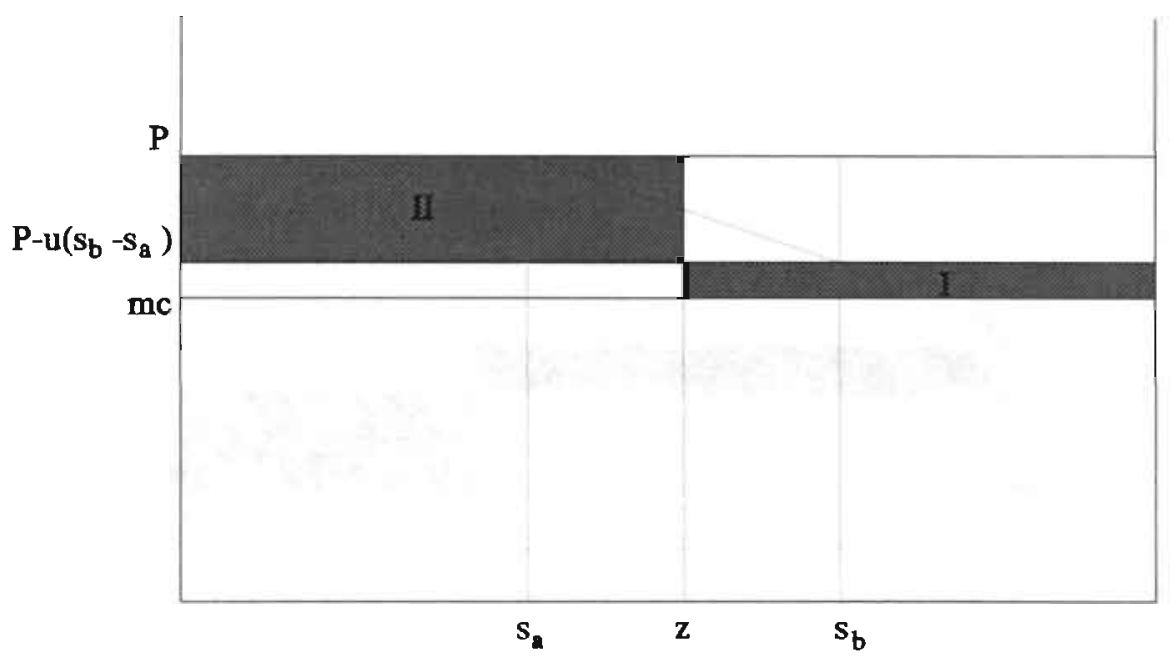

Figure 3.3B: The profitability of undercutting

Both firms have an incentive to undercut the rival firm when locations are close together. However, when the rival's price is low enough, there is an incentive to raise price again. There is no way out of this problem: The invisible hand is not able to solve the price instability problem. Figure 3.4 illustrates the instability by presenting reaction curves for $Q_{a}=Q_{b}, m c=0, s_{a}=0.3$ and $s_{b}=0.7$. When the rival's price is lower than $\mathrm{P}^{\circ}$, there is an incentive to raise price and the profit margin. When the rival's price exceeds this level, there is an incentive to lower price and capture all demand. The discontinuities at $\mathrm{P}^{*}$ illustrate the non-existence of a Nash equilibrium in prices. The non-existence may be explained as follows. It only pays to follow a low price strategy $T_{L}$ when the rival firm follows a high price strategy $T_{H}$, because the latter fact enables the low-price firm to attract all demand at profitable margins. This makes area $\mathrm{I}$ in Figure 3.3A large. If the competing enterprise has a low price as well, the firm in question is no longer able to obtain all demand at profitable margins. This being so, it is better to increase the profit margin somewhat by raising price. As a result, there are no symmetric Nash equilibria $\left[\left(T_{L}, T_{L}\right) ;\left(T_{H}, T_{H}\right)\right]$. There are also no asymmetric Nash equilibria $\left[\left(T_{L}, T_{H}\right) ;\left(T_{L}, T_{H}\right)\right]$, since the undercut firm always has an incentive to lower its price. 
D'Aspremont, Gabszewicz and Thisse (1979) propose a solution for this problem. As already stated in the introduction to this chapter, D'Aspremont et al. (1979) reformulate consumer utility in order to be able to derive a Nash equilibrium in prices. The discontinuities in demand and profits disappear as soon as utility losses are assumed to be quadratic instead of linear. When utility losses are quadratic, marginal losses are an increasing function of distance; when utility losses are linear, they are constant. A priori, both specifications are plausible from an economic point of view. Whether they also are from an empirical point of view, is hard to say. As far as we know, there is no empirical literature on the shape of utility losses. ${ }^{(8)}$ However, D'Aspremont et al.'s (1979) solution is not robust with respect to changes in the specification of utility losses, since a minor change in this respect may make the price solution unstable again. When utility losses are linear-quadratic instead of quadratic, there is no stable solution any more. Gabszewicz and Thisse (1986) show that continuity of demand and profits does not suffice to establish price stability in certain horizontal differentiation models. Anderson (1988: 485-6) shows that there is no stable price equilibrium in any horizontal differentiation model with linearquadratic utility losses. This is due to the fact that demand curves are kinked as a consequence of which profits are not quasi-concave and reactions functions are discontinuous. Price stability requires profits to be concave for all possible combinations of locations. This puts severe restrictions on the required convexity of utility losses.

Because of its lack of robustness, quadratic utility losses are not a much more attractive solution than linear losses. Second, linear losses are, a priori, not less plausible from an empirical point of view as quadratic losses are. Therefore we will propose another way out: We will presume utility losses to be linear and present two price equilibria which are reasonable from an economic point of view. Let us change the set up outlined in Section 2 slightly in order to preserve the model as set out by Hotelling (1929). A firm has no incentive to lower its price when its rival is able to respond instantaneously to a price decrease. When this is so, firms are likely to acknowledge that no firm will accept a solution in which it has no demand. Perceiving their mutual interdependence firms are likely to abstain from trying to drive their rival out of the market. This seems a reasonable point of departure, especially because the Nash concept is somewhat myopic in this context. The price solution given by Hotelling is not a Nash equilibrium because the firms consider a price decrease without taking the reaction of the rival firm into account. But rational

(8) All empirical literature known to us impose linear or quadratic utility losses. Lindsey et al. (1991) presume that transport costs are linear in video-retailing. Bouckaert and Degryse (1995) presume that waiting time is linear in banking. Following Anderson et al. (1989), Feenstra and Levinsohn (1995) model quadratic utility losses for a vector of characteristics referring to the U.S. automobile industry. In theoretical work, the specifications are usually chosen for analytical convenience. The pre-occupation with linear utility losses may be due to the specification chosen by Hotelling (1929). 
firms are likely to take such a reaction into account and to consider the end result. ${ }^{(9)}$ When prices cannot be adjusted instantaneously, the price behaviour postulated below is likely to make sense in a repeated game structure. ${ }^{(10)}$ A firm may not undercut a rival firm when the latter may retaliate in future periods. Lerner and Singer (1937) therefore impose one restriction on the price game: Each firm serves at least his backyard. ${ }^{(11)}$

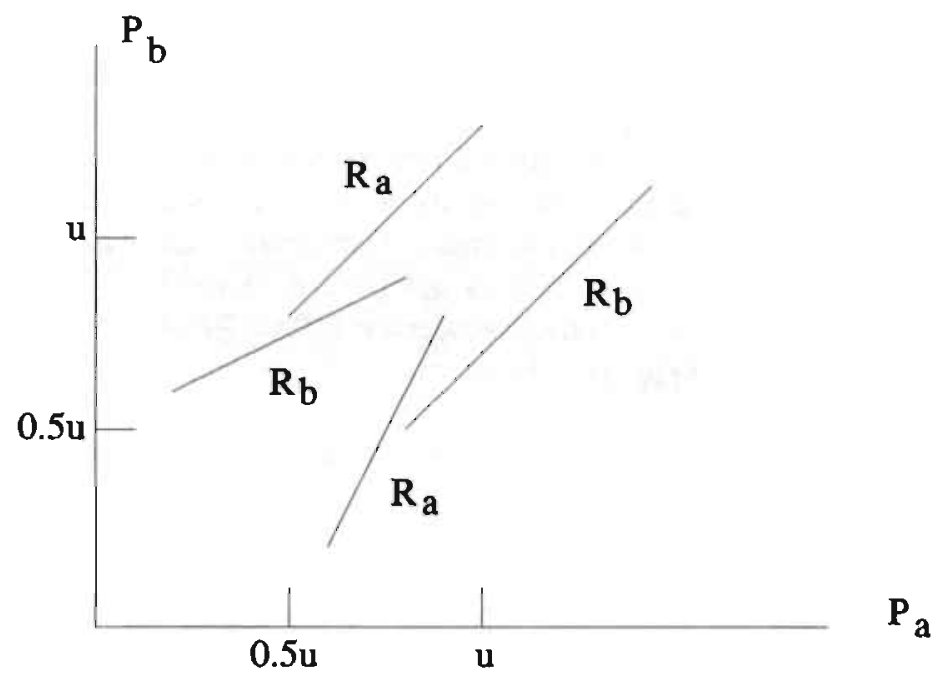

Figure 3.4: Reaction functions in prices

The argument can be illustrated with the help of a simple price game [Table 3.4]. When the firms do not enter each other's backyards, gross profits $\pi$ equal $\pi_{1}$. When one of the firms defects from this solution, the rival firm sets a price which forestalls successful entry into his backyard. One may suppose that the rival firm is able to react before consumers are able to respond. This assumption is not usual in industrial organization, but is not implausible since demand in general responds sluggishly

(9) Aumann and Myerson (1988) employ this reasoning with respect to coalition formation: 'When a player considers forming a link with another one, he does not simply ask himself whether he may expect to be better off with this link than without it, given the previously existing structure. Rather, he looks ahead and asks himself, "Suppose we form this new link, will other players be motivated to form further new links that were not worthwhile for them before? Where will this lead? Is the end result good or bad for me?" "

(10) This solution depends on the discount rate [Folk Theorem] [Fudenberg and Tirole (1991: 152)].

(11) Eaton (1972: 269) and Novshek (1980: 314) use this argument as well. 
[Spence (1983: 986n)]. Gross profits then are $\pi_{2} \because \pi_{1}{ }^{(12)}$ Given the assumptions made, not entering the rival's backyard dominates breaching the tacit agreement not to do so. Fast (and infrequent) price responses are observed in petrol-retailing. etc. In general, the Hotelling scenario is applicable when price competition is soft. Price competition may be soft for the following reasons. (1) Firms may respect each other's market shares to a certain extent. Price and market sharing agreements were abundant (until recently) in the Netherlands. Price competition is also absent in the U.S. industries for cigarettes, breakfast cereals, turbogenerators and gasoline [Scherer and Ross (1990)]. (2) Firms do not have excess capacity [Kreps and Scheinkman (1983)]. As long as there was no excess capacity, price competition was soft in the U.S. steel and automobile industries [Scherer and Ross (1990)]. Prices have been competitive since the moment at which European and Japanese completed the reconstruction of their industries and caused worldwide excess capacity. (3) Firms do not compete with respect to price. This explains why political parties tend to offer similar programs and broadcasting corporations have similar programs [Tirole (1988)]. (4) Products may be sufficiently and irreversibly differentiated. Since the Hotelling price equilibrium is not implausible, it is justified to derive equilibrium prices, quality rises and locations on the basis of Hotelling's original model; the more so as Hotelling prices give an upper bound to price strategies. The Hotelling scenario will be derived in Section 3 .

Table 3.4

Price equilibrium in a spatial differentiation model

\begin{tabular}{|c|c|c|c|}
\hline & & \multicolumn{2}{|l|}{ Firm B } \\
\hline & & Defect & Respect \\
\hline \multirow[t]{2}{*}{ Firm A } & Defect & $\left(\pi_{2}, \pi_{2}\right)$ & $\left(\pi_{2}, \pi_{2}\right)$ \\
\hline & Respect & $\left(\pi_{2}, \pi_{2}\right)$ & $\left(\pi_{1}, \pi_{1}\right)$ \\
\hline
\end{tabular}

However, a Hotelling price equilibrium does not emerge, when a price above the competitive level induces hit-and-run entry by the rival firm. This scenario is likely when reaction times are long or when there is mutual distrust between the firms. The latter may be due to personal characteristics [Chapter 5, Sub-sections 3.2 and 5.2]. When hit-and-run entry is likely, firms try to establish a sustainable price outcome. They set prices such that entry into their backyards is deterred. The price 'equilibrium' may be seen as the outcome of a one-shot Prisoner's Dilemma Game, although the outcome is not a Nash equilibrium as argues above. In an infinite horizon game, the dilemma may be overcome [Fudenberg and Tirole (1991)]. Sustainable prices give a lower bound to the price strategy set. This interpretation of

(12) One may show that $\pi_{1}$ equals $0.5 \mathrm{u}$ and $\pi_{2}$ has a maximum value equal to $0.25 \mathrm{u}$ [Subsection 4.1]. 
sustainability as an equilibrium concept differs somewhat from the definition laid down by Baumol et al. (1982), since we now consider two incumbent firms. In Section 4 we will therefore establish a limit price equilibrium. The following features enhance limit pricing scenarios. (1) There is a large excess capacity in the industry. Dodgson et al. (1992) show that bus-miles have a strong negative influence on profitability in the bus-service industry. (2) Management teams behave competitively, partly because of mutual distrust. Competition between Bic and Gillette in razor blades and lighters is primarily as fierce as it is, because Bic's owner, baron De Bich, behaves extremely competitive [Hatten and Hatten (1988)]. (3) Product differentiation is not feasible because consumers do not have a large desire for variety or market demand is concentrated. One could also consider mixed strategies [Dasgupta and Maskin (1986)]. However, mixed strategies have, among other things, the drawback that there are multiple Nash equilibria in mixed strategies. Moreover, mixed strategies are usually introduced as a deus ex machina for deriving equilibrium solutions. In particular, there is no justification, in terms of firms' behaviour, for the use of mixed strategies in spatial price competition [Gabszewicz and Thisse (1986: 31)].

Table 3.2

A comparison of horizontal differentiation models

$\begin{array}{llll}\text { Reference } & \begin{array}{l}\text { Utility } \\ \text { losses }\end{array} & \begin{array}{l}\text { Solution for } \\ \text { instability }\end{array} & \begin{array}{l}\text { Degree of } \\ \text { differentiation }\end{array} \\ \text { AG\&T (1979) } & \text { Quadratic } & \text { No instability } & \begin{array}{l}\text { Maximum } \\ \mathrm{s}_{\mathrm{a}}=0 ; \mathrm{s}_{\mathrm{b}}=1\end{array} \\ \text { Hotelling (1929) } & \text { Linear } & \begin{array}{l}\text { Recognition of } \\ \text { mutual dependence }\end{array} & \begin{array}{l}\text { Minimum } \\ \mathrm{s}_{\mathrm{a}}=\mathrm{s}_{\mathrm{b}}=\mathbf{0 . 5}\end{array} \\ \begin{array}{l}\text { Bunte (1997) } \\ \text { Limit price scenario }\end{array} & \text { Linear } & \text { Limit pricing } & \begin{array}{l}\text { Intermediate } \\ \mathrm{s}_{\mathrm{a}}=0.25 ; \mathrm{s}_{\mathrm{b}}=0.75\end{array}\end{array}$

This section analyses variety and quality competition on the basis of Hotelling's (1929) original differentiation model. Prices are viable in this framework if firms recognize their mutual interdependence [Table 3.2]. Firms maximize profits and expect their rival firms to maximize profits as well. When firms decide on variety and quality in the first period of the competition game, they take the competition process in the second period into account. For this reason, the model is solved backwardly. The outcomes consequently fulfil the principles of backward induction and sub-game perfection. For this reason, the price decision is derived in Sub-section 3.1 , the quality (or R\&D) decision in Sub-section 3.2 and the variety decision in 
Sub-section 3.3. When all the decisions have been derived, the R\&D equilibrium is investigated more carefully in Sub-section 3.4. We show why the duopolists face a Prisoner's Dilemma with respect to investments in R\&D. In Sections 3 to 7 the firms start from symmetric positions: Initial quality is the same for both firms.

\subsection{Prices}

In the second period of the competition game the firms decide at which prices to sell their respective varieties. As is usual in spatial differentiation models, we employ the Bertrand postulate instead of the Coumot postulate. ${ }^{(13)}$ The Bertrand result is obtained as a limit value. The firms determine their respective prices by maximizing gross profits. Gross profits are given by the product of the price-cost margin and firm demand

$\pi_{\mathrm{a}, 2}=\mathrm{X}_{\mathrm{a}, 2}\left(\mathrm{P}_{\mathrm{a}, 2}-\mathrm{mc}\right)$ and

$\pi_{b, 2}=X_{b, 2}\left(P_{b, 2}-m c\right)$.

Demand $X$ is given by equations (3a) and (3b). Maximizing gross profits with respect to price gives the following Nash equilibrium in prices [Appendix B]

$$
\begin{aligned}
& P_{a, 2}=m c+\frac{1}{3}\left[\left(Q_{a, 2}-Q_{b, 2}\right)+u\left(s_{a}+s_{b}\right)+2 u\right] \text { and } \\
& P_{b, 2}=m c+\frac{1}{3}\left[\left(Q_{b, 2}-Q_{a, 2}\right)-u\left(s_{a}+s_{b}\right)+4 u\right] .
\end{aligned}
$$

The price levels given by equations (6a) and (6b) correspond with the price levels in Hotelling's original equilibrium. In a symmetric equilibrium both $\mathrm{Q}_{\mathrm{a}}=\mathrm{Q}_{\mathrm{b}}$ and $\left(\mathrm{s}_{\mathrm{a}}+\mathrm{s}_{\mathrm{b}}\right)$ $=1$. This being so, it is easy to see that equilibrium prices approach the Bertrand solution $(\mathrm{P}=\mathrm{mc})$ when $\mathrm{u}$ approaches zero, i.e. when the desire for variety diminishes and products become more homogeneous. This also holds for Ramsey prices, as we will show below. Equations (6a) and (6b) give the outcomes of the second period's competition process. This knowledge enables firms to determine the ultimate effects of their $R \& D$ and variety decisions. Let us turn to the $R \& D$ decision.

(13) In spatial competition the Bertrand postulate suffices to derive a continuous demand function. This result and the fact that price policy strikes common sense more than quantity policy does, probably explain the popularity of the Bertrand concept in spatial analysis. Price competition has one additional technical advantage over quantity competition. Price competition causes a split of the market into different segments. In case of Cournot competition freight absorption may occur as a consequence of which market segments overlap [Beckman and Thisse (1986)]. This implies that results are not necessarily robust for the type of competition investigated. 


\subsection{Product quality}

In the second stage of the first period the firms decide on the quality increases to be pursued and thus on the R\&D costs to be incurred. When deciding on $R \& D$, firms maximize ret profits with respect to quality rises. When they do so, they take account of the competitive process in the second period and the prices set. The firms decide on the quality rises to be pursued by maximizing profits net of $R \& D$ outlays. The firms' optimization problems look as follows [Appendix B and C]

$\operatorname{Max} \Pi_{a}=X_{a, 2}\left(P_{a, 2}-m c\right)-S_{a, 1}$ and
$\operatorname{Max} \Pi_{b}=X_{b, 2}\left(P_{b, 2}-m c\right)-S_{b, 1}$

Substituting for $P, X$ and SC using equations (6a), (6b), (3a), (3b) and (4b), respectively, and using the symmetry condition $-Q_{a, 2}-Q_{b, 2}=\Delta Q_{a, 1}-\Delta Q_{b, 1}$ - gives

$\operatorname{Max} \Pi_{\mathrm{a}}=\frac{1}{18 \mathrm{u}}\left[\left(\Delta \mathrm{Q}_{\mathrm{a}, 1}-\Delta \mathrm{Q}_{\mathrm{b}, 1}\right)+\mathrm{u}\left(\mathrm{s}_{\mathrm{a}}+\mathrm{s}_{\mathrm{b}}\right)+2 \mathrm{u}\right]^{2}-\mu\left(\Delta \mathrm{Q}_{\mathrm{a}, 1}\right)^{2}$ and

$\operatorname{Max} \Pi_{b}=\frac{1}{18 u}\left[\left(\Delta Q_{b, 1}-\Delta Q_{a, 1}\right)-u\left(s_{a}+s_{b}\right)+4 u\right]^{2}-\mu\left(\Delta Q_{b, 1}\right)^{2}$

Note that the special case of symmetry in locations $\left(\mathrm{s}_{\mathrm{a}}+\mathrm{s}_{\mathrm{h}}=1\right)$ produces symmetric profit equations, since both $u\left(s_{a}+s_{b}+2\right)$ and $u\left(4-s_{a}-s_{h}\right)$ then are reduced to $3 u$. Note that gross profits may be written as $\left(\mathrm{P}_{\mathrm{j}}-\mathrm{mc}\right)^{2} / 2 \mathrm{u}$. Maximizing (8a) and (8b) with respect to $\Delta Q_{B}$ and $\Delta Q_{b}$, respectively, gives the following Nash solution after some substitution [Appendix C]

$$
\begin{aligned}
& \Delta \mathrm{Q}_{\mathrm{a}, 1}=\frac{18 \mu \mathrm{u}\left(2 \mathrm{u}+\mathrm{u}\left(\mathrm{s}_{\mathrm{a}}+\mathrm{s}_{\mathrm{b}}\right)\right)-6 \mathrm{u}}{18 \mu \mathrm{u}(18 \mu \mathrm{u}-2)} \text { and } \\
& \Delta \mathrm{Q}_{\mathrm{b}, 1}=\frac{18 \mu \mathrm{u}\left(4 \mathrm{u}-\mathrm{u}\left(\mathrm{s}_{\mathrm{a}}+\mathrm{s}_{\mathrm{b}}\right)\right)-6 \mathrm{u}}{18 \mu \mathrm{u}(18 \mu \mathrm{u}-2)} .
\end{aligned}
$$

The second-order condition is fulfilled when $18 \mu \mathrm{u}>1$ and the stability condition when $18 \mu \mathrm{u}>2$. The stability condition guarantees an equilibrium process to the Nash equilibrium, as it does in case of Cournot (1838) competition. In order to satisfy the second-order condition, the increase in marginal costs (as a function of the quality rise), $2 \mu$, needs to exceed the increase in marginal revenues, $2 /(18 u)$. The increase in marginal revenue decreases in the desire for variety $u$, because market share (demand) is less sensitive for quality differentials the higher $u$ is. The stability condition is satisfied when a firm reacts to a rival's quality increase with a less than proportional quality rise. Now, this only occurs when the increase in marginal costs, $2 \mu$, is high enough in relation to the increase in marginal revenues, $2 /(18 \mathrm{u})$. Now the price and $R \& D$ decisions are derived, we may turn to the decision on variety. In the next sub-section we will argue that the firms locate symmetrically $\left(s_{a}+s_{b}=1\right)$. When 
this is so, the quality improvements reduce to $\Delta Q_{a}=\Delta Q_{b}=(1 / 6 \mu)$. In equilibrium $\left[\left(\mathrm{s}_{\mathrm{a}}+\mathrm{s}_{\mathrm{b}}\right)=1\right]$, we have a negative relation between product innovations and invesiment costs only. Other variables, in particular utility costs $u$, do not influence the result. This is due to the fact that marginal revenues - a function of $u$ - are not effected by the rise in quality when the latter is symmetric. Since the quality rise influences sunk costs only, the cost parameter $\mu$ is the only parameter left in equations (9a) and (9b) (if the varieties are symmetrically located). As a result, quality increases benefit consumers only [Sub-section 3.4].

\subsection{Variety}

The optimization problems faced by the firms in the first stage of the first period can be derived by substituting for $\Delta Q_{a}$ and $\Delta Q_{b}$ in equations (8a) and (8b) using equations (9a) and (9b). The maximization problems now are as follows [Appendix C]

$\operatorname{Max} \Pi_{\mathrm{a}}=\mu[18 \mu \mathrm{u}-1]\left[\frac{18 \mu \mathrm{u}\left(2 \mathrm{u}+\mathrm{u}\left(\mathrm{s}_{\mathrm{a}}+\mathrm{s}_{\mathrm{b}}\right)\right)-6 \mathrm{u}}{18 \mu \mathrm{u}(18 \mu \mathrm{u}-2)}\right]^{2}$ and
$\operatorname{Max} \Pi_{\mathrm{b}}=\mu[18 \mu \mathrm{u}-1]\left[\frac{18 \mu \mathrm{u}\left(4 \mathrm{u}-\mathrm{u}\left(\mathrm{s}_{\mathrm{a}}+\mathrm{s}_{\mathrm{b}}\right)\right)-6 \mathrm{u}}{18 \mu \mathrm{u}(18 \mu \mathrm{u}-2)}\right]^{2}$

Note that net profits may be written as $\mu(18 \mu \mathrm{u}-1)\left(\Delta \mathrm{Q}_{\mathrm{j}}\right)^{2}$. Maximizing (10a) and (10b) towards $s_{a}$ and $s_{b}$, respectively, gives

$$
\begin{aligned}
& \frac{\partial \Pi_{\mathrm{a}}}{\partial \mathrm{s}_{\mathrm{a}}}=\frac{2 \mu \mathrm{u}(18 \mu \mathrm{u}-1)}{(18 \mu \mathrm{u}-2)}\left[\frac{18 \mu \mathrm{u}\left(2 \mathrm{u}+\mathrm{u}\left(\mathrm{s}_{\mathrm{a}}+\mathrm{s}_{\mathrm{b}}\right)\right)-6 \mathrm{u}}{18 \mu \mathrm{u}(18 \mu \mathrm{u}-2)}\right]>0 \text { and } \\
& \frac{\partial \Pi_{\mathrm{b}}}{\partial \mathrm{s}_{\mathrm{b}}}=\frac{-2 \mu \mathrm{u}(18 \mu \mathrm{u}-1)}{(18 \mu \mathrm{u}-2)}\left[\frac{18 \mu \mathrm{u}\left(4 \mathrm{u}-\mathrm{u}\left(\mathrm{s}_{\mathrm{a}}+\mathrm{s}_{\mathrm{b}}\right)\right)-6 \mathrm{u}}{18 \mu \mathrm{u}(18 \mu \mathrm{u}-2)}\right]<0 .
\end{aligned}
$$

Recall that the following assumptions are made with respect to the maximization problem. The firms have symmetric starting positions. This allows one to impose symmetry on the final solutions. Moreover, by assumption [Appendix A], firm A is located to the left of firm B. Symmetry in location implies $\left(s_{a}+s_{b}\right)=1 .^{(14)}$ Symmetry in location reduces the terms between []-brackets in equation (11a) and in equation $(11 b)$ to $1 / 6 \mu>0$. Recall that the stability condition for the R\&D game requires that $18 \mu \mathrm{u}>2$. This implies that equation (11a) is positive, while equation (11b) is negative. Because of symmetry and $s_{a} \leq s_{b}$, we have $s_{a}=s_{b}=0.5$. There is

(14) When $s_{a}=\phi, s_{b}=(1-\phi)$, and thus $\left(s_{a}+s_{b}\right)=\phi+(1-\phi)=1$ for $0 \leq \phi \leq 0.5$. 
minimum differentiation. The argument for this tendency comes down to Hotelling's original argument. A firm makes its variety similar to its rival's in order to gain market share. This result is not surprising, since we argued that the stability problem stressed by D'Aspremont, Gabszewicz and Thisse (1979) may not be as important as they argue. Since we employ the same specifications as Economides (1989), the derivations correspond perfectly with those obtained by Economides. The conclusion drawn from the derivations, however, differs. Economides argues that there is maximum differentiation for those parameter values for which $1<18 \mu \mathrm{u}<2$ as this would invert the signs in equations (1la) and (1lb). However, we know from the analysis in Sub-section 3.2 that these parameter values can be excluded for stability reasons. Thus Economides' (main) conclusion is not valid: The model supports minimum differentiation only. ${ }^{(15)}$ Zhang (1995) similarly concludes that pricematching is associated with minimum product differentiation. Product differentiation indeed seems minimum in the (U.S.) industries for cigarettes, breakfast cereals, gasoline and broadcasting [Scherer and Ross (1990)].

The results of this section so far may be summarized as follows. There is minimum differentiation $\left(s_{a}=s_{b}=0.5\right)$ : Both firms locate in the centre of the market. The firms strive for the following quality improvement: $\Delta Q_{a}=\Delta Q_{b}=1 / 6 \mu$ and set the following prices: $P_{a}=P_{b}=(m c+u)$. Prices approach marginal costs - the Bertrand result - when $u$ goes to zero, i.e. when there is less desire for variety and goods become more homogeneous. Net profits are $\Pi_{a}=\Pi_{b}=(u / 2)[1-1 /(18 \mu \mathrm{u})]>0{ }^{(16)}$ So, net profits decrease when u decreases. However, there is a strictly positive lower bound to both the desire for variety $u$ and net profits due to the second order and the stability conditions $(18 \mu \mathrm{u}>2)$. So, barrier market outcomes are only approached when $\mu$ is sufficiently high. We could go over to study the limit price scenario, but before we do so, we investigate the R\&D equilibrium generated by the Hotelling scenario more closely in Sub-section 3.4.

\subsection{The $R \& D$ game as a Prisoner's Dilemma}

In order to study the R\&D equilibrium more carefully one should throw a glance at equations (8a) and (8b). We know from Sub-section 3.3 that the firms locate symmetrically: $\left(s_{a}+s_{b}\right)=1$. One may now easily observe that if both firms pursue the same quality increase, their profits are reduced. Gross profits are constant, while R\&D costs are incurred. Why do the firms then invest at all? Table 3.5 below illustrates that the firms face a Prisoner's Dilemma with respect to investments in product R\&D. The following inequalities can be shown to hold for both firms

(15) Sorenson (1995) also uses the same specification as Economides does. He reports the same stability condition as we do. He does not address the variety decision, since he is interested in the R\&D decision only.

(16) Note that the term between []-brackets is larger than 0.5 and smaller than 1 for $18 \mu \mathrm{u}>$ 2. 


\section{[Appendix D]}

$\Pi_{i}\left(\Delta Q_{i}^{*}, 0\right)>\Pi_{i}(0,0)>\Pi_{i}\left(\Delta Q_{i}^{*}, \Delta Q_{j}^{*}\right)>\Pi_{i}\left(0, \Delta Q_{j}{ }^{*}\right)>0$,

where $\{i, j\} \in\{a, b\}$ and $i \neq j$, and the superscript ${ }^{\cdot}$ denotes the optimal investment level as given by equations (9a) and (9b). For simplicity, one may appoint profit levels to the above profit functions: $\Pi_{i}\left(\Delta Q_{i}, 0\right)=4 ; \Pi_{i}(0,0)=3 ; \Pi_{i}\left(\Delta Q_{i}^{*}, \Delta Q_{i}{ }^{*}\right)=2$; $\Pi_{i}\left(0, \Delta Q_{j}^{*}\right)=1$. Table 3.5 may now be constructed. The table clearly shows that $\Delta \mathrm{Q}=$ $\Delta Q^{*}$ is a dominating strategy for both firms, although $\Delta Q=0$ is optimal from the firms' point of view. When both firms invest, gross profits remain constant, while net profits are diminished with R\&D expenses: Both firms do not receive a penny for the investment made. However, the firms do not have any incentive to leave the market, because net profits are larger than zero (if the stability condition holds) [Sub-section 3.3]. The result that firms overinvest from the perspective of industry profits is not unfamiliar to the R\&D literature [Wright (1983) and Reinganum (1989)]. Product R\&D wars are found in the PC market [WSJE: 2-11-95], but also in the markets for drugs [WSJE: 24/5-11-95], cosmetics [NRC: 14-2-95], jet engines [BW: 27-3-95] and cars [BW: 17-4-95].

Table 3.5

The investment decision as a Prisoner's Dilemma

\begin{tabular}{|l|l|l|l|}
\hline \multicolumn{2}{|c|}{} & Firm B \\
\cline { 3 - 4 } \multicolumn{2}{|c|}{} & $\Delta \mathrm{Q}=0$ & $\Delta \mathrm{Q}=\Delta \mathrm{Q}^{\circ}$ \\
\hline Firm A & $\Delta \mathrm{Q}=0$ & $(3,3)$ & $(1,4)$ \\
\hline & $\Delta \mathrm{Q}=\Delta \mathrm{Q}^{\circ}$ & $(4,1)$ & $(2,2)$ \\
\hline
\end{tabular}

This result shows that competition may generate socially valuable outcomes. In the above model firms are forced to innovate and to pass all surplus created through to the consumers. The firms would have been better off if they did not innovate at all. Note that this result also holds for process innovations and, in particular, advertising. One only has to relable the variables in order to derive the same conclusion. The above result is not uncommon in the literature on advertising. Schmalensee (1986) and Dixit and Norman (1978), for instance, conclude that net profits are likely to be dissipated when market shares are sensitive to advertising. There is, however, one difference between quality improvements and advertising in that the former creates value, while the latter does not do so necessarily [Dixit and Norman (1978)]. A classic example of advertising wars is the U.S cigarette industry [Scherer and Ross (1990)]. Advertising expenses dissipate net profits substantially unless halted by government policy: A ban on television ads in 1970 reduced outlays from $\$ 315$ in 1970 to $\$ 252$ in 1971 while raising profits accordingly [op. cit.: 596]. Other example are the Dutch market for shampoos [NRC: 14-2-1995] and the European market for sanitary towels following the introduction of Always. 
In this section limit pricing is presented as a solution to the problem of price instubility associated with linear utility losses in Hotelling's (1929) differentiation framework [Table 3.2]. Price instability may occur when firms have an incentive (and the intent) to undercut the rival firm. Limit pricing deters entry into one's backyard and thus prevents total exit. When utility losses are quadratic, there is maximum product differentiation as a result of which the instability problem becomes irrelevant [D'Aspremont, Gabszewicz and Thisse (1979)]. When utility losses are linear, but firms tacitly agree not to undercut each other, there is minimum differentiation [Section 3]. Firms locate in the centre of the market in order to gain as much market share as is possible.

Table 3.2

A comparison of horizontal differentiation models

\begin{tabular}{|c|c|c|c|}
\hline Reference & $\begin{array}{l}\text { Utility } \\
\text { losses }\end{array}$ & $\begin{array}{l}\text { Solution for } \\
\text { instability }\end{array}$ & $\begin{array}{l}\text { Degree of } \\
\text { differentiation }\end{array}$ \\
\hline ACikT (1979) & Quadratic & No instability & $\begin{array}{l}\text { Maximum } \\
s_{a}=0 ; s_{b}=1\end{array}$ \\
\hline Hotelling (1929) & Linear & $\begin{array}{l}\text { Recognition of } \\
\text { mutual dependence }\end{array}$ & $\begin{array}{l}\text { Minimum } \\
s_{\mathrm{a}}=\mathrm{s}_{\mathrm{h}}=0.5\end{array}$ \\
\hline $\begin{array}{l}\text { Bunte }(1997) \\
\text { Limit price scenario }\end{array}$ & Linear & Limit pricing & $\begin{array}{l}\text { Intermediate } \\
\mathrm{s}_{\mathrm{a}}=0.25 ; \mathrm{s}_{\mathrm{b}}=\end{array}$ \\
\hline
\end{tabular}

Firms have an incentive to expel their rival from the market when they offer similar varieties for sale [Figure 3.3A]. When the varieties are differentiated enough, there is no such incentive [Figure 3.3B]. Limit pricing is only relevant when locations are such that there is an incentive to undercut the rival firm. In all other cases the results of the Hotelling scenario are relevant. This makes the analysis of the previous section relevant for the analysis in this section as well. The results of the previous section may also be used in order to determine the parameter values for which the Hotelling price equilibrium is vulnerable to undercutting. These parameter values determine when the Hotelling outcomes are applicable and when limit pricing is relevant. Before the equilibrium prices, qualities and varieties are derived, the ranges in which the Hotelling outcomes or limit pricing are relevant, are determined. This is done in Sub-section 4.1. In Sub-section 4.2 the equilibrium prices are postulated. Thereupon product quality is derived in Sub-section 4.3 and product variety in Sub-section 4.4 . 


\subsection{Price instability}

Sub-section 2.3 shows that it is profitable to undercut the rival firm when firms are located close together [Figure 3.3A]. When locations are far enough apart, Hotelling prices are stable [Figure 3.3B]. Now the solutions of the Hotelling scenario are derived [Section 3], one may find out which locations $\left(s_{a}\right.$ and $s_{b}$ ) are vulnerable to undercutting and which are not. This is the objective of this sub-section. In order to find these locations one may solve for the locations for which the firms are indifferent between expelling the rival firm or not. The firms are indifferent between both strategies when they are equally profitable. Since the firms have symmetric starting positions, they have the same quality level in period 2 of the competition game; they are located symmetrically as well $\left(\mathrm{s}_{\mathrm{a}}+\mathrm{s}_{\mathrm{b}}=1\right)$. Gross profits under the Hotelling scenario can be shown to equal $(\mathrm{u} / 2)$. The profitability of the alternative strategy may be determined as follows. When firm $B$ prices according to equation (6b), firm A may expel firm B from the market by setting the following price level

$P_{a}=P_{b}-u\left(s_{b}-s_{a}\right)-\omega=m c+u-u\left(s_{b}-s_{a}\right)-\omega$,

where $\omega \downarrow 0$. Firm $A$ induces consumers located at and to the right of $s_{b}$ to buy its product if: (1) it undercuts firm $B$ : $P_{a}=P_{b}-\omega$; (2) it reduces its price further - with $\mathrm{u}\left(\mathrm{s}_{\mathrm{b}}-\mathrm{s}_{\mathrm{a}}\right)$ - in order to compensate the consumers for the additional loss of utility incurred by buying at $s_{a}$ rather than $s_{b}$. Since firm $B$ is expelled from the market at this price level, revenues equal $P_{a}$ (demand equals 1 ). When $\omega$ is approximately equal to 0 , gross profits in case of undercutting equal gross profits under the Hotelling scenario when $\left(s_{b}-s_{a}\right)=0.5$. Imposing symmetry, we have $s_{a}=0.25$ and $s_{b}=0.75$. So, when $\mathrm{s}_{\mathrm{a}} \leq 0.25$ and $\mathrm{s}_{\mathrm{b}} \geq 0.75$, undercutting is not profitable. The Hotelling prices are stable for these values of $s_{a}$ and $s_{b}$. However, because the Hotelling outcomes apply, the firms want to locate closer to the centre: $s_{a} \geq 0.25$ and $s_{b} \leq 0.75$. The locations for which the Hotelling outcomes are sustainable, are depicted by areas I(a) and $I(b)$ in Figure 3.5. When $s_{a}>0.25$ and $s_{b}<0.75$, undercutting is profitable. As a result, the Hotelling price equilibrium may break down due to hit-and-run behaviour.

\begin{tabular}{cccccc} 
& $\mathrm{I}(\mathrm{a})$ & 1 & $\Pi$ & \multicolumn{2}{c}{$\mathrm{I}(\mathrm{b})$} \\
\hline 0 & & 0.25 & & 0.75 & 1
\end{tabular}

Figure 3.5: The relevance of limit pricing

The locations for which the Hotelling price equilibrium is vulnerable to undercutting and for which limit pricing is relevant, are depicted by area II in Figure 3.5. When firms acknowledge the resulting instability, they seek for a sustainable outcome and set a price that deters entry into their backyard. In the remaining part of this section prices, R\&D outlays and varieties based on limit prices are derived. An analysis of prices, R\&D outlays and varieties in area II is particularly important, 
since there is a tendency to make varieties alike in the Hotelling scenario [Section 3]. The duopolists locate somewhere in area II unless there is an opposing tendency in area II. We have not determined the equilibrium locations yet. We only know that the equilibrium locations are somewhere in area II (or at the borders).

\subsection{Prices}

Entry into one's backyard is deterred when the rival firm has to incur a gross loss in order to enter. Or to put it somewhat differently: When the rival firm has to sell below marginal cost in order to enforce successful entry. The highest price level a firm may assure thus equals the delivered price of the rival firm selling at marginal cost corrected for the quality differential ${ }^{(17)}$

$$
\begin{aligned}
& P_{a, 2}=m c+\left(Q_{a, 2}-Q_{b, 2}\right)+u\left(s_{b}-s_{a}\right) \text { and } \\
& P_{b, 2}=m c+\left(Q_{b, 2}-Q_{a, 2}\right)+u\left(s_{b}-s_{2}\right) .
\end{aligned}
$$

Note that these prices do not constitute a Nash equilibrium. Given the price level of the competing firm one may want to raise its price level. However, this would give the rival enterprise an incentive to lower its price and capture all market demand. This is after all the reason that there is no equilibrium in pure strategies. However. we think it is nevertheless usetul to study the outcomes of some likely scenario's, among which the limit price scenario. This scenario is attractive since limit prices constitute the only sustainable price equilibrium [Chapter 1]. The limit price scenario is also interesting, because it gives a lower bound to the range of possible prices.

\subsection{Product quality}

In the second stage of the first period firms maximize profits net of R\&D outlays. The respective optimization problems faced by firm $\mathrm{A}$ and $\mathrm{B}$ again are

$\operatorname{Max} \Pi_{\mathrm{a}}=\mathrm{X}_{\mathrm{a}, 2}\left(\mathrm{P}_{\mathrm{a}, 2}-\mathrm{mc}\right)-\mathrm{SC}_{\mathrm{a}, 1}$ and
$\operatorname{Max} \Pi_{\mathrm{b}}=\mathrm{X}_{\mathrm{b}, 2}\left(\mathrm{P}_{\mathrm{b}, 2}-\mathrm{mc}\right)-\mathrm{SC}_{\mathrm{b}, 1}$

These equations may be simplified by substituting $\mathrm{P}, \mathrm{X}$ and $\mathrm{SC}$ as given by equations

(17) Entry is deterred effectively when prices are set according to equations (6a') and (6b'). Professor Muysken draw my attention to the possibility that these levels may not be necessary. They probably are not when opportunity costs are taken into account. Prices thus may be higher than suggested. Future research must investigate this possibility. Therefore, some caution is warranted with respect to the solutions presented in this section. 
$\left(6 a^{\prime}\right),\left(6 b^{\prime}\right),(3 a),(3 b)$ and (4b) and by employing the symmetry condition: $Q_{a, 2}-Q_{b, 2}=$ $\Delta Q_{a, 1}-\Delta Q_{b}$. . This gives the following two optimization problems [Appendix E]

$\operatorname{Max} \Pi_{a}=\frac{1}{2 u}\left[\Delta Q_{a, 1}-\Delta Q_{b, 1}+u\left(s_{b}-s_{a}\right)\right]\left[\Delta Q_{b, 1}-\Delta Q_{a, 1}+u\left(s_{a}+s_{b}\right)\right]-\mu\left(\Delta Q_{a, 1}\right)^{2}$ and

$\operatorname{Max} \Pi_{b}=\frac{1}{2 u}\left[\Delta Q_{b, 1}-\Delta Q_{a, 1}+u\left(s_{b}-s_{s}\right)\right]\left[\Delta Q_{a, 1}-\Delta Q_{b, 1}-u\left(s_{a}+s_{b}\right)+2 u\right]-\mu\left(\Delta Q_{b, 1}\right)^{2}$.

Maximizing the above equations with respect to $\Delta Q_{a}$ and $\Delta Q_{b}$, respectively, gives the following Nash equilibrium [Appendix E]

$$
\begin{aligned}
& \Delta \mathrm{Q}_{\mathrm{a}, 1}=\frac{(2 \mu \mathrm{u}+1) \mathrm{s}_{\mathrm{a}}+\left(1-\mathrm{s}_{\mathrm{b}}\right)}{4 \mu(\mu \mathrm{u}+1)} \text { and } \\
& \Delta \mathrm{Q}_{\mathrm{b}, 2}=\frac{\mathrm{s}_{\mathrm{a}}+(2 \mu \mathrm{u}+1)\left(1-\mathrm{s}_{\mathrm{b}}\right)}{4 \mu(\mu \mathrm{u}+1)} .
\end{aligned}
$$

The second-order condition and the stability condition are fulfilled when $\mu$ and $u$ are larger than 0 . The latter is natural to assume, since $R \& D$ expenses and utility losses cannot be negative. There are no real restrictions on the parameters $\mu$ and $u$, because marginal revenues turn negative when the quality rise strived for becomes too large [Appendix E]. The profit margin rises with quality, but demand falls. The fall in demand is only compensated for small quality rises. Because demand falls when quality rises, product $R \& D$ is a strategic complement rather than a strategic substitute in case of limit pricing. ${ }^{(18)}$ In the Hotelling scenario product $R \& D$ is a strategic substitute. The scenarios differ in this respect, because quality differences are completely compensated by price differences in case of limit pricing and only partially in the Hotelling scenario. Now the equilibrium quality rises have been derived we may turn over to the decision on product variety.

\subsection{Product variety}

The optimization problems faced by the firms in the first stage of the first period can be derived by substituting for $\Delta Q_{a}$ and $\Delta Q_{b}$ in equations (8a') and (8b') using equations (9a') and (9b'). The optimization problems are as follows

(18) A variable is a strategic substitute whenever a rise in that variable lowers rival firm profits; it is a strategic complement when the rise raises rival firm profits [Tirole (1988: 208)]. Quantities (or capacities) often are strategic substitutes, while prices often are strategic complements. 


$$
\begin{aligned}
\Pi_{\mathrm{a}}= & \frac{1}{2 \mathrm{u}}\left[\frac{2 \mu \mathrm{u}\left(1-\mathrm{s}_{\mathrm{a}}-\mathrm{s}_{\mathrm{b}}\right)}{4 \mu(\mu \mathrm{u}+1)}+\mathrm{u}\left(\mathrm{s}_{\mathrm{a}}+\mathrm{s}_{\mathrm{b}}\right)\right]\left[\frac{2 \mu \mathrm{u}\left(\mathrm{s}_{\mathrm{a}}+\mathrm{s}_{\mathrm{b}}-1\right)}{4 \mu(\mu \mathrm{u}+1)}+\mathrm{u}\left(\mathrm{s}_{\mathrm{b}}-\mathrm{s}_{\mathrm{a}}\right)\right] \\
& -\mu\left[\frac{(2 \mu \mathrm{u}+1) \mathrm{s}_{\mathrm{a}}+\left(1-\mathrm{s}_{\mathrm{b}}\right)}{4 \mu(\mu \mathrm{u}+1)}\right]^{2} \text { and } \\
\Pi_{\mathrm{b}}= & \frac{1}{2 \mathrm{u}}\left[\frac{2 \mu \mathrm{u}\left(\mathrm{s}_{\mathrm{a}}+\mathrm{s}_{\mathrm{b}}-1\right)}{4 \mu(\mu \mathrm{u}+1)}-\mathrm{u}\left(\mathrm{s}_{\mathrm{a}}+\mathrm{s}_{\mathrm{b}}\right)+2 \mathrm{u}\right]\left[\frac{2 \mu \mathrm{u}\left(1-\mathrm{s}_{\mathrm{a}}-\mathrm{s}_{\mathrm{b}}\right)}{4 \mu(\mu \mathrm{u}+1)}+\mathrm{u}\left(\mathrm{s}_{\mathrm{b}}-\mathrm{s}_{\mathrm{a}}\right)\right] \\
& -\mu\left[\frac{\mathrm{s}_{\mathrm{a}}+(2 \mu \mathrm{u}+1)\left(1-\mathrm{s}_{\mathrm{b}}\right)}{4 \mu(\mu \mathrm{u}+1)}\right]^{2} .
\end{aligned}
$$

Maximizing (10a) and (10b) with respect to $s_{a}$ and $s_{b}$, respectively, gives [Appendix $\mathrm{F}]$

$$
\begin{aligned}
& \frac{\partial \Pi_{\mathrm{a}}}{\partial \mathrm{s}_{\mathrm{a}}}=-\frac{(2 \mu \mathrm{u}+1)^{2}\left((2 \mu \mathrm{u}+1) \mathrm{s}_{\mathrm{a}}+\left(1-\mathrm{s}_{\mathrm{b}}\right)\right)}{8 \mu(\mu \mathrm{u}+1)^{2}}<0 \text { and } \\
& \frac{\partial \Pi_{\mathrm{b}}}{\partial \mathrm{s}_{\mathrm{b}}}=\frac{(2 \mu \mathrm{u}+1)^{2}\left(\mathrm{~s}_{\mathrm{a}}+(2 \mu \mathrm{u}+1)\left(1-\mathrm{s}_{\mathrm{b}}\right)\right)}{8 \mu(\mu \mathrm{u}+1)^{2}}>0 .
\end{aligned}
$$

We again use the assumption of symmetric starting positions to impose symmetry on the final solutions as given by equations (1la') and $\left(11 b^{\prime}\right):\left(s_{a}+s_{b}\right)-1$ where $0 \leq s_{a} \leq$ $s_{b} \leq 1$. These conditions suffice to make equation (1 la) negative and equation (1 lb) positive. This implies that the firms have an incentive to move away from the centre of the market when limit pricing is relevant, i.e. in area II of Figure 3.5.

This section may be concluded as follows. When products are sufficiently differentiated $\left(s_{a} \leq 0.25\right.$ and $\left.s_{b} \geq 0.75\right)$, the Hotelling outcomes apply. The firms make their products more alike and move towards the centre of the market: $\mathrm{d} \Pi_{\mathrm{a}} / \mathrm{ds}_{\mathrm{a}}>$ 0 and $d \Pi_{b} / d s_{b}<0$. When products are not sufficiently differentiated $\left(0.25 \leq s_{a} \leq s_{b} \leq\right.$ 0.75), limit pricing is relevant. The firms make their products less alike and move away from the centre of the market: $d \Pi_{\mathrm{a}} / \mathrm{ds}_{\mathrm{a}}<0$ and $\mathrm{d} \Pi_{\mathrm{b}} / \mathrm{ds}_{\mathrm{b}}>0$. Since two opposing forces drive the location decisions, firm $A$ locates at 0.25 in equilibrium, and firm $B$ at 0.75 . There is neither maximum nor minimum product differentiation. This result contrasts with D'Aspremont et al. (1979) - maximum differentiation - and Hotelling (1929) - minimum differentiation [Table 3.2]. The equilibrium varieties are optimal from a social point of view, as will be shown in Sections 5 and 6 . The bus companies investigated by Dodgson et al. (1992) suffered losses (or a reduction in profits), because the amount of bus-miles offered was too high. A (further) reduction in bus-miles - the number of services - would have allowed a price rise and an incrense in profits. It is to be expected that bus services are further differentiated in this market in order to improve profitability.

The firms locate at the borders of area I where the Hotelling outcomes apply 
with area II where limit pricing results are relevant. In order to determine according to which investment and price rules the firms behave, we compare net profitability under the Hotelling outcomes with those under limit pricing. Net profits under the Hotelling outcomes are: $\Pi=(\mathrm{u} / 2)[1-1 /(18 \mu u)]$; net profits in case of limit pricing are: $\Pi=(u / 4)[1-1 /(16 \mu \mathrm{u})]$. Net profits are higher under the Hotelling outcomes if $144 \mu \mathrm{u}>1$. The solutions for the Hotelling scenario only hold if $18 \mu \mathrm{u}>2$. When this condition is satisfied, net profits are larger under the Hotelling outcomes. So, ${ }^{(19)}$ if $18 \mu \mathrm{u}>2$, the firms - located at 0.25 and 0.75 respectively - invest and price according to the Hotelling rules. The duopolists both invest $(1 / 36 \mu)$ to obtain a quality improvement equal to $(1 / 6 \mu)$ and set a price equal to $(\mathrm{mc}+\mathrm{u})$. Net profits again are $(\mathrm{u} / 2)[1-1 /(18 \mu \mathrm{u})]$. Barrier market results again are approached when the desire for variety as expressed by u decreases.

\section{Benchmarks}

In order to carry out a welfare analysis of market performance in the Hotelling [Section 3] and the limit price scenario [Section 4], we shall construct benchmarks: These of the social planner and of the monopolist. In both benchmarks there is the option to provide either one or two varieties. If the benchmarks provide only one variety, they would face a disadvantage relative to the market from the economic point of view, because consumers would incur higher utility losses. The social planner and the monopolist incur $R \& D$ expenses for both product varieties separately. The varieties are assumed to differ sufficiently so that expending is required for both. This assumption also facilitates a comparison of market performance with the performance of the social planner and the monopolist. The social planner and the monopolist would have an advantage relative to the market, when this assumption would be dropped, because they would not suffer from the cost of duplication then. The assumption does not seem unreasonable for the example of the car industry mentioned in Sub-section 2.1. The social planner and the monopolist, of course, start with the same quality levels as the duopolists do, for both varieties. For this reason, the subscripts are dropped in this section all together.

\subsection{The social planner}

Social welfare is defined as the sum of consumer surplus and industry profits. It is easy to see that social welfare is maximized at any price below ( $\left.Q-\mathrm{ud}^{*}\right)$, where $d^{*}$ is the maximum distance to be incurred, as long as it is optimal to cover the whole market. ${ }^{(20)}$ This implies that maximization of the planner's objective function does

(19) Recall the possible implications indicated by footnote 17 .

(20) The social planner covers the whole market from any location as long as $\left(Q_{1}-m c\right)>u$. Compare this condition with the one in footnote 5 . 
not suffice to determine the price level. Social planners are likely to be more preoccupied with the consumers' well-being than with the capital owners' [Introduction]. Following this reasoning the social planner's objective function is further specified. The social planner maximizes consumer surplus, be it under the constraint that all costs are covered by the revenues. ${ }^{(2)}$ This condition facilitates a comparison of the planner's performance with the market's performance. The social planner thus sets a Ramsey price. The equilibrium outcomes are first derived for the case in which one variety is offered first. Thereupon the results are given for the case in which there are two varieties. Having done so, the results may be compared.

One variety

The social planner's optimization problem is the following

$\Sigma=Q+\Delta Q-P-u \frac{s^{2}}{2}-u \frac{(1-s)^{2}}{2}$

subject to $P \geq\left(m c+\mu(\Delta Q)^{2}\right)$. Maximizing gives

$P=m c+\mu(\Delta Q)^{2}$.

Maximizing equation (13) towards $\Delta \mathrm{Q}$ subject to equation (14) produces

$\Delta Q=\frac{1}{2 \mu}$.

Maximizing (13) towards s gives

$\mathrm{s}=0.5$.

Given these values social welfare can be shown to equal

$\Sigma=\mathrm{Q}_{0}+\frac{\mathrm{l}}{4 \mu}-\frac{\mathrm{u}}{4}-\mathrm{mc}$.

Two varietics

The social planner's optimization problem now is

$\Sigma=\mathrm{Q}+\Delta \mathrm{Q}-\mathrm{P}-\mathrm{us}^{2}-\mathrm{u}(0.5-\mathrm{s})^{2}$

(21) This objective function still maximizes social welfare defined as the sum of consumer surplus and industry profits. 
subject to $\mathrm{P} \geq\left(\mathrm{mc}+2 \mu(\Delta \mathrm{Q})^{2}\right)$. Maximizing gives

$\mathrm{P}=\mathrm{mc}+2 \mu(\Delta \mathrm{Q})^{2}$.

Maximizing equation (13') towards $\Delta \mathrm{Q}$ subject to equation (14') gives

$\Delta Q=\frac{1}{4 \mu}$

Maximizing (13') towards s reveals

$s=0.25$.

The equilibrium locations thus are 0.25 and 0.75 . Given these values social welfare can be shown to equal

$\Sigma=Q_{0}+\frac{1}{8 \mu}-\frac{u}{8}-\mathrm{mc}$.

When equations (17) and (17') are compared, one may conclude that the social planner will provide one variety when $\mu \mathrm{u} \leq 1$ and two when $\mu \mathrm{u}>1$. It is intuitively plausible that the planner wants to provide two varieties when utility losses or innovation costs are high. When utility losses are high, consumers put great value on differences in variety. So it is better to have two varieties. When innovation costs are high, it is better to spread costs by providing two varieties because of the convexity of the R\&D cost equation.

\subsection{The monopolist}

We discuss the results for one variety first, then those for two varieties. We conclude with a comparison.

One variety

The monopolist faces the following optimization problem

$\Pi=\mathrm{P}-\mathrm{mc}-\mu(\Delta \mathrm{Q})^{2}$, 
when it is profitable to serve the whole market. ${ }^{(22)}$ However, the price level then is restricted by the following equality

$$
\mathrm{P}=\min [(\mathrm{Q}, \Delta \mathrm{Q}-\mathrm{us}),(\mathrm{Q}+\Delta \mathrm{Q}-\mathrm{u}(1-\mathrm{s})] .
$$

Maximizing equation (18) towards $\Delta Q$ subject to equation (19) generates

$$
\Delta Q=\frac{1}{2 \mu}
$$

Maximizing (18) subject to (19) towards $s$ gives

$$
\mathrm{s}=0.5 \text {. }
$$

Given these values profits can be shown to equal

$$
\Pi=\mathrm{Q}_{0}+\frac{\mathrm{l}}{4 \mu}-\frac{\mathrm{u}}{2}-\mathrm{mc} .
$$

Two varietics

The monopolist now faces the following optimization problem

$$
\Pi=P-m c-2 \mu(\Delta Q)^{2},
$$

when it is profitable to serve the whole market. However, the price level then is restricted by the following equality ${ }^{(23)}$

$$
P=\min [(Q+\Delta Q-u s),(Q+\Delta Q-u(0.5-s)] .
$$

Maximizing equation (18') towards $\Delta Q$ subject to equation (19') produces

$$
\Delta \mathrm{Q}=\frac{1}{4 \mu}
$$

Maximizing (18') subject to $\left(19^{\circ}\right)$ towards s gives

(22) From footnote 5 we know that the duopolists cover the whole market at the duopoly prices for any combination of locations when $\left(Q_{1}-\mathrm{mc}\right) \geq 2 \mathrm{u}$. The monopolist prefers to cover the whole market at any location when $\left(Q_{1}-u\right)>\left(Q_{1}+m c\right) / 2$ or $\left(Q_{1}-m c\right)>2 u$.

(23) See footnote 22 . 
$\mathrm{s}=0.25$.

The equilibrium locations again are 0.25 and 0.75 . Given these values profits can be shown to equal

$\Pi=\mathrm{Q}_{0}+\frac{1}{8 \mu}-\frac{\mathrm{u}}{4}-\mathrm{mc}$.

The monopolist will provide one variety when $\mu \mathrm{u} \leq 0.5$ and two when $\mu \mathrm{u}>0.5$. The monopolist is somewhat less efficient in this respect than the social planner. This is due to the fact that the monopolist is not able to reap consumer surplus.

\begin{tabular}{|c|c|c|c|c|c|c|c|}
\hline \multicolumn{8}{|c|}{$\begin{array}{l}\text { Table } 3.6 \\
\text { Surpluses arising from the innovations }\end{array}$} \\
\hline & & $\mathrm{s}_{\mathrm{a}}$ & $s_{b}$ & $\Delta \mathrm{Q}$ & $\mathrm{CS}$ & $\Pi$ & $\Sigma$ \\
\hline \multirow[t]{2}{*}{ Duopoly } & Hotelling & 0.5 & 0.5 & $1 / 6 \mu$ & $1 / 6 \mu$ & $-1 / 18 \mu$ & $1 / 9 \mu$ \\
\hline & $\begin{array}{l}\text { Limit } \\
\text { price }\end{array}$ & 0.25 & 0.75 & $1 / 6 \mu$ & $1 / 6 \mu$ & $-1 / 18 \mu$ & $1 / 9 \mu$ \\
\hline \multirow{2}{*}{$\begin{array}{l}\text { Social } \\
\text { planner }\end{array}$} & $\mu \mathrm{u} \leq 1$ & 0.5 & - & $1 / 2 \mu$ & $1 / 4 \mu$ & 0 & $1 / 4 \mu$ \\
\hline & $\mu \mathrm{u}>1$ & 0.25 & 0.75 & $1 / 4 \mu$ & $1 / 8 \mu$ & 0 & $1 / 8 \mu$ \\
\hline \multirow[t]{2}{*}{ Monopolist } & $\mu \mathrm{u} \leq 0.5$ & 0.5 & - & $1 / 2 \mu$ & 0 & $1 / 4 \mu$ & $1 / 4 \mu$ \\
\hline & $\mu \mathrm{u}>0.5$ & 0.25 & 0.75 & $1 / 4 \mu$ & 0 & $1 / 8 \mu$ & $1 / 8 \mu$ \\
\hline
\end{tabular}

6

A comparison

Now the benchmarks' decisions are derived, we may compare market performance in the Hotelling [Section 3] and limit price scenario [Section 4] with the performance of the benchmark social planner and monopolist [Section 5]. We consider the welfare effects of the quality rise first and total welfare afterwards. Table 3.6 gives the effects of the quality rise, and Table 3.7 the overall effects. The quality increase $\Delta Q$ indicated in Table 3.6 refers to one product; consumer surplus, profits and social welfare refer to the industry. Industry profits are twice the level of profits mentioned in Sections 3 and 4. The parameter values are supposed to be such that all agents are able to cover the market at the above given prices. This condition is fulfilled when $\left(\mathrm{Q}_{1}-\mathrm{mc}\right) \geq 2 \mathrm{u}^{(24)}$

The duopoly offers too many varieties when $\mu \mathrm{u}<1$. The social planner abstains from offering two varieties for these parameter values, because the decrease in utility

(24) This condition in fact guarantees that the market is covered for any combination of locations in the first period of the competition game. 
lusses does not counterbalance the surplus arising from one big innovation [Table 3.7]. The locations chosen in the Hotelling scenario are far from optimal, since wasteful duplication of resources occurs. However, it is noteworthy that varieties are chosen optimally in the limit price scenario. The monopolist performs slightly worse in terms of variety choice than the social planner does. This is due to the fact that the monopolist is not able to reap consumer surplus.

The incentive to innovate is substantially smaller for the duopolists than it is for the social planner and the monopolist. When the latter two invest in two varieties, the duopolists' level of quality change equals (2/3) of the social planner's and the monopolist's. When the latter two invest in one variety, the duopolists' level equals just a (1/3) of the benchmarks' levels. Price competition between the two firms completely corrodes the surplus arising from the quality rise. The firms invest in $\mathrm{R} \& D$ only in order to forestall an inroad in their market share by the rival firm [Section 3]. With respect to social welfare the duopoly performs somewhat worse than the social planner and the monopolist do. This is due to the fact that the duopolists underinvest. The monopolist performs well because it is able to appropriate all additional surplus. This is due to the assumption that all consumers buy one good only and that the market is covered.

\begin{tabular}{|c|c|c|c|c|}
\hline \multicolumn{5}{|c|}{$\begin{array}{l}\text { Table } 3.7 \\
\text { Total surplus }\end{array}$} \\
\hline & & $\mathrm{CS}$ & $\Pi$ & $\Sigma$ \\
\hline \multirow[t]{2}{*}{ Duopoly } & Hotelling & $\gamma+1 / 6 \mu-5 u / 4$ & $\mathrm{u}-1 / 18 \mu$ & $\gamma+1 / 9 \mu-\mathrm{u} / 4$ \\
\hline & I.imit price & $\gamma+1 / 6 \mu-9 u / 8$ & $\mathrm{u}-1 / 18 \mu$ & $\gamma+1 / 9 \mu-\mathrm{u} / 8$ \\
\hline \multirow{2}{*}{$\begin{array}{l}\text { Social } \\
\text { planner }\end{array}$} & $\mu \mathrm{u} \leq \mathrm{I}$ & $\gamma+1 / 4 \mu-u / 4$ & 0 & $\gamma+1 / 4 \mu-\mathrm{u} / 4$ \\
\hline & $\mu \mathrm{u}>\mathrm{I}$ & $\gamma+1 / 8 \mu-u / 8$ & 0 & $\gamma+1 / 8 \mu-u / 8$ \\
\hline \multirow[t]{2}{*}{ Monopolist } & $\mu \mathrm{u} \leq 0.5$ & $\mathrm{u} / 4$ & $\gamma+1 / 4 \mu-u / 2$ & $\gamma+1 / 4 \mu-\mathrm{u} / 4$ \\
\hline & $\mu \mathrm{u}>0.5$ & $\mathrm{u} / 8$ & $\gamma+1 / 8 \mu-u / 4$ & $\gamma+1 / 8 \mu-\mathrm{u} / 8$ \\
\hline
\end{tabular}

A social planner may of course be interested in the division of surplus between the consumers and the entrepreneurs. So let us analyse consumer surplus and industry profits. Table 3.6 shows that the duopolists are forced to transfer the entire surplus arising from the quality rises through to the consumers. Competition forces the firms to pass all surplus to the consumers. In this sense, competition is very efficient in the above model. The social planner realizes a higher quality rise than the duopolists, but charges a reward for the costs sunk and passes less surplus through to the consumers, when he invests in two varieties. The monopolist keeps the entire surplus. Profits are the mirror image of consumer surplus. Since the duopolists are forced to transfer the entire surplus arising from the quality rise to the consumers, their profits are lowered with R\&D outlays.

The social planner's total consumer surplus, of course, is larger than the duopolists', as is shown by Table 3.7. The parameter $\gamma$ equals $\left(\mathrm{Q}_{1}-\mathrm{mc}\right)$, the difference 
between initial quality and marginal surplus. This difference equals original surplus gross of utility losses. The social planner offers a higher consumer surplus than the duopolists and the monopolist do. The duopolists offer more consumer surplus than the monopolist does. The restriction necessary to guarantee market coverage suffices to establish these inequalities. For profits the ordering is reversed for the same reason. With respect to total welfare the social planner and the monopolist clearly outperform the duopolists, be it that the difference between the limit price scenario and the social planner's results need not to be that high.

The conclusions drawn in this section's welfare analysis hinge on the tendency of market participants to underinvest in R\&D. In the next section we investigate whether private and public policy measures may improve the market's performance with respect to $R \& D$.

7 Policy

The previous section shows that the market performs rather poorly with respect to R\&D efforts. The quality changes pursued by the duopolists equal $(1 / 3)$ or $(2 / 3)$ of the changes pursued by the social planner and the monopolist. The duopolists are likely to perform even worse relative to the social planner and the monopolist when the latter two do not have to duplicate R\&D expenses. In this section we study what policy measures, either public or private, may overcome the tendency to underinvest. There are two ways to increase the incentive to invest: The costs or the returns of $R \& D$ may be shared. Costs may be shared by the government through subsidies or tax grants. Government policies with respect to education and science may promote the dissemination of knowledge an so the returns of research (and development). There are also private institutions allowing firms to share the costs and returns to R\&D. One of them, joint ventures, are very popular among firms. They are also popular among governments, among other things because they do not require public resources. In 1994, the European Commission allowed joint ventures between, for instance, Philips and Osram (leadglass) and Pasteur and Merck (vaccines) [EC (1995)].

This section is based on the analysis in Section 3. The analysis performed below follows D'Aspremont and Jaquemin (1988) closely. The section differs from this paper, and the papers elaborating this paper [De Bondt and Veugelers (1991), Kamien, Muller and Zang (1992) and Suzumura (1992)], in the sense that D'Aspremont and Jaquemin's employ a demand function based on a quadratic utility function, while we use Hotelling's horizontal differentiation framework. We assume that the duopolists are located symmetrically $\left(s_{\mathrm{a}}+\mathrm{s}_{\mathrm{b}}=1\right)$ and that - in equilibrium the Hotelling scenario is applicable. As argued above, the incentive to perform R\&D may be influenced by sharing the costs or the retums associated with product development. Part of the R\&D costs may be borne by the rival firm [Katz (1986)] or the government. In this section we assume that $(1-\varsigma) \%$ of R\&D expenses are covered by the firm itself, while $\varsigma \%$ is covered by the rival firm or by a government subsidy. The returns to R\&D may be shared by knowledge spillovers [De Bondt and 
Veugelers (1991)]. It is likely that some knowledge spills over freely, but firms may raise knowledge spillovers by cooperating on product development. When the firms form a research joint venture (RJV), all knowledge obtained is shared and duplication of resources is prevented [Kamien, Muller and Zang (1992)]. We assume that $\beta \%$ of a firm's R\&D efforts $X$ spills over to its competitor freely. When the duopolists form a RJV, the spillover rate rises to $\beta=1$. Now when there is price competition in the second period of the competition game, first period profits are as follows

$$
\begin{aligned}
& \Pi_{a}=\frac{1}{18 u}\left[R_{a}+\beta R_{b}-R_{b}-\beta R_{a}+3 u\right]^{2}-(1-\varsigma) \mu R_{a}^{2} \text { and } \\
& \Pi_{b}=\frac{1}{18 u}\left[R_{b}+\beta R_{a}-R_{a}-\beta R_{b}+3 u\right]^{2}-(1-\varsigma) \mu R_{b}^{2} .
\end{aligned}
$$

Since the quality changes now depend on the R\&D efforts pursued by both firms, the quality change $\Delta Q$ is rewritten in terms of $R \& D$ efforts $R$. We now have $Q_{a, 2}=Q_{a, 1}+$ $R_{b, 1}+\beta R_{b, 1}$ for firm $A$, and vice versa for firm $B$. Because of symmetry, $Q_{a, 1}=Q_{b, 1}$. This explains why equations (8a) and (8b) may be rewritten into equations (8a") and $\left(8 b^{\prime \prime}\right)$, respectively. The above equations show that some policies are likely to make things worse. The spillover rate reduces private returns to investment, since (gross) profits depend on the difference in R\&D efforts. Spillovers reduce the possibility to increase (or reduce) the quality gap relative to one's competitor, since a rise in quality is (partly) matched by a rise in one's rival's quality. In the case of a RJV it would even be totally matched: Gross profits would no longer rise with R\&D efforts.

D'Aspremont and Jaquemin (1988) distinguish three possible policies

(1) no coordination;

(2) coordination in R\&D;

(3) coordination in R\&D and price.

In scenario (1) the firms do not cooperate on R\&D or price. This scenario refers to competition. The scenarios analysed in Section 3 (and 4) fall in this category. In scenario (2) the firms cooperate with respect to R\&D. Second-period competition remains Bertrand (or Cournot). Cooperation is interpreted by D'Aspremont and Jaquemin (1988) as maximizing industry profits with respect to $R \& D$. In this way, the externalities caused by spillovers are internalized. In scenario (3) the firms cooperate with respect to both policy variables. This scenario comes down to the behaviour of the monopolist firm analysed in Section 5. Kamien, Muller and Zang (1992) extend these policy options with the possibility to form a RJV. When a RJV is formed, $\beta=1$; otherwise $\beta<1$.

Scenario (1) gives the following solution [Appendix G]

$R_{a}=\frac{(1-\beta)}{6 \mu(1-\varsigma)}$ and 
$R_{b}=\frac{(1-\beta)}{6 \mu(1-\zeta)}$.

These expressions, of course, are similar to equations (9a) and (9b). Because firms do not cooperate in $R \& D$ in scenario (1), the only legitimate interpretation of cost sharing in this scenario is a government grant. Subsidies - or alternatively favourable tax regimes - are effective policies, since they decrease R\&D costs. Spillovers reduce R\&D efforts, because they affect the firms' ability to appropriate the surplus created by innovations.

The duopolists cooperate with respect to product development when they both invest such that industry profits are maximized [D'Aspremont and Jaquemin (1988)]. Doing so would lead to an equilibrium investment of $(1-\beta) /(3 \mu(1-\varsigma)$ ) in scenario (2). But when both firms would pursue that quality rise, that would actually diminish net protits, as can be easily seen from equations (8a") and (8b"). Firms would do better, if one firm would invest. Industry gross profits would rise, since gross profits are a quadratic function of the quality difference. The investing firm gains more profits than its competitor loses. The other firm could be compensated by a side payment. RJV's do not make sense because, if R\&D efforts would spill over completely, R\&D efforts would not improve the investing firm's strategic advantage and consequently industry gross profits. Scenario (3) equals the monopolist's scenario treated in Subsection 5.2. This would lead to an optimal investment policy and maximize social welfare, but would be detrimental to consumer well-being. For this reason, the European Commission (1995) does not permit cooperation between firms to be extended to price policy. Joint development and production are only allowed, when there is separate distribution or effective (potential) competition from other sources [EC (1995)]. Whether the former condition is sufficient, may be questioned. This argument played an important role in the Philips-Osram joint venture for leadglass.

Cooperation in R\&D, a RJV policy in particular, is ineffective in spurring R\&D efforts as long as there is Bertrand competition in prices. When the firms are not able to appropriate (a part of) the surplus created by innovations, they abstain from doing so. Firms only invest in R\&D - with cooperation or not - when price competition is sufficiently soft. This result sketches the dilemma of policy makers: They face the classic choice between high prices and a high innovation rate - policy (3) - or low prices and a low innovation rate - policy (1). This section thus addresses the classical trade-off between static and dynamic efficiency again. The trade-off is particularly sharp in the above model, because market demand is (perfectly) inelastic. The dilemma is not that dramatic when demand is elastic [D'Aspremont and Jaquemin (1988)]. In the above model, consumer well-being is definitely favoured by competition in terms of both $R \& D$ and price - policy (1). This result indicates why the European Commission should only grant exemptions for cooperative R\&D agreements on basis of article 85(3) of the Rome Treaty, if consumers are expected to benefit from the innovations through price competition. In the above model, the only feasible and effective policy instrument, not effecting price competition, is a government subsidy or, equivalently, a favourable tax regime. It stimulates R\&D 
efforts by lowering R\&D costs [equations (9a") and (9b")].

Section 7 concludes the welfare analysis [Sections 5 and 6] of market performance in the Hotelling [Section 3] and the limit price scenario [Section 4] with a policy analysis. The next two sections extend the Hotelling scenario in two ways which fall somewhat out of the main line of this thesis. The reader who is primarily interested in (the welfare analysis of) benchmark scenarios may want to skip them. In section 8 the implications of an asymmetry in the initial quality levels are analysed. Section 9 studies differences in expectation formation in case of uncertainty with respect to R\&D costs.

\section{8}

\section{Asymmetry in quality}

In this section we will investigate in what way the results of the Hotelling scenario [Section 3] change when there are (small) differences in the initial quality levels. Since there is no clear-cut solution to the variety decisions, we do not analyse them in this section. Like Sorenson (1995), we simply suppose that firm A is located at 0 and firm $\mathrm{B}$ at 1 . When this assumption holds, the firms are sufficiently differentiated for the analysis in this section to hold. At the end of this section we will consider the assumption carefully. This section resembles Sorenson's (1995) analysis of quality differences. Sorenson employs the same model as we do. We merely add two points to Sorenson's analysis. (1) We analyse the implications for social welfare. (2) We provide thorough comparative statics.

Without loss of generality we assume that firm A's initial quality is larger than firm B's $\left(Q_{a, 1}>Q_{b, 1}\right)$, where subscript 1 denotes period 1 . The analysis in Section 3 is still applicable as far as prices are concerned. Reduced-form profits in terms of qualities now are

$$
\begin{aligned}
& \Pi_{\mathrm{a}}=\frac{1}{18 \mathrm{u}}\left[\left(\mathrm{Q}_{\mathrm{a}, 1}+\Delta \mathrm{Q}_{\mathrm{a}, 1}-\mathrm{Q}_{\mathrm{b}, 1}-\Delta \mathrm{Q}_{\mathrm{b}, \mathrm{l}}\right)+3 \mathrm{u}\right]^{2}-\mu\left(\Delta \mathrm{Q}_{\mathrm{a}, \mathrm{1}}\right)^{2} \text { and } \\
& \Pi_{\mathrm{b}}=\frac{1}{18 \mathrm{u}}\left[\left(\mathrm{Q}_{\mathrm{b}, \mathrm{l}}+\Delta \mathrm{Q}_{\mathrm{b}, 1}-\mathrm{Q}_{\mathrm{a}, 1}-\Delta \mathrm{Q}_{\mathrm{a}, \mathrm{l}}\right)+3 \mathrm{u}\right]^{2}-\mu\left(\Delta \mathrm{Q}_{\mathrm{b}, 1}\right)^{2} .
\end{aligned}
$$

Equations (8a) and (8b) in Section 3 differ from the above equations as a consequence of the difference in initial qualities. In Section 3 the initial qualities drop out of the reduced profits equations because of the symmetry assumption. In this section this is no longer the case. Maximizing net profits with respect to $\Delta Q_{a, 1}$ and $\Delta Q_{b, 1}$, respectively, gives the following Nash solution after some substitution $[\text { Appendix H] }]^{(25)}$

(25) When the quality difference is large, $\Delta Q_{b}$ becomes negative. This would imply that firm $B$ does not consider investing in product $R \& D$. We assume throughout this section that the quality difference is 'sufficiently' small. 
$\Delta Q_{a, 1}=\frac{Q_{a, 1}-Q_{b, 1}}{18 \mu u-2}+\frac{1}{6 \mu}$ and

$\Delta Q_{b, 1}=\frac{Q_{b, 1}-Q_{a, 1}}{18 \mu u-2}+\frac{1}{6 \mu}$.

Equations (9a"') and (9b"') resemble equations (9a) and (9b). The latter two equations reduce to $\Delta Q_{a}=\Delta Q_{b}=1 /(6 \mu)$ when $s_{a}=0$ and $s_{b}=1$. The only difference then is due to the first term at the right hand side which describes the implications of the difference in initial qualities. Recall that we assumed $18 \mu \mathrm{u}>2$ in order to meet the stability requirement for the product $R \& D$ decisions.

The influence of a difference in initial qualities is summarized by Table 3.8, which gives the comparative statics of the $R \& D$ decision as given by equations (9a"') and (9b"'). Recall that firm A has a quality advantage $\left(Q_{a, 1}>Q_{b, 1}\right)$. The table shows that firm A raises its product R\&D efforts and firm B lowers them when the quality gap between the two firms widens. The leading firm is spurred to widen the quality gap by spending more on $R \& D$, while at the same time the lagging firm is forced to cut on R\&D outlays. The strategic advantage the firm ahead possesses, enables it to widen the quality gap. The asymmetry between the firms thus is likely to grow. This result corresponds with the first-mover advantage found in the literature on entry deterrence and R\&D [Tirole (1988), Beath et al. (1989), Reinganum (1989) and Gilbert (1989)]. This result may be explained as follows. When a firm's initial quality level is higher than its competitor's, the former's demand will be higher than the latter's, ceteris paribus. When demand is higher, sunk costs do not bear as much on profits, since they may be spread over more consumers. A higher initial quality level reduces average costs via demand. Now this result is derived, we may investigate what implications asymmetry in initial qualities has for social welfare. In Appendix I we investigate the influence of a difference in initial qualities on consumer surplus and industry profits holding the average initial quality level constant. We merely present the result over here.

\begin{tabular}{||l|l|l|l||}
\hline \hline $\begin{array}{l}\text { Table 3.8 } \\
\text { Comparative statics }\end{array}$ \\
\hline$\partial \Delta \mathrm{Q}_{\mathrm{a}, 1} / \partial\left(\mathrm{Q}_{\mathrm{a}, 1}-\mathrm{Q}_{\mathrm{b}, 1}\right)$ & + & $\partial \Delta \mathrm{Q}_{\mathrm{b}, 1} / \partial\left(\mathrm{Q}_{\mathrm{a}, 1}-\mathrm{Q}_{\mathrm{b}, 1}\right)$ & - \\
\hline$\partial \Delta \mathrm{Q}_{\mathrm{a}, 1} / \partial \mu$ & - & $\partial \Delta \mathrm{Q}_{\mathrm{b}, 1} / \partial \mu$ & $+/-$ \\
\hline$\partial \Delta \mathrm{Q}_{\mathrm{a}, 1} / \partial \mathrm{u}$ & - & $\partial \Delta \mathrm{Q}_{\mathrm{b}, 1} / \partial \mathrm{u}$ & + \\
\hline
\end{tabular}

Proposition 3.1. Let firm A's initial quality be given by $(\mathrm{Q}+\alpha)$ and firm B's initial quality by $(\mathrm{Q}-\alpha)$. Both consumer surplus and industry profits rise when $\alpha$ rises.

Proof. See Appendix I.

As a corollary to this result, we have that social welfare rises when $\alpha$ rises. This 
result may be interpreted as follows. Consumer surplus benefits from the asymmetry in initial quality, because the high-quality firm is spurred to increase its product R\&D efforts while price competition remains fierce enough to let the consumers benefit on average. A change in quality is only partly undone by a change in price [equations (6a) and (6b)]. The consumers buying from the high-quality firm consequently gain, whereas the other consumers lose. But since the surplus offered by the high-quality firm rises and the surplus offered by the low-quality firm falls, the market share of the high-quality firm increases. This makes consumer surplus rise on net. The strategic advantage of the leader enables him to increase market share and profit margin at the detriment of the rival firm. The leader is able to monopolize the market. The industry develops from a duopoly to a monopoly. This makes industry profits grow.

The influence of innovation costs $\mu$ is in line with intuition, at least for the leading firm, i.e. firm $A$. When innovation costs rise, firm $A$ cuts on R\&D expenses. However, firm B's R\&D efforts may increase. This result may be explained as follows. Cost increases per se lead to a slow down of the innovation pace. However, the very fact that firm $A$ has an incentive to cut back on R\&D expenses, may spur firm $B$ to do more on R\&D. Or, to put it another way, it becomes more expensive for firm A to gain market share. So, he will be satisfied with a smaller gain in market share. Firm B thus is able to preserve more of its share. A similar argument holds for utility losses $u$. When firms are in symmetric positions, the impact of a rise in utility losses on R\&D spending is nil [Sub-section 3.3]. However, when firms are not in symmetric positions, the high-quality firm (firm A) cuts back on R\&D, while its rival performs more $R \& D$. This result may be explained by the fact that an increase in u shelters the lagging firm more from competition. Since consumers value variety more when $u$ rises, tougher price competition is needed to gain market share.

We assumed throughout this section that firm $\mathrm{A}$ is located at 0 and firm $\mathrm{B}$ at 1 . When the variety decisions would have been endogenous, the firms would again have an incentive to minimise product differentiation [Bunte (1995)]. However, minimum differentiation $-\mathrm{s}_{\mathrm{a}}=\mathrm{s}_{\mathrm{b}}=0.5$ - is not an equilibrium at the Hotelling prices, since quality differences are only made up by price differences for (2/3) [Sub-section 3.1]. An equilibrium at Hotelling prices is only sustainable when the products are sufficiently differentiated. Future research is needed to indicate what the precise equilibrium locations are (or may be). The analysis by Bunte (1995) indicates that all the results presented in this section also hold for other locations than $s_{a}=0$ and $s_{b}=$ 1 , as long as products are sufficiently differentiated (in period 2).

The analysis in this section again shows that first-mover advantages are likely to be reinforced through time. As in Chapter 2, this suggests a natural and gradual tendency towards monopolization. In this section, the high-quality firm invests more in product innovation than its lagging rival. This reinforces the leading firm's competitive advantage. However, the welfare analysis indicates that a first-mover advantage in terms of initial quality is beneficial for both consumer surplus and industry profits, because the leading firm is spurred to perform R\&D. One may thus conclude as follows. A quality lead is probably beneficial for consumers, as long as the competitive threat is fierce enough to enforce competitive pricing by the leading 
firm. In the long run, the competitive threat may weaken when there indeed is a natural tendency to monopolization. The competitive threat is likely to be sustained when the desire for variety is large enough.

The $R \& D$ process is surrounded with uncertainty. In order to incorporate an element of uncertainty into the model a stochastic element is introduced. In this section $\mu$ is drawn from some distribution. Uncertainty may influence firm performance. Firms may be heterogeneous in various aspects, among others things with respect to the amount of information they have available. On the basis of common sense one may predict that firms with more knowledge perform better than firms with less. We will investigate whether this is so. This is done in order to find out which type of firm is likely to be selected by the market process: Firms with a higher return are more likely to stay in the market. In this section there is uncertainty with respect to R\&D costs. The parameter $\mu$ is treated as a random variable.

As in Sections 3 and 4 the firms start from symmetric starting positions in terms of quality and variety. The distribution of the random variable is the same for both firms. This implies that, in principle, they are equally efficient. Suppose without loss of generality that firm A (the incumbent) has more information on the distribution of the random variable than firm B (the entrant) does. On average, firm A and firm B are equally likely to estimate the expected value of the random variable correctly. Both firms may have observed some drawings from the distribution in the past, firm A simply somewhat more than firm B. Because of this firm A is likely to be more accurate in estimating the expected value of the random variable. The variance of the estimate is consequently lower for firm A than for firm B.

The firms do not have any information on each other's information. Therefore, they simply assume that the rival firm has the same information as they $\mathrm{do}^{(2())}$ and suppose that the estimate of the random variable made by the rival firm equals theirs. So, for firm $A$ we have $E_{a}[\mu]=E_{a}\left[E_{b}[\mu]\right]$ and vice versa for firm $B$. $E_{i}[\mu]$ denotes firm i's estimate of the random variable $[i \in\{a, b\}] . E_{i}[\mu]$ is a parameter in the profit equations. Since it enters the equations linearly, the distribution of the random variable does not complicate the optimization process described in Section 3 any further. This being so, the firms expect' the quality increases to be equal

$$
\Delta Q_{i, 1}=\frac{1}{6 E_{i}\left[\mu_{i, 1}\right]}=\frac{1}{6 E_{i}\left[E_{j}\left[\mu_{j, 1}\right]\right]}=E_{i}\left[\Delta Q_{j, 1}\right]
$$

where $i \in\{a, b\}, j \in\{a, b\}$ and $i \neq j$. One must realise that the actual value of the random variable does not influence the profits of the rival firm, since the random variable influences sunk costs only. The quality rise pursued does influence one's

(26) This, of course, implies an element of non-rationality. 
rival's profits, but since the quality rise pursued is agreed upon in the first period of the competition game, the actual value of the random variable is of no importance for the rival's profits. However, since firm $A$ is more accurate in estimating than firm B, we know that $\mathrm{E}\left[\left(\sigma_{\mu, \mathrm{a}}\right)^{2}\right]<\mathrm{E}\left[\left(\sigma_{\mu, \mathrm{b}}\right)^{2}\right]$, where $\mathrm{E}\left[\left(\sigma_{\mu, \mathrm{i}}\right)\right]^{2}$ represents the expected variance of $i$ 's estimation of $\mu[i \in\{a, b\}]$. Capital $E$ - contrary to $E_{i}$ - denotes expected rather than estimated. The difference in the expected variance is not known to the firms in the model. This possibility is precluded by the above assumption that the firms suppose that the rival's estimate of the random variable equals their own estimate. We use this difference to derive the following inequality. The expected investment levels of both firms relate to each other as follows

$$
\mathrm{E}\left[1 /\left(6 \mathrm{E}_{\mathrm{a}}\left[\mu_{\mathrm{a}, 1}\right]\right)\right]<\mathrm{E}\left[1 /\left(6 \mathrm{E}_{\mathrm{b}}\left[\mu_{\mathrm{b}, 1}\right]\right)\right] \text {, }
$$

which is due to Jensen's inequality [Mood et al. (1986)]. Type B firms consequently invest more, on average, than their counterparts. This is not surprising, since the investment is a convex function of $\mathrm{E}[\mu]$ and the variance of B's estimations is larger. This can also be illustrated for a simple distribution. Suppose that there are two possible drawings - $(E[\mu]-x)$ and $(E[\mu]+x)$ - with probability 0.5 each. Firm A knows the distribution of the random variable $-E_{a}[\mu]=E[\mu]$ - while firm $B$ infers its estimate from one drawing in the past. Firm B's estimate equals $E_{b}[\mu]=E[\mu]-x$ with probability 0.5 or $E_{b}[\mu]=E[\mu]+x$ with again probability 0.5 . Notice that the expected value of firm A's estimate equals the expected value of firm B's estimate, while the variance of firm B's estimate exceeds firm A's.

Firm A's expected quality increase is $E\left[\Delta Q_{a}\right]=1 /(6 E[\mu])$. Firm $B$ pursues one of the following two quality increases: (1) $\Delta \mathrm{Q}_{\mathrm{b}}=\Delta \mathrm{Q}(\mathrm{E}[\mu]-\mathrm{x})\left[\mathrm{E}_{\mathrm{b}}[\mu]=(\mathrm{E}[\mu]-\mathrm{x})\right]$ or (2) $\Delta \mathrm{Q}_{\mathrm{b}}=\Delta \mathrm{Q}(\mathrm{E}[\mu]+\mathrm{x})\left[\mathrm{E}_{\mathrm{b}}[\mu]=(\mathrm{E}[\mu]+\mathrm{x})\right]$ where $\Delta \mathrm{Q}()$ denotes $\Delta \mathrm{Q}()=1 /\left(6 \mathrm{E}_{\mathrm{i}}[\mu]\right)$. The first quality increase is larger than firm A's, while the second is smaller. Because of the convexity of $\Delta Q()$ the overinvestment in case (1) - $\Delta Q(E[\mu]-x)-\Delta Q(E[\mu])-$ is larger than the underinvestment in case (2) $-\Delta Q(E[\mu])-\Delta Q(E[\mu]+x)$ [Figure 3.6]. Consequently, firm B's expected quality increase: $E\left[\Delta Q_{b}\right]=[\Delta Q(E[\mu]-x)+$ $\Delta \mathrm{Q}(\mathrm{E}[\mu]+\mathrm{x})] / 2$ is larger than firm A's. Type $\mathrm{B}$ firms thus invest more, on average. than their counterparts. ${ }^{(27)}$

What does this imply for gross and net profits? When the type B firm invests slightly more, on average, than its counterparts, the former's gross profits are higher

(27) Let us come back to the element of non-rationality referred to in the previous footnote. The rational incumbent, in particular, is likely to take account of the impact of the information asymmetry and to invest accordingly. This may be so, but even then the rational incumbent is likely to invest less. Because of the stability requirements the incumbent reacts to the entrant's overinvestment with a less than proportional overinvestment. The difference in investment behaviour may also be interpreted in terms of differences towards risk-taking. Risk-averse firms gather more information and estimate more accurately than their risk-loving counterparts do. Risk-loving firms are either more lucky or pour more money down the drain. 
than in the perfect-information Cournot-Nash equilibrium, while the latter's gross profits are lower [equations (8a) and (8b)]. Net profits of both firms decrease. Because both firms are likely to overinvest relative to the perfect-information Cournot-Nash equilibrium, net profits are likely to decrease. Firm B's net profits remain about constant due to the first order-condition, at least as long as the (relative) overinvestment is not too large. Firm A's profits decrease somewhat more because firm B's relative overinvestment is detrimental to firm A's gross profits $\left[\partial \Pi_{\mathrm{a}} / \partial \mathrm{Q}_{\mathrm{b}}<0\right]$. So, we expect firm $\mathrm{B}$ - the entrant - to make larger net profits, on average, when its relative overinvestment is not too large. Overinvestments are not likely to be large when the entrant has about the same information as the incumbent or when uncertainty is small. In order to see whether overinvestments are more detrimental to the incumbent or the entrant some simulations are performed.

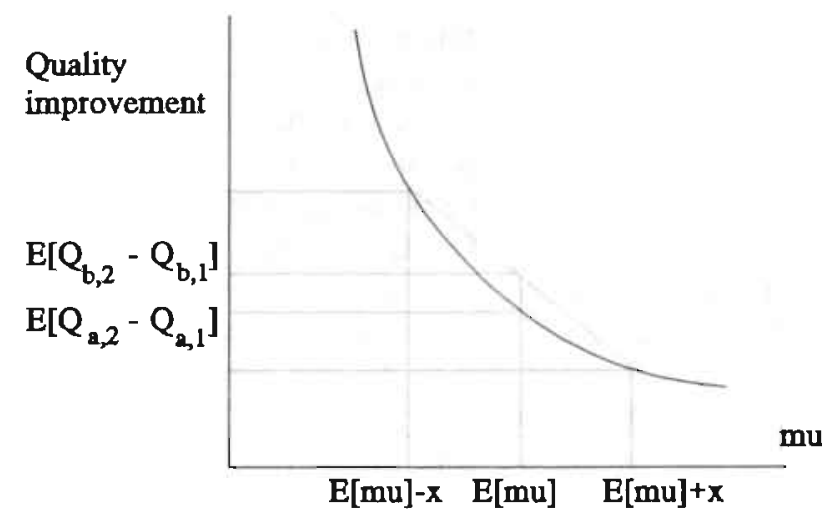

Firm 3.6: Quality improvements and estimation heterogeneity

In order to perform simulations we used the expectation mechanisms introduced in Chapter $2 .^{(28)}$ We argued above that firms with less information - with high variance estimators - invest more, on average, and earn more gross and net profits. However, when the investments made become very large, firms with less information may earn lower net profits. This implies that we expect BL 1 to perform better relative to all other expectation mechanisms, BL 2 to be better than all other mechanisms but BL 1, and BL 3 and AE to outperform RATEX. We performed 5000 replications per couple of expectation mechanisms. The parameters employed are given by Table 3.9. The distribution of the random variable is based on a normal distribution with a mean $\rho_{\mu}$ equal to 1 and a variance $\sigma_{\mu}{ }^{2}$ equal to 0.05 . However, the

(3) The expectation mechanism refers to estimating the random variable. In this chapter rationality refers to information on the distribution of $\mu$ only: A rational firm knows the distribution of the random variable. All firms know the model in section 3 . They only do not know each other's information, and suppose that rival investment is equal to their own investment. 
distribution is truncated (symmetrically) in order to exclude negative drawings and in order to take account of the fact that the random variable enters the denominator of the R\&D rule [equation (9a)]. ${ }^{(29)}$ Firm performance is given by Table 3.10 .

Table 3.9

Parameter values

$$
\begin{array}{ll}
\mathrm{Q}_{\mathrm{I}}=2 & \rho_{\mu}=1 \\
\mathrm{mc}_{1}=1 & \sigma_{\mu}{ }^{2}=0.05 \\
\mathrm{t}=0.25 &
\end{array}
$$

The table shows that firms with less information on $R \& D$ costs invest more in $R \& D$ than firms with more information. Gross profits consequently are higher for firms with less information. Net profits are slightly higher as well. Our hypotheses thus are confirmed by the data. In order to test our hypotheses more rigorously, we

investigated the robustness of the results for several values of the variance of the normal distribution from which values of the random variable are drawn. For each value of the variance 5000 replications were performed. The test refers to competition between a firm with expectation mechanism BL 3 and one with expectation mechanism RATEX. The results are given by Figures 3.7 to 3.9.

The figures show that the firm with expectation mechanism BL 3 invests more, on average, when the variance of the distribution increases, as may be expected. As a consequence of this its gross profits increase while gross profits of the rival firm go down. Net profits of both firms decrease. The firm with rational expectations suffers a loss in gross (and net) profits because its rival overinvests in product quality. Net profits of the firm with BL 3 go down despite the increase in gross profits because its R\&D expenses go up. This result is due to the fact that overinvestment does not constitute a Coumot-Nash equilibrium in terms of product R\&D. The 'true' CournotNash equilibrium would be given by the investment decisions of two firms employing rational expectations. But more important, Figure 3.9 shows that BL 3 obtains larger net profits, on average, than RATEX. Only in 13 out of 100 instances RATEX performed better (when we neglect the case with a variance equal to zero). Those instances refer to a relatively high variance of the distribution drawn from. The variance rises from 0 to 2 with increases equal to 0.02 . The lowest variance at which RATEX obtained larger net profits, on average, is 1.16 . Figures 3.10 to 3.12 give R\&D outlays, gross and net profits for BL 1 and RATEX. A comparison with Figures 3.7 to 3.9 suggests that a firm with less information only performs better when his estimator is just a little bit less precise. This is not surprising because (relative) overinvestments remain small when the estimator is only a little bit less precise. We may conclude that it pays to be somewhat irrational when uncertainty is not too large. The results suggest that there is an optimal degree of rationality unequal to perfect rationality (in the sense defined above) [Van Witteloostuijn (1996)]. This result contrasts with the results of Chapter 2 where 'rationality' definitely paid.

(29) Values smaller than 0.1 and larger than $1.9\left(2 p_{\mu}-0.1\right)$ are rejected. The simulation program draws as long as is necessary to obtain a value between 0.1 and 1.9 . The variance of the distribution is adjusted accordingly. 


\begin{tabular}{||l|l|l|l||}
\hline \multicolumn{2}{|l|}{$\begin{array}{l}\text { Table } 3.10 \\
\text { Firm performance }\end{array}$} \\
\hline Expectations & R\&D outlays & Gross Profits & Net profits \\
\hline AE I & .0343 & .1281 & .0938 \\
AE II & .0303 & .1235 & .0932 \\
\hline AE I & .0340 & .1282 & .0942 \\
AE III & .0293 & .1232 & .0939 \\
\hline AE I & .0338 & .1283 & .0956 \\
AE IV & .0292 & .1230 & .0952 \\
\hline AE I & .0342 & .1291 & .0949 \\
RATEX & .0278 & .1221 & .0942 \\
\hline AE II & .0301 & .1258 & .0938 \\
AE III & .0295 & .1235 & .0932 \\
\hline AE II & .0304 & .1283 & .0946 \\
AE IV & .0292 & .1230 & .0938 \\
\hline AE II & .0302 & .1266 & .0964 \\
RATEX & .0276 & .1238 & .0962 \\
\hline AE III & .0293 & .1250 & .0956 \\
AE IV & .0296 & .1255 & .0959 \\
\hline AE III & .0291 & .1260 & .0969 \\
RATEX & .0279 & .1242 & .0963 \\
\hline AE IV & .0293 & .1261 & .0968 \\
RATEX & .0279 & .1241 & .0962 \\
\hline \hline
\end{tabular}

The simulations confirm the hypotheses given above. (1) Firms with less information overinvest, on average, and consequently earn larger gross profits. (2) Firms with less information (entrants) earn larger net profits when their information is only a little bit inferior to that of the firm with more information or when uncertainty is small. Entrants are more likely to displace incumbents - creative destruction is more likely - when they have a small information lag and when uncertainty is small. This, again, suggests the potency of related entry since firms from related industries are likely candidates for 'small laggard' positions. This result also suggests that lagging firms are likely to leapfrog firms ahead in the end. Lagging firms tend to invest less in $R \& D$ because they face a strategic disadvantage [Section 8]. However, because they gather less information on the R\&D process as a consequence, they may become more 'optimistic' than their rivals and invest more in $R \& D$ in the end. On the other hand, the variability in net profits of firms with little information is higher as well. This makes creative destruction less likely. 

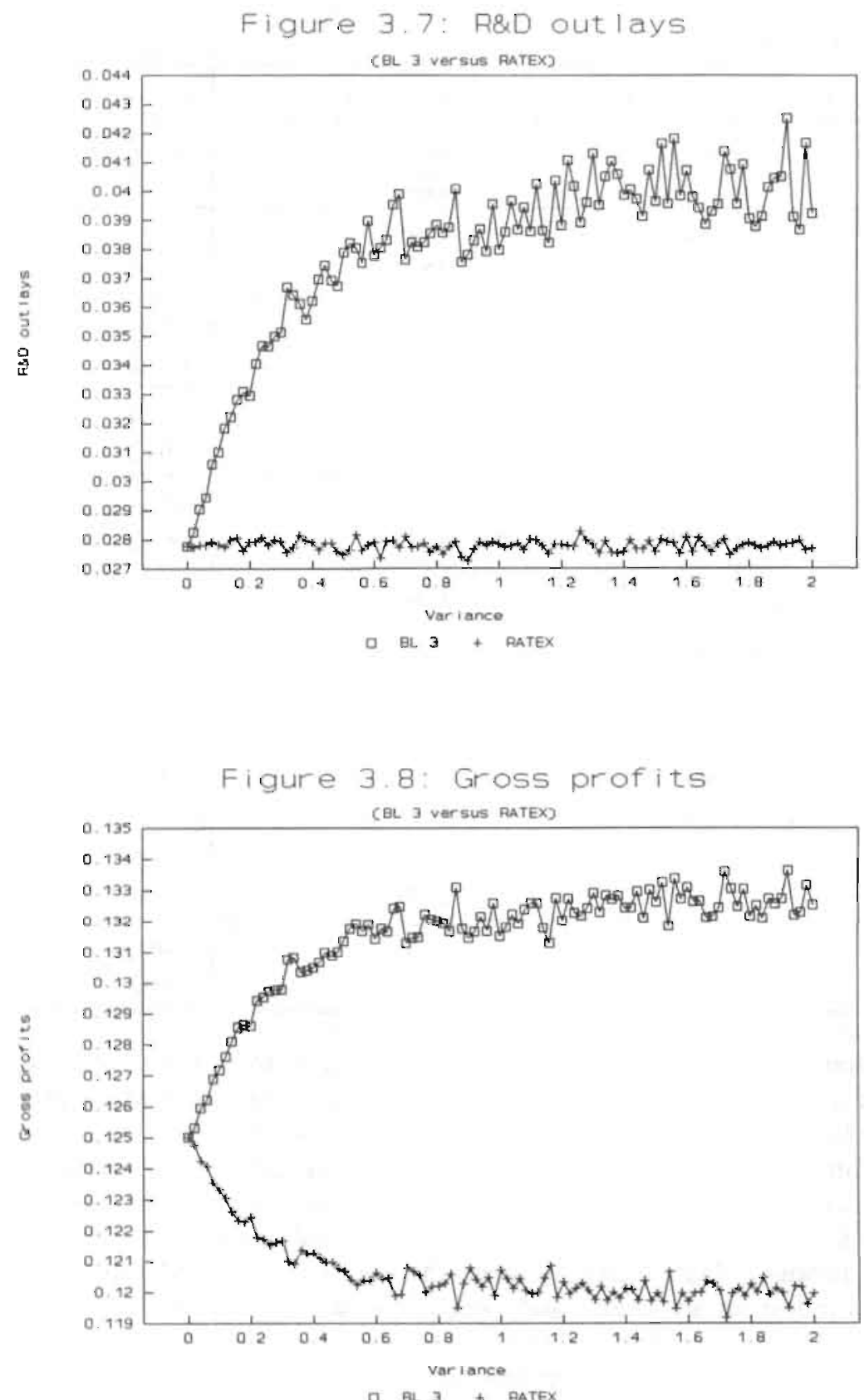

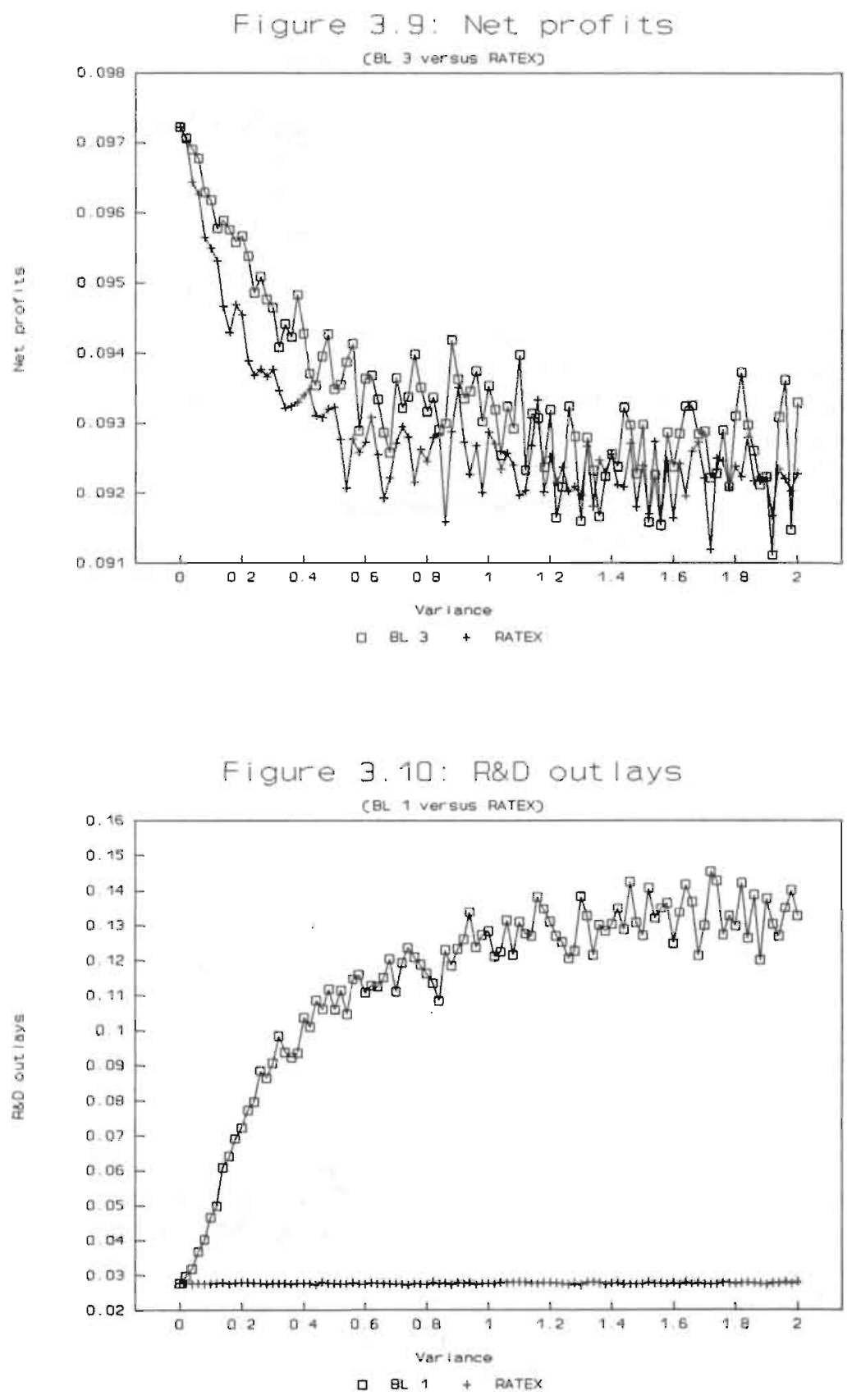
Figure 3.11: Gross prof its

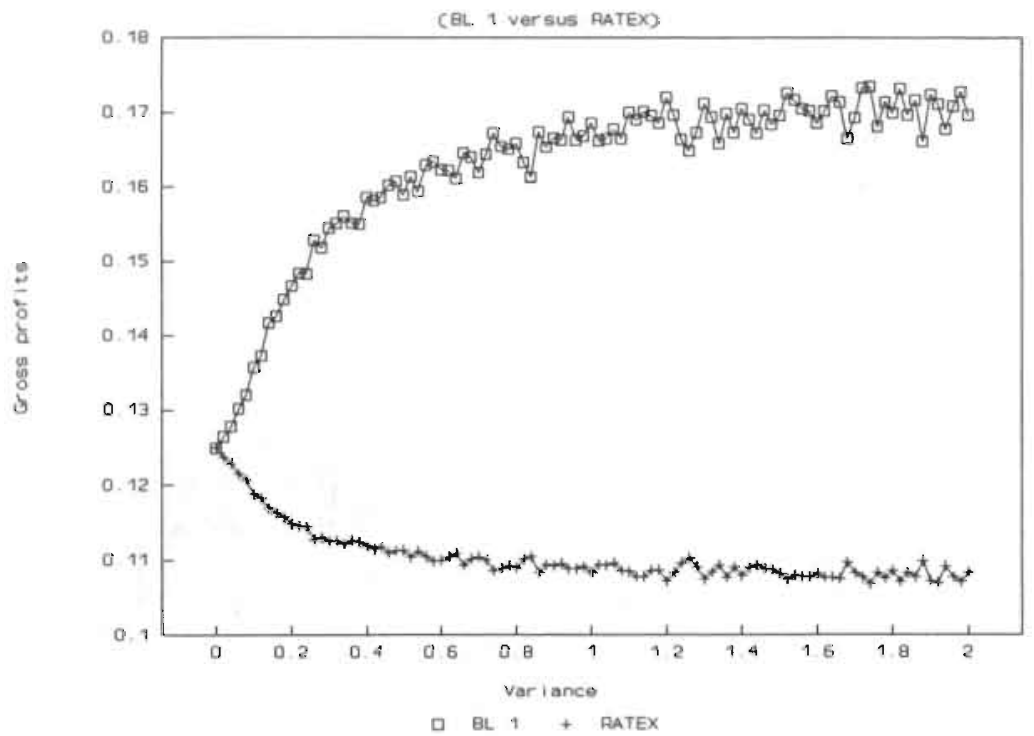

Figure 3.12: Net profits

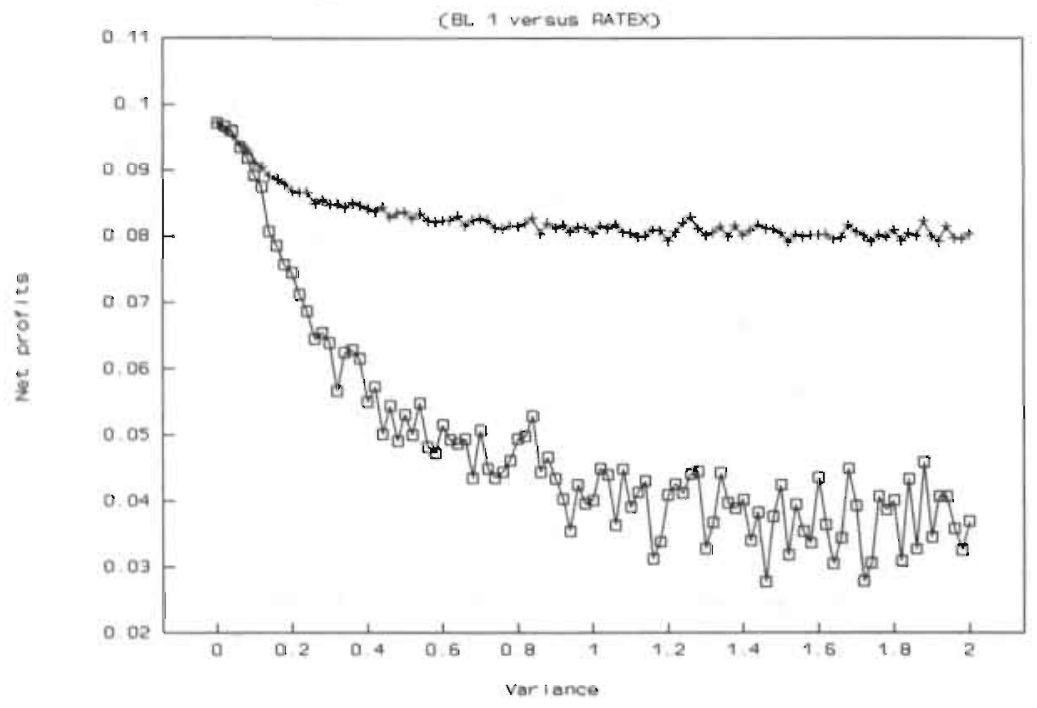

드 $\boldsymbol{\imath}+$ BATEX 
The chapter analyses decisions on quality and variety in Hotelling's original horizontal differentiation model. Two scenario's are discussed within this framework. In the first scenario the firms acknowledge their mutual interdependence and tacitly agree to respect each other's market segments. When they do so, prices are relatively high. Given the peace on the price front firms try to raise market share and profits by investing in product R\&D and by choosing a location in the centre of the market. The latter result corresponds with Hotelling's minimum differentiation result and thus contradicts Economides' (1989) maximum differentiation result. Economides employs the same model as we do, but forgets to take the stability condition with respect to the $R \& D$ decision into account. The maximum differentiation result was obtained by most papers elaborating on the contribution of D'Aspremont, Gabszewicz and Thisse (1979). However, recently Neven and Thisse (1989) and Irmen and Thisse (1995) stress that when more than one characteristic is studied, minimum differentiation may be obtained for all but one characteristic. Maximum differentiation on the most important characteristic suffices to soften price competition sufficiently. This explains why Hotelling seems to be almost right after all.

In the second scenario the firms try to capture each other's market segments: Hitand-run entry is an important phenomenon. In order to forestall total entry into one's market segment prices are set such that they are undercut proof. ${ }^{(30)}$ This solution to the price instability problem is related to the literature on limit pricing and contestability, but is new in the current context. Because price competition increases when firms are located close together, firms locate such that they are no longer vulnerable to hit-and-run entry. As a result there is neither minimum nor maximum differentiation in the limit pricing scenario. The locations the duopolists choose are even optimal from a social point of view.

In both scenario's the firms invest in product $R \& D$ in order to gain market share. However, in equilibrium market shares and equilibrium prices are not effected by the investments in product R\&D. All surplus is passed through to the consumers. R\&D efforts are detrimental to net profits only. Competition turns out to be efficient in this respect. Because the firms are not able to appropriate any surplus arising from product innovations, they underinvest in product $R \& D$. However, the resulting loss in social welfare seems negligible. The duopolists may not obtain any part of the surplus created by the product innovations, but they do make positive profits. However, gross and net profits decrease, when the desire for variety diminishes and products become more homogeneous from the consumers' perspective. The scenarios thus obtain barrier market-like results in that price approaches average and marginal costs when the desire for variety diminishes and that the surplus from product innovations accrues to consumers only. Note, however, that product differentiation is not optimal in the Hotelling scenario and that firms underinvest in product $R \& D$ in

(30) This term is used by Poddar (1995). Poddar uses the concept in a different context. The meaning consequently is somewhat different. 
both scenarios.

The Hotelling scenario is extended in three ways in order to incorporate elements of policy, asymmetry, and uncertainty and firm performance. Interfirm spillovers and (RJV) policies directed to increasing the spillover rate reduce the degree of appropriability and thereby the incentive to innovate. Spillovers reduce the private return to investment in $\mathrm{R} \& \mathrm{D}$, since quality increases do not lead to market expansion. Since all consumers buy one product in equilibrium, market demand is given. The duopolists are only able to overcome the tendency to underinvest when they are allowed to cooperate in prices. As a result, the government faces the classic dilemma between static and dynamic efficiency: A high innovation rate may be obtained at the cost of high prices, and vice versa. In the above model, consumers definitely are better off with low prices (and a low innovation rate). This result indicates why the European Commission should only grant exemptions for cooperative R\&D agreements, such as research joint ventures, on basis of article 85(3) of the Rome Treaty, if consumers are expected to benefit from the innovations through price competition. The only policies which may increase $R \& D$ efforts, are government subsidies or favourable tax regimes, because they reduce R\&D costs effectively.

An asymmetry in initial quality gives the leading firm a strategic advantage ensuring it a larger market share than the lagging firm, ceteris paribus. This fact reduces the leading firm's $R \& D$ costs (relative to its demand). This explains why the leading firm invests more in R\&D than the lagging firm. As a consequence of this, the asymmetry widens through time: There is a natural tendency towards monopolization. This result accords with the first-mover advantage found in the literature on entry deterrence and R\&D [Tirole (1988), Beath et al. (1989), Gilbert (1989) and Reinganum (1989)] and corresponds with the results of Chapter 2. In an asymmetric duopoly quality rises faster than in a symmetric duopoly while price competition remains fierce. As a consequence, consumer surplus and industry profits grow when the asymmetry becomes larger. Dominant positions thus favour consumer well-being, as long as fringe firms are able to exert competitive pressure on prices. Fringe firms are able to do so, when there are market niches to be exploited by differentiating one's variety from the dominant firm's variety.

The incentive to invest less than the high-quality firm may be compensated by a difference in available information on the R\&D process. Section 9 shows that new (or lagging) firms are likely to earn larger net profits, on average. This result is due to the fact that entrants (or laggards) overinvest, on average, because of their lack of knowledge on the R\&D process. As a result, they earn larger gross profits than the incumbents. But more important, the overinvestments reduce the incumbents' net profits more than the entrants'. The entrants' net profits are constant due to the firstorder condition, at least when the overinvestments are small enough, while the incumbents' net profits strictly decrease with the entrants' overinvestments. The overinvestments are relatively small when the incumbents have a small information advantage or uncertainty is small. Because of the higher profitability entrants survive the competition process more often. This result illustrates the potency of related entry since firms from related industries are probable candidates for 'small laggard' positions. This also makes leapfrogging probable since lagging firms have less 
information on the $R \& D$ process than leading firms which performed more $R \& D$ in the past. Both interpretations accord with the idea behind creative destruction.

In the introduction we argued that there are two ways out of the Bertrand paradox: (1) product differentiation and (2) capacity restrictions. This chapter shows that the Bertrand paradox is resolved when products are differentiated. Bertrand competition and investment in R\&D may be reconciled when product's are differentiated, even when average total costs are decreasing. Compare this result with those in the previous chapter. The results generated are competitive as before. The duopolists invest in product $R \& D$ and again pass all surplus created through to the consumers. The next chapter will discuss a model with capacity restrictions. 


\section{Appendices to Chapter 3}

\section{A Consumer demand}

For the marginal consumer the following equality holds [Figure 3.2]

$Q_{a}-P_{a}-u\left|s_{d}-z\right|=Q_{b}-P_{b}-u\left|s_{b}-z\right|$

or rather

$Q_{a}-P_{a}-u\left(z-s_{a}\right)=Q_{b}-P_{b}-u\left(s_{b}-z\right)$

By substitution we have

$$
\begin{aligned}
& 2 u z=Q_{a}-Q_{b}-P_{a}+P_{b}+u\left(s_{a}+s_{b}\right) \Leftrightarrow \\
& z=X_{a}=\frac{1}{2 u}\left(Q_{a}-Q_{b}-P_{a}+P_{b}+u\left(s_{a}+s_{b}\right)\right) .
\end{aligned}
$$

$\mathrm{X}_{\mathrm{b}}$ equals (1-z) [Figure 3.2]. By substitution one may derive

$$
(1-z)=X_{b}=\frac{1}{2 u}\left(Q_{b}-Q_{a}-P_{b}+P_{a}-u\left(s_{a}+s_{b}\right)+2 u\right) .
$$

\section{B Prices in the Hotelling scenario}

The firms determine their respective prices by maximising gross profits. Gross profits are given by the product of the price-cost margin and firm demand

$$
\begin{aligned}
& \pi_{\mathrm{a}}=\mathrm{X}_{\mathrm{a}}\left(\mathrm{P}_{\mathrm{a}}-\mathrm{mc}\right) \text { and } \\
& \pi_{\mathrm{b}}=\mathrm{X}_{\mathrm{b}}\left(\mathrm{P}_{\mathrm{b}}-\mathrm{mc}\right) .
\end{aligned}
$$

Substituting for demand $X_{a}$ and $X_{b}$ gives [equation (3a) and (3b)]

$$
\begin{aligned}
& \pi_{\mathrm{a}}=\frac{1}{2 \mathrm{u}}\left[\mathrm{Q}_{\mathrm{a}}-\mathrm{Q}_{\mathrm{b}}-\mathrm{P}_{\mathrm{a}}+\mathrm{P}_{\mathrm{b}}+\mathrm{u}\left(\mathrm{s}_{\mathrm{a}}+\mathrm{s}_{\mathrm{b}}\right)\right]\left[\mathrm{P}_{\mathrm{a}}-\mathrm{mc}\right] \text { and } \\
& \pi_{\mathrm{a}}=\frac{1}{2 \mathrm{u}}\left[\mathrm{Q}_{\mathrm{b}}-\mathrm{Q}_{\mathrm{a}}-\mathrm{P}_{\mathrm{b}}+\mathrm{P}_{\mathrm{a}}-\mathrm{u}\left(\mathrm{s}_{\mathrm{a}}+\mathrm{s}_{\mathrm{b}}\right)+2 \mathrm{u}\right]\left[\mathrm{P}_{\mathrm{b}}-\mathrm{mc}\right]
\end{aligned}
$$

Maximising gross profits with respect to $\mathrm{P}_{\mathrm{a}}$ and $\mathrm{P}_{\mathrm{b}}$ gives the following first order conditions 
$\frac{d \pi_{a}}{d P_{a}}=\frac{1}{2 u}\left(Q_{a}-Q_{b}+P_{b}+u\left(s_{a}+s_{b}\right)+m c-2 P_{a}\right)=0$ and
$\frac{d \pi_{b}}{d P_{b}}=\frac{1}{2 u}\left(Q_{b}-Q_{a}+P_{a}-u\left(s_{a}+s_{b}\right)+2 u+m c-2 P_{b}\right)=0$.

Solving for $P_{a}$ from (3A.4) gives

$P_{a}=\frac{1}{2}\left(Q_{a}-Q_{b}+P_{b}+u\left(s_{a}+s_{b}\right)+m c\right)$.

Substituting for $\mathrm{P}_{\mathrm{a}}$ in equation (3A.5) gives

$$
\begin{aligned}
& \frac{1}{2}\left(Q_{b}-Q_{a}-u\left(s_{a}+s_{b}\right)+4 u+3 m c-3 P_{b}\right)=0 \Leftrightarrow \\
& P_{b}=m c+\frac{1}{3}\left[\left(Q_{b}-Q_{a}\right)-u\left(s_{a}+s_{b}\right)+4 u\right] .
\end{aligned}
$$

Substituting equation (6b) into equation (3A.6) gives

$$
\begin{aligned}
& P_{a}=\frac{1}{2}\left[\frac{2}{3}\left(Q_{a}-Q_{b}+u\left(s_{a}+s_{b}\right)\right)+\frac{4}{3} u+2 m c\right] \Leftrightarrow \\
& P_{a}=m c+\frac{1}{3}\left[\left(Q_{a}-Q_{b}\right)+u\left(s_{a}+s_{b}\right)+2 u\right] .
\end{aligned}
$$

\section{Reduced form profits}

$P_{a}$ and $P_{b}$ may be substituted into equation (3a) and (3b) in order to derive demand as a function of quality and variety. Substituting $P_{a}$ and $P_{b}$ into equation (3a) gives

$X_{d}=(1 / 2 u)\left[Q_{a}-Q_{b}-P_{a}+P_{b}+u\left(s_{a}+s_{b}\right)\right] \Leftrightarrow$

$X_{a}=(1 / 2 u)\left[Q_{a}-Q_{b}-\left[\underline{m c}+(1 / 3)\left(Q_{a}-Q_{h}+u\left(s_{a}+s_{b}\right)+2 u\right)\right]+\left[\underline{m c}+(1 / 3)\left(Q_{b}-Q_{a}-u\left(s_{a}+s_{b}\right)+4 u\right)\right]\right.$ $\left.+\mathrm{u}\left(\mathrm{s}_{\mathrm{a}}+\mathrm{s}_{\mathrm{b}}\right)\right] \Leftrightarrow$

$\mathrm{X}_{\mathrm{a}}=(1 / 2 \mathrm{u})\left[(1 / 3)\left(\mathrm{Q}_{\mathrm{a}}-\mathrm{Q}_{\mathrm{b}}+\mathrm{u}\left(\mathrm{s}_{\mathrm{a}}+\mathrm{s}_{\mathrm{b}}\right)+2 \mathrm{u}\right)\right]\left(=(1 / 2 \mathrm{u})\left[\mathrm{P}_{\mathrm{a}}-\mathrm{mc}\right]\right)$.

Substituting for $\mathrm{P}_{\mathrm{a}}$ and $\mathrm{P}_{\mathrm{b}}$ in equation (3b) gives

$X_{b}=(1 / 2 u)\left[Q_{b}-Q_{a}-P_{b}+P_{a}-u\left(s_{a}+s_{b}\right)+2 u\right] \Leftrightarrow$

$X_{b}=(1 / 2 u)\left[Q_{b}-Q_{a}-\left[m c+(1 / 3)\left(Q_{b}-Q_{a}-u\left(s_{a}+s_{b}\right)+4 u\right)\right]+\left[m c+(1 / 3)\left(Q_{a}-Q_{b}+u\left(s_{a}+s_{b}\right)+2 u\right)\right]\right.$ $\left.-\mathrm{u}\left(\mathrm{s}_{\mathrm{a}}+\mathrm{s}_{\mathrm{b}}\right)+2 \mathrm{u}\right] \Leftrightarrow$ 
$\mathrm{X}_{\mathrm{b}}=(1 / 2 \mathrm{u})\left[(1 / 3)\left(\mathrm{Q}_{\mathrm{b}}-\mathrm{Q}_{\mathrm{a}}-\mathrm{u}\left(\mathrm{s}_{\mathrm{a}}+\mathrm{s}_{\mathrm{b}}\right)+4 \mathrm{u}\right)\right]\left(=(1 / 2 \mathrm{u})\left[\mathrm{P}_{\mathrm{b}}-\mathrm{mc}\right]\right)$.

By definition $\mathrm{Q}_{\mathrm{a}, 2}=\mathrm{Q}_{\mathrm{a}, 1}+\Delta \mathrm{Q}_{\mathrm{a}, 1}$ and $\mathrm{Q}_{\mathrm{b}, 2}=\mathrm{Q}_{\mathrm{b}, 1}+\Delta \mathrm{Q}_{\mathrm{b}, 1}$. In section 3 and 4 we assume symmetry between the two firms: $\mathrm{Q}_{\mathrm{a}, 1}=\mathrm{Q}_{\mathrm{b}, \mathrm{l}}$. Therefore $\mathrm{Q}_{\mathrm{a}, 2}-\mathrm{Q}_{\mathrm{b}, 2}=\Delta \mathrm{Q}_{\mathrm{a}, 1}-\Delta \mathrm{Q}_{\mathrm{b}, 1}$.

\section{Product R\&D in the Hotelling scenario}

The firms decide on the quality rises to be pursued by maximising profits net of R\&D outlays. The firms' optimisation problems look as follows

$\operatorname{Max} \Pi_{\mathrm{a}}=\mathrm{X}_{\mathrm{a}, 2}\left(\mathrm{P}_{\mathrm{a}, 2}-\mathrm{mc}\right)-\mathrm{SC}_{\mathrm{a}, 1}$ and

$\operatorname{Max} \Pi_{b}=\mathrm{X}_{\mathrm{b}, 2}\left(\mathrm{P}_{\mathrm{b}, 2}-\mathrm{mc}\right)-\mathrm{SC}_{\mathrm{b}, 1}$.

Substituting for $P, X$ and SC using equations (6a), (6b), (3A.7), (3A.8) and (4b) respectively and employing the symmetry assumption: $Q_{a, 2} Q_{b, 2}=\Delta Q_{a, 1}-\Delta Q_{b, 1}$ gives

$\operatorname{Max} \Pi_{\mathrm{a}}=\frac{1}{18 \mathrm{u}}\left[\left(\Delta \mathrm{Q}_{\mathrm{a}, 1}-\Delta \mathrm{Q}_{\mathrm{b}, 1}\right)+\mathrm{u}\left(\mathrm{s}_{\mathrm{a}}+\mathrm{s}_{\mathrm{b}}\right)+2 \mathrm{u}\right]^{2}-\mu\left(\Delta \mathrm{Q}_{\mathrm{a}, \mathrm{l}}\right)^{2}$ and

$\operatorname{Max} \Pi_{b}=\frac{1}{18 u}\left[\left(\Delta Q_{b, 1}-\Delta Q_{a, 1}\right)-u\left(s_{a}+s_{b}\right)+4 u\right]^{2}-\mu\left(\Delta Q_{b, 1}\right)^{2}$.

Maximising (8a) and (8b) with respect to $\Delta Q_{a}$ and $\Delta Q_{b}$ respectively gives the following first order conditions

$$
\begin{aligned}
& \frac{d \Pi_{\mathrm{a}}}{\mathrm{d}\left(\Delta \mathrm{Q}_{\mathrm{a}}\right)}=\frac{2}{18 \mathrm{u}}\left[\Delta \mathrm{Q}_{\mathrm{a}}-\Delta \mathrm{Q}_{\mathrm{b}}+\mathrm{u}\left(\mathrm{s}_{\mathrm{a}}+\mathrm{s}_{\mathrm{b}}\right)+2 \mathrm{u}\right]-2 \mu \Delta \mathrm{Q}_{\mathrm{a}}=0 \text { and } \\
& \frac{\mathrm{d} \Pi_{\mathrm{b}}}{\mathrm{d}\left(\Delta \mathrm{Q}_{\mathrm{b}}\right)}=\frac{2}{18 \mathrm{u}}\left[\Delta \mathrm{Q}_{\mathrm{b}}-\Delta \mathrm{Q}_{\mathrm{a}}-\mathrm{u}\left(\mathrm{s}_{\mathrm{a}}+\mathrm{s}_{\mathrm{b}}\right)+4 \mathrm{u}\right]-2 \mu \Delta \mathrm{Q}_{\mathrm{b}}=0 .
\end{aligned}
$$

Solving for $\Delta Q_{b}$ using equation (3A.9) gives

$$
\Delta \mathrm{Q}_{\mathrm{b}}=\Delta \mathrm{Q}_{\mathrm{a}}+\mathrm{u}\left(\mathrm{s}_{\mathrm{a}}+\mathrm{s}_{\mathrm{b}}\right)+2 \mathrm{u}-18 \mu \mathrm{u} \Delta \mathrm{Q}_{\mathrm{a}}
$$

Solving for $\Delta Q_{b}$ in equation (3A.10) gives

$$
\Delta \mathrm{Q}_{\mathrm{b}}-\Delta \mathrm{Q}_{\mathrm{a}}-\mathrm{u}\left(\mathrm{s}_{\mathrm{a}}+\mathrm{s}_{\mathrm{b}}\right)+4 \mathrm{u}-18 \mu \mathrm{u} \Delta \mathrm{Q}_{\mathrm{b}}=0 \Leftrightarrow
$$

$\left[\Delta \mathrm{Q}_{\mathrm{a}}+\mathrm{u}\left(\mathrm{s}_{\mathrm{a}}+\mathrm{s}_{\mathrm{b}}\right)+2 \mathrm{u}-18 \mu \mathrm{u} \Delta \mathrm{Q}_{\mathrm{a}}\right]-\Delta \mathrm{Q}_{\mathrm{a}}-\mathrm{u}\left(\mathrm{s}_{\mathrm{a}}+\mathrm{s}_{\mathrm{b}}\right)+4 \mathrm{u}-18 \mu \mathrm{u}\left[\Delta \mathrm{Q}_{\mathrm{a}}+\mathrm{u}\left(\mathrm{s}_{\mathrm{a}}+\mathrm{s}_{\mathrm{b}}\right)+2 \mathrm{u}-18 \mu \mathrm{u} \Delta \mathrm{Q}_{\mathrm{a}}\right]=0 \Leftrightarrow$ $18 \mu \mathrm{u}(18 \mu \mathrm{u}-2) \Delta \mathrm{Q}_{\mathrm{a}}=18 \mu \mathrm{u}\left[\mathrm{u}\left(\mathrm{s}_{\mathrm{a}}+\mathrm{s}_{\mathrm{h}}\right)+2 \mathrm{u}\right]-6 \mathrm{u} \Leftrightarrow$ 


$$
\Delta \mathrm{Q}_{\mathrm{a}}=\frac{18 \mu \mathrm{u}\left(2 \mathrm{u}+\mathrm{u}\left(\mathrm{s}_{\mathrm{a}}+\mathrm{s}_{\mathrm{b}}\right)\right)-6 \mathrm{u}}{18 \mu \mathrm{u}(18 \mu \mathrm{u}-2)} \text {. }
$$

Substituting equation (9a) into equation (3A.11) gives

$$
\Delta \mathrm{Q}_{\mathrm{b}}=\frac{18 \mu \mathrm{u}\left(4 \mathrm{u}-\mathrm{u}\left(\mathrm{s}_{\mathrm{a}}+\mathrm{s}_{\mathrm{b}}\right)\right)-6 \mathrm{u}}{18 \mu \mathrm{u}(18 \mu \mathrm{u}-2)}
$$

after tedious substitution. Note that when the firms are located symmetrically $\left[\left(\mathrm{s}_{\mathrm{a}}+\mathrm{s}_{\mathrm{b}}\right)\right.$ $=1],\left(2 \mathrm{u}+\mathrm{u}\left(\mathrm{s}_{\mathrm{a}}+\mathrm{s}_{\mathrm{b}}\right)\right)$ and $\left(4 \mathrm{u}-\mathrm{u}\left(\mathrm{s}_{\mathrm{a}}+\mathrm{s}_{\mathrm{b}}\right)\right)$ both reduce to $3 \mathrm{u}$ again, making $\Delta \mathrm{Q}_{\mathrm{a}}=\Delta \mathrm{Q}_{\mathrm{b}}$.

The second order and stability conditions

The profit functions reach maximums when $\partial^{2} \Pi_{i} / \partial\left(\Delta Q_{j}\right)^{2}<0$. It can be easily seen from equation (3A.9) and (3A.10) that $\partial^{2} \Pi_{j} / \partial\left(\Delta Q_{j}\right)^{2}=2 / 18 \mathrm{u}-2 \mu$. The second order condition thus requires $18 \mu \mathrm{u}>1$. Equation (3A.9) and (3A.10) can be rewritten to

$\Delta \mathrm{Q}_{\mathrm{a}}=\left[2 \mathrm{u}+\mathrm{u}\left(\mathrm{s}_{\mathrm{a}}+\mathrm{s}_{\mathrm{b}}\right)-\Delta \mathrm{Q}_{\mathrm{b}}\right] /(18 \mu \mathrm{u}-\mathrm{l})$ and

$\Delta \mathrm{Q}_{\mathrm{b}}=\left[4 \mathrm{u}-\mathrm{u}\left(\mathrm{s}_{\mathrm{a}}+\mathrm{s}_{\mathrm{b}}\right)-\Delta \mathrm{Q}_{\mathrm{a}}\right] /(18 \mu \mathrm{u}-1)$.

Stability requires $(18 \mu \mathrm{u}-1)>1$ or $18 \mu \mathrm{u}>2$.

\section{Reduced form profits}

The equilibrium solutions for $\Delta \mathrm{Q}_{\mathrm{a}}$ and $\Delta \mathrm{Q}_{\mathrm{b}}$ may be used to derive net profits as a function of variety only. Substituting equations (9a) and (9b) into equation (8a) gives

$$
\begin{aligned}
& \Pi_{a}=\frac{1}{18 u}\left[\left(\Delta Q_{a}-\Delta Q_{b}\right)+u\left(s_{a}+s_{b}\right)+2 u\right]^{2}-\mu\left(\Delta Q_{a}\right)^{2} \Leftrightarrow \\
& \Pi_{a}=\frac{1}{18 u}\left[\frac{18 \mu u\left(2 u\left(s_{a}+s_{b}\right)-2 u\right)}{18 \mu u(18 \mu u-2)}+u\left(s_{a}+s_{b}\right)+2 u\right]^{2}- \\
& \quad \mu\left[\frac{18 \mu u\left(2 u+u\left(s_{a}+s_{b}\right)\right)-6 u}{18 \mu u(18 \mu u-2)}\right]^{2} \Leftrightarrow \\
& \Pi_{a}=\frac{1}{18 u}\left[\frac{18 \mu u\left[18 \mu u\left(2 u+u\left(s_{a}+s_{b}\right)\right)-6 u\right]}{18 \mu u(18 \mu u-2)}\right]^{2}-\mu\left[\frac{18 \mu u\left(2 u+u\left(s_{u}+s_{b}\right)\right)-6 u}{18 \mu u(18 \mu u-2)}\right]^{2} \Leftrightarrow \\
& \Pi_{a}=\left[\frac{(18 \mu u)^{2}-18 \mu u}{18 u}\right]\left[\frac{18 \mu u\left(2 u+u\left(s_{a}+s_{b}\right)\right)-6 u}{18 \mu u(18 \mu u-2)}\right]^{2} \Leftrightarrow
\end{aligned}
$$




$$
\Pi_{\mathrm{a}}=\mu[18 \mu \mathrm{u}-\mathrm{l}]\left[\frac{18 \mu \mathrm{u}\left(2 \mathrm{u}+\mathrm{u}\left(\mathrm{s}_{\mathrm{a}}+\mathrm{s}_{\mathrm{b}}\right)\right)-6 \mathrm{u}}{18 \mu \mathrm{u}(18 \mu \mathrm{u}-2)}\right]^{2} .
$$

Firm B's profits may be reduced to a function of $s_{b}$ in a similar way. Note that when tirms are located symmetrically $\left[\left(\mathrm{s}_{\mathrm{a}}+\mathrm{s}_{\mathrm{b}}\right)=1\right]$, equation $(10 \mathrm{a})$ and $(10 \mathrm{~b})$ coincide since both $\left(2 \mathrm{u}+\mathrm{u}\left(\mathrm{s}_{\mathrm{a}}+\mathrm{s}_{\mathrm{b}}\right)\right)$ and $\left(4 \mathrm{u}-\mathrm{u}\left(\mathrm{s}_{\mathrm{a}}+\mathrm{s}_{\mathrm{b}}\right)\right)$ then reduce to $3 \mathrm{u}$.

\section{The R\&D game as a Prisoner's Dilemma}

The following inequalities must be shown to hold

$\Pi_{i}\left(\Delta Q_{i}^{*}, 0\right)>\Pi_{i}(0,0)>\Pi_{i}\left(\Delta Q_{i}^{*}, \Delta Q_{j}^{*}\right)>\Pi_{i}\left(0, \Delta Q_{j}{ }^{\prime}\right)>0$,

where $\{i, j\} \in\{a, b\}$ and $i \neq j$, and the superscript ${ }^{*}$ denotes the optimal investment level as given by equation (9a) and (9b). Recall that in a symmetric equilibrium $s_{a}=$ $\mathrm{s}_{\mathrm{b}}=0.5$ and $\Delta \mathrm{Q}_{\mathrm{a}}-\Delta \mathrm{Q}_{\mathrm{b}}=1 / 6 \mu$. The first inequality holds when

$$
\begin{aligned}
& (1 / 18 u)(1 / 6 \mu+3 u)^{2}-\mu(1 / 6 \mu)^{2}>(1 / 18 u)(3 u)^{2} \Leftrightarrow \\
& (1 / 18 u)\left(1 / 36 \mu^{2}+u / \mu\right)-1 / 36 \mu>0 \Leftrightarrow \\
& 1 / 36 \mu^{2}+u / 2 \mu>0 .
\end{aligned}
$$

Since $u$ and $\mu$ are larger than zero, this inequality holds. The second inequality holds when

$(1 / 18 u)(3 u)^{2}>(1 / 18 u)(3 u)^{2}-\mu(1 / 6 \mu)^{2}$.

This inequality holds because $\mu>0$. The third inequality holds when

$$
\begin{aligned}
& (1 / 18 u)(3 u)^{2}-\mu(1 / 6 \mu)^{2}>(1 / 18 u)(3 u-1 / 6 \mu)^{2} \Leftrightarrow \\
& 9 u^{2}-u / 2 \mu>9 u^{2}-u / \mu+1 / 36 \mu^{2} \Leftrightarrow \\
& u / 2 \mu>1 / 36 \mu^{2} \Leftrightarrow \\
& 18 \mu u>1 .
\end{aligned}
$$

The latter inequality holds when $18 \mu \mathrm{u}>1$, id est when the second order condition holds. So in all relevant cases, the third inequality holds as well. This leaves the last inequality. $\Pi_{i}\left(0, \Delta \mathrm{Q}_{j}\right)>0$ when $(1 / 18 \mathrm{u})(3 \mathrm{u}-1 / 6 \mu)^{2}>0$ or $18 \mu \mathrm{u}>1$. The same argument applies as for the third inequality which proves the entire set of inequalities.

\section{E Product R\&D in the limit price scenario}

The firms determine product $R \& D$ by maximizing net profits with respect to product 
R\&D. Net profits are given by equation (7a) and (7b)

$\operatorname{Max} \Pi_{\mathrm{a}}=\mathrm{X}_{\mathrm{a}, 2}\left(\mathrm{P}_{\mathrm{a}, 2}-\mathrm{mc}\right)-\mathrm{SC}_{\mathrm{a}, 1}$ and

$\operatorname{Max} \Pi_{b}=X_{b, 2}\left(P_{b, 2}-m c\right)-S_{b, 1}$.

When the firms decide on product $R \& D$ they know what prices they will set. Prices as a function of quality and variety are given by equation (6a') and (6b')

$P_{a, 2}=m c+\left(Q_{a, 2}-Q_{b, 2}\right)+u\left(s_{b}-s_{a}\right)$ and

$P_{b, 2}=m c+\left(Q_{b, 2}-Q_{a, 2}\right)+u\left(s_{b}-s_{a}\right)$.

We may now substitute these prices into the demand equations given by equation (3a) and (3b)

$$
\begin{aligned}
X_{a, 2}= & \frac{1}{2 u}\left[Q_{a, 2}-Q_{b, 2}-P_{a, 2}+P_{b, 2}+u\left(s_{a}+s_{b}\right)\right]=\frac{1}{2 u}\left[Q_{b, 2}-Q_{a, 2}+u\left(s_{a}+s_{b}\right)\right] \text { and } \\
X_{b, 2}= & \frac{1}{2 u}\left[Q_{b, 2}-Q_{a, 2}-P_{b, 2}+P_{a, 2}-u\left(s_{a}+s_{b}\right)+2 u\right]= \\
& \frac{1}{2 u}\left[Q_{a, 2}-\Delta Q_{b, 2}-u\left(s_{a}+s_{b}\right)+2 u\right] .
\end{aligned}
$$

Note that the price solution given by equations (6a') and (6b') has the peculiar consequence that demand decreases when one's quality rises, and increases with the quality of the rival firm. This characteristic has consequences for the nature of R\&D competition. The price and demand equations can be used to derive net profits as a function of quality and variety. Substituting equation (6a'), (6b'), (3A.14) and $(3 \mathrm{~A} .15)$ and (4b) into equation (7a) and (7b) and using the symmetry assumption: $\mathrm{Q}_{\mathrm{a}, 2}-\mathrm{Q}_{\mathrm{b}, 2}=\Delta \mathrm{Q}_{\mathrm{a}, 1}-\Delta \mathrm{Q}_{\mathrm{b}, 1}$ gives

$\operatorname{Max} \Pi_{\mathrm{a}}=\frac{1}{2 \mathrm{u}}\left[\Delta \mathrm{Q}_{\mathrm{a}, 1}-\Delta \mathrm{Q}_{\mathrm{b}, 1}+\mathrm{u}\left(\mathrm{s}_{\mathrm{b}}-\mathrm{s}_{\mathrm{a}}\right)\right]\left[\Delta \mathrm{Q}_{\mathrm{b}, 1}-\Delta \mathrm{Q}_{\mathrm{a}, 1}+\mathrm{u}\left(\mathrm{s}_{\mathrm{a}}+\mathrm{s}_{\mathrm{b}}\right)\right]-\mu\left(\Delta \mathrm{Q}_{\mathrm{a}, \mathrm{l}}\right)^{2}$ and

$\operatorname{Max} \Pi_{b}=\frac{1}{2 u}\left[\Delta Q_{b, 1}-\Delta Q_{a, 1}+u\left(s_{b}-s_{a}\right)\right]\left[\Delta Q_{a, 1}-\Delta Q_{b, 1}-u\left(s_{a}+s_{b}\right)+2 u\right]-\mu\left(\Delta Q_{b, 1}\right)^{2}$.

Maximising the above equations with respect to $\Delta \mathrm{Q}_{\mathrm{a}}$ and $\Delta \mathrm{Q}_{\mathrm{b}}$ respectively gives the following first order conditions

$$
\begin{aligned}
& \frac{d \prod_{a}}{d\left(\Delta Q_{a}\right)}=\frac{1}{2 u}\left[2\left(\Delta Q_{b}-\Delta Q_{a}+u s_{a}\right)\right]-2 \mu \Delta Q_{a}=0 \text { and } \\
& \frac{d \Pi_{b}}{d\left(\Delta Q_{b}\right)}=\frac{1}{2 u}\left[2\left(\Delta Q_{a}-\Delta Q_{b}+u\left(1-s_{b}\right)\right)\right]-2 \mu \Delta Q_{b}=0
\end{aligned}
$$


Rewriting equation (3A.16) gives

$\Delta Q_{b}=(2 \mu u+1) \Delta Q_{a}-u s_{a}$.

We may now solve for $\Delta \mathrm{Q}_{\mathrm{a}}$ using equation (3A.17) and (3A.18)

$\Delta Q_{a}-(2 \mu u+1) \Delta Q_{b}+u\left(1-s_{b}\right)=0 \Leftrightarrow$

$\Delta \mathrm{Q}_{\mathrm{a}}-(2 \mu \mathrm{u}+1)\left[(2 \mu \mathrm{u}+1) \Delta \mathrm{Q}_{\mathrm{a}}-\mathrm{us}_{\mathrm{a}}\right]+\mathrm{u}\left(1-\mathrm{s}_{\mathrm{b}}\right)=0 \Leftrightarrow$

$(2 \mu \mathrm{u}+1) u s_{\mathrm{a}}+\mathrm{u}\left(1-\mathrm{s}_{\mathrm{b}}\right)=[4 \mu \mathrm{u}(4 \mu \mathrm{u}+1)] \Delta \mathrm{Q}_{\mathrm{a}} \Leftrightarrow$

$\Delta Q_{a}=\frac{(2 \mu u+1) s_{a}+\left(1-s_{b}\right)}{4 \mu(\mu u+1)}$.

Substituting $\Delta \mathrm{Q}_{\mathrm{a}}$ in equation (3A.18) gives

$$
\begin{aligned}
& \Delta Q_{b}=(2 \mu u+1) \Delta Q_{a}-s_{a} \Leftrightarrow \\
& \Delta Q_{b}=\frac{(2 \mu u+1)^{2} s_{a}+(2 \mu u+1)\left(1-s_{b}\right)-4 \mu u(\mu u+1) s_{a}}{4 \mu(\mu u+1)} \Leftrightarrow \\
& \Delta Q_{b}=\frac{s_{a}+(2 \mu u+1)\left(1-s_{b}\right)}{4 \mu(\mu u+1)} .
\end{aligned}
$$

The second order and stability conditions

The second order derivative of net profits with respect to the quality change pursued equals $\partial^{2} \Pi_{\mathrm{j}} / \partial\left(\Delta \mathrm{Q}_{\mathrm{j}}\right)^{2}=-(1 / \mathrm{u}+2 \mu)$. This condition is satisfied when $\mu$ and $\mathrm{u}$ are larger than zero. ${ }^{(31)}$ Equation (3A.16) and (3A.17) can be rewritten to

$$
\begin{aligned}
& \Delta \mathrm{Q}_{\mathrm{a}}=\left(\mathrm{us}_{\mathrm{a}}+\Delta \mathrm{Q}_{\mathrm{b}}\right) /(2 \mu \mathrm{u}+1) \text { and } \\
& \Delta \mathrm{Q}_{\mathrm{b}}=\left(\mathrm{u}\left(1-\mathrm{s}_{\mathrm{b}}\right)+\Delta \mathrm{Q}_{\mathrm{a}}\right) /(2 \mu \mathrm{u}+1) .
\end{aligned}
$$

The stability condition requires $1 /(2 \mu u+1)<1$. This condition thus is satisfied for all

(31) Note that the second order derivates of gross profits are negative as well $(-1 / u)$. The first order derivatives of gross profits are

$\mathrm{d} \pi_{\mathrm{a}} / \mathrm{d} \Delta \mathrm{Q}_{\mathrm{a}}=(1 / \mathrm{u})\left[\Delta \mathrm{Q}_{\mathrm{b}}-\Delta \mathrm{Q}_{\mathrm{a}}+\mathrm{us}_{\mathrm{a}}\right] \geq 0$ when $\Delta \mathrm{Q}_{\mathrm{b}} \geq \Delta \mathrm{Q}_{\mathrm{a}}$; $\mathrm{d} \pi_{\mathrm{b}} / \mathrm{d} \Delta \mathrm{Q}_{\mathrm{b}}=(\mathrm{l} / \mathrm{u})\left[\Delta \mathrm{Q}_{\mathrm{a}}-\Delta \mathrm{Q}_{\mathrm{b}}+\mathrm{u}\left(1-\mathrm{s}_{\mathrm{b}}\right)\right] \geq 0$ when $\Delta \mathrm{Q}_{\mathrm{a}} \geq \Delta \mathrm{Q}_{\mathrm{b}}$,

as is desirable from an economic point of view. 
values of $\mu$ and $u$ larger than 0 . Note that in the limit price scenario the quality increase pursued is a strategic complement rather than a strategic substitute, as is the case in the Hotelling scenario.

\section{F Product variety in the limit price scenario}

The optimisation problems faced by the firms in the first stage of the first period can be derived by substituting for $\Delta Q_{a}$ and $\Delta Q_{b}$ in equations (8a') and (8b') using equations $\left(9 a^{\prime}\right)$ and $\left(9 b^{\prime}\right)$. The optimisation problems are as follows

$$
\begin{aligned}
\Pi_{a}= & \frac{1}{2 u}\left[\frac{2 \mu u\left(1-s_{a}-s_{b}\right)}{4 \mu(\mu u+1)}+u\left(s_{a}+s_{b}\right)\right]\left[\frac{2 \mu u\left(s_{a}+s_{b}-1\right)}{4 \mu(\mu u+1)}+u\left(s_{b}-s_{a}\right)\right] \\
& -\mu\left[\frac{(2 \mu u+1) s_{a}+\left(1-s_{b}\right)}{4 \mu(\mu u+1)}\right]^{2} \text { and } \\
\Pi_{b}= & \frac{1}{2 u}\left[\frac{2 \mu u\left(s_{a}+s_{b}-1\right)}{4 \mu(\mu u+1)}-u\left(s_{a}+s_{b}\right)+2 u\right]\left[\frac{2 \mu u\left(1-s_{a}-s_{b}\right)}{4 \mu(\mu u+1)}+u\left(s_{b}-s_{a}\right)\right] \\
& -\mu\left[\frac{s_{a}+(2 \mu u+1)\left(1-s_{b}\right)}{4 \mu(\mu u+1)}\right]^{2}
\end{aligned}
$$

Maximising (10a) with respect to $s_{a}$ gives the following first order condition

$$
\begin{aligned}
\frac{\partial \Pi_{a}}{\partial s_{a}}= & \frac{2 \mu u+1}{4(\mu u+1)}\left[\frac{2 \mu u\left(s_{a}+s_{b}-1\right)}{4 \mu(\mu u+1)}+u\left(s_{b}-s_{a}\right)\right]-\frac{2 \mu u+1}{4(\mu u+1)}\left[\frac{2 \mu u\left(1-s_{a}-s_{b}\right)}{4 \mu(\mu u+1)}+u\left(s_{a}+s_{b}\right)\right]- \\
& \frac{4 \mu u+2}{4(\mu u+1)}\left[\frac{(2 \mu u+1) s_{a}+\left(1-s_{b}\right)}{4 \mu(\mu u+1)}\right] \Leftrightarrow \\
\frac{\partial \Pi_{a}}{\partial s_{a}} & =\frac{2 \mu u+1}{4(\mu u+1)}\left[\frac{-4 \mu u\left(1-s_{a}-s_{b}\right)-8 \mu u(\mu u+1) s_{a}-2(2 \mu u+1) s_{a}-2\left(1-s_{b}\right)}{4 \mu(\mu u+1)}\right] \Leftrightarrow \\
\frac{\partial \Pi_{a}}{\partial s_{a}} & =-\frac{(2 \mu u+1)^{2}\left((2 \mu u+1) s_{a}+\left(1-s_{b}\right)\right)}{8 \mu(\mu u+1)^{2}}<0 .
\end{aligned}
$$

The derivative of $\Pi_{b}$ towards $s_{b}$ can be determined likewise. Note the symmetry in the outcomes. 


$$
\frac{\partial \mathrm{I}_{\mathrm{b}}}{\partial \mathrm{s}_{\mathrm{b}}}=\frac{(2 \mu \mathrm{u}+1)^{2}\left(\mathrm{~s}_{\mathrm{a}}+(2 \mu \mathrm{u}+1)\left(1-\mathrm{s}_{\mathrm{b}}\right)\right)}{8 \mu(\mu \mathrm{u}+1)^{2}}>0 .
$$

\section{G Equilibrium quality and variety under policy}

The maximization process in the second stage of the first period is as follows. Net profits are given by equation ( $8 \mathrm{a}$ ") and (8b")

$$
\begin{aligned}
& \operatorname{Max} \Pi_{a}=\frac{1}{18 u}\left[(1-\beta) R_{a}-(1-\beta) R_{b}+u\left(s_{a}+s_{b}\right)+2 u\right]^{2}-(1-\varsigma) \mu R_{a}^{2} \text { and } \\
& \operatorname{Max} \Pi_{b}=\frac{1}{18 u}\left[(1-\beta) R_{b}-(1-\beta) R_{a}-u\left(s_{a}+s_{b}\right)+4 u\right]^{2}-(1-\varsigma) \mu R_{b}^{2} .
\end{aligned}
$$

When $\beta=0$, the maximization problem is as in Section 3.2. The first order conditions are as follows

$$
\begin{aligned}
& \frac{d \Pi_{a}}{d R_{a}}=\frac{2(1-\beta)}{18 u}\left[(1-\beta) R_{a}-(1-\beta) R_{b}+u\left(s_{a}+s_{b}\right)+2 u\right]-2(1-\varsigma) \mu R_{a}=0 \text { and } \\
& \frac{d \Pi_{b}}{d R_{b}}=\frac{2(1-\beta)}{18 u}\left[(1-\beta) R_{b}-(1-\beta) R_{a}-u\left(s_{a}+s_{b}\right)+4 u\right]-2(1-\varsigma) \mu R_{b}=0
\end{aligned}
$$

The second order condition is fulfilled whenever $(1-\beta)^{2} / 18 u<(1-\zeta) \mu \Leftrightarrow(1-\beta)^{2} /(1-\zeta)$ $<18 \mu \mathrm{u}$. The stability condition is met when $2(1-\beta)^{2} /(1-\varsigma)<18 \mu \mathrm{u}$. Equation (3A.22) can be rewritten to

$$
\mathrm{R}_{\mathrm{b}}=\mathrm{R}_{\mathrm{a}}+\frac{\mathrm{u}\left(\mathrm{s}_{\mathrm{a}}+\mathrm{s}_{\mathrm{b}}+2\right)}{(1-\beta)}-\frac{18 \mu \mathrm{u}(1-\varsigma) \mathrm{R}_{\mathrm{a}}}{(1-\beta)^{2}} .
$$

Equation (3A.24) may be used to substitute for $R_{b}$ in equation (3A.23) in order to solve for firm $A$ 's $R \& D$ efforts $R_{a}$.

$$
\begin{aligned}
& \mathrm{R}_{\mathrm{b}}-\mathrm{R}_{\mathrm{a}}+\frac{\mathrm{u}\left(4-\mathrm{s}_{\mathrm{a}}-\mathrm{s}_{\mathrm{b}}\right)}{(1-\beta)}-\frac{18 \mu \mathrm{u}(1-\zeta) \mathrm{R}_{\mathrm{b}}}{(1-\beta)^{2}}=0 \Leftrightarrow \\
& {\left[\mathrm{R}_{\mathrm{a}}+\frac{\mathrm{u}\left(\mathrm{s}_{\mathrm{a}}+\mathrm{s}_{\mathrm{b}}+2\right)}{(1-\beta)}-\frac{18 \mu \mathrm{u}(1-\varsigma) \mathrm{R}_{\mathrm{a}}}{(1-\beta)^{2}}\right]-\mathrm{R}_{\mathrm{a}}+\frac{\mathrm{u}\left(4-\mathrm{s}_{\mathrm{a}}-\mathrm{s}_{\mathrm{b}}\right)}{(1-\beta)}-} \\
& \quad \frac{18 \mu \mathrm{u}(1-\zeta)}{(1-\beta)^{2}}\left[\mathrm{R}_{\mathrm{a}}+\frac{\mathrm{u}\left(\mathrm{s}_{\mathrm{a}}+\mathrm{s}_{\mathrm{b}}+2\right)}{(1-\beta)}-\frac{18 \mu \mathrm{u}(1-\zeta) \mathrm{R}_{\mathrm{a}}}{(1-\beta)^{2}}\right]=0 \Leftrightarrow
\end{aligned}
$$




$$
\begin{aligned}
& R_{a}\left[\frac{(18 \mu u(1-\varsigma))^{2}}{(1-\beta)^{4}}-\frac{2(18 \mu u(1-\varsigma))}{(1-\beta)^{2}}\right]=\frac{18 \mu u(1-\varsigma) u\left(s_{a}+s_{b}+2\right)}{(1-\beta)^{3}}-\frac{6 u}{(1-\beta)} \Leftrightarrow \\
& R_{a}=\frac{(1-\beta)}{6 \mu(1-\varsigma)}\left[\frac{\frac{18 \mu u(1-\varsigma)}{(1-\beta)^{2}} \frac{u\left(s_{a}+s_{b}+2\right)}{3 u}-2}{\frac{18 \mu u(1-\varsigma)}{(1-\beta)^{2}}-2}\right] .
\end{aligned}
$$

Note that when $\left(\mathrm{s}_{\mathrm{a}}+\mathrm{s}_{\mathrm{b}}\right)=1$, id est locations are symmetric, equation (3A.25) reduces to $\mathrm{R}_{\mathrm{a}}=(1-\beta) /(6 \mu(1-\zeta))$, the equilibrium solution given by equation (9a"). In a similar way one may find firm $B$ 's equilibrium $R \& D$ efforts $R_{b}$

$$
R_{b}=\frac{(1-\beta)}{6 \mu(1-\varsigma)}\left[\frac{\frac{18 \mu u(1-\varsigma)}{(1-\beta)^{2}} \frac{u\left(4-s_{a}-s_{b}\right)}{3 u}-2}{\frac{18 \mu u(1-\varsigma)}{(1-\beta)^{2}}-2}\right]
$$

Equations (3A.25) and (3A.26) constitute the Nash-equilibrium in R\&D efforts. Both equations may be substituted into equation ( $8 \mathrm{a}$ ") in order to derive firm $A$ 's reduced profits as a function of the varieties only.

$$
\begin{aligned}
& \Pi_{a}=\frac{1}{18 u}\left[\frac{(1-\beta)^{2}}{6 \mu(1-\varsigma)} \frac{\frac{18 \mu u(1-\varsigma)}{(1-\beta)^{2}} \frac{2 u\left(s_{a}+s_{b}-1\right)}{3 u}}{\frac{18 \mu u(1-\varsigma)}{(1-\beta)^{2}}-2}+u\left(s_{a}+s_{b}+2\right)\right]^{2}- \\
& (1-\varsigma) \mu\left[\frac{(1-\beta)}{6 \mu(1-\varsigma)} \frac{\frac{18 \mu u(1-\varsigma)}{(1-\beta)^{2}} \frac{u\left(s_{a}+s_{b}+2\right)}{3 u}-2}{\frac{18 \mu u(1-\varsigma)}{(1-\beta)^{2}}-2}\right]^{2} \Leftrightarrow \\
& \begin{aligned}
\Pi_{a}= & \frac{1}{18 u}\left[\frac{(1-\beta)^{2}}{6 \mu(1-\varsigma)} \frac{36 \mu u^{2}(1-\varsigma)\left(s_{a}+s_{b}-1\right)}{3 u\left[18 \mu u(1-\varsigma)-2(1-\beta)^{2}\right]}+u\left(s_{a}+s_{b}+2\right)\right]^{2}- \\
& (1-\varsigma) \mu\left[\frac{(1-\beta)}{6 \mu(1-\varsigma)} \frac{18 \mu u^{2}(1-\varsigma)\left(s_{a}+s_{b}+2\right)-6 u(1-\beta)^{2}}{3 u\left[18 \mu u(1-\varsigma)-2(1-\beta)^{2}\right]}\right]^{2} \Leftrightarrow
\end{aligned} \\
& \Pi_{\mathrm{a}}=\frac{1}{18 \mathrm{u}}\left[\frac{18 \mu \mathrm{u}^{2}(1-\varsigma)\left(\mathrm{s}_{\mathrm{a}}+\mathrm{s}_{\mathrm{b}}+2\right)-6 \mathrm{u}(1-\beta)^{2}}{18 \mu \mathrm{u}(1-\varsigma)-2(1-\beta)^{2}}\right]^{2} \text { - }
\end{aligned}
$$




$$
\begin{aligned}
& (1-\varsigma) \mu\left[\frac{(1-\beta)}{6 \mu(1-\varsigma)} \frac{18 \mu u^{2}(1-\varsigma)\left(s_{\lrcorner}+s_{b}+2\right) \cdot 6 u(1-\beta)^{2}}{3 u\left[18 \mu u(1-\varsigma)-2(1-\beta)^{2}\right]}\right]^{2} \Leftrightarrow \\
& \Pi_{a}=\left[\frac{1}{18 u} \cdot \frac{(1-\varsigma) \mu(1-\beta)^{2}}{(18 \mu u(1-\varsigma))^{2}}\right]\left[\frac{18 \mu u^{2}(1-\varsigma)\left(s_{a}+s_{h}+2\right)-6 u(1-\beta)^{2}}{18 \mu u(1-\varsigma)-2(1-\beta)^{2}}\right]^{2} \Leftrightarrow \\
& \Pi_{\mathrm{a}}=\mu(1-\varsigma)\left[18 \mu \mathrm{u}(1-\varsigma)-(1-\beta)^{2}\right]\left[\frac{18 \mu \mathrm{u}^{2}(1-\varsigma)\left(\mathrm{s}_{\mathrm{a}}+\mathrm{s}_{\mathrm{b}}+2\right)-6 \mathrm{u}(1-\beta)^{2}}{18 \mu \mathrm{u}(1-\varsigma)\left[18 \mu \mathrm{u}(1-\varsigma)-2(1-\beta)^{2}\right]}\right]^{2} \text {. }
\end{aligned}
$$

Firm A's equilibrium location may be derived by maximizing reduced profits as given by equation ( $3 \mathrm{~A} .27$ ) towards $\mathrm{s}_{\mathrm{a}}$. This gives

$$
\begin{aligned}
\frac{d \Pi_{a}}{d s_{s}}= & \frac{2 \mu u(1-\varsigma)\left[18 \mu u(1-\varsigma)-(1-\beta)^{2}\right]}{18 \mu u(1-\varsigma)-2(1-\beta)^{2}} . \\
& {\left[\frac{18 \mu u^{2}(1-\varsigma)\left(s_{a}+s_{b}+2\right)-6 u(1-\beta)^{2}}{18 \mu u(1-\varsigma)\left[18 \mu u(1-\varsigma)-2(1-\beta)^{2}\right]}\right]^{2}>0 . }
\end{aligned}
$$

as before since $18 \mu \mathrm{u}(1-\zeta)>2(1-\beta)^{2}$ in order to meet the stability condition for the product R\&D game [compare this result with the one in Appendix 3.3]. For firm B one may similarly find that $d \Pi_{b} / d_{b}<0$. Since both firms have a tendency to locate closer towards the rival firm and both firms are in symmetric positions, the equilibrium locations again are $s_{a}=s_{b}=0.5$. This being so, equilibrium R\&D efforts are $R_{\mathrm{a}}=R_{b}=(1-\beta) /(6 \mu(1-\zeta))$ and equilibrium prices $P_{a}=P_{b}=m c+u$.

\section{H Product R\&D and variety under asymmetry}

Net profits in terms of quality and variety are already given by equation (8a) and $(8 b)$ in section 3.2 . The only difference between reduced profits given in section 3.2 and reduced profits given in section 7 is that in section 3.2 initial qualities drop out because of symmetry while they do not in section 7. Net profits are [Appendix 3.2]

$$
\begin{aligned}
& \Pi_{\mathrm{a}}=\frac{1}{18 \mathrm{u}}\left[\left(\mathrm{Q}_{\mathrm{a}}+\Delta \mathrm{Q}_{\mathrm{a}}-\mathrm{Q}_{\mathrm{b}}-\Delta \mathrm{Q}_{\mathrm{b}}\right)+3 \mathrm{u}\right]^{2}-\mu\left(\Delta \mathrm{Q}_{\mathrm{a}}\right)^{2} \text { and } \\
& \Pi_{\mathrm{b}}=\frac{1}{18 \mathrm{u}}\left[\left(\mathrm{Q}_{\mathrm{b}}+\Delta \mathrm{Q}_{\mathrm{b}}-\mathrm{Q}_{\mathrm{a}}-\Delta \mathrm{Q}_{\mathrm{a}}\right)+3 \mathrm{u}\right]^{2}-\mu\left(\Delta \mathrm{Q}_{\mathrm{b}}\right)^{2} .
\end{aligned}
$$

The first order conditions are 
$\frac{\mathrm{d} \Pi_{\mathrm{a}}}{\mathrm{d}\left(\Delta \mathrm{Q}_{\mathrm{a}}\right)}=\frac{2}{18 \mathrm{u}}\left[\left(\mathrm{Q}_{\mathrm{a}}+\Delta \mathrm{Q}_{\mathrm{a}}-\mathrm{Q}_{\mathrm{b}}-\Delta \mathrm{Q}_{\mathrm{b}}\right)+3 \mathrm{u}\right]-2 \mu \Delta \mathrm{Q}_{\mathrm{a}}=0$ and

$\frac{d \Pi_{b}}{d\left(\Delta Q_{b}\right)}=\frac{2}{18 u}\left[\left(Q_{b}+\Delta Q_{b}-Q_{a}-\Delta Q_{a}\right)+3 u\right]-2 \mu \Delta Q_{b}=0$.

Rearranging equation (3A.31) gives

$\Delta \mathrm{Q}_{\mathrm{b}}=\left(\mathrm{Q}_{\mathrm{a}}-\mathrm{Q}_{\mathrm{b}}\right)+(1-18 \mu \mathrm{u}) \Delta \mathrm{Q}_{\mathrm{a}}+3 \mathrm{u}$.

Substituting equation (3A.33) into equation (3A.32) gives firm A's equilibrium quality increase

$\left(\mathrm{Q}_{\mathrm{b}}-\mathrm{Q}_{\mathrm{a}}\right)+(1-18 \mu \mathrm{u}) \Delta \mathrm{Q}_{\mathrm{b}}-\Delta \mathrm{Q}_{\mathrm{a}}+3 \mathrm{u}=0 \Leftrightarrow$

$\left(\mathrm{Q}_{\mathrm{b}}-\mathrm{Q}_{\mathrm{a}}\right)+(1-18 \mu \mathrm{u})\left[\left(\mathrm{Q}_{\mathrm{a}}-\mathrm{Q}_{\mathrm{b}}\right)+(1-18 \mu \mathrm{u}) \Delta \mathrm{Q}_{\mathrm{a}}+3 \mathrm{u}\right]-\Delta \mathrm{Q}_{\mathrm{a}}+3 \mathrm{u}=0 \Leftrightarrow$ $18 \mu \mathrm{u}(18 \mu \mathrm{u}-2) \Delta \mathrm{Q}_{\mathrm{a}}=18 \mu \mathrm{u}\left[\left(\mathrm{Q}_{\mathrm{a}}-\mathrm{Q}_{\mathrm{b}}\right)+3 \mathrm{u}\right]-6 \mathrm{u} \Leftrightarrow$

$\Delta Q_{a}=\frac{Q_{a}-Q_{b}}{18 \mu u-2}+\frac{1}{6 \mu}$.

The above equation equals the original equation plus a correction for the quality difference. The equilibrium quality change pursued by firm $\mathrm{B}$ can now easily be derived by substituting equation (9a"') into equation (3A.33)

$\Delta Q_{b}=\frac{Q_{b}-Q_{a}}{18 \mu u-2}+\frac{1}{6 \mu}$.

Equation (9a"') and equation (9b"') are equal to each other except for the term comprising the quality difference.

\section{Consumer surplus and industry profits in case of asymmetry}

Consumer surplus CS equals

$C S=\left(Q_{a}+\Delta Q_{a}-P_{a}\right) X_{a}+\left(Q_{b}+\Delta Q_{b}-P_{b}\right) X_{b}-u X_{a}^{2} / 2-u X_{b}^{2} / 2$.

Consumer surplus is depicted by Figure 3.2 (with $s_{a}=0$ and $s_{b}=1$ ). Substituting for $\mathrm{X}_{\mathrm{a}}, \mathrm{X}_{\mathrm{b}}, \mathrm{P}_{\mathrm{a}}$ and $\mathrm{P}_{\mathrm{b}}$ gives

$\mathrm{CS}=[\mathrm{I} /(36 \mathrm{u})]\left[\mathrm{Q}_{\mathrm{a}}+\Delta \mathrm{Q}_{\mathrm{a}}-\mathrm{Q}_{\mathrm{b}}-\Delta \mathrm{Q}_{\mathrm{b}}\right]^{2}+(1 / 2)\left[\mathrm{Q}_{\mathrm{a}}+\Delta \mathrm{Q}_{\mathrm{a}}+\mathrm{Q}_{\mathrm{b}}+\Delta \mathrm{Q}_{\mathrm{b}}\right]-[\mathrm{mc}+\mathrm{u}]-\mathrm{u} / 4$.

When we substitute for $\Delta \mathrm{Q}_{\mathrm{a}}$ and $\Delta \mathrm{Q}_{\mathrm{b}}$ the above equation reduces to 
$\mathrm{CS}=[1 /(36 \mathrm{u})]\left[18 \mu \mathrm{u}\left(\mathrm{Q}_{\mathrm{a}}-\mathrm{Q}_{\mathrm{b}}\right) /(18 \mu \mathrm{u}-2)\right]^{2}+(1 / 6 \mu)-[\mathrm{mc}+\mathrm{u}]-\mathrm{u} / 4$.

Now, when $\mathrm{Q}_{\mathrm{a}}=(\mathrm{Q}+\alpha)$ and $\mathrm{Q}_{\mathrm{b}}=(\mathrm{Q}-\alpha)$ the equation can be further reduced to $\mathrm{CS}=[1 /(36 \mathrm{u})][18 \mu \mathrm{u}(2 \alpha) /(18 \mu \mathrm{u}-2)]^{2}+(1 / 6 \mu)-[\mathrm{mc}+\mathrm{u}]-\mathrm{u} / 4$.

Differentiating towards $\alpha$ gives

$\partial \mathrm{CS} / \partial \alpha=[2 \mu \alpha /(18 \mu \mathrm{u}-2)][18 \mu \mathrm{u}(2 \alpha) /(18 \mu \mathrm{u}-2)]>0$.

Industry profits $\Pi$ equal

$\Pi=\left(P_{a}-m c\right) X_{a}+\left(P_{b}-m c\right) X_{b}-\mu\left(\Delta Q_{a}\right)^{2}-\mu\left(\Delta Q_{b}\right)^{2}$.

Substituting $\mathrm{P}_{\mathrm{a}}, \mathrm{P}_{\mathrm{b}}, \mathrm{X}_{\mathrm{a}}$ and $\mathrm{X}_{\mathrm{b}}$ gives

$\Pi=(1 / 18 \mathrm{u})\left(\mathrm{Q}_{\mathrm{a}}+\Delta \mathrm{Q}_{\mathrm{a}}-\mathrm{Q}_{\mathrm{b}}-\Delta \mathrm{Q}_{\mathrm{b}}+3 \mathrm{u}\right)^{2}+(1 / 18 \mathrm{u})\left(\mathrm{Q}_{\mathrm{b}}+\Delta \mathrm{Q}_{\mathrm{b}}-\mathrm{Q}_{\mathrm{a}}-\Delta \mathrm{Q}_{\mathrm{a}}+3 \mathrm{u}\right)^{2}-\mu\left(\Delta \mathrm{Q}_{\mathrm{a}}\right)^{2}-\mu\left(\Delta \mathrm{Q}_{\mathrm{b}}\right)^{2}$

Substituting $\Delta \mathrm{Q}_{\mathrm{a}}$ and $\Delta \mathrm{Q}_{\mathrm{b}}$ gives

$\Pi=(1 / 18 u)\left[18 \mu u\left(Q_{n}-Q_{b}\right) /(18 \mu u-2)+3 u\right]^{2}+(1 / 18 u)\left[18 \mu u\left(Q_{b}-Q_{2}\right) /(18 \mu u-2)+3 u\right]^{2}-$ $\mu\left[\left(\mathrm{Q}_{\mathrm{a}}-\mathrm{Q}_{\mathrm{b}}\right) /(18 \mu \mathrm{u}-2)+1 /(6 \mu)\right]^{2}-\mu\left[\left(\mathrm{Q}_{\mathrm{b}}-\mathrm{Q}_{\mathrm{a}}\right) /(18 \mu \mathrm{u}-2)+1 /(6 \mu)\right]^{2}$.

Substituting for $\mathrm{Q}_{\mathrm{a}}=(\mathrm{Q}+\alpha)$ and $\mathrm{Q}_{\mathrm{b}}=(\mathrm{Q}-\alpha)$ gives

$\Pi=(1 / 18 \mathrm{u})[18 \mu \mathrm{u}(2 \alpha) /(18 \mu \mathrm{u}-2)+3 \mathrm{u}]^{2}+(1 / 18 \mathrm{u})[18 \mu \mathrm{u}(-2 \alpha) /(18 \mu \mathrm{u}-2)+3 \mathrm{u}]^{2}-$ $\mu[2 \alpha /(18 \mu \mathrm{u}-2)+1 /(6 \mu)]^{2}-\mu[-2 \alpha /(18 \mu \mathrm{u}-2)+1 /(6 \mu)]^{2}$.

Differentiating towards $\alpha$ gives

$\partial \mathrm{TL} / \partial \alpha=[4 \mu /(18 \mu \mathrm{u}-2)][18 \mu \mathrm{u}(2 \alpha) /(18 \mu \mathrm{u}-2)+3 \mathrm{u}]-[4 \mu /(18 \mu \mathrm{u}-2)][18 \mu \mathrm{u}(-2 \alpha) /(18 \mu \mathrm{u}-$ $2)+3 \mathrm{u}]-[4 \mu /(18 \mu \mathrm{u}-2)][2 \alpha /(18 \mu \mathrm{u}-2)+1 /(6 \mu)]+[4 \mu /(18 \mu \mathrm{u}-2)][-2 \alpha /(18 \mu \mathrm{u}-2)+$ $1 /(6 \mu)] \Leftrightarrow$

$\partial \Pi / \partial \alpha=[4 \mu /(18 \mu \mathrm{u}-2)][18 \mu \mathrm{u}(4 \alpha) /(18 \mu \mathrm{u}-2)]-$

$[4 \mu /(18 \mu \mathrm{u}-2)][4 \alpha /(18 \mu \mathrm{u}-2)] \Leftrightarrow$

$\partial \Pi / \partial \alpha=\left[16 \mu \alpha /(18 \mu \mathrm{u}-2)^{2}\right][18 \mu \mathrm{u}-1]>0$. 


\section{Chapter}

\section{Multimarket competition with intrafirm spillovers and capacity constraints}

\section{Introduction}

Economic literature devotes much attention to substitutability in consumption. The degree of substitutability in consumption is one of the key factors explaining the degree of competitiveness. Average (and marginal) cost pricing is more likely when goods are close substitutes (in consumption). As has been argued in Chapter 1, this result is not unfamiliar to the theory of monopolistic competition, limit price theory and the concept of workable competition. In Chapter 3 we saw that prices approach marginal cost when (the desire for) variety diminishes. However, substitutability in production may be as important a phenomenon as substitutability in consumption. Recently, Hewlett-Packard - a manufacturer of office equipment like printers entered the PC-market [BW: 21-8-1995]. Its reputation for good service and reliability enabled it to invade the PC-market with success. Intel decided to invade the PCmarket from the market for micro-processors in 1990 [BW: 9-10-1995]. Intel was aware that vertical integration was essential for its position in the market for microprocessors. Gross profits of traditional PC-makers have been under pressure ever since. They declined from $12 \%$ in 1990 to $5-6 \%$ in 1994 and 1995. Key technologies also prove the importance of substitutability in production. Philips' knowledge on semi-conductors, for instance, enable it to 'apply its chip skills to new generations of products, from smart car-navigation to wrist-watch phones' [BW: 14-8-1995]. Substitutability in production may explain average cost pricing just like substitutability in consumption does. In this chapter attention will be paid to substitutability in production and to a related concept: The general nature of knowledge.

In Chapters 2 and 3, the entry threat is not hindered by capacity constraints. In this chapter, however, the implications of this assumption are studied by incorporating capacity constraints into the model [Table 4.2]. The cost structure in this chapter is equivalent to the one employed in Chapter 3 (and throughout the economic text books [Tirole (1988)]). The Bertrand paradox does not arise in this chapter, because there are quality differences between the firms. Competition stems from firms in technologically related industries. These firms are able to offer similar qualities as the incumbent firm. The quality differences enable incumbents to make gross profits from which the R\&D expenses may be recouped. The gross margin in Chapter 3 originated from the desire for variety, and not from differences in variety. Since consumer heterogeneity plays no role in Chapter 4 , we again start with a representative consumer. 
Table 4.1

A comparison of Chapters 2 to 4

Analytical Model features
techniques

2 Game theory Average total costs constant

Prices approach marginal Simulations Representative consumer No capacity constraints Geographically separated cost when entry costs fall Optimal investment in $R \& D$ markets

Duplications of efforts Industries are monopolized when entry costs are low

3 Microeconomics Game theory
Average variable costs constant Differentiated consumers No capacity constraints One (segmented) market
Prices approach marginal cost when there is less desire for variety

Underinvestment in R\&D All surplus from innovations accrues to consumers Product differentiation is optimal in case of hit-andrun entry; otherwise it is not

Prices approach marginal cost when spillovers and capacity rise Firms do not invest in R\&D when spillovers are high
4 Game theory Average variable costs constant Representative consumer Capacity constraints Two markets with substitutes in production

This chapter integrates two strands of literature: The first discusses the influence of the multiple employability of knowledge on R\&D performance; the second analyzes multimarket competition subject to capacity constraints. Both the first and this paragraph give some examples of the multiple employability of knowledge. This feature is one of the major factors explaining the boost in technological progress and diversification. The latter phenomenon explains the surge in multimarket competition, the second point of analysis in this chapter; the former phenomenon is probably the most important competitive instrument in the post-war era. Both features explain why industries 'which were once cosy havens for making easy profits are now subject to vigorous competition' [Grant (1991: 117)]. Examples of the multiple use of knowledge are abound. Several techniques employed in the petroleum industry have multiple applications. Geophysical exploitation techniques like electromagnetic, seismic and gravity methods, for instance, may be used for the exploitation of oil, coal, geothermal energy and uranium [Teece (1980)]. Up until now we referred to the use of knowledge only; however, we may refer to the use of goodwill as well. An 
example of the latter case is umbrella branding [Wernerfeldt (1988)]. This concept refers to the use of a brand name in order to indicate the quality of products added to one's product line. Hewlett-Packard's entry in the PC market is an example of this phenomenon. Sullivan (1990: 326-7) mentions the positive influence of (the publicity surrounding) the introduction of a new Jaguar type on the sales of old Jaguar types. In this chapter the multiple use of knowledge is introduced in the form of interproduct spillovers. Since the products modelled below are no substitutes in consumption, the products refer to different markets. The spillovers thus are not only interproduct, but also intermarket. In order to stress the importance of the multiple employability of technology, the spillovers are assumed to be intrafirm. The spillover rate $\beta$ may be seen as the degree in which knowledge has generic attributes [Teece (1980: 226)]. In principle, the spillovers may also be interpreted as being interfirm [D'Aspremont and Jaquemin (1988)]. Interproduct spill-overs enable (potential) entrants to deliver products at about the same quality as incumbent firms do, and thus explain the establishment of competitive prices when capacity is large enough.

Substitutability in production and the multiple employability of knowledge are likely to be important in a multimarket context. Potential entrants are incumbent in geographically different or technologically related markets [Calem (1988: 171)]. For this reason we present a simple two-markets model in which both markets are occupied by one firm each. The products sold in the two markets are no substitutes in consumption. Both firms have a certain capacity which they may employ for one or both markets. The firms invest in product $R \& D$ in order to raise the quality of the product in their home market. As a by-product of their R\&D efforts the firms are able to produce the good in the entry market at a higher quality level as well. In this way, interproduct (and intrafirm) spillovers of $R \& D$ production are incorporated. This chapter shows that barrier market outcomes are obtained for high capacity levels, provided that interproduct spillovers are not too high. When capacity is high, accommodating entry is not profitable because residual demand is low. When spillovers are high, entry deterrence is not profitable because entry can only be deterred at a price near marginal cost.

As stated above, the surge in multimarket competition may be explained by the growing importance of substitutability in production and the multiple employability of knowledge. Multimarket competition has one important characteristic which distinguishes it from single market competition. The strategy of one firm may not only affect the strategy of the rival firm in the market in which the strategy is pursued, but also in another market [Bulow, Geanakoplos and Klemperer (1985: 4889)]. Because the behaviour of a rival firm influences profits, a firm should consider three mechanisms when it decides upon strategy. Strategies affect profits directly, but also through rival firm behaviour in the market in which the strategies are pursued as well as those in which they are not. Strategies influence rival firm behaviour in markets in which the strategies are not pursued, when there are multimarket spillovers. There is a multimarket spillover, when firm A's strategy in market $\mathrm{X}, \mathrm{T}_{\mathrm{a}}{ }^{\mathrm{X}}$, influences the profitability of its strategy in market $\mathrm{Y}, \mathrm{T}_{\mathrm{a}}^{\mathrm{y}}$; in short, $\partial^{2} \Pi /\left(\partial \mathrm{T}_{\mathrm{a}}^{\mathrm{x}} \mathrm{T}_{\mathrm{a}}{ }^{y}\right) \neq 0$ [op. cit.: 493]. In this chapter a quality rise in one market leads to a quality rise in the other market. The latter increases the consumers' willingness to pay and 
(marginal) profitability in the other market. Multimarket spillovers also play a large role in the current literature on multimarket competition subject to capacity constraints [Anderson and Fischer (1989) and Venables (1990)]. In these papers, the spillover refers to decisions on capacity and output rather than quality. Firms decide on the division of output over markets in such a way that all three mechanisms mentioned above are accounted for. The capacity decisions taken by the firms give their allocation decisions some commitment value. ${ }^{(1)}$ In the analysis of this chapter the rival firm's opportunity profits determine a firm's profit opportunities and thereby its strategies. Opportunity profits depend on (excess) capacity and differences in quality, the exogenous commitments available in this chapter.

The analysis in this chapter is in line of contestability theory [Baumol (1982) and Baumol et al. (1982)]. Van Wegberg and Van Witteloostuijn (1992) (henceforth W\&W) adapt the concept to a multimarket context. This chapter will be primarily based on $\mathrm{W} \& \mathrm{~W}$. There are not many contributions on multimarket competition within the tradition of contestability (or Bertrand competition). Most contributions employ the Cournot postulate [Calem (1988) and Zappe and Horowitz (1993)]. Calem (1988) resembles contestability analysis since he studies penetrable markets. W\&W conclude that firms deter entry when capacity is large. This chapter reaches a similar result. Cournot models usually derive cross-hauling equilibria [Anderson and Fischer (1989), Calem (1988) and Dei (1990)]. This result is not surprising as Bertrand competition is characterized by a sharp discontinuity in demand while Cournot competition is not. This fact makes entry deterrence profitable under Bertrand competition and all but profitable under Cournot competition. W\&W consequently derive competitive prices for levels of capacity which are sufficiently high, while Calem (1988) and Dei (1990) do not. However, this result is reversed, when the capacity decision is endogenized. When firms decide on capacity, besides price or output, Bertrand competition generates Cournot outcomes [Kreps and Scheinkman (1983)], while Cournot models reach competitive solutions [Zappe and Horowitz (1993)]. The latter paper argues that firms resort to higher output levels, since both firms have an incentive to increase capacity (and output). This argument resembles the Prisoner Dilemma's story in Chapter 3 [Sub-section 3.4].

As stated, above the chapter follows W\&W (1992) closely. It extends their analysis by incorporating decisions on product $R \& D$ and differentiation in the analysis. The chapter shows that decisions on entry and entry deterrence do not depend on capacity only, but also on interproduct spillovers. This chapter differs from $W \& W$ in another respect. W\&W study simultaneous decision making only, whereas this chapter focuses on both simultaneous and sequential decision making. Section 3 shows that firms may be better off in an asymmetric solution. However, these solutions require coordination between the duopolists and thus do not arise since decisions are taken non-cooperatively and simultaneously. Because some coordination is required so as to establish a Nash-equilibrium, oligopolist enterprises may collude by setting prices sequentially. Price leadership is a well known device to

(1) See Dixit (1980) for an (early) analysis on strategic commitments. 
establish a cooperative solution [Scherer en Ross (1990: 248n)]. In Markham (1951) the large capacity firm sets the monopoly prices and allows fringe firms to undercut him. In this chapter the firms have equal capacity: The leader sets a limit price and leaves (monopoly profits on) residual demand for the follower. However, an asymmetry is needed in order to endogenize Stackelberg-leadership [Hamilton and Slutsky (1990)]. When one firm prefers to wait for the other player to decide and the other prefers to play first, a sequential equilibrium is the unique subgame perfect Nashequilibrium [op. cit.: 37]. In future research an asymmetry with respect to the spillover rate or capacity may enable us to endogenize Stackelberg-leadership. For the moment, the result that the leader leaves residual demand for the follower seems to describe the position of Volkswagen relative to Fiat rather well [Kirman and Schüller (1990: 71)]. Volkswagen deters entry into its German home market and enters the Italian market on a small scale. Fiat allows entry in order to earn monopoly rents (including $\mathrm{X}$-inefficiency) in its home market. This result may as well hold for Japanese car manufacturers relative to American and European car producers. The Japanese deter entry into their home market, enter the American and European markets and leave profitable residual demand for domestic producers.

Barrier market outcomes are only reached when both firms invest in R\&D. If capacity and interproduct spillovers are high, the degree of appropriability is low. This implies that when R\&D costs are high, the market may only support one or even no firm. The quality differences between the firms generate Ricardian rents [Peteraf (1993)]. A resource provides positive rents, when it is valuable, rare, imperfectly imitable and non-substitutable [Barney (1991)]. In this chapter, the quality differences due to imperfect imitability allow the rents needed to cover R\&D outlays. Whenever firms are not able to coordinate on the investment decision, investment may be either excessive or too low. Loury (1979) also concludes that R\&D outlays per firm and industry wide decrease with the number of competitors. This need not be the case when R\&D outlays are variable instead of fixed costs [Lee and Wilde (1980: 436)]. However, the latter assumption is rather peculiar and will not be employed in this chapter.

The chapter is constructed as follows. Section 2 gives the decision structure of the competition game, and introduces the demand and cost relations. In Section 3 the decisions on $R \& D$, price and quantity are analyzed in a game with a simultaneous decision structure. Section 4 analyzes the decisions in a game with a sequential decision structure. Section 5 concludes with a discussion.

\section{A general outline}

\subsection{The structure of the model}

This section gives a general outline of the model analyzed below. The structure chosen follows W\&W (1992) closely. The model is analyzed using a two-period 
competition game. The second period is subdivided into four stages. ${ }^{(2)}$ In the model there are two markets ( $\mathrm{X}$ and $\mathrm{Y}$ ), each occupied by one incumbent firm ( $\mathrm{A}$ and $\mathrm{B}$, respectively). In the second period of the game both firms decide whether to enter their rival's market or not. Per type decisions are taken simultaneously. In the first period the firms decide on product R\&D. In the second period quantity and price decisions are taken. In the first stage the firms determine the price in their home market. Thus, firm A decides on the price in market $\mathrm{X}$ and firm $\mathrm{B}$ decides on the price in market $Y$. In the second stage the firms decide on the prices they set in their entry markets. So, firm A determines its price in market $\mathrm{Y}$ and firm $\mathrm{B}$ in market $\mathrm{X}$. When prices have been set, the firms decide how to divide their capacities over the markets. I.e. they decide on how much to supply in market $\mathrm{X}$ and how much in market Y. They do so in the third stage of the second period. When prices and quantities supplied are set, transactions take place. The consumer thus comes into the picture in the fourth stage of the second period. The model's structure is depicted by Table 4.2.

\begin{tabular}{|c|c|c|c|c|c|}
\hline \multirow[t]{2}{*}{ Period } & \multirow[t]{2}{*}{ Stage } & \multicolumn{2}{|l|}{ Firm A } & \multicolumn{2}{|l|}{ Firm B } \\
\hline & & Market X & Market Y & Market X & Market Y \\
\hline 1 & 1 & \multicolumn{2}{|l|}{ R\&D decision } & \multicolumn{2}{|l|}{ R\&D decision } \\
\hline \multirow[t]{4}{*}{2} & 1 & Price decision & & & Price decision \\
\hline & 2 & & Price decision & Price decision & \\
\hline & 3 & \multicolumn{2}{|c|}{ Supply decision } & \multicolumn{2}{|c|}{ Supply decision } \\
\hline & 4 & \multicolumn{2}{|c|}{ Market transactions } & \multicolumn{2}{|c|}{ Market transactions } \\
\hline
\end{tabular}

(2) As in the previous two chapters, we employ a two-period model in order to indicate a difference between decisions involving irreversible investments in sunk costs (period 1) and decisions which do not (period 2). This distinction does not preclude a certain order of the decisions taken within one (or both) of the two periods. For this reason, period 2 is subdivided into four stages in this chapter. We could, of course, have modelled a five-period game as well. 


\subsection{Demand and cost relations}

\subsubsection{Demand}

The utility of a representative consumer is dependent on the consumption of three goods: $\mathrm{X}, \mathrm{Y}$ and $\mathrm{Z}$. We will concentrate our attention on the consumption of two goods: $\mathrm{X}$ and $\mathrm{Y} ; \mathrm{Z}$ is the numéraire commodity. The utility derived from the consumption of $X$ and $Y$ is a function of their respective quality levels, $Q^{x}$ and $Q^{y}$. The consumer buys one unit of $X$ and one unit of $Y$ only, if he buys $X$ and $Y$ at all. ${ }^{(3)}$ The consumer buys one unit of $X(Y)$ if the consumption of $X(Y)$ favours his level of well-being more than the forgone consumption of $Z$ would. Consumer utility $U$ is modelled as follows

$U=\delta^{x} Q^{x}+\delta^{y} Q^{y}+Z$,

where $\delta^{x}\left(\delta^{y}\right)$ is 1 when $\mathrm{X}(\mathrm{Y})$ is bought and 0 when $\mathrm{X}(\mathrm{Y})$ is not bought. We are particularly interested in those cases in which both $\mathrm{X}$ and $\mathrm{Y}$ are wanted. The budget constraint equals

$\delta^{x} P^{x}+\delta^{y} P^{y}+Z \leq W$,

where $\mathrm{P}^{\mathrm{x}}$ and $\mathrm{P}^{\mathrm{y}}$ denote the prices of the goods $\mathrm{X}$ and $\mathrm{Y}$, respectively, and $\mathrm{W}$ represents consumer income. The price of the numéraire commodity $(Z)$ is 1 . Income $W$ is so high that consumers are always able to buy both $X$ and $Y$ should they want to. By substituting equation (2) into equation (1) the latter can be rearranged into

$U=\delta^{x}\left(Q^{x}-P^{x}\right)+\delta^{y}\left(Q^{y}-P^{y}\right)+W$.

The representative consumer buys $X(Y)$ only when the difference between quality and price is non-negative. Otherwise, he abstains from buying $X(Y)$. We assume that there are $\mathrm{N}$ consumers. So, in both markets (potential) market demand equals $\mathrm{N}$. Each firm has a small advantage relative to its competitor in its home market. This advantage is laid down in Assumption 1.

Assumption 4.l. Consumers buy the product offering the highest level of surplus, provided that this level is non-negative. If the incumbent's price-quality offer is equivalent to the entrant's offer, all demand goes to the incumbent.

This advantage, which is well-known from the literature on contestability, characterizes one of the pure strategy equilibria to be derived in the next section. So, when

(3) The consumer may buy both one unit of $X$ - a food processor - or one unit of $Y$ - a coffee maker - or one unit of $\mathrm{X}$ and one of $\mathrm{Y}$ - both a food processor and a coffee maker. 
firm $A(B)$ đoes not make a worse price-quality offer in market $X(Y)$ than firm $B$ (A) does, the demand for firm $\mathrm{A}^{*} \mathrm{~s}\left(\mathrm{~B}^{*} \mathrm{~s}\right)$ product is equal to $\mathrm{N}$. However, when $\mathrm{A}$ decides to sell less than $\mathrm{N}$ in market $\mathrm{X}$, firm $\mathrm{B}$ may satisfy residual demand, provided that it does not offer negative utility to the consumers.

\subsubsection{Costs}

Contrary to Chapters 2 and 3 , the firms have the disposal over limited capacity in this chapter. Assumption 4.2 describes the firms' production technology.

Assumption 4.2. The capacities of both firms equal $\mathrm{K}$, where $\mathrm{N}<\mathrm{K} \leq 2 \mathrm{~N}$. ${ }^{(4)}$ Both firms are able to produce both products at constant marginal cost mc - up to capacity - without incurring any switching costs.

Capacity is more than sufficient to satisfy home market demand, but it is not larger than the amount necessary to satisfy demand in both markets. Note that there are no switching costs in terms of process technology: Substitutability in production is perfect.

With respect to product quality, firm $A$ and $B$ again have the same initial positions: $Q_{a, 1}{ }^{x}=Q_{b, 1}{ }^{x}=Q_{a, 1}{ }^{y}=Q_{b, 1}{ }^{y}$. Subscripts a and $b$ refer to the respective firms (A and $\mathrm{B}$ ), subscript 1 to period 1 and superscripts $\mathrm{x}$ and $\mathrm{y}$ to the respective goods and markets ( $\mathrm{X}$ and $\mathrm{Y}$ ). In order to simplify the calculations, the above assumption is sharpened as follows.

Assumption 4.3. $\mathrm{Q}_{\mathrm{a}, 1}{ }^{\mathrm{x}}=\mathrm{Q}_{\mathrm{b}, 1}{ }^{\mathrm{x}}=\mathrm{Q}_{\mathrm{a} .1 .}{ }^{\mathrm{y}}=\mathrm{Q}_{\mathrm{b}, 1}{ }^{\mathrm{y}}=\mathrm{mc} .^{(5)}$

With respect to product innovations, the following set of assumptions is made.

Assumption 4.4. Firm A (B) may raise the quality of its good in market $\mathrm{X}$ (Y) from period 1 to period 2 with $\Delta Q^{*}$ at cost $S C$, where both $\Delta Q^{*}$ and $S C$ are constant. When firm $A(B)$ increases the quality of its good in market $X(Y)$, it is also able to increase the quality of its good in market $Y(X)$ with $\beta \Delta Q^{*}$, where $0 \leq \beta \leq 1$. Firm $A$ only invests in product X's quality and firm B only in product Y's quality.

(4) The results for $K=2 \mathrm{~N}$ can be shown to hold for $\mathrm{K}>2 \mathrm{~N}$ as well.

(5) This assumption may be defended on the following ground. Utility equals the difference between quality and price. There may be a competitive fringe in market $X$ and $Y$ which is able to produce at quality $Q_{1,1}{ }^{j}[i \in\{a, b\}$ and $j \in\{x, y\}]$. When this is so, firm $A$ and firm $B$ can only elevate price over marginal cost when they have a higher quality than the fringe firms. The mark up over marginal cost depends on the quality increase $\Delta Q^{*}$ acquired in the $R \& D$ process: $P=m c+\phi \Delta Q^{*}[0 \leq \phi \leq 1]$. This would suffice to defend the above assumption. 
The following remarks can be made with respect to this assumption. (1) Improving upon product quality entails sunk costs. (2) Raising product quality in one market enables firms to raise product quality in related markets as well. In this way, intrafirm and interproduct spillovers are incorporated into the model. The spillover rate $\beta$ may be seen as the degree in which knowledge has generic attributes [Teece (1980: 226)]. (3) When $\beta<1$, firm A faces a barrier to entry into market $Y$. This barrier could also have been modelled using a pure entry cost $\varepsilon$ [W\&W (1992)]. (4) We again impose symmetry: $\Delta Q_{a}{ }^{*}=\Delta Q_{b}{ }^{*}, S_{a}=S C_{b}$ and $\beta_{a}=\beta_{b}$. In future research we will check whether the symmetry assumption may be relaxed.

We may summarize the above as follows. (1) There are no switching costs in terms of process technology, but firms may run into a capacity constraint. (2) Improving upon quality entails the sinking of costs. (3) There are no pure entry costs, but since inter-product spillovers generally are not perfect, the entrants face a barrier to entry relative to the incumbents.

In principle, the decisions on $R \& D$, prices and supply are governed by the assumption of profit maximization. However, in order to reduce the number of equilibria, some additional assumptions are made.

Assumption 4.5. (i) Firms maximize profits. (ii) When a firm faces positive demand in both markets and the gross profit margin is the same in both markets, the home market is supplied first. (iii) When more than one strategy leads to the same level of profits, the strategy leading to the highest production level is preferred. (iv) When a successful entry strategy does not raise profits or production, the entry market price is set at the monopoly level.

According to part (ii) of the above assumption, firms have a small preference for their home market, just like consumers do. Part (iii) implies, among other things, that if the gross profit margin is zero, a firm meets all demand it faces, at least in so far it does not have a more profitable option. It also implies that price strategies leading to a zero profit equilibria with positive consumer demand are preferred over those leading to zero profit equilibria without any consumer demand.

Now demand and costs are fully sketched, we may turn to analyze the outcomes of the competition process. Before the decisions are analyzed, a benchmark is defined in order to compare the results achieved with this benchmark. We again follow W\&W (1992: 443) closely. Equilibria may be characterized by the prices set and the supplies offered for sale: $\left(\mathrm{P}_{\mathrm{a}}{ }^{\mathrm{x}}, \mathrm{P}_{\mathrm{a}}{ }^{y}, \mathrm{P}_{\mathrm{b}}{ }^{\mathrm{x}}, \mathrm{P}_{\mathrm{b}}{ }^{y}, \mathrm{~S}_{\mathrm{a}}{ }^{x}, \mathrm{~S}_{\mathrm{a}}{ }^{y}, \mathrm{~S}_{\mathrm{b}}{ }^{\mathrm{x}}, \mathrm{S}_{\mathrm{b}}{ }^{y}\right)$ where $\mathrm{S}^{j}$ denotes supply (i $\in\{a, b\}$ and $j \in\{x, y\})$. W\&W define an (imperfect) contestable equilibrium by $\left(P_{a}{ }^{x}\right.$ $=m c+\varepsilon, P_{a}{ }^{y}=m c+\varepsilon+\eta, P_{b}{ }^{x}=m c+\varepsilon+\eta, P_{b}{ }^{y}=m c+\varepsilon, S_{a}{ }^{x}=X(m c+\varepsilon), S_{a}{ }^{y}=0, S_{b}{ }^{x}=0$, $S_{b}{ }^{y}=Y(m c+\varepsilon)$ ). $X$ and $Y$ represent demand in market $X$ and $Y$, respectively; $\varepsilon$ is an entry cost - analogous to the quality differential $(1-\beta) \Delta Q^{*}$ - and $\eta$ is a non-negative parameter. Since $\eta$ is not negative, the entrant's price is not lower than the incumbent's price as a consequence of which entry is forestalled. The equilibrium is characterized by the fact that entry is deterred. The contestability equilibrium is (only) perfect if $\varepsilon$ equals zero [Baumol (1982)]. In this case the equilibrium price reduces to marginal cost. The equilibrium is also characterized by the fact that all 
demand is met and there is no excess supply.

W\&W's definition refers to a situation of mutual entry deterrence. This does not imply anything for the mark-up over marginal cost. The latter is even substantial if $\varepsilon$ is sufficiently large. For this reason, it is more appropriate to refer to the above defined equilibrium as a limit price equilibrium instead of an (imperfect) contestable equilibrium. For this reason we define equilibrium analogous to W\&W, but refer to it as a limit price scenario.

Definition 4.1. A limit price scenario is defined as $\left(\Delta \mathrm{Q}_{\mathrm{a}}=\Delta \mathrm{Q}^{*}, \Delta \mathrm{Q}_{\mathrm{b}}=\Delta \mathrm{Q}^{*}, \mathrm{P}_{\mathrm{a}}{ }^{\mathrm{x}}=\right.$ $m c+(1-\beta) \Delta Q^{*}, P_{a}{ }^{y}=m c+\eta, P_{b}{ }^{x}=m c+\eta, P_{b}{ }^{y}=m c+(1-\beta) \Delta Q^{*}, S_{a}{ }^{x}=N, S_{a}{ }^{y}=0, S_{b}{ }^{x}=0$, $S_{\mathrm{b}}{ }^{\mathrm{y}}=\mathrm{N}$ ) where $\eta \geq 0$.

In the limit price equilibrium entry is deterred. The equilibrium price exceeds marginal cost with the quality difference that results when both firms invest in product R\&D. The equilibrium constitutes a perfect barrier market equilibrium if the mark-up over marginal cost is equal to average sunk cost ( $\mathrm{SC} / \mathrm{N}$ ) [ $\mathrm{Van}$ Witteloostuijn and Maks (1988)]. It constitutes an imperfect barrier market equilibrium if the mark-up is slightly higher. As stated above, the inability to supply the same quality is a barrier to entry in Bain's (1956) sense. Like W\&W we also require that in equilibrium supply equals demand and that there is no excess supply $\left(S_{a}{ }^{y}=0\right.$ and $\left.S_{b}{ }^{x}=0\right)$.

\section{Simultaneity}

In this section we will investigate for which values of $\beta$ and $\mathrm{K}$ Nash-equilibria may be derived from the above demand and supply conditions. We will show that the firms face a coordination problem when there is some scope for imperfect competition. In the next section we will investigate the nature of equilibria in a sequential decision structure.

In order to derive subgame perfect equilibria the principle of backward induction should be applied. The price and supply decisions are therefore studied before the $R \& D$ decisions are. In this section we will pinpoint our attention to the case in which both firms invested in product R\&D. The other cases are trivial in terms of price and supply equilibria [Appendix A]. When firm A has invested and firm B not, firm A may charge a mark-up equal to $\Delta Q^{*}$ in market $X$ and $\beta \Delta Q^{*}-\omega$ in market $Y$ where $\omega \downarrow$ 0 . When firm $B$ has invested and firm $A$ not, firm $B$ may charge a mark-up equal to $\Delta Q^{*}$ in market $Y$ and $\beta \Delta Q^{*}-\omega$ in market $X$. When both firms do not invest, gross profits are zero.

This leaves the case in which both firms invest in product $R \& D$. In this case firm A has quality $\left(m c+\Delta Q^{*}\right)$ in market $X$, its home market, and quality $\left(m c+\beta \Delta Q^{*}\right)$ in market $Y$; firm $B$ has quality $\left(m c+\beta \Delta Q^{*}\right)$ in market $X$ and quality $\left(m c+\Delta Q^{*}\right)$ in market $Y$. In principle, prices are continuous variables. However, the set of possible prices may be subdivided in a way which allows one to trace the further implications of the price decisions more easily. With respect to the home market price, a distinction is made between the set of prices enabling the rival to undercut the 
a price leaving a non-negative profit margin, and the set of prices which does not. Firm $A$ is undercut whenever $\left(Q_{a}{ }^{x}-P_{a}{ }^{x}\right)<\left(Q_{b}{ }^{x}-P_{b}{ }^{x}\right)$. Since both firms invested in product $R \& D, Q_{a}{ }^{x}=m c+\Delta Q^{*}$ and $Q_{b}{ }^{x}=m c+$

$\beta \Delta Q^{*}$. Undercutting firm $A$ is possible at a non-negative profit rate if $m c \leq P_{b}{ }^{x}$. Successful undercutting is possible with a non-negative profit margin if $m c \leq \mathrm{P}_{b}{ }^{{ }^{x}}<$ $\mathrm{P}_{\mathrm{a}}{ }^{\mathrm{x}}+\left(\mathrm{Q}_{\mathrm{b}}{ }^{\mathrm{x}}-\mathrm{Q}_{\mathrm{a}}{ }^{\mathrm{x}}\right) \Leftrightarrow \mathrm{mc} \leq \mathrm{P}_{\mathrm{b}}{ }^{\mathrm{x}}<\mathrm{P}_{\mathrm{a}}{ }^{\mathrm{x}}+(\beta-1) \Delta \mathrm{Q}^{*} \Leftrightarrow \mathrm{mc}+(1-\beta) \Delta \mathrm{Q}^{*} \leq \mathrm{P}_{\mathrm{b}}{ }^{\mathrm{x}}+(1-\beta) \Delta \mathrm{Q}^{*}<\mathrm{P}_{\mathrm{a}}{ }^{\mathrm{x}}$. (A similar argument applies to market $Y$.) The set of prices inhibiting successful entry at a non-negative profit rate thus equals $\left[\mathrm{mc}, \mathrm{mc}+(1-\beta) \Delta \mathrm{Q}^{*}\right]$ and the one enabling successful entry at such a rate $\left\langle\mathrm{mc}+(1-\beta) \Delta \mathrm{Q}^{*}, \mathrm{mc}+\Delta \mathrm{Q}^{*}\right]$. In the analysis below, the first set is restricted to the maximum price making undercutting unprofitable.

Assumption 4.6. The home market price is either $\mathrm{P}=m c+(1-\beta) \Delta \mathrm{Q}^{*}$ or $\mathrm{P}=\mathrm{mc}+\mu \Delta \mathrm{Q}^{*}$ where $\mu<(1-\beta) \leq 1$.

In the analysis below, the first strategy $-P=\operatorname{mc}+(1-\beta) \Delta Q^{*}-$ is referred to as entry deterrence and is indicated by capital $D$. The second strategy $-P=m c+\mu \Delta Q^{*}-$ is referred to as entry accommodation and is indicated by capital $C$. To recapitulate the above, the first strategy does not enable the rival firm to undercut the incumbent at a price not lower than marginal cost, while the second strategy does.

With respect to the entry market price, there again are two options: The entry price is set such that the incumbent is undercut or such that it is not. With respect to these options, the following assumptions are made.

Assumption 4.7. When a firm decides to undercut its rival, it does so slightly. When a firm decides to forgo undercutting, it sets a price skimming all consumer surplus.

If firm $A$ decides to undercut firm $B$, we have $P_{a}^{y}=m c+\left[\mu_{b}^{y}-(1-\beta)\right] \Delta Q^{*}-\omega$ where $\omega \downarrow$ 0 . If firm $A$ decides to forgo undercutting, we have $P_{a}^{y}=m c+\beta \Delta Q^{*}$. In the analysis below, the undercutting is indicated by capital $\mathrm{E}$; forgoing entry is indicated by capital F.

The firms may follow two types of strategies with respect to home market prices and also with respect to entry market prices. As a result, sixteen possibilities need to be considered. Appendix B discusses the supply decisions of all sixteen cases as well as the decisions on the entry market prices for the (D,D)-, the (C,D)- and the (D,C)subgames. These decisions are used to summarize gross profits in normal form [Table 4.3]. Table 4.3 neglects some strategies with respect to entry market prices, since they are either dominated or ruled by Assumption 4.5 (iv). This assumption implies that a firm forgoes entry if undercutting does not increase either profits or production. Appendix B shows that undercutting - strategy E - does not raise either profits or production in the (D,D)-subgame. In fact, any pair of strategies in this subgame leads to the same levels of production and market prices. For this reason we assume that the firms forgo entry in this subgame [Assumption 4.5 (iv)]. Appendix B also shows that in the (D,C)- and (C,D)-subgames the deterring firm plays always undercuts its rival in order to raise profits (or production). The accommodating firm either prefers forgoing entry or is indifferent between undercutting and forgoing. In 


\begin{tabular}{|c|c|c|c|c|}
\hline \multicolumn{5}{|c|}{$\begin{array}{l}\text { Table } 4.3 \\
\text { The price game in a normal form setting }\end{array}$} \\
\hline & & \multicolumn{3}{|l|}{ Firm B } \\
\hline & & $\mathrm{D}$ & \multicolumn{2}{|l|}{$\mathrm{A}$} \\
\hline \multirow[t]{3}{*}{ Firm A } & $\mathrm{D}$ & $\begin{array}{l}\pi_{a}(D, F)=1-\beta \\
\pi_{b}(D, F)=1-\beta\end{array}$ & \multicolumn{2}{|c|}{$\begin{array}{l}\pi_{a}(D, E)=\max \left[(1-\beta)+(\kappa-1)\left(\mu_{b}-1+\beta\right),(\kappa-1)(1-\beta)+\left(\mu_{b}-1+\beta\right)\right] \\
\pi_{b}(A, F)=(2-\kappa) \mu_{b} \text { or }(2-\kappa) \beta^{*}\end{array}$} \\
\hline & \multirow[t]{2}{*}{$\mathrm{A}$} & \multirow[t]{2}{*}{$\begin{array}{l}\pi_{2}(A, F)=(2-\kappa) \mu_{2} \text { or }(2-\kappa) \beta^{* *} \\
\pi_{b}(D, E)=\max \left[(1-\beta)+(\kappa-1)\left(\mu_{2}-1+\beta\right)\right. \\
\left.\quad(\kappa-1)(1-\beta)+\left(\mu_{2}-1+\beta\right)\right]\end{array}$} & $\begin{array}{l}\pi_{a}(A, E)=\mu_{b}-1+\beta \\
\pi_{b}(A, E)=\mu_{a}-1+\beta\end{array}$ & $\begin{array}{l}\pi_{a}(A, E)=\max \left[\mu_{a}+(\kappa-1)\left(\mu_{b}-1+\beta\right),\right. \\
\left.(\kappa-1) \mu_{a}+\left(\mu_{b}-1+\beta\right)\right] \\
\pi_{b}(A, F)=(2-\kappa) \mu_{b} \text { or }(2-\kappa) \beta^{\dagger}\end{array}$ \\
\hline & & & $\begin{array}{l}\pi_{a}(A, F)=(2-\kappa) \mu_{a} \text { or }(2-K) \beta^{\ddagger} \\
\pi_{b}(A, E)=\max \left[\mu_{b}+(\kappa-1)\left(\mu_{a}-1+\beta\right)\right. \\
\left.\quad(\kappa-1) \mu_{b}+\left(\mu_{a}-1+\beta\right)\right]\end{array}$ & $\begin{array}{l}\pi_{\mathrm{a}}(\mathrm{A}, \mathrm{F})=\mu_{\mathrm{a}} \\
\pi_{\mathrm{b}}(\mathrm{A}, \mathrm{F})=\mu_{\mathrm{b}}\end{array}$ \\
\hline \multicolumn{5}{|c|}{$\begin{array}{l}\text { Firm B's gross profits depend on the way firm A allocates its capacity over the two markets. The latter depends on the } \\
\text { profitability of the two markets. When } 1-\beta \geq \mu_{b}-1+\beta \text {, firm A supplies its home markets first. Firm B obtains gross } \\
\text { profits from residual demand }(2-\kappa) \text { in its home market: } \pi_{b}=(2-\kappa) \mu_{b} \text {. When } 1-\beta<\mu_{b}-1+\beta, \pi_{b}=(2-\kappa) \beta \text {. } \\
\text { When } 1-\beta \geq \mu_{a}-1+\beta, \pi_{a}=(2-\kappa) \mu_{a} ; \text { otherwise, } \pi_{a}=(2-\kappa) \beta \text {. } \\
\text { When } \mu_{a} \geq \mu_{b}-1+\beta, \pi_{b}=(2-\kappa) \mu_{b} ; \text { otherwise, } \pi_{b}=(2-\kappa) \beta \text {. } \\
\text { When } \mu_{b} \geq \mu_{a}-1+\beta, \pi_{a}=(2-\kappa) \mu_{a} ; \text { otherwise, } \pi_{a}=(2-\kappa) \beta \text {. }\end{array}$} \\
\hline
\end{tabular}


the latter case the accommodating firm is assumed to forgo entry because of Assumption 4.5 (iv).

In Table 4.3 gross profits are normalized for (1) the quality increase $\Delta Q^{*}$ and (2) the number of consumers. (1) The mark-up over marginal cost is always a multiplicative function of $\Delta Q^{*}$. This allows us to divide gross profits by $\Delta Q^{*}$ without loss of generality. (2) The number of consumers served per market equals $\mathrm{N}, \mathrm{K}-\mathrm{N}$ or $2 \mathrm{~N}-\mathrm{K}$ [Table 4.3]. In Table 4.3, demand is normalized by dividing through $\mathrm{N}$. Demand is represented by $1, \kappa-1$ or $2-\kappa$ respectively, where $\kappa=K / N$. The main results of this section are laid down in the following proposition. Thereupon we provide the proof and some discussion. The strategies indicated in the proposition refer to price strategies only. The decisions on supply are left out of consideration. They are implicitly taken into account, since the supply strategies [Appendix B] are used to construct Table 4.3 on the basis of which we will analyse the price decisions.

Proposition 4.I. (i) ((C,E); (C,E)) and ((C,F); (C,F)) are no Nash-equilibria of the $\left(\Delta Q^{*}, \Delta Q^{*}\right)$-subgame. (ii) When $\kappa>1+\beta,((D, F) ;(D, F))$ is a Nash-equilibrium of the $\left(\Delta Q^{*}, \Delta Q^{*}\right)$-subgame. (iii) When $\kappa \leq 1+\beta$, but $\kappa>(3 / 2)$ and $\kappa>3-1 / \beta,((D, F) ;(D, F))$ again is a Nash-equilibrium of the $\left(\Delta Q^{*}, \Delta Q^{*}\right)$-subgame.

Proof. (i) There are three symmetric outcomes: ((D,F); (D,F)), ((C,E); (C,E)) and $((C, F) ;(C, F))$ where the first term in ()-brackets denotes firm A's strategy and the second firm B's. Take outcome ( $(\mathrm{C}, \mathrm{F}) ;(\mathrm{C}, \mathrm{F}))$. Suppose that both firms accommodated entry and consider whether to undercut or to forgo entry. It is easy to infer from Table 4.3 that $(\mathrm{F} ; \mathrm{F})$ is not a Nash-equilibrium of the (C,C)-subgame, since undercutting raises gross profits (or production) given the rival's strategy since $\kappa>1$. This implies that $((\mathrm{C}, \mathrm{F}) ;(\mathrm{C}, \mathrm{F}))$ is not a Nash-equilibrium. Take outcome ((C,E); $(\mathrm{C}, \mathrm{E})$ ). Suppose that $(\mathrm{E}, \mathrm{E})$ is a Nash-equilibrium of the $(\mathrm{C}, \mathrm{C})$-subgame. Than it is easy to infer from Table 4.3 that entry deterrence dominates entry accommodation since $K>1$. This implies that $((\mathrm{C}, \mathrm{E})$; $(\mathrm{C}, \mathrm{E}))$ cannot be a Nash-equilibrium. Under (ii) and (iii) we prove that $((\mathrm{D}, \mathrm{F}) ;(\mathrm{D}, \mathrm{F}))$ is a Nash-equilibrium for the indicated values of $\beta$ and $\kappa$.

(ii) Consider ((D,F); $(D, F))$. When limit prices are set in the first stage of period 2 , the firms have no incentive to undercut each other in the second stage [Appendix B]. In the first stage of the second period the firms consider whether entry deterrence is more profitable than entry accommodation. The highest level of profits obtained by the firm accommodating entry is (2- $\kappa)$. The firm accommodating entry prefers entry deterrence whenever $(1-\beta) \geq(2-\kappa) \Leftrightarrow \kappa \geq 1+\beta$. For these values of $\beta$ and $\kappa,((D, F)$; $(D, F))$ is a Nash-equilibrium and the asymmetric outcomes $((D, F) ;(C, E))$ and $((C, E)$; $(D, F))$ are not. These values are indicated by area $I$ in Figure $4.1 .((D, F) ;(D, F))$ is not a unique Nash-equilibrium, since $((D, F) ;(D, E)),((D, E) ;(D, F))$ and $((D, E) ;(D, E))$ are Nash-equilibria as well. However, all four equilibria lead to the same outcomes in terms of production and market prices [Appendix B]. In order to know whether there are equilibria leading to other outcomes in terms of production and market price, it is necessary to check whether there are Nash-equilibria in which both furms accommo- 
date entry. However, from (i) we know that only the asymmetric outcomes in which both firms accommodate may be Nash-equilibria. In these equilibria, the accommodating firm obtains a maximum of $(2-\kappa)$. Since it may obtain a minimum of (1- $\beta$ ) by deterring entry, entry accommodation cannot be a Nash-equilibrium for $\kappa>1+\beta$. As a result, equilibrium production and market prices are given by $((D, F) ;(D, F))$.

(iii) However, there are more values of $\beta$ and $\kappa$ for which the limit price scenario constitutes a Nash-equilibrium, since gross profits on residual demand may be lower than (2-K). Suppose that firm A considers accommodating entry. Profits from residual demand depend on the mark-up charged in the home market $\mu_{\mathrm{a}}$ and firm B's supply policy. Firm $B$ serves its home market first whenever the profit margin in its home market $(1-\beta)$ is not lower than the profit margin in firm A's market $\left(\mu_{\mathrm{a}}-1+\beta\right)$, i.e. $1-\beta$ $\geq \mu_{\mathrm{a}}-1+\beta \Leftrightarrow 2-2 \beta \geq \mu_{\mathrm{a}}$, where $\mu_{\mathrm{a}} \leq 1$. Firm A's gross profits from residual demand in its home market are $(2-\kappa) \mu_{\mathrm{a}}$, where $\mu_{\mathrm{a}}=2-2 \beta \leq 1$, while gross profits from residual demand in firm B's market equal (2-K) $\beta$. Residual demand in the home market is more profitable when $(2-\kappa)(2-2 \beta) \geq(2-\kappa) \beta \Leftrightarrow \beta \leq(2 / 3)$. If $0.5<\beta \leq(2 / 3)$ firm $A$ does not charge the monopoly price when it accommodates entry in order to prevent total entry. If $\beta>(2 / 3)$, firm $A$ prefers total over partial entry. If $0 \leq \beta \leq 0.5$, firm $A$ deters entry when $1-\beta \geq 2-\kappa \Leftrightarrow \kappa \geq 1+\beta$, as before. If $0.5<\beta \leq(2 / 3)$, firm $A$ prefers entry deterrence as long as $1-\beta \geq(2-\kappa)(2-2 \beta) \Leftrightarrow \kappa \geq(3 / 2)$. If $(2 / 3)<\beta \leq 1$, entry deterrence is a Nash-equilibrium when $1-\beta \geq(2-\kappa) \beta \Leftrightarrow \kappa \geq 3-1 / \beta$. This proves the second part of the proposition. However, this equilibrium does not necessarily characterize production and market prices, since outcomes in which both firms accommodate entry may be Nash-equilibria as well. In Appendix C, however, we will prove that there are no Nash-equilibria in which both firms accommodate entry for these values of $\beta$ and $\kappa$. The additional values of $\beta$ and $\kappa$ for which production and market prices are characterized by $((\mathrm{D}, \mathrm{F}) ;(\mathrm{D}, \mathrm{F}))$ are indicated by area II in Figure 4.1. Q.E.D.

Figure 4.1 gives the Nash-equilibria in $(\beta, \kappa)$-space. Since all Nash-equilibria discussed above characterize a unique pattern of production and market prices, we have that entry is deterred in areas I and II. Proposition 4.1 suffices to show that production and market prices are not uniquely determined in area III, since only asymmetric Nash-equilibria may exist in this area. Even if there are asymmetric Nash-equilibria, the firms face a coordination problem. Appendix D discusses some asymmetric Nash-equilibria. Since the equilibria are asymmetric, coordination is required. Coordination does not come about in a purely non-cooperative world. Coordination suffices to establish an asymmetric Nash-equilibrium, since - by definition - no firm has any incentive to diverge from such an outcome.

Consider area I. Entry deterrence is more profitable when capacity is relatively large. When capacity is large, there is less residual demand for the firm being undercut in both markets. Entry deterrence is less profitable when the quality levels are similar, i.e. when the spillover rate is high. In such a situation the barrier market price approaches marginal cost. This explains why entry deterrence is profitable if $\kappa$ $\geq 1+\beta$. In area II the market leader has an incentive to enter totally. This makes entry 


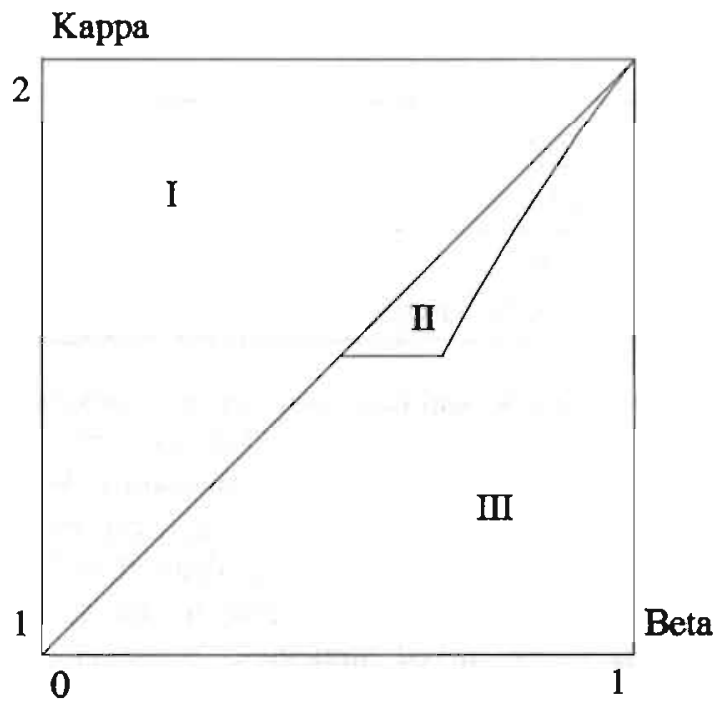

Figure 4.1: Sequential price equilibria

accommodation less profitable since the profit margin from residual demand is lower, either because the mark-up set in the home market is lower in order to prevent total entry or because residual demand is left in the entrant's market where the accommodating firm's quality is lower. This explains why entry deterrence is a Nash-equilibrium in area II as well. In areas I and II equilibrium production and market prices are characterized by $((D, F) ;(D, F))$. These areas correspond with W\&W's definition of imperfect contestability. Perfect contestability is only reached for $\beta=1$ and $\kappa \geq 2$ [Baumol (1982)].

There are no symmetric Nash-equilibria in which both firms accommodate entry for the following reasons. If both firms accommodate entry, a firm does not forgo entry, when the rival firm does, since the latter fact enables it to employ residual capacity profitably. A firm does not accommodate entry, when the rival firm does and the firms have an incentive to undercut each other in the $(\mathrm{C}, \mathrm{C})$-subgame. If the firm accommodates entry, part of its capacity would not be employed, while it would be fully and profitably employed if the firm deterred entry.

In the first period of the competition game the firms have to decide whether they want to invest in $R \& D$ or not. Since the other values of $\beta$ and $\kappa$ require at least some coordination, we restrict our attention to areas I and II of Figure 4.1. In these areas gross profits are $(1-\beta) N \Delta Q^{*}$. Sunk cost may be defined as $S C=\sigma N \Delta Q^{*}(\sigma>0)$ without any loss of generality. Net profits thus are $(1-\beta-\sigma) N \Delta Q^{*}$. The pay-off matrix for areas I and II is given by Table 4.4. 


\begin{tabular}{|c|c|c|c|}
\hline & & \multicolumn{2}{|l|}{ Firm B } \\
\hline & & $\Delta Q=0$ & $\Delta Q=\Delta Q^{*}$ \\
\hline Firm A & $\begin{array}{l}\Delta Q=0 \\
\Delta Q=\Delta Q^{*}\end{array}$ & $\begin{array}{l}(0,0) \\
\left([1+\beta(\kappa-1)-\sigma] N \Delta Q^{*}, 0\right)\end{array}$ & $\begin{array}{l}\left(0,[1+\beta(\kappa-1)-\sigma] N \Delta Q^{*}\right) \\
\left((1-\beta-\sigma) N \Delta Q^{*},(1-\beta-\sigma) N \Delta Q^{*}\right)\end{array}$ \\
\hline
\end{tabular}

When $(\beta+\sigma) \leq 1$, both firms invest and earn non-negative profits. Sunk costs are low enough to allow both duopolists to invest. When $[1+\beta(\kappa-1)-\sigma]<0$, both firms do not invest. Sunk costs would even be too high for a monopolist. When $-\beta<\sigma-1<\beta(\kappa-$ 1), an investment in R\&D is profitable when the rival firm abstains from investing. There are two equilibria $\left(\Delta Q^{*}, 0\right)$ and $\left(0, \Delta Q^{*}\right)$. The firms thus face a dilemma. When the firms do not cooperate, they may either decide to invest or not to do so. One could solve this dilemma using mixed strategies. However, for the moment we restrict attention to pure strategy equilibria. The dilemma illustrates why several outcomes may be observed in practice. The outcomes do not even necessarily correspond with the equilibrium outcomes. Excess capacity may be attended with net losses or a absence of investments in R\&D [Loury (1979)]. When firms face net losses, they may coordinate as follows in order to solve the above dilemma. Firms may exchange technologies in such a way that intrafirm spillovers are reduced. When firms do so, the entry barrier is raised ( $\beta$ is reduced). This may make profits in the south-east quadrant positive and allow entry deterring co-existence.

The above conclusions can also be presented graphically. Figure 4.2 gives the equilibrium outcomes for $\sigma=0.4$. Area I(a) represents the limit price scenario and accords with the south east quadrant of Table 4.4. The border between area I(a) and area I(b) represents all perfect barrier market equilibria: Net profits are zero. The area (just) to the left of the border comprises imperfect barrier market solutions. Area I(b) corresponds with the south-west and the north-east quadrants of Table 4.4. The firms face a dilemma whether to invest or not. Area II refers to area III of Figure 4.1: Price coordination is or may be required for these values of $\beta$ and $\kappa$. Since price leadership is one of the most practised ways to establish price coordination [Scherer and Ross (1990)], we will now explore what kind of price (and R\&D) equilibria price leadership evolve, when firms decide on prices sequentially.

\section{Sequentiality}

In this section decisions are taken sequentially rather than simultaneously. Section 3 shows that when capacity is small relative to intrafirm spillovers $[\kappa<(1+\beta)]$, it is profitable to raise price above the barrier market level. However, Section 3 also reveals that some coordination is required in order to establish a price-equilibrium for these capacity levels. We therefore allow firms to coordinate somewhat more. In this 


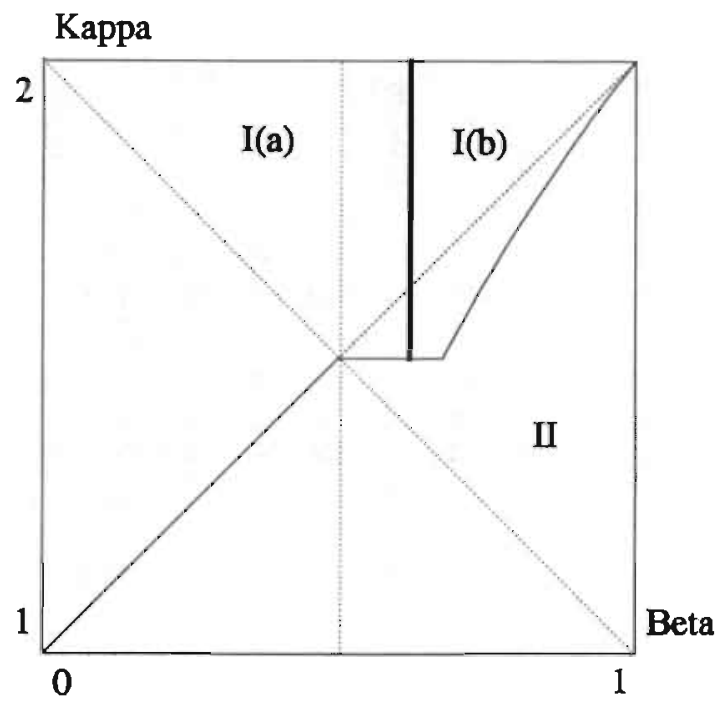

Figure 4.2: Simultaneous price and R\&D equilibria

section firms cooperate by setting prices sequentially: One of the firms acts as a price leader. Price leadership is a well known device to establish a cooperative solution [Scherer en Ross (1990: 248n)]. In Markham (1951) the price leader sets a monopoly price and allows followers to undercut him. In this chapter the leader sets a limit price and leaves (monopoly profits) from residual demand for the follower. This result may, for example, describe the (European) car industry rather well [Kirman and Schüller (1990: 71)].

The decision structure laid down in Table 4.2 is still valid in general. But now we assume that firm A decides in its home market price before firm $B$ does, and also on its entry market price before firm $B$ does. The decision structure of the $\left(\Delta Q^{\circ}\right.$, $\Delta \mathrm{Q}^{*}$ )-subgame is now given by Table 4.5 . We still assume that the firms decide on (R\&D) and supply simultaneously. As before, capital D refers to entry deterrence by limit pricing and capital $\mathrm{C}$ to entry accommodation. Capital $\mathrm{F}$ indicates forgoing entry and capital E undercutting. With respect to entry accommodation, the following assumption is made.

Assumption 4.8. When a firm accommodates entry, price is set at the monopoly level: $\mathrm{P}=\mathrm{mc}+\beta \Delta \mathrm{Q}^{*}$.

The outcomes of the (D,D)-, the (C,D)- and the (D,C)-subgames may be inferred from Appendix B. All four outcomes of the (D,D)-subgame lead to the same levels of gross profits. By Assumption 4.5 (iv) both firms forgo entry, since entry does not raise either gross profits or production. In the (C,D)- and (D,C)-subgames, the deterring firm always prefers to undercut its accommodating rival, since undercutting raises gross profits (or production). The accommodating firm forgoes entry, since forgoing entry may raise gross profits and will not lower them [Assumption 4.5 (i) 
Table 4.5: Sequential structure of the high-qualities subgame

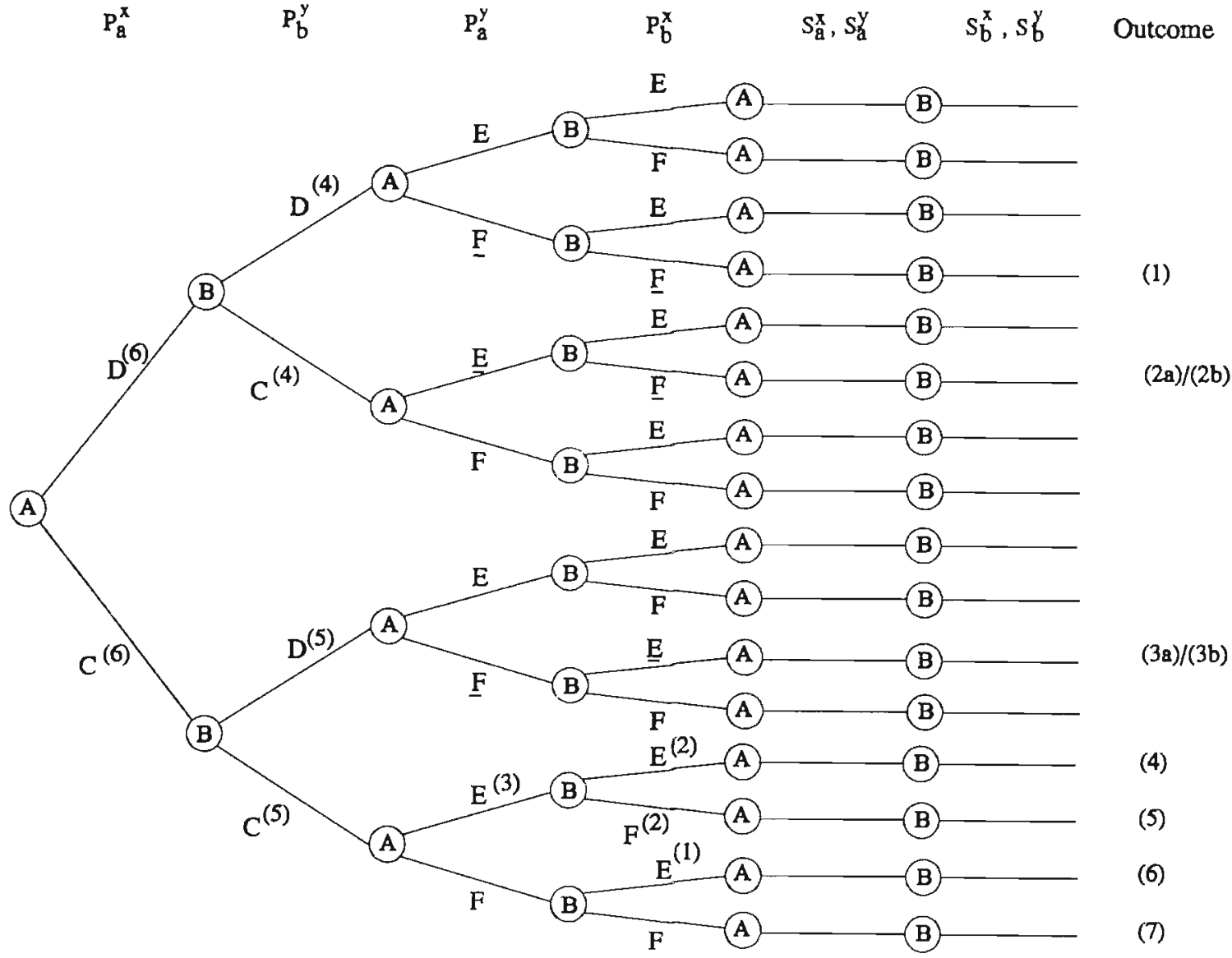


and (iv)]. The equilibrium strategies in the (D,D)-, (C,D)- and (D,C)-subgames are underlined. Table 4A.3 gives gross profits of all seven outcomes [Appendix E]. The superscripts $\left(^{*}\right)$ in Table 4.5 give the subgame perfect equilibria. We will now establish a proposition first, prove it afterwards and interpret it in the end.

Proposition 4.2. (i) When either $\beta \leq 0.5$ and $\kappa>1+\beta$ or $\beta>0.5, \kappa>3-1 / \beta$ and $\kappa>$ $(3-2 \beta) /(2-\beta),((D, F) ;(D, F))$ is a Nash-equilibrium. (ii) When $\beta \leq 0.5$ and $1+\beta<\kappa<$ $(1+2 \beta) /(1+\beta),((D, E) ;(C, F))$ is a Nash-equilibrium characterized by partial entry. (iii) When $\beta>0.5$ and $3-1 / \beta<\kappa<(3-2 \beta) /(2-\beta),((D, E) ;(C, F))$ is a Nash-equilibrium characterized by total entry. (iv) When $\kappa<(1+2 \beta) /(1+\beta)$ and $\kappa<(3-2 \beta) /(2-\beta)$, $((\mathrm{C}, \mathrm{E}) ;(\mathrm{C}, \mathrm{F}))$ is a Nash-equilibrium.

The proof is deferred to Appendix E.

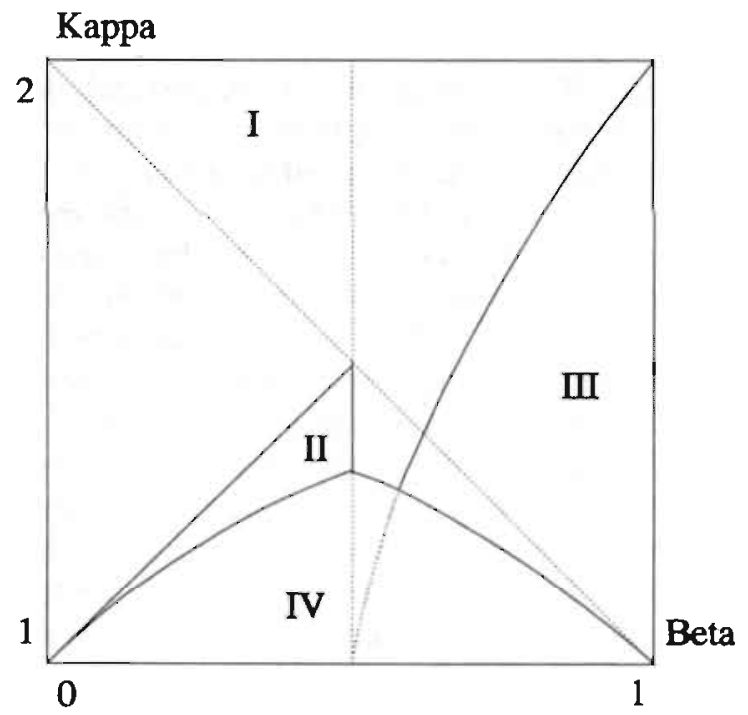

Figure 4.3: Sequential price equilibria

The proposition is depicted by Figure 4.3. In area I limit prices are set. In areas II, III and IV firm B allows firm A to enter its home market and charges the monopoly price. In areas II and III firm A sets the limit price in order to deter entry by firm B. In area IV firm $A$ also charges the monopoly price. Area $I$ is similar to area $I$ in Figure 4.1. Since firm A has a first mover advantage, firm B is the one who has to choose between entry deterrence and monopoly profits from residual demand. When firm B decides between these options, it takes capacity and interproduct spillovers into account. When (excess) capacity becomes larger, residual demand becomes lower. So, the larger capacity is, the lower profits from residual demand are. This makes entry deterrence more profitable than accommodating entry when capacity is high. Entry can be deterred by limit pricing. The limit price is low when interproduct spillovers are high since the quality difference between the firms is small. Entry 
deterrence thus produces low profits when interproduct spillovers are high and thus is less profitable than accommodating entry at high spillover rates. Firm B knows that firm A will serve firm B's home market first when it accommodates entry and the spillover rate exceeds $0.5{ }^{(6)}$ When firm A serves firm B's home market first, firm $B$ receives profits from residual demand in market $X$. Since its quality is lower in market $\mathrm{X}$ than in market $\mathrm{Y}{ }^{(7)}$ profits from residual demand are lower. Entry deterrence thus becomes more attractive relative to entry accommodation. This explains the extension of area I beyond the line $\kappa=1+\beta$. The above explains part (i) of Proposition 4.2. Note that area I in Figure 4.3 coincides with area I and II of Figure 4.1, with the exception of the area in which $\beta>0.5$ and $\kappa<(3 / 2)$. This difference is due to the restriction in the set of prices the accommodating firm may choose. In Section 3 the accommodating firm chooses between entry deterrence and partial entry, and in Section 4 between entry deterrence and total entry. In Section 3 the accommodating firm sets a limit price in order to forestall total entry. In this section this possibility is precluded.

In areas II, III and IV monopoly profits on residual demand are larger than profits under entry deterrence. This explains why firm B contents himself with residual demand, even when it concerns residual demand in firm A's home market. The mark-up over marginal cost is $\Delta Q^{*}$ in firm $B^{\prime}$ s home market and $\beta \Delta Q^{*}$ in firm A's home market. When interproduct spillovers are high, monopoly profits on residual demand in the entry market are high enough for firm B to accommodate total entry [part (iii) of Proposition 4.2]. ${ }^{(8)}$ Firm B may content himself with monopoly profits on residual demand, which does not imply that it does not want to enter firm A's home market. When firm A would accommodate entry into its home market, firm B may not satisfy himself with monopoly profits on residual demand. Firm B may earn larger profits by deterring entry into its home market and undercutting firm A. Firm A consequently may have to deter entry in its home market. When firm A accommodates entry, firm $B$ has a choice between entry deterrence in market $Y$ and undercutting firm $\mathrm{A}$ in market $\mathrm{X}$ on the one hand and accommodating entry into market $\mathrm{Y}$ on the other hand. The first strategy results in more demand, the second strategy produces a higher profit margin per unit demand. The latter creates an opportunity cost. The opportunity cost is only worth making when the increase in demand compensates for the loss in profits due to the price decrease, i.e. when capacity is high.

This explains why firm B is tempted to deter entry in market $\mathrm{Y}$ and undercut firm $A$ in market $X$ in areas II and III, while it is not in area IV. This explains part

(6) When firm B accommodates entry and firm A deters entry, firm A's profit margin in market $X$ is $(1-\beta) \Delta Q^{*}$ while it is $\beta \Delta Q^{*}$ in market $Y$. Firm $A$ serves its home market first when $(1-\beta) \geq \beta$ or $0.5 \geq \beta$.

(7) Firm B's profits from residual demand are $(2 \mathrm{~N}-\mathrm{K}) \Delta \mathrm{Q}^{\circ}$ in market $\mathrm{Y}$ and $(2 \mathrm{~N}-\mathrm{K}) \beta \Delta \mathrm{Q}^{*}$ in market X.

(s) Firm $A$ will serve the entry market first when $\beta \geq 0.5$. See previous footnote. 
(ii), (iii) and (iv) of Proposition 4.2. In the latter area (excess) capacity is too low to compensate for the opportunity cost of losing monopoly profits on residual demand. In areas II and III firm A needs to deter entry in order to guarantee maximum demand; in area IV firm A may accommodate entry. Accommodating entry is more attractive at intermediate values of the spillover rate because the profit margin is quite low at these values when the alternative strategy is followed [Figure 4.3]. When $\beta$ is close to 0 , the mark-up in the home market when deterring entry is about equal to $\Delta Q^{*}$. When $\beta$ is close to 1 , the mark-up in the entry market is also close to $\Delta Q^{*}$. Notice that areas II and IV in Figure 4.3 coincide with areas IV and III in Figure 4A.1; area III in Figure 4.3 resembles area VI in Figure 4A.1. The difference is due to the additional restrictions on price imposed in this section.

\begin{tabular}{|c|c|c|}
\hline \multicolumn{3}{|c|}{$\begin{array}{l}\text { Table } 4.6 \\
\text { Gross profits }\end{array}$} \\
\hline Area & Firm A & Firm B \\
\hline $\begin{array}{l}\text { I } \\
\text { II } \\
\text { III } \\
\text { IV }\end{array}$ & $\begin{array}{l}N(1-\beta) \Delta Q^{*} \\
N \Delta Q^{*}+(K-N) \beta \Delta Q^{*} \\
N(1-\beta) \Delta Q^{*}+(K-N) \beta \Delta Q^{*} \\
(K-N)(1-\beta) \Delta Q^{*}+N \beta \Delta Q^{*}\end{array}$ & $\begin{array}{l}N(1-\beta) \Delta Q^{*} \\
(2 N-K) \Delta Q^{*} \\
(2 N-K) \beta \Delta Q^{*} \\
(2 N-K) \Delta Q^{*}\end{array}$ \\
\hline
\end{tabular}

Table 4.6 summarizes the equilibrium outcomes in terms of gross profits. Notice that firm A's gross profits are larger than firm B's: It pays to have a first-mover advantage. Recall that the above outcomes only result when both firms have an incentive to invest in $R \& D$. $R \& D$ costs may again be given by $S C=\sigma N \Delta Q^{*}$. Because firm A's gross profits are not smaller than firm B's, firm A will always invest unless an investment does not pay off for a monopolist firm. ${ }^{(9)}$ When firm B does not invest while firm A does, firm A receives monopoly profits in both markets. When R\&D costs are small enough, both firms invest. The profit levels given in Table 4.6 enable us to derive the values of $\beta$ and $\kappa$ for which firm $B$ does not invest. This enables us to exclude one area from Figure 4.3: The area in which firm B does not invest. In Figure 4.4 results are given for $\sigma=0.4$. All areas accord with Figure 4.3 with the exception of area $V$. In this area firm $A$ is the only firm investing in R\&D. This enables firm A to appropriate all surplus. The solid line between areas I and $V$ represents perfect barrier market scenarios. Points to the left of this line represent imperfect barrier market scenarios.

(9) When decisions on R\&D are taken simultaneously, expected profits are larger for firm A than they are for firm B. This implies that firm A is more likely to be the first investor than firm $B$. 


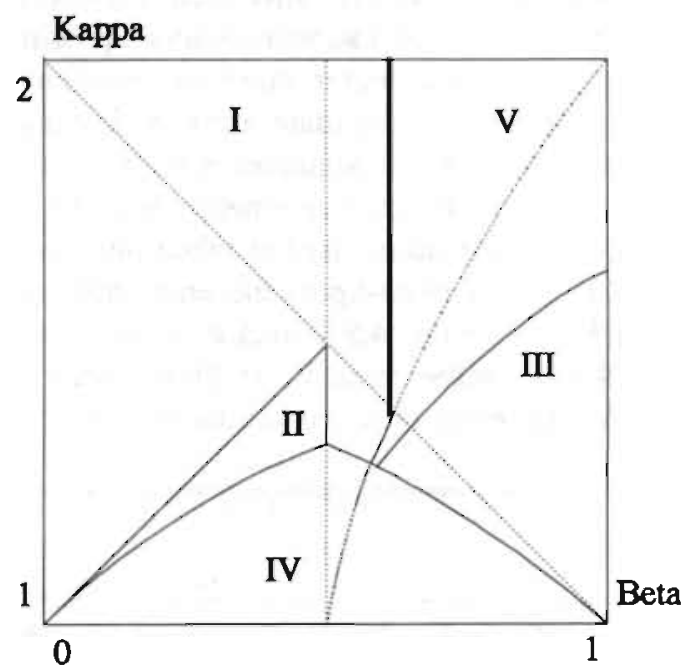

Figure 4.4: Sequential price and $R \& D$ equilibria $($ sigma $=0.4)$

\section{Discussion}

The chapter gives a simple example of a multimarket framework in which substitutability in production and interproduct and intrafirm spillovers determine whether competitive prices are set. The duopolists are able to enter each other's markets because they have some excess capacity and because they acquire knowledge which may to some degree be used in other markets. The fact that firms in technologically related markets are able to offer equivalent products using spare capacity limits the possibilities to set monopoly prices. Competitive prices are set when excess capacity is high and knowledge spillovers are high. When excess capacity of the rival firm is high, residual demand and profits are low when a firm is undercut. When knowledge spillovers are high. the limit price exceeds marginal costs slightly, since the quality of the rival product is almost as high. Thus when excess capacity is sufficiently large and spillovers are sufficiently high, competitive prices are set. As long as R\&D costs are sufficiently small, the competitive nature of price competition does not kcep the furms from investing. The chapter hereby provides an example in which investment in R\&D is combined with competitive pricing. The chapter extends the results of $\mathrm{W} \& \mathrm{~W}$ to a dynamic framework and thus gives an example of a barrier market scenario. In a barrier market scenario static and dynamic efficiency are combined [Van Witteloostuijn and Maks (1988)]. The chapter thus shows that contestable results may be reached in a dynamic framework.

When excess capacity is small or spillovers are low, prices above the limit price level are profitable. However, there is no Nash-equilibrium in pure strategies for these levels of capacity and spillovers. This is due to the fact that both firms have an incentive to sell as much as possible. It is more profitable to be undercut than to 
deter entry. However, it is even more profitable to undercut the rival firm while not being undercut yourself. Since both firms face this dilemma, they have to weigh the likelihood to be undercut against the likelihood to be able to undercut. In principle, one could solve this dilemma using mixed strategies. However, we followed another way. Price equilibria may be derived when firms are able to coordinate or when some asymmetry allows the coordination problem to be solved. In this chapter we analyzed price and R\&D equilibria under one type of asymmetry: We modelled a sequential decision structure in order to introduce a price leader. The latter phenomenon is one of the more well-known mechanisms to establish coordination between firms [Markham (1951)]. In this chapter we do not yet endogenize price leadership. This is somewhat problematic in the above model, since the duopolists are symmetric in the above model. In future research we will drop this assumption and assume that excess capacity and the spillover rate are firm specific. These extensions may allow endogenizing price leadership. The asymmetric version of the model is related to the literature on Stackelberg equilibria. In general, one may expect the more advantaged firm - higher capacity or higher spillover rate - to act as Stackelberg leader. However, a priori there is an argument against this reasoning in this setting. The more advantaged firm suffers less from being undercut than the less advantaged firm, at least when the advantage refers to capacity. This gives the less advantaged a larger incentive to deter entry. The entry deterring price depends on the spillover rate of the rival firm. This makes entry deterrence more profitable for the firm with the higher spillover rate.

The chapter also shows that firms face an investment dilemma when investing in $R \& D$ is profitable for one firm, but not for two. This dilemma may cease to exist in asymmetric versions of the above model. In future research we will find out whether these asymmetries - firm specific capacities and spillover rates - may solve this problem. However, there are also some other ways out of the dilemma. Solutions may be found using mixed strategies or other decision rules such as maximin [Van Witteloostuijn (1990: 164n)]. Firms may swap products in order to reduce spillovers between the segments in which the firms are active. Exchanging technologies enables firms to specialize in market segments which are safe from entry. This policy widens the quality difference between the firms and increases gross profits. As such it is not desirable from the consumers' points of view, but it is necessary to have both firms investing in R\&D. The latter is necessary to generate surplus for the consumers at all. Exchanging technologies seems desirable from the consumers' points of view, when firms face difficulties in recouping $R \& D$ expenses, i.e. when spillovers and $R \& D$ expenses are high. So, there again is a trade-off between static and dynamic efficiency. High spillovers are desirable in order to have low profit margins; low spillovers make the surplus arising from innovations appropriable. When firms coordinate, they may invest alternately. This type of solution is only possible when investments now do not influence investment opportunities in a later stage [Beath et al. (1989)].

In the above model the spillover rate is interpreted as an intrafirm effect in order to stress the importance of the multiple employability of technology. However, it may be interpreted as an interfirm effect - or a combination of both - as well 
[D'Aspremont and Jaquemin (1988)]. As far as spillovers are interfirm, they may be influenced by patent (and trademark) policies. Patents reduce interfirm spillovers and may mend the possible lack of appropriability. They may also cause excessive gross and net profits. Cooperation between firms with respect to $R \& D$ would raise the spillover rate. Since this would reduce gross profits, firms are not likely to do so. 


\section{Appendices to Chapter 4}

\section{A Equilibrium profits when at least one firm does not invest in R\&D}

Case 1: Both firms do not invest in R\&D

$\mathrm{Q}_{\mathrm{a}}{ }^{\mathrm{x}}=\mathrm{Q}_{\mathrm{a}}{ }^{\mathrm{y}}=\mathrm{Q}_{\mathrm{b}}{ }^{\mathrm{x}}=\mathrm{Q}_{\mathrm{b}}{ }^{\mathrm{y}}=\mathrm{mc}$

Supply

- When $P_{i}^{j}<m c[i \in\{a, b\} ; j \in\{x, y\}]$, the mark-up mu ${ }_{i}^{j}$ is negative. Since supplying is not profitable, firm i will abstain from doing so.

- When $P_{i}^{j}>m c$, demand is zero. Since supply will not be met by consumer demand, firm i will abstain from producing.

- When $\mathrm{P}_{\mathrm{a}}{ }^{\mathrm{x}}=\mathrm{mc}\left(\mathrm{P}_{\mathrm{b}}{ }^{\mathrm{y}}=\mathrm{mc}\right)$, the mark-up $\mathrm{mu}_{\mathrm{a}}{ }^{\mathrm{x}}\left(\mathrm{mu}_{\mathrm{b}}{ }^{y}\right)$ equals zero and consumer demand equals N. Firm A (B) will meet all demand [Assumption 4.5 (ii) and (iii)].

- When $P_{a}^{y}=m c\left(P_{b}{ }^{x}=m c\right)$, the mark-up equals zero and demand is positive, unless firm $B$ (A) sells at marginal cost as well. When demand is positive, firm A (B) serves market $Y$, otherwise it does not [Assumption 4.5 (iii)]. Firm A (B) meets all demand in market $\mathrm{Y}(\mathrm{X})$ fully if $\mathrm{P}_{\mathrm{a}}{ }^{\mathrm{x}}\left(\mathrm{P}_{\mathrm{b}}{ }^{\mathrm{y}}\right) \neq \mathrm{mc}$; otherwise it supplies residual capacity [Assumption 4.5 (ii)].

\section{Entry market prices}

- When $P_{a}{ }^{x}=m c$, it is not possible to enter successfully with a non-negative mark-up. In this case, firm $B$ sets the monopoly price: $P_{b}{ }^{x}=m c$ [Assumption 4.5 (iv)]. When $\mathrm{P}_{\mathrm{a}}{ }^{\mathrm{x}}<\mathrm{mc}$ or $\mathrm{P}_{\mathrm{a}}{ }^{\mathrm{x}}>\mathrm{mc}$, entry is possible at a non-negative margin. In this case, firm $\mathrm{B}$ again sets $P_{b}{ }^{x}=m c$ [Assumption 4.5 (iii)].

- Firm $A$ also sets $P_{a}^{y}=m c$.

Home market prices

- Firm B sets $\mathrm{P}_{\mathrm{b}}{ }^{y}=\mathrm{mc}$ in order to obtain maximum (home market) demand [Assumption 4.5 (ii) and (iii)].

- Firm $A$ sets $P_{a}{ }^{x}=m c$.

In equilibrium, $\mathrm{P}_{\mathrm{a}}^{\mathrm{x}}=\mathrm{P}_{\mathrm{a}}^{\mathrm{y}}=\mathrm{P}_{\mathrm{b}}{ }^{\mathrm{x}}=\mathrm{P}_{\mathrm{b}}{ }^{\mathrm{y}}=$ mc. Further, $\mathrm{S}_{\mathrm{a}}{ }^{\mathrm{x}}=\mathrm{S}_{\mathrm{b}}{ }^{\mathrm{y}}=\mathrm{N}$ and $\mathrm{S}_{\mathrm{a}}{ }^{y}=\mathrm{S}_{\mathrm{b}}{ }^{x}=0$. Firm A's gross profits are $\pi_{a}=\pi_{b}=0$. Notice that any other strategy, not restricted by Assumption 4.5, would also have led to this level of gross profits.

Case 2: Firm A invests in R\&D while firm B does not

$Q_{a}{ }^{x}=m c+\Delta Q^{*}, Q_{a}{ }^{y}=m c+\beta \Delta Q^{*}, Q_{b}{ }^{x}=Q_{b}{ }^{y}=m c$

Firm B's behaviour is described by Case 1 . Firm B sets the following prices: $P_{b}{ }^{x}=$ 
$\mathrm{P}_{:,}=\mathrm{mc}$, and supplies any demand it meets. Its gross profits are zero. For firm A the following holds.

- Firm A does not serve market $X$ if $P_{a}^{x}<m c$ - negative gross profit margin - or $P_{a}^{x}$ $>\mathrm{mc}+\Delta \mathrm{Q}^{*}$ - no demand; firm $\mathrm{A}$ does not serve market $\mathrm{Y}$ if $\mathrm{P}_{\mathrm{a}}^{\mathrm{y}}<\mathrm{mc}$ or $\mathrm{P}_{\mathrm{a}}{ }^{y}>$ $\mathrm{mc}+\beta \Delta \mathrm{Q}^{*}$.

- For any $\mathrm{P}_{\mathrm{a}}{ }^{\mathrm{x}} \in\left[\mathrm{mc}, \mathrm{mc}+\Delta \mathrm{Q}^{*}\right]$ - given $\mathrm{P}_{\mathrm{b}}{ }^{\mathrm{x}}-\mathrm{CS}_{\mathrm{a}}{ }^{\mathrm{x}} \geq \mathrm{CS}_{\mathrm{b}}{ }^{\mathrm{x}}$. Then, because of Assumption 4.1, firm $A$ 's demand in market $X$ equals $N$. Firm $A$ is willing to meet all this demand at any $\mathrm{P}_{\mathrm{a}}{ }^{\mathrm{x}} \in\left[\mathrm{mc}, \mathrm{mc}+\Delta \mathrm{Q}^{*}\right]$ as long as $\mathrm{P}_{\mathrm{a}}{ }^{x} \geq \mathrm{P}_{\mathrm{a}}{ }^{y}$ [Assumption 4.5 (ii)]. If $\mathrm{P}_{\mathrm{a}}{ }^{x}<$ $\mathrm{P}_{2}{ }^{y}$ and demand equals $\mathrm{N}$ in market $\mathrm{Y}$ as well, firm $\mathrm{A}$ uses residual capacity to serve market X.

- For any $\mathrm{P}_{\mathrm{a}}{ }^{y} \in\left[\mathrm{mc}, \mathrm{mc}+\beta \Delta \mathrm{Q}^{*}\right\rangle$ - given $\mathrm{P}_{\mathrm{b}}{ }^{\mathrm{y}}-\mathrm{CS}_{\mathrm{a}}{ }^{y}>\mathrm{CS}_{\mathrm{b}}{ }^{y}$. Then, because of Assumption 4.1, firm $\mathrm{A}$ 's demand in market $\mathrm{Y}$ equals $\mathrm{N}$. Firm $\mathrm{A}$ is willing to meet all this demand at any $\mathrm{P}_{\mathrm{a}}^{\mathrm{y}} \in\left[\mathrm{mc}, \mathrm{mc}+\beta \Delta \mathrm{Q}^{*}\right\rangle$ as long as $\mathrm{P}_{\mathrm{a}}{ }^{\mathrm{x}}<\mathrm{P}_{\mathrm{a}}{ }^{y}$ [Assumption 4.5 (ii)]. If $P^{x} \geq P_{4}^{y}$, firm $A$ uses residual capacity to serve market $Y$. If $P_{a}{ }^{y}=m c+\beta \Delta Q^{*}$, firm $A$ 's demand in market $Y$ is zero, given $P_{b}{ }^{y}$. Given firm $B$ 's preference for its home market, firm $A$ will not even obtain residual demand at this price level.

- Firm A's demand for product $Y$ is only positive when $P_{a}^{y}<m c+\beta \Delta Q^{*}$. Firm $A$ thus maximizes the gross profit margin in market $Y$ - subject to the demand constraint by setting price somewhat below the monopoly price: $P_{a}^{y}=m c+\beta \Delta Q^{*}-\omega$ where $\omega \downarrow 0$. Firm $A^{\prime}$ 's demand equals $N$ for any $P_{a}{ }^{x} \leq m c+\Delta Q^{*}$. So, it maximizes the gross profit margin by setting price at the monopoly level: $P_{a}^{x}=m c+\Delta Q^{*}$.

- In equilibrium, we have $P_{a}{ }^{x}=m c+\Delta Q^{*}, P_{a}{ }^{y}=m c+\beta \Delta Q^{*}-\omega, P_{b}{ }^{x}=P_{b}{ }^{y}=m c$. Since $P_{a}{ }^{x}$ $>\mathrm{P}_{\mathrm{a}}{ }^{\mathrm{y}}, \mathrm{S}_{\mathrm{a}}{ }^{\mathrm{x}}=\mathrm{N}, \mathrm{S}_{\mathrm{a}}{ }^{\mathrm{y}}=\mathrm{K}-\mathrm{N}, \mathrm{S}_{\mathrm{b}}{ }^{\mathrm{x}}=0$ and $\mathrm{S}_{\mathrm{b}}{ }^{y}=2 \mathrm{~N}-\mathrm{K}$. Gross profits are $\pi_{\mathrm{a}}=\mathrm{N} \Delta \mathrm{Q}^{*}+$ (K-N) $\beta \Delta Q^{*}$ for firm $A$ and $\pi_{h}=0$ for firm $B$.

Case 3: Firm $B$ invests in $R \& D$ while firm A does not

This case is analogous to case 2. In equilibrium, we have $P_{a}^{x}=P_{a}^{y}=m c, P_{b}^{x}=$ $m c+\beta \Delta Q^{x}-\omega$ and $P_{b}{ }^{y}=m c+\Delta Q^{*}$. Further, $S_{a}{ }^{x}=2 N-K, S_{a}{ }^{y}=0, S_{b}{ }^{x}=K-N$ and $S_{b}{ }^{y}=N$. Gross profits are $\pi_{\mathrm{a}}=0$ for firm $A$ and $\pi_{b}=N \Delta Q^{*}+(K-N) \beta \Delta Q^{*}$ for firm $B$.

\section{B Decisions on supply}

By assumption, the qualities in period 2 are as follows in case 4 to $19: Q_{a}{ }^{x}=Q_{b}{ }^{y}=$ $m c+\Delta Q^{*}$ and $Q_{a}{ }^{y}=Q_{b}{ }^{x}=m c+\beta \Delta Q^{*}$.

The $(D, D)$-subgame

Case 4: Strategy pair ((D,E); $(D, E))$

- By assumption, $P_{a}{ }^{x}=P_{b}{ }^{y}=m c+(1-\beta) \Delta Q^{*}$ and $P_{a}{ }^{y}=P_{b}{ }^{x}=m c-\omega$ where $\omega \downarrow 0$. - As a result $\mathrm{CS}_{\mathrm{a}}{ }^{x}<\mathrm{CS}_{\mathrm{b}}{ }^{x}$ and $\mathrm{CS}_{\mathrm{a}}{ }^{y}>\mathrm{CS}_{\mathrm{b}}{ }^{y}$. Firm $\mathrm{A}^{\prime} \mathrm{s}$ demand in market $\mathrm{Y}$ equals $\mathrm{N}$; firm $B$ 's demand in market $X$ equals $N$. 
- The mark-ups mu are as follows: $\mathrm{mu}_{\mathrm{a}}{ }^{\mathrm{x}} \geq 0, \mathrm{mu}_{\mathrm{a}}{ }^{\mathrm{y}}<0, \mathrm{mu}_{\mathrm{b}}{ }^{\mathrm{x}}<0$ and $\mathrm{mu}_{\mathrm{b}}{ }^{\mathrm{y}} \geq 0$.

- Since its mark-up in market $\mathrm{Y}$ is negative, firm A will not serve market $\mathrm{Y}$, no matter what firm B does.

- Since its mark-up in market $X$ is negative, firm $B$ will not serve market $X$, no matter what firm A does.

- As a result firm $A$ will supply $N$ units in market $X$ and firm $B N$ units in market Y.

Case 5: Strategy pair ((D,E); (D,F))

- By assumption, $\mathrm{P}_{\mathrm{a}}^{\mathrm{x}}=\mathrm{P}_{\mathrm{b}}{ }^{y}=\mathrm{mc}+(1-\beta) \Delta \mathrm{Q}^{*}, \mathrm{P}_{\mathrm{a}}{ }^{\mathrm{y}}=\mathrm{mc}-\omega$ where $\omega \downarrow 0$ and $\mathrm{P}_{\mathrm{b}}{ }^{\mathrm{x}}=$ $m c+\beta \Delta Q^{*}$.

- As a result $\mathrm{CS}_{\mathrm{a}}{ }^{\mathrm{x}} \geq \mathrm{CS}_{\mathrm{b}}{ }^{\mathrm{x}}$ and $\mathrm{CS}_{\mathrm{a}}{ }^{\mathrm{y}}>\mathrm{CS}_{\mathrm{b}}{ }^{\mathrm{y}}$. Firm $\mathrm{A}$ 's demand equals $\mathrm{N}$ in both markets.

- The mark-ups mu are as follows: $\mathrm{mu}_{\mathrm{a}}{ }^{\mathrm{x}} \geq 0, \mathrm{mu}_{\mathrm{a}}{ }^{\mathrm{y}}<0, \mathrm{mu}_{\mathrm{b}}{ }^{\mathrm{x}} \geq 0$ and $\mathrm{mu}_{\mathrm{b}}{ }^{\mathrm{y}} \geq 0$.

- Since its mark-up in market $X$ is non-negative while its mark-up in market $Y$ is negative, firm $A$ will supply $N$ units to market $X$ and none to market $Y$.

- As a result, firm $B$ will supply $N$ units to market $Y$.

Case 6: Strategy pair $((\mathrm{D}, \mathrm{F}) ;(\mathrm{D}, \mathrm{E}))$

This case is analogous to Case 5. In equilibrium, firm $\mathrm{A}$ will produce $\mathrm{N}$ units for market $\mathrm{X}$ and firm $\mathrm{B} \mathrm{N}$ units for market $\mathrm{Y}$.

Case 7: Strategy pair $((\mathrm{D}, \mathrm{F}) ;(\mathrm{D}, \mathrm{F}))$

- By assumption, $\mathrm{P}_{\mathrm{a}}{ }^{\mathrm{x}}=\mathrm{P}_{\mathrm{b}}{ }^{\mathrm{y}}=\mathrm{mc}+(1-\beta) \Delta \mathrm{Q}^{*}, \mathrm{P}_{\mathrm{a}}^{\mathrm{y}}=\mathrm{P}_{\mathrm{b}}{ }^{\mathrm{x}}=\mathrm{mc}+\beta \Delta \mathrm{Q}^{*}$.

- As a result $\mathrm{CS}_{a}{ }^{x} \geq \mathrm{CS}_{b}{ }^{x}$ and $\mathrm{CS}_{a}{ }^{y} \leq \mathrm{CS}_{b}{ }^{y}$. Firm $\mathrm{A}^{\text {'s }}$ demand equals $\mathrm{N}$ in market $\mathrm{X}$; firm B's demand equals $\mathrm{N}$ in market $\mathrm{Y}$.

- The mark-ups mu are as follows: $\mathrm{mu}_{\mathrm{a}}{ }^{\mathrm{x}} \geq 0, \mathrm{mu}_{\mathrm{a}}{ }^{\mathrm{y}} \geq 0, \mathrm{mu}_{\mathrm{b}}{ }^{\mathrm{x}} \geq 0$ and $\mathrm{mu}_{\mathrm{b}}{ }^{y} \geq 0$.

In this case both firms want to serve both markets, since all gross profit margins are non-negative. Is there an equilibrium in which firm A serves part of market $Y$ ? For this to be the case, firm B should not fully supply market Y. However, even if firm $B$ supplies market $X$ fully, it will always have some residual capacity left for market $Y$. Since firm B's profits in market $Y$ are non-negative, it will use this capacity to serve demand in market $Y$. But when firm B employs all residual capacity for market Y, firm A has residual capacity it may employ in market X. Firm A will, of course, employ this capacity to increase output in market $X$, thereby creating additional residual capacity for firm $B$, and so on. In the end both firms will supply their home markets only. 
Entry market prices in the (D,D)-subgame

So, in all cases of the (D,D)-subgame (Case 4 to 7 ), firm $A$ supplies $N$ units to its home market $(\mathrm{X})$ and firm $\mathrm{B} \mathrm{N}$ units to its home market $(\mathrm{Y})$. Equilibrium profits of the (D,D)-subgame thus are $\pi_{a}=\pi_{b}=N(1-\beta) \Delta Q^{\circ}$. This being so, we assume that the firms forgo entry in the (D,D)-subgame [Assumption 4.5 (iv)].

\section{The $(D, C)$-subgame}

Case 8: Strategy pair $((\mathrm{D}, \mathrm{E}) ;(\mathrm{C}, \mathrm{E}))$

- By assumption, $P_{a}^{x}=m c+(1-\beta) \Delta Q^{*}, P_{b}{ }^{y}=m c+\mu_{b} \Delta Q^{*}, P_{a}{ }^{y}=m c+\left[\mu_{b}-(1-\beta)-\omega\right] \Delta Q^{*}$ and $P_{b}{ }^{x}=m c-\omega$ where $(1-\beta)<\mu_{b} \leq 1$ and $\omega \downarrow 0$.

- As a result $\mathrm{CS}_{\mathrm{a}}{ }^{\mathrm{x}}<\mathrm{CS}_{\mathrm{b}}{ }^{{ }^{x}}$ and $\mathrm{CS}_{\mathrm{a}}{ }^{y}>\mathrm{CS}_{\mathrm{b}}{ }^{y}$. Firm A's demand equals $\mathrm{N}$ in market $\mathrm{Y}$; firm $B$ 's demand equals $N$ in market $X$.

- The mark-ups mu are as follows: $\mathrm{mu}_{\mathrm{a}}{ }^{\mathrm{x}} \geq 0, \mathrm{mu}_{\mathrm{a}}{ }^{\mathrm{y}} \geq 0, \mathrm{mu}_{\mathrm{b}}{ }^{\mathrm{x}}<0$ and $\mathrm{mu}_{\mathrm{b}}{ }^{\mathrm{y}} \geq 0$.

- In equilibrium, firm B will not serve market $X$ since its gross profit margin in this market is negative.

- As a result, firm A will be able and willing to produce up till capacity. The most profitable market is served first. When both markets are equally profitable, the home market is preferred due to Assumption 4.5 (ii).

- Firm B will serve residual in its home market $(Y)$, it will not serve residual demand in market $\mathrm{X}$.

- To summarize, if $(1-\beta) \geq \mu_{b}-(1-\beta)-\omega$, firm $A$ produces $N$ units for market $X$, (K-N) units for market $Y$ and firm $B(2 \mathrm{~N}-\mathrm{K})$ units for market $\mathrm{Y}$. Firm A's gross profits are $\pi_{a}=N(1-\beta) \Delta Q^{*}+(K-N)\left[\mu_{b}-(1-\beta)-\omega\right] \Delta Q^{*}$ and firm B's gross profits $\pi_{b}=(2 N-$ K) $\mu_{b} \Delta Q^{*}$. However, if $(1-\beta)<\mu_{b}-(1-\beta)-\omega$, firm $A$ produces $N$ units for market $Y$, (K$N)$ units for market $X$ and firm $B$ does not produce at all. Firm $A^{\prime}$ 's gross profits are $\pi_{a}=(K-N)(1-\beta) \Delta Q^{*}+N\left[\mu_{b}-(1-\beta)-\omega\right] \Delta Q^{*}$ and firm B's gross profits $\pi_{b}=0$.

Case 9: Strategy pair ((D,E); (C,F))

- By assumption, $P_{a}{ }^{x}=m c+(1-\beta) \Delta Q^{*}, P_{b}{ }^{y}=m c+\mu_{b} \Delta Q^{*}, P_{a}{ }^{y}=m c+\left[\mu_{b}-(1-\beta)-\omega\right] \Delta Q^{*}$ and $P_{b}{ }^{x}=m c+\beta \Delta Q^{*}$ where $(1-\beta)<\mu_{b} \leq 1$ and $\omega \downarrow 0$.

- As a result $\mathrm{CS}_{\lrcorner}{ }^{\mathrm{x}} \geq \mathrm{CS}_{\mathrm{b}}{ }^{\mathrm{x}}$ and $\mathrm{CS}_{\mathrm{a}}{ }^{y}>\mathrm{CS}_{\mathrm{b}}{ }^{y}$. Firm A's demand equals $\mathrm{N}$ in both markets.

- - The mark-ups mu are as follows: $\mathrm{mu}_{\mathrm{a}}{ }^{\mathrm{x}} \geq 0, \mathrm{mu}_{\mathrm{a}}{ }^{\mathrm{y}} \geq 0, \mathrm{mu}_{\mathrm{b}}{ }^{\mathrm{x}} \geq 0$ and $\mathrm{mu}_{\mathrm{b}}{ }^{\mathrm{y}} \geq 0$.

- Firm A faces positive demand in both markets and will simply serve its most profitable market first.

- Firm B will serve residual demand in both markets, since its gross profit margins are non-negative in both markets.

- To summarize, if $(1-\beta) \geq \mu_{b}-(1-\beta)-\omega$, firm A produces $N$ units for market $X,(K-N)$ units for market $Y$ and firm $B(2 N-K)$ units for market $Y$. Firm $A$ 's gross profits are 
$\pi_{\mathrm{a}}=\mathrm{N}(1-\beta) \Delta \mathrm{Q}^{*}+(\mathrm{K}-\mathrm{N})\left[\mu_{\mathrm{b}}-(1-\beta)-\omega\right] \Delta \mathrm{Q}^{*}$ and firm B's gross profits $\pi_{\mathrm{b}}=(2 \mathrm{~N}$ K) $\mu_{b} \Delta Q^{*}$. However, if $(1-\beta)<\mu_{b}-(1-\beta)-\omega$, firm $A$ produces $N$ units for market $Y$, (K$N)$ units for market $X$ and firm $B(2 N-K)$ units in market for market $X$. Firm A's gross profits are $\pi_{\mathrm{a}}=(\mathrm{K}-\mathrm{N})(1-\beta) \Delta \mathrm{Q}^{*}+N\left[\mu_{\mathrm{b}}-(1-\beta)-\omega\right] \Delta \mathrm{Q}^{*}$ and firm B's gross profits $\pi_{\mathrm{b}}=(2 \mathrm{~N}-\mathrm{K}) \beta \Delta \mathrm{Q}^{*}$.

\section{Case 10: Strategy pair ((D,F): (C,E))}

- By assumption, $\mathrm{P}_{\mathrm{a}}{ }^{\mathrm{x}}=\mathrm{mc}+(1-\beta) \Delta \mathrm{Q}^{*}, \mathrm{P}_{\mathrm{b}}{ }^{\mathrm{y}}=\mathrm{mc}+\mu_{\mathrm{b}} \Delta \mathrm{Q}^{*}, \mathrm{P}_{\mathrm{a}}{ }^{\mathrm{y}}=\mathrm{mc}+\beta \Delta \mathrm{Q}^{*}$ and $\mathrm{P}_{\mathrm{b}}{ }^{\mathrm{x}}=\mathrm{mc-}$ $\omega$ where $(1-\beta)<\mu_{b} \leq 1$ and $\omega \downarrow 0$.

- As a result $\mathrm{CS}_{\mathrm{a}}{ }^{\mathrm{x}}<\mathrm{CS}_{\mathrm{b}}{ }^{\mathrm{x}}$ and $\mathrm{CS}_{\mathrm{a}}{ }^{y} \leq \mathrm{CS}_{\mathrm{b}}{ }^{\mathrm{y}}$. Firm B's demand equals $\mathrm{N}$ in both markets.

- The mark-ups mu are as follows: $\mathrm{mu}_{\mathrm{a}}{ }^{\mathrm{x}} \geq 0, \mathrm{mu}_{\mathrm{a}}{ }^{\mathrm{y}} \geq 0, \mathrm{mu}_{\mathrm{b}}{ }^{\mathrm{x}}<0$ and $\mathrm{mu}_{\mathrm{b}}{ }^{y} \geq 0$.

- Firm B faces positive demand in both markets but also a negative gross profit margin in market $X$. It will thus serve market $Y$, its home market, only.

- This gives firm $A$ the opportunity to serve market $X$ fully.

- To summarize, firm $B$ produces $N$ units for market $Y$ and firm $A N$ units for market X. Firm A's gross profits are $\pi_{a}=N(1-\beta) \Delta Q^{*}$ and firm B's gross profits $\pi_{b}=$ $\mathrm{N} \mu_{\mathrm{b}} \Delta \mathrm{Q}^{*}$

Case 11: Strategy pair ((D,F); $(\mathrm{C}, \mathrm{F}))$

- By assumption, $\mathrm{P}_{\mathrm{a}}{ }^{\mathrm{x}}=\mathrm{mc}+(1-\beta) \Delta \mathrm{Q}^{*}, \mathrm{P}_{\mathrm{b}}{ }^{y}=m c+\mu_{\mathrm{b}} \Delta \mathrm{Q}^{*}$ and $\mathrm{P}_{\mathrm{a}}^{\mathrm{y}}=\mathrm{P}_{\mathrm{b}}{ }^{\mathrm{x}}=\mathrm{mc}+\beta \Delta \mathrm{Q}^{*}$ where $(1-\beta)<\mu_{b} \leq 1$.

- As a result $\mathrm{CS}_{\mathrm{a}}{ }^{\mathrm{x}} \geq \mathrm{CS}_{\mathrm{b}}{ }^{\mathrm{x}}$ and $\mathrm{CS}_{\mathrm{a}}{ }^{\mathrm{y}} \leq \mathrm{CS}_{b}{ }^{y}$. Firm A's demand equals $\mathrm{N}$ in market $\mathrm{X}$; firm B's demand equals $\mathrm{N}$ in market $\mathrm{Y}$.

- The mark-ups mu are as follows: $\mathrm{mu}_{\mathrm{a}}{ }^{\mathrm{x}} \geq 0, \mathrm{mu}_{\mathrm{a}}{ }^{\mathrm{y}} \geq 0, \mathrm{mu}_{\mathrm{b}}{ }^{\mathrm{x}} \geq 0$ and $\mathrm{mu}_{\mathrm{b}}{ }^{\mathrm{y}} \geq 0$.

In this case both firms want to serve both markets, since all gross profit margins are non-negative. The outcome is analogous to the outcome in Case 7: Firm B produces $\mathrm{N}$ units for market $\mathrm{Y}$ and firm $\mathrm{A} N$ units for market $\mathrm{X}$. Firm A's gross profits are $\pi$ : $=N(1-\beta) \Delta Q^{*}$ and firm B's gross profits $\pi_{b}=N \mu_{b} \Delta Q^{*}$.

Entry market prices in the (D,C)-subgame

We may now compare Case 8 to 11 and hereby study the decision on entry market prices [Table 4A.1]. In this table all terms are divided by $\Delta Q^{*}$ and $N ; \kappa=K / N$. For firm $A$, strategy $E$ strictly dominates strategy $F$, unless $\left[\mu_{b}-(1-\beta)-\omega\right]=0$. In the latter case, strategies $E$ and $F$ are equally profitable. Strategy $E$ is preferred nevertheless, since it leads to a higher production level [Assumption 4.5 (iii)]. Given firm A's strategy (E), firm B either prefers strategy $F$ or chooses it since successful entry does not increase either profits or production [Assumption 4.5 (iv)]. This implies that in the $(D, C)$-subgame the outcome $(E, F)$ is the outcome for all possible values of $\beta, K$ and $\mu_{\mathrm{b}}$. Equilibrium profits of the (D,C)-subgame are as follows: $\pi_{\mathrm{a}}=\max [\mathrm{N}(1-\beta)+$ 
$\left.(K-N)\left[\mu_{b}-(1-\beta)-\omega\right],(K-N)(1-\beta)+N\left[\mu_{b}-(1-\beta)-\omega\right]\right]$ and $\pi_{b}=\left[(2 N-K) \mu_{b},(2 N-K) \beta\right]$.

$\begin{aligned} & \text { Table 4A.1 } \\ & \text { Strategies in the (C,D)-subgame }\end{aligned}$
\[ \begin{array}{lllll}P_{\mathrm{a}}{ }^{y} & \mathrm{P}_{\mathrm{b}}{ }^{\mathrm{x}} & \pi_{\mathrm{a}} & \pi_{\mathrm{b}} \\ \text { Case } 8 & \text { E } & \text { E } & \begin{array}{c}\max \left[(1-\beta)+(\kappa-1)\left[\mu_{\mathrm{b}}-(1-\beta)\right],\right. \\ \left.(\kappa-1)(1-\beta)+\left[\mu_{\mathrm{b}}-(1-\beta)\right]\right]\end{array} & {\left[(2-\kappa) \mu_{\mathrm{b}}, 0\right]} \\ \text { Case } 9 & \text { E } & \text { F } & \begin{array}{c}\max \left[(1-\beta)+(\kappa-1)\left[\mu_{\mathrm{b}}-(1-\beta)\right],\right. \\ \left.(\kappa-1)(1-\beta)+N\left[\mu_{\mathrm{b}}-(1-\beta)\right]\right]\end{array} & {\left[(2-\kappa) \mu_{\mathrm{b}},(2-\kappa) \beta\right]} \\ \text { Case 10 } & \text { F } & \text { E } & \begin{array}{c}\mathrm{N}(1-\beta) \\ \mathrm{N}(1-\beta)\end{array} & \mathrm{N} \mu_{\mathrm{b}} \\ \text { Case 11 } & \text { F } & \text { F } & \mathrm{N} \mu_{\mathrm{b}}\end{array} \]

The (C,D)-subgame

These cases are analogous to Case 8 to 11 . We simply state that the equilibrium profits of the (C,D)-subgame are as follows: $\pi_{\mathrm{a}}=\left[(2 \mathrm{~N}-\mathrm{K}) \mu_{\mathrm{a}},(2 \mathrm{~N}-\mathrm{K}) \beta\right]$ and $\pi_{\mathrm{b}}=$ $\max \left[N(1-\beta)+(K-N)\left[\mu_{2}-(1-\beta)-\omega\right],(K-N)(1-\beta)+N\left[\mu_{2}-(1-\beta)-\omega\right]\right]$.

\section{The (C,C)-subgame}

Case 16: Strategy pair $((\mathrm{C}, \mathrm{E}) ;(\mathrm{C}, \mathrm{E}))$

- By assumption, $P_{a}{ }^{x}=m c+\mu_{a} \Delta Q^{*}, P_{b}{ }^{y}=m c+\mu_{b} \Delta Q^{*}, P_{a}^{y}=m c+\left[\mu_{b}-(1-\beta)-\omega\right] \Delta Q^{*}$ and $P_{\mathrm{b}}{ }^{\mathrm{x}}=\mathrm{mc}+\left[\mu_{\mathrm{a}}-(1-\beta)-\omega\right] \Delta \mathrm{Q}^{*}$ where $(1-\beta)<\mu \leq 1$ and $\omega \downarrow 0$.

- As a result $\mathrm{CS}_{\mathrm{a}}{ }^{\mathrm{x}}<\mathrm{CS}_{\mathrm{b}}{ }^{\mathrm{x}}$ and $\mathrm{CS}_{\mathrm{a}}{ }^{\mathrm{y}}>\mathrm{CS}_{\mathrm{b}}{ }^{\mathrm{y}}$. Firm $\mathrm{A}^{ } \mathrm{s}$ demand equals $\mathrm{N}$ in market $\mathrm{Y}$; firm B's demand equals $\mathrm{N}$ in market $\mathrm{X}$.

- The mark-ups mu are as follows: $\mathrm{mu}_{\mathrm{a}}{ }^{\mathrm{x}} \geq 0, \mathrm{mu}_{\mathrm{a}}{ }^{y} \geq 0, \mathrm{mu}_{\mathrm{h}}{ }^{\mathrm{x}} \geq 0$ and $\mathrm{mu}_{\mathrm{h}}{ }^{y} \geq 0$.

In this case both firms want to serve both markets, since all gross profit margins are non-negative. The outcome is analogous to the outcome in Case 7: Firm A produces $\mathrm{N}$ units for market $\mathrm{Y}$ and firm $\mathrm{B} \mathrm{N}$ units for market $\mathrm{X}$. Note that the firms serve their entry markets rather than their home markets. Firm A's gross profits are $\pi_{3}=$ $N\left[\mu_{b}-(1-\beta)-\omega\right] \Delta Q^{*}$ and firm B's gross profits $\pi_{b}=N\left[\mu_{n}-(1-\beta)-\omega\right] \Delta Q^{*}$.

Case 17: Strategy pair ((C,E); (C.F))

- By assumption, $P_{a}{ }^{x}=m c+\mu_{n} \Delta Q^{*}, P_{b}{ }^{y}=m c+\mu_{b} \Delta Q^{*}, P_{:}^{y}=m c+\left[\mu_{b}-(1-\beta)-\omega\right] \Delta Q^{*}$ and $P_{h}{ }^{*}=m c+\beta \Delta Q^{*}$ where $(1-\beta)<\mu \leq 1$ and $\omega \downarrow 0$.

- As a result $\mathrm{CS}_{a}{ }^{x} \geq \mathrm{CS}_{b}{ }^{x}$ and $\mathrm{CS}_{a}{ }^{y}>\mathrm{CS}_{h}{ }^{y}$. Firm $A^{\prime}$ 's demand equals $\mathrm{N}$ in both markets.

- The mark-ups mu are as follows: $\mathrm{mu}_{\mathrm{s}}{ }^{\mathrm{x}} \geq 0, \mathrm{mu}_{\mathrm{a}}{ }^{\mathrm{y}} \geq 0, \mathrm{mu}_{\mathrm{b}}{ }^{\mathrm{x}} \geq 0$ and $\mathrm{mu}_{\mathrm{b}}{ }^{\mathrm{y}} \geq 0$. 
- Firm A faces positive demand in both markets while its gross profit margins are non-negative. This enables firm $A$ to serve the most profitable market fully and employ residual capacity for the other market.

- Firm B will serve residual demand in either market, since its gross profit margins are non-negative.

- To summarize, if $\mu_{a} \geq \mu_{b}-(1-\beta)-\omega$, firm A produces $N$ units for market $X,(K-N)$ units for market $Y$ and firm $B(2 \mathrm{~N}-\mathrm{K})$ units for market $Y$. Firm $A$ 's gross profits are $\pi_{\mathrm{a}}=\mathrm{N} \mu_{\mathrm{a}} \Delta \mathrm{Q}^{*}+(\mathrm{K}-\mathrm{N})\left[\mu_{\mathrm{b}}-(1-\beta)-\omega\right] \Delta \mathrm{Q}^{*}$ and firm $\mathrm{B}^{\prime}$ s gross profits $\pi_{\mathrm{b}}=(2 \mathrm{~N}-\mathrm{K}) \mu_{\mathrm{b}} \Delta \mathrm{Q}^{*}$. However, if $\mu_{a}<\mu_{0}-(1-\beta)-\omega$, firm A produces $N$ units for market $Y$, (K-N) units for market $X$ and firm $B(2 N-K)$ units in market for market $X$. Firm $A$ 's gross profits are $\pi_{\mathrm{a}}=(\mathrm{K}-\mathrm{N}) \mu_{\mathrm{a}} \Delta \mathrm{Q}^{*}+\mathrm{N}\left[\mu_{\mathrm{b}}-(1-\beta)-\omega\right] \Delta \mathrm{Q}^{*}$ and firm B's gross profits $\pi_{\mathrm{b}}=(2 \mathrm{~N}-\mathrm{K}) \beta \Delta \mathrm{Q}^{*}$.

Case 18: Strategy pair $((C, F) ;(C, E))$

- By assumption, $P_{a}{ }^{x}=m c+\mu_{a} \Delta Q^{*}, P_{b}^{y}=m c+\mu_{b} \Delta Q^{*}, P_{a}^{y}=m c+\beta \Delta Q^{*}$ and $P_{b}{ }^{x}=$ $m c+\left[\mu_{a}-(1-\beta)-\omega\right] \Delta Q^{*}$ where $(1-\beta)<\mu \leq 1$ and $\omega \downarrow 0$.

- As a result $\mathrm{CS}_{\mathrm{a}}{ }^{\mathrm{x}}<\mathrm{CS}_{\mathrm{b}}{ }^{\mathrm{x}}$ and $\mathrm{CS}_{\mathrm{a}}{ }^{{ }} \leq \mathrm{CS}_{\mathrm{b}}{ }^{y}$. Firm $\mathrm{B}$ 's demand equals $\mathrm{N}$ in both markets.

- The mark-ups mu are as follows: $\mathrm{mu}_{\mathrm{a}}{ }^{\mathrm{x}} \geq 0, \mathrm{mu}^{\mathrm{d}}{ }^{\mathrm{y}} \geq 0, \mathrm{mu}_{\mathrm{h}}{ }^{\mathrm{x}} \geq 0$ and $\mathrm{mu}_{\mathrm{h}}{ }^{\mathrm{y}} \geq 0$.

This case is analogous to Case 17. If $\mu_{\mathrm{b}} \geq \mu_{\mathrm{a}}-(1-\beta)-\omega$, firm $\mathrm{B}$ produces $N$ units for market $\mathrm{Y},(\mathrm{K}-\mathrm{N})$ units for market $\mathrm{X}$ and firm $\mathrm{A}(2 \mathrm{~N}-\mathrm{K})$ units for market $\mathrm{X}$. Firm B's gross profits are $\pi_{b}=N \mu_{b} \Delta Q^{*}+(K-N)\left[\mu_{a}-(1-\beta)-\omega\right] \Delta Q^{*}$ and firm A's gross profits $\pi_{a}=$ $(2 N-K) \mu_{a} \Delta Q^{*}$. However, if $\mu_{b}<\mu_{a}-(1-\beta)-\omega$, firm $B$ produces $N$ units for market $X$, $(\mathrm{K}-\mathrm{N})$ units for market $\mathrm{Y}$ and firm $A(2 \mathrm{~N}-\mathrm{K})$ units in market for market $\mathrm{Y}$. Firm B's gross profits are $\pi_{b}=(K-N) \mu_{b} \Delta Q^{*}+N\left[\mu_{a}-(1-\beta)-\omega\right] \Delta Q^{*}$ and firm A's gross profits $\pi_{a}=$ $(2 \mathrm{~N}-\mathrm{K}) \beta \Delta \mathrm{Q}^{\circ}$.

Case 19: Strategy pair $((\mathrm{C}, \mathrm{F}) ;(\mathrm{C}, \mathrm{F}))$

- By assumption, $P_{a}^{x}=m c+\mu_{a} \Delta Q^{*}, P_{b}{ }^{y}=m c+\mu_{b} \Delta Q^{*}, P_{i i}^{y}=P_{b}{ }^{x}=m c+\beta \Delta Q^{*}$ where (1B) $<\mu \leq 1$.

- As a result $\mathrm{CS}_{\mathrm{a}}{ }^{\mathrm{x}} \geq \mathrm{CS}_{\mathrm{b}}{ }^{\mathrm{x}}$ and $\mathrm{CS}_{\mathrm{a}}{ }^{\mathrm{y}} \leq \mathrm{CS}_{\mathrm{b}}{ }^{\mathrm{y}}$. Firm A's demand in market $\mathrm{X}$ equals $\mathrm{N}$; firm $B$ 's demand in market $Y$ equals $N$.

- The mark-ups mu are as follows: $\mathrm{mu}_{\mathrm{a}}{ }^{\mathrm{x}} \geq 0, \mathrm{mu}_{\mathrm{a}}{ }^{\mathrm{y}} \geq 0, \mathrm{mu}_{\mathrm{b}}{ }^{\mathrm{x}} \geq 0$ and $\mathrm{mu}_{\mathrm{b}}{ }^{\mathrm{y}} \geq 0$.

In this case both firms will supply their home markets fully [Case 7]. Fquilibrium profits are $\pi_{\mathrm{a}}=\mathrm{N} \mu_{\mathrm{a}} \Delta \mathrm{Q}^{*}$ and $\pi_{\mathrm{b}}=\mathrm{N} \mu_{\mathrm{b}} \Delta \mathrm{Q}^{*}$.

\section{The non-existence of Nash-equilibria with both firms accommodating entry (area II)}

From Proposition 4.1 we already know that $((C, E) ;(C, E))$ and $((C, F) ;(C, F))$ do not constitute Nash-equilibria. We now have to check whether $((\mathrm{C}, \mathrm{E}) ;(\mathrm{C}, \mathrm{F}))$ and $((\mathrm{C}, \mathrm{F})$; 
$(C, E))$ are Nash-equilibria in area II of Figure 4.1.

Proposition 4A.1. ((C,E); (C,F)) and $((\mathrm{C}, \mathrm{F}) ;(\mathrm{C}, \mathrm{E}))$ are no Nash-equilibria of the $\left(\Delta Q^{*}, \Delta Q^{*}\right)$-subgame for the values of $\beta$ and $\kappa$ indicated by area II of Figure 4.1.

Proof. Equilibrium production and market prices are characterized by $((\mathrm{D}, \mathrm{F}) ;(\mathrm{D}, \mathrm{F}))$ if $((\mathrm{C}, \mathrm{E}) ;(\mathrm{C}, \mathrm{F}))$ and $((\mathrm{C}, \mathrm{F})$; and $(\mathrm{C}, \mathrm{E}))$ are no Nash-equilibria in this area. Consider $((C, F) ;(C, E))$. The latter outcome is a Nash-equilibrium if both firms have no incentive to charge a different mark-up. One may infer from Table 4.3 that firm $\mathrm{B}$ has two opposing incentives. It needs to charge a low mark-up in order to induce firm A to accommodate entry. It wants to charge a higher mark-up, when firm A accommodates entry. ((C,F); $(C, E))$ is only a Nash-equilibrium if firm B's mark-up is low enough to induce firm A to accommodate entry. But firm B will only charge the low mark-up if firm $A$ exerts a credible threat in case of out-of-equilibrium behaviour by firm B. Firm A's threat to undercut firm B is credible if $(E, E)$ or $(E, F)$ is a Nashequilibria of the $(\mathrm{C}, \mathrm{C})$-subgame.

Consider (E.E). The latter is a Nash-equilibrium if - among other things - any rise in $\mu_{b}$ causes firm $A$ to prefer $(E, E)$ over $(F, E)$. The latter occurs if $\mu_{b}-1+\beta>(2$ к) $\mu_{a}$ [or $\mu_{b}-1+\beta>(2-\kappa) \beta$ ]. Firm B has no incentive to charge a higher mark-up if $\mu_{b}$ $1+\beta=(2-\kappa) \mu_{a}$ [or $\left.\mu_{b}-1+\beta>(2-\kappa) \beta\right]$. However, when $\mu_{b}$ fulfils either one of these equalities, firm A prefers entry deterrence over entry accommodation since $\kappa>1$ [Table 4.3].

Consider $(E, F)$. The latter is a Nash-equilibrium if $\mu_{a}$ is low enough to let furm $B$ prefer $(E, F)$ over $(E, E)$. This is so if $(1) \mu_{a}-1+\beta<(2-\kappa) \mu_{b}$ or $(2) \mu_{a}-1+\beta<(2-\kappa) \beta$. The highest mark-up firm A may charge then equals (1) $\mu_{\mathrm{u}}=(1-\beta)+(2-\kappa) \mu_{\mathrm{b}}$ or $(2) \mu_{\mathrm{a}}=1$ $\beta+(2-\kappa) \beta$. But for these mark-ups firm A prefers entry deterrence over entry accommodation. Consider case (1). Entry deterrence is more profitable, since (2- $\kappa)[1-\beta+(2-$ к) $\left.\mu_{b}\right]<(1-\beta)+(\kappa-1)\left(\mu_{b}-1+\beta\right) \Leftrightarrow(2-\kappa)^{2} \mu_{b}<(\kappa-1) \mu_{b} \Leftrightarrow(2-\kappa)^{2}<(\kappa-1)$. This inequality holds, because $(2-\kappa)^{2}<0.25$ and $(\kappa-1)>0.5$ for $\kappa>(3 / 2)$. Consider case (2). In this case $\mu_{b}>\mu_{2}+1-\beta$. Otherwise, firm A would not prefer total entry. Again, firm A prefers entry deterrence over entry accommodation, since $(2-\kappa)[1-\beta+(2-\kappa) \beta]<(1$ $\beta)+(\kappa-1)\left[\mu_{b}-1+\beta\right] \Leftrightarrow(2-\kappa)^{2} \beta<(\kappa-1) \mu_{b} \Leftrightarrow(2-\kappa)^{2} \beta<(\kappa-1)[2-2 \beta+(2-\kappa) \beta+\phi](\phi>0)$. Recall that $\mu_{\mathrm{b}}>\mu_{\mathrm{a}}+(1-\beta)$ and $\mu_{\mathrm{a}}=(1-\beta)+(2-\kappa) \beta$. The inequality holds, because $(2-\kappa)^{2}$ $<(2-\kappa)(\kappa-1)$ for $\kappa>(3 / 2)$.

When $\kappa>(3 / 2)$, there are no levels of $\mu_{a}$ and $\mu_{b}$ for which (1) (E,E) and (E,F) are Nash-equilibria of the (C,C)-subgame and (2) firm $A$ has no incentive to deter entry. As a result, ((C,E): $(C, F))$ and $((C, F) ;(C, E))$ are no Nash-equilibria in area II of Figure 4.1. Q.E.D.

\section{Asymmetric Nash-equilibria under simultaneous decision making}

This Appendix presents some asymmetric Nash-equilibria in prices under simultaneous decision making. When the firms coordinate on the outcomes, they adhere to the agreements made if the outcomes involve Nash-equilibria. The firms have no 
incentive to diverge from agreed upon Nash-equilibria by definition. The outcomes of Proposition 4A.2 are depicted in Figure 4A.1. Area I and II refer to the limit price equilibria derived in Section 3.

Proposition 4A.2. (i) When $\kappa \leq(1+2 \beta) /(1+\beta)$ and $\kappa \leq(3-2 \beta) /(2-\beta),((C, F) ;(C, E))$ and $((\mathrm{C}, \mathrm{E}) ;(\mathrm{C}, \mathrm{F}))$ are Nash-equilibria with $\mu_{\mathrm{a}}=\mu_{\mathrm{b}}=1$ : The prices set skim all consumer surplus. (ii) When $(1+2 \beta) /(1+\beta) \leq \kappa<1+\beta$ and $\beta \leq 0.5,((C, F)$; $(D, E))$ and $((D, E)$; $(\mathrm{C}, \mathrm{F}))$ are Nash-equilibria: The firm accommodating entry charges the monopoly price $(\mu=1)$ in its home market. (iii) When $(3-2 \beta) /(2-\beta) \leq \kappa \leq 2 /(2-\beta)$ and $0.5<\beta \leq$ $(2 / 3),((C, F) ;(D, E))$ and $((D, E) ;(C, F))$ are Nash-equilibria: The firm accommodating entry sets a price lower than the monopoly prices in order to deter total entry. (iv) When $(3-2 \beta) /(2-\beta) \leq \kappa \leq 1+\beta$ and $(2 / 3) \leq \beta \leq 1,((C, F) ;(D, E))$ and $((D, E) ;(C, F))$ are Nash-equilibria: Entry is total.

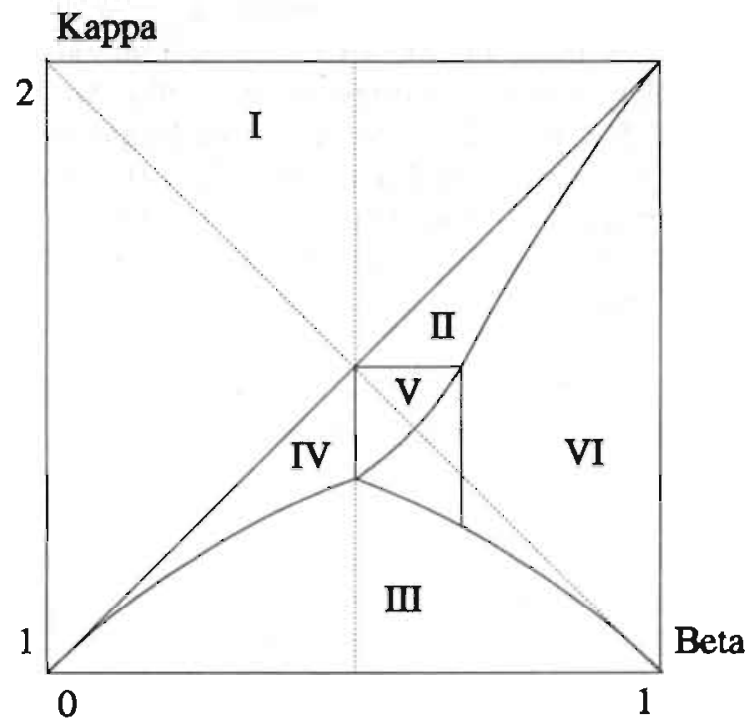

Figure 4A.1: Sequential price equilibria

Proof. (i) Suppose firm A plays (C,F) and firm B (C,E). Both firms charge the full mark-up: $\mu_{a}=\mu_{b}=1$. Consider the decisions on the entry prices [Table 4A.2]. It is obvious that firm $B$ has no reason to defect. Firm $A$ does not undercut firm $B$, when $\beta<(2-\kappa) \Leftrightarrow \kappa<2-\beta$. Consider the decisions on the home market prices. Firm $B$ has no incentive to set the limit price, as long as firm $A$ has no incentive to undercut it in the second stage of period 2: $\kappa<2-\beta$ [Table 4.3]. Firm A does not defect from accommodating entry, if $(1-\beta)+(\kappa-1) \beta<(2-\kappa) \Leftrightarrow \kappa<(1+2 \beta) /(1+\beta)[\beta \leq 0.5]$ or $(\kappa-$ $1)(1-\beta)+\beta<(2-\kappa) \Leftrightarrow \kappa<(3-2 \beta) /(2-\beta)[\beta>0.5]$ [Table 4.3]. So, when the latter two conditions do not hold, firm $A$ will not defect from charging a full mark-up and forgoing entry. The last condition also guarantees that $\kappa<2-\beta$. The values of $\beta$ and $\kappa$ for which $((C, F) ;(C, E))$ and $((C, E) ;(C, F))$ with $\mu_{a}=\mu_{b}=1$ are Nash-equilibria, are given by area $\mathrm{III}$ in Figure 4A.1. 


\begin{tabular}{|c|c|c|c|}
\hline \multicolumn{4}{|c|}{$\begin{array}{l}\text { Table 4A.2 } \\
\text { Pay-off structure of (C,C)-subgame }\left(\mu_{a}=\mu_{b}=1\right)\end{array}$} \\
\hline & & \multicolumn{2}{|l|}{ Firm B } \\
\hline & & $E$ & $\mathrm{~F}$ \\
\hline \multirow[t]{2}{*}{ Firm A } & $\mathrm{E}$ & $\begin{array}{l}\pi_{\mathrm{a}}=\beta \\
\pi_{\mathrm{b}}=\beta\end{array}$ & $\begin{array}{l}\pi_{\mathrm{a}}=1+(\kappa-1)(1-\beta) \\
\pi_{\mathrm{b}}=(2-\kappa)\end{array}$ \\
\hline & $\mathrm{F}$ & $\begin{array}{l}\pi_{\mathrm{a}}=(2-\kappa) \\
\pi_{\mathrm{b}}=1+(\kappa-1)(1-\beta)\end{array}$ & $\begin{array}{l}\pi_{\mathrm{a}}=1 \\
\pi_{\mathrm{b}}=1\end{array}$ \\
\hline
\end{tabular}

Consider $((C, F) ;(D, E))$ and $((D, E)) ;(C, F))$. Suppose that firm A plays $(C, F)$ and firm $B(D, E)$. We already know that firm $A$ does not defect from playing $(C, F)$ as long as we are not in areas I or II of Figure 4A.1. An accommodating firm charges the maximum mark-up, unless it wants to forestall total entry. So, we have $\mu_{\mathrm{a}}=1$ if $\beta \leq$ 0.5 and $\mu_{\mathrm{a}}=2-2 \beta$ if $0.5<\beta \leq(2 / 3)$ [proof (iii) of Proposition 4.1]. Since firm $A$ expects to acquire profits from residual demand in firm B's market, it is profitable to charge the full mark-up $\left(\mu_{a}=1\right)$ in its home market if $(2 / 3)<\beta \leq 1 .{ }^{(10)}$ This leaves firm B's behaviour only. Firm B might accommodate entry. When firm B would do so, it will charge a full mark-up. This mark-up suffices to forestall total entry. (11)

(ii) Consider the (C,C)-subgame for $\beta \leq 0.5$ with $\mu_{\mathrm{a}}=\mu_{\mathrm{b}}=1$ [Table 4A.3]. In this subgame there are two Nash-equilibria: $(F, E)$ and $(E, F)$. The firm forgoing entry will not defect from doing so, as long as $2-\kappa>\beta$. Suppose firm A plays $E$ in case firm $B$ defects in stage 1 and firm $B$ strategy $F$. In this case $(E, F)$ is the outcome of the (C,C)-subgame. Firm $B$ will then not defect from deterring entry in the first stage, when $(1-\beta)+(\kappa-1) \beta>(2-\kappa) \Leftrightarrow \kappa>(1+2 \beta) /(1+\beta)$. As a result, we have $((C, F) ;(D, E))$ and $((\mathrm{D}, \mathrm{E}) ;(\mathrm{C}, \mathrm{F}))$ as Nash-equilibria in area IV of Figure 4A.1. ${ }^{(12)}$

(10) There is a small chance that firm B supplies its home market first after all. This argument may be supported with a reference to the 'trembling hand' concept [Tirole (1991)].

(11) When firm B unexpectedly plays (C,F), firm A may undercut firm B. When $\mu_{a}=1$, firm A prefers to serve its home market first. When $\mu_{\mathrm{a}}=2-2 \beta$, firm A serves its home market first if $2-2 \beta \geq \mu_{b}-1+\beta \Leftrightarrow 3-3 \beta \geq \mu_{b}$, where $\mu_{b} \leq 1$. This implies that firm B may set $\mu_{\mathrm{b}}=1$ if $0.5<\beta \leq(2 / 3)$ as well in order to preclude total entry.

(12) When $(F, E)$ is the outcome of the (C,C)-subgame, there is no Nash-equilibrium in area IV of Figure 4A.1. So, the full Nash-equilibrium is described as follows. Firm A plays $C$ in stage 1 and $F$ in stage 2 unless $(C, C)$ is the outcome of the first stage. In this case, it plays E. Firm B plays D in stage 1 and $E$ in stage 2 unless $(C, C)$ is the outcome of the first stage. In this case, it plays F. 
(iii) Consider the (C,C)-subgame for $0.5<\beta \leq(2 / 3)$ [and $\kappa<(3 / 2)$ ] with $\mu_{\mathrm{a}}=2-2 \beta$ and $\mu_{b}=1$. The pay-off structure of this subgame is given by Table 4A.3. There are two Nash-equilibria for this sub-game: $(E, F)$ and $(F, E)$. (E,F) is a Nash-equilibrium for all values of $\beta$ and $\kappa$ indicated above. (F,E) is a Nash-equilibrium if $\beta \leq(2-\kappa)$ (2$2 \beta) \Leftrightarrow \kappa \geq(4-5 \beta) /(2-2 \beta)$. When $(E, F)$ is the outcome of the $(C, C)$-subgame, firm B's gross profits are $\pi_{b}=2-\kappa$ when it accommodates entry. Firm B prefers entry deterrence if $\kappa(1-\beta)>2-\kappa \Leftrightarrow \kappa>2 /(2-\beta)$. So, for $(3 / 2)>\kappa>2 /(2-\beta),((C, F) ;((D, E))$ constitutes a Nash-equilibrium [area $\mathrm{V}$ in Figure 4A.1]. When $(F, E)$ would be the outcome, entry deterrence would not be a Nash-equilibrium. ${ }^{(13)}$

\begin{tabular}{|c|c|c|c|}
\hline \multicolumn{4}{|c|}{$\begin{array}{l}\text { Table 4A.3 } \\
\text { Pay-off structure of }(C, C) \text {-subgame }\left[\mu_{a}=2-2 \beta \text { and } \mu_{b}=1\right]\end{array}$} \\
\hline & & \multicolumn{2}{|l|}{ Firm B } \\
\hline & & $\mathrm{E}$ & $\mathrm{F}$ \\
\hline \multirow[t]{2}{*}{ Firm A } & E & $\begin{array}{l}\pi_{\mathrm{a}}=\beta \\
\pi_{\mathrm{b}}=1-\beta\end{array}$ & $\begin{array}{l}\pi_{\mathrm{a}}=(2-2 \beta)+(\kappa-1) \beta \\
\pi_{\mathrm{b}}=(2-\kappa)\end{array}$ \\
\hline & $\mathrm{F}$ & $\begin{array}{l}\pi_{a}=(2-\kappa)(2-2 \beta) \\
\pi_{b}=1+(\kappa-1)(1-\beta)\end{array}$ & $\begin{array}{l}\pi_{\mathrm{a}}=2-2 \beta \\
\pi_{b}=1\end{array}$ \\
\hline
\end{tabular}

(iv) Consider the (C,C)-subgame for $(2 / 3)<\beta \leq 1$ with $\mu_{a}=1$ and $\mu_{b}=1$. We know from (ii) that there are three Nash-equilibria: (F,E) and (E,F) $[\kappa<2-\beta]$ and $(E, E)[\kappa>2-\beta]$. We know from Proposition 4.1 that $((C, E)$; $(C, E))$ is not sustainable. When $(E, F)$ is the outcome of the $(C, C)$ subgame, we know from (ii) that firm $B$ prefers entry deterrence over entry accommodation. This again implies that $((C, F)$; $(\mathrm{D}, \mathrm{E}))$ and $((\mathrm{D}, \mathrm{E}) ;(\mathrm{C}, \mathrm{E})$ are Nash-equilibria [area VI in Figure 4A.1]. Q.E.D.

In area III excess capacity is very small. This explains why an accommodating firm may content itself with residual demand since residual demand and profit margins are high under entry accommodation when excess capacity is small. In areas IV, V and VI, the entering firm must content itself with a lower profit margin in its home market in order to prevent an undercutting strategy by the accommodating firm. This is not surprising because entry accommodation is less profitable since capacity is higher. In area $\mathrm{V}$ the accommodating firm does not charge the monopoly price in order to prevent total entry. In area VI entry is total. The entering firm charges the barrier market price in its home market: $P=m c+(1-\beta) \Delta Q^{*}$, and the monopoly price in the entry market: $P=m c+\beta \Delta Q^{*}$. The barrier market price is low since spillovers are high while the entry market price is high for the same reason. The accommodating firm is satisfied with total entry since the profit margin in the entry market $\left(\beta \Delta Q^{*}\right)$ is high due to the high spillover rate.

113) See previous footnote. 


\section{E $\quad$ Proof of Proposition 4.2}

The proof of Proposition 4.2 runs as follows. The numbers refer to the superscripts in Table 4.5.

(1) Compare outcome (8) and (9) for firm B. Table 4A.4 clearly shows that firm B's profits are higher under outcome (8) than under outcome (9). Firm B is thus likely to choose solution (8).

(2) Compare outcome (6) and (7) for firm B. Firm B chooses outcome (6) whenever $N\left[Q_{b}{ }^{x}-m c\right]>(2 N-K)\left[Q_{b}{ }^{y}-m c\right] \Leftrightarrow N \beta \Delta Q^{*}>(2 N-K) \Delta Q^{*} \Leftrightarrow \beta>2-K$.

(3) Compare outcome (6) and (7) on the one hand with outcome (8) on the other hand for firm A. Outcome (6) is more profitable than outcome (8), when $N\left[Q_{a}{ }^{y}\right.$ $\mathrm{mc}]>(2 \mathrm{~N}-\mathrm{K})\left[\mathrm{Q}_{\mathrm{a}}{ }^{\mathrm{x}}-\mathrm{mc}\right] \Leftrightarrow \mathrm{N} \beta \Delta \mathrm{Q}^{*}>(2 \mathrm{~N}-\mathrm{K}) \Delta \mathrm{Q}^{*} / \mathrm{N} \Leftrightarrow \beta>2-\kappa$. Outcome (6) is more profitable than outcome (8) for those values of $\beta$ and $\kappa$ for which outcome (6) holds. Solution (7) is more profitable than solution (8) since $N \geq(2 N-K)$.

\begin{tabular}{|l|l|l||}
\hline \multicolumn{2}{||l||}{$\begin{array}{l}\text { Table 4A.4 } \\
\text { Firm profits }\end{array}$} \\
\hline $\begin{array}{l}\text { Out- } \\
\text { come }\end{array}$ & Firm A & Firm B \\
\hline$(1)$ & $N\left[Q_{a}{ }^{x}-Q_{b}{ }^{x}\right]$ & $N\left[Q_{b}{ }^{y}-Q_{a}{ }^{y}\right]$ \\
$(2 a)$ & $N\left[Q_{a}{ }^{x}-Q_{b}{ }^{x}\right]+(K-N)\left[Q_{a}{ }^{y}-m c\right]$ & $(2 N-K)\left[Q_{b}{ }^{y}-m c\right]$ \\
$(2 b)$ & $N\left[Q_{a}{ }^{y}-m c\right]+(K-N)\left[Q_{a}{ }^{x}-Q_{b}{ }^{x}\right]$ & $(2 N-K)\left[Q_{b}{ }^{x}-m c\right]$ \\
$(3 a)$ & $(2 N-K)\left[Q_{a}{ }^{x}-m c\right]$ & $N\left[Q_{b}{ }^{y}-Q_{a}{ }^{y}\right]+(K-N)\left[Q_{b}{ }^{x}-m c\right]$ \\
$(3 b)$ & $(2 N-K)\left[Q_{a}{ }^{y}-m c\right]$ & $N\left[Q_{b}{ }^{x}-m c\right]+(K-N)\left[Q_{b}{ }^{y}-Q_{a}{ }^{y}\right]$ \\
$(4)$ & $N\left[Q_{a}{ }^{y}-m c\right]$ & $N\left[Q_{b}{ }^{x}-m c\right]$ \\
$(5)$ & $N\left[Q_{a}{ }^{x}-m c\right]+(K-N)\left[Q_{a}{ }^{y}-m c\right]$ & $(2 N-K)\left[Q_{b}{ }^{y}-m c\right]$ \\
$(6)$ & $(2 N-K)\left[Q_{a}{ }^{x}-m c\right]$ & $N\left[Q_{b}{ }^{y}-m c\right]+(K-N)\left[Q_{b}{ }^{x}-m c\right]$ \\
$(7)$ & $N\left[Q_{a}{ }^{x}-m c\right]$ & $N\left[Q_{b}{ }^{y}-m c\right]$ \\
\hline \hline
\end{tabular}

(4) Compare outcome (1) with outcome (2a) and (2b). Outcome (2a) is relevant when $\beta \leq 0.5$ and outcome (2b) when $\beta>0.5$. This is so, because firms supply the most profitable market first. When $\beta \leq 0.5$, market $X$ is more profitable (and vice versa) since $\left[\mathrm{Q}_{\mathrm{a}}{ }^{\mathrm{x}}-\mathrm{Q}_{\mathrm{b}}{ }^{\mathrm{x}}\right] \geq\left[\mathrm{Q}_{\mathrm{a}}{ }^{\mathrm{y}}-\mathrm{mc}\right] \Leftrightarrow(1-\beta) \geq \beta \Leftrightarrow 0.5 \geq \beta$.

- Compare outcome (1) with outcome (2a) for firm B. Firm B prefers outcome (1) whenever $N\left[Q_{b}{ }^{y}-Q_{a}{ }^{y}\right]>(2 N-K)\left[Q_{b}{ }^{y}-m c\right] \Leftrightarrow N(1-\beta) \Delta Q^{*}>(2 N-K) \Delta Q^{*} \Leftrightarrow \beta<$ $\kappa-1$.

- Compare outcome (1) with outcome (2b) for firm B $(\beta>0.5)$. Firm B prefers outcome (1) over outcome (2) whenever $N\left[Q_{b}{ }^{y}-Q_{a}{ }^{y}\right]>(2 N-K)\left[Q_{x}{ }^{b}-m c\right] \Leftrightarrow N(1-\beta)$ $>(2 \mathrm{~N}-\mathrm{K}) \mathrm{\beta} \Leftrightarrow \kappa>3-1 / \beta$. 
The preference of firm B may be given in a $(\beta, \kappa)$-space [Figure 4A.2]. In area I and III solution (1) is preferred, in area II solution (2a) and in area IV solution (2b). in areas I and III firm B deters entry. In areas II and IV he accommodates entry.

(5) Figure 4A.3 describes firm B's options in ( $\beta, \kappa)$-space when firm A chooses entry accommodation in the first stage. Firm $B$ chooses between outcome (4a) and (4b) on the one hand and outcome (6) and (7) on the other hand. When $\beta \leq 0.5$, outcome (4a) applies and when $\beta>0.5$, outcome (4b) does [point 6 above]. When $\beta>2-\kappa$, solution (6) applies and when $\beta<2-\kappa$, solution (7) does [point (2) above].

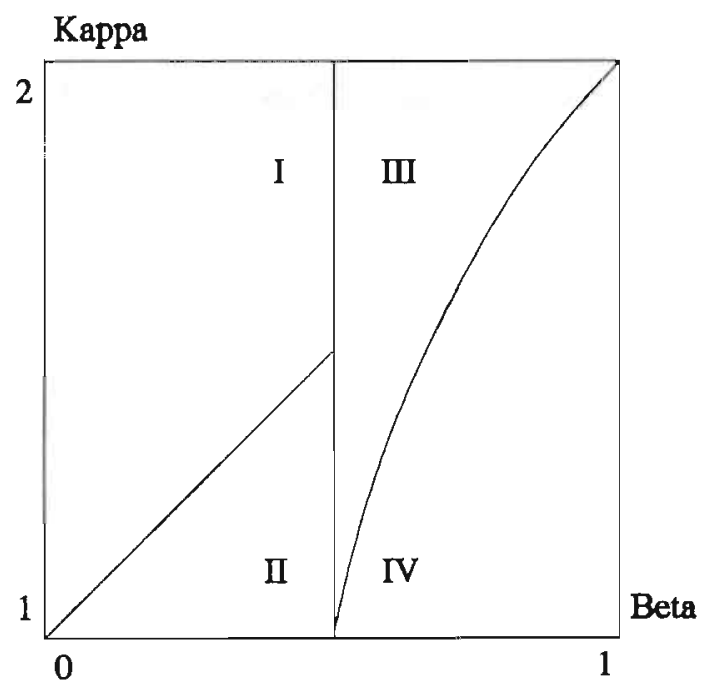

Figure 4A.2: Deterrence versus accommodation

(Firm A deters)

- Consider area I. Firm B compares outcome (4a) with outcome (6). Outcome (4a) is preferred whenever $N\left[\mathrm{Q}_{b}{ }^{y}-\mathrm{Q}_{\mathrm{a}}{ }^{\mathrm{y}}\right]+(\mathrm{K}-\mathrm{N})\left[\mathrm{Q}_{b}{ }^{\mathrm{x}}-\mathrm{mc}\right]>\mathrm{N}\left[\mathrm{Q}_{b}{ }^{\mathrm{x}}-\mathrm{mc}\right] \Leftrightarrow \mathrm{N}(\mathrm{l}-$ $\beta) \Delta Q^{*}+(K-N) \beta \Delta Q^{*}>N \beta \Delta Q^{*} \Leftrightarrow N(1-3 \beta)+\beta K>0 \Leftrightarrow \kappa<3-1 / \beta$. For $0 \leq \beta \leq$ 0.5 this condition always holds. In area I firm $B$ prefers solution (4a).

- Consider area II. Firm B compares outcome (4a) with outcome (7). Firm B prefers outcome $(4 a)$ whenever $N\left[Q_{b}{ }^{y}-Q_{a}{ }^{y}\right]+(K-N)\left[Q_{b}{ }^{x}-m c\right]>(2 N-K)\left[Q_{b}{ }^{y}-m c\right] \Leftrightarrow$ $\mathrm{N}(1-\beta)+(\mathrm{K}-\mathrm{N}) \beta>(2 \mathrm{~N}-\mathrm{K}) \Leftrightarrow \kappa>(1+2 \beta) /(1+\beta)$. Area II can be split in two parts: In the upper part firm $B$ prefers solution (4a), in the lower part he prefers solution (7).

- Consider area III. Firm B compares outcome (4b) with outcome (6). It is easy to infer from Table 4A.4 that firm B will always prefer solution (4b).

- Consider area IV. Firm B compares outcome (4b) with outcome (7). Firm B prefers outcome (4b) whenever $\mathrm{N}\left[\mathrm{Q}_{b}{ }^{\mathrm{x}}-\mathrm{mc}\right]+(\mathrm{K}-\mathrm{N})\left[\mathrm{Q}_{b}{ }^{{ }}{ } \mathrm{Q}_{a}{ }^{y}\right]>(2 \mathrm{~N}-\mathrm{K})\left[\mathrm{Q}_{b}{ }^{y}-\mathrm{mc}\right] \Leftrightarrow$ $\mathrm{N} \beta+(\mathrm{K}-\mathrm{N})(1-\beta)>(2 \mathrm{~N}-\mathrm{K}) \Leftrightarrow \mathrm{K}>(3-2 \beta) /(2-\beta)$. Area IV may thus be subdivided 


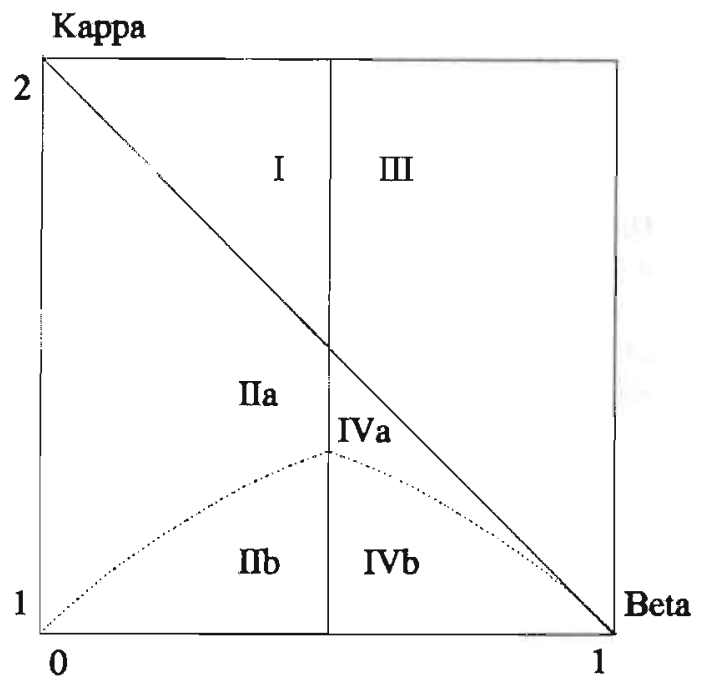

Figure 4A.3: Deterrence versus accommodation (Firm A accommodates)

in two subareas: In the upper part outcome (4b) is preferred, in the lower part outcome (7).

To summarize things firm B prefers entry deterrence in areas I, IIa, III and IVa. In areas IIb and IVb he prefers entry accommodation.

(6) Firm $\mathrm{A}$ is confronted with a choice between solutions as given by Figure 4A.4. This figure comprises Figure 4A.2 and Figure 4A.3.

- Consider area I. Firm A compares outcome (1) with outcome (4a). Firm A prefers outcome (1) whenever $N\left[Q_{a}{ }^{x}-Q_{b}{ }^{x}\right]>(2 N-K)\left[Q_{a}{ }^{x}-m c\right] \Leftrightarrow \beta<\kappa-1$. This condition holds per definition in areas I and II. In areas I and II firm A deters entry.

- Consider area II. Firm A weighs outcomes (2a) and (4a). Firm A prefers outcome $(2 \mathrm{a})$ when $N\left[\mathrm{Q}_{\mathrm{a}}{ }^{\mathrm{x}} \mathrm{Q}_{b}{ }^{\mathrm{x}}\right]+(\mathrm{K}-\mathrm{N})\left[\mathrm{Q}_{\mathrm{a}}{ }^{\mathrm{y}}-\mathrm{mc}\right]>(2 \mathrm{~N}-\mathrm{K})\left[\mathrm{Q}_{\mathrm{a}}{ }^{\mathrm{x}}-\mathrm{mc}\right] \Leftrightarrow \mathrm{N}(1-\beta)+(\mathrm{K}-\mathrm{N}) \beta$ $>(2 N-K) \Leftrightarrow K>(1+2 \beta) /(1+\beta)$. Since area III is defined by this condition, furm $A$ prefers entry deterrence (outcome (2a)).

- Consider area III. Firm A weighs outcomes (2a) and (7). Firm A prefers outcome (7) because $N\left[Q_{a}{ }^{x} Q_{b}{ }^{x}\right]+(K-N)\left[Q_{a}{ }^{y}-m c\right]<N\left[Q_{a}{ }^{x}-m c\right]+(K-N)\left[Q_{a}{ }^{y}-m c\right]$. This condition holds because $Q_{b}{ }^{x} \geq$ mc. So, in area IV firm $A$ accommodates entry.

- Consider areas IV. Firm A chooses between outcome (1) and (4b). Firm A prefers outcome (1) when $N\left[Q_{2}{ }^{x}-Q_{b}{ }^{x}\right]>(2 N-K)\left[Q_{a}{ }^{y}-m c\right] \Leftrightarrow N(1-\beta)>(2 N-K) \beta \Leftrightarrow$ $\kappa>3-1 / \beta$. This condition holds since it defines areas $V$ and VI. Firm $A$ thus chooses for entry deterrence in areas V and VI.

- Take areas V. Firm A now weighs outcomes (2b) and (4b). It is easy to see that solution (2a) is more preferable since $\mathrm{N}>2 \mathrm{~N}-\mathrm{K}$. 
- Consider area VI. Firm A now weighs outcome (2b) and outcome (7). Firm A prefers outcome (7) since $N\left[Q_{a}{ }^{y}-m c\right]+(K-N)\left[Q_{a}{ }^{x}-Q_{b}{ }^{x}\right]<N\left[Q_{a}{ }^{x}-m c\right]+(K-N)\left[Q_{a}{ }^{y}\right.$ $m c]$. This is due to the fact that $\mathrm{Q}_{a}{ }^{y} \leq \mathrm{Q}_{\mathrm{a}}{ }^{\mathrm{x}}$ and the fact that $\left[\mathrm{Q}_{a}{ }^{\mathrm{x}}-\mathrm{Q}_{\mathrm{b}}{ }^{\mathrm{x}}\right] \leq\left[\mathrm{Q}_{\mathrm{a}}{ }^{\mathrm{y}}\right.$-mc $]$ for $\beta \geq 0.5$. Firm $A$ thus again prefers entry accommodation.

- Consider area VII. Firm A now considers outcome (1) and outcome (7). It is easy to derive from Table 4A.4 that outcome (7) is more profitable since $Q_{b}{ }^{x} \geq$ mc. Firm A thus chooses entry accommodation in area IX.

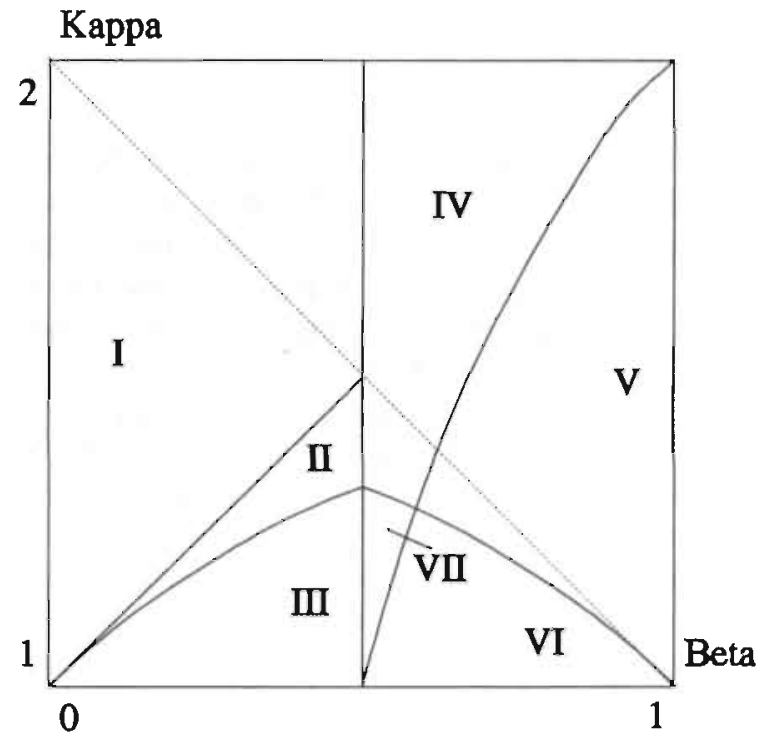

Figure 4A.4: Deterrence versus accommodation 



\section{Chapter}

\section{An experimental study of price and investment behaviour}

\section{Introduction}

In Chapters 2 to 4 we developed some scenarios characterized by static and dynamic efficiency. Chapter 2 shows that static efficiency may bo combined with (optimal) investments in $R \& D$ in homogeneous goods industries, when average total costs are constant over a (substantial) range of output. Chapter 3 shows that firms in horizontally differentiated industries pursue quality improvements for the benefit of the consumer. Chapter 4 demonstrates that the possibility to exploit consumers is limited when rival firms have excess capacity and product knowledge has a general nature $\beta$ is high. However, the results derived in Chapters 2 to 4 , as always in industrial organization, depend on the assumptions made. The Bertrand behavioural postulate in particular may not have been innocent. The validity of this postulate was more or less taken for granted. In this chapter, the validity of this assumption will be investigated in three related experiments. We test whether Bertrand conditions enforce marginal cost pricing. This is done for Chapter 2's model in particular, since the experiments are based on this model. Chapter 2 has been chosen as reference point since it was the first chapter completed.

This chapter is not the first experimental study on price behaviour. Price policy has always been one of the most popular research subjects in experimental economics. Various market configurations have been studied, among them double auctions and posted offer methods. Most studies on double auctions and posted offer methods attain the following results. ${ }^{(1)}$

(1) Prices converge to competitive levels [Davis and Holt (1993: 136 and 183).

(2) Prices are higher under the posted offer method than they are in the case of double auctions. They also converge more slowly to the competitive level under the posted offer method. This is due to the fact that buyers face a take-it-orleave-it price under the posted offer method, while they do not in the case of a double auction [op. cit.: 181].

(3) The results mentioned under points (1) and (2) are reached for a small number of persons (4 to 6) [op. cit.].

(4) More cartels are formed when players played before [Benson and Faminow

(1) In double auctions (large numbers of) both sellers and buyers make bids and counterbids. In posted-offer markets only sellers make bids. 
(1988)] or when they played for some time [Alger (1987)]. Game experience facilitates cooperation. In general, communication facilitates cooperation, but it may also intensify competition when one of parties cheats [Davis and Holt (1993)]. Cartelization is more easy to establish under the posted offer method than it is with double auctions.

Several studies on the posted offer method are inspired by contestability theory, for instance Coursey, Isaac and Smith (1984) (henceforth CIS), Coursey, Isaac, Luke and Smith (1984) (henceforth CILS) and Millner, Pratt and Reilly (1990) (henceforth MPR). The studies by CIS and CILS both support the contestability hypothesis, even though the available technologies exhibit increasing returns to scale. Price approximately equals average total costs, even though average total costs decline and exceed marginal costs. The study by CILS even indicates that sunk costs do not necessarily inhibit the establishment of a competitive price equilibrium. This result supports the barrier market hypothesis. The set-up chosen by CIS and CILS is criticized by MPR, however. ${ }^{(2)}$ MPR developed an alternative model in which time is continuous. In this model, the players are able to enter, to exit or to adjust prices at any moment in time. According to MPR, this adjustment (and a few others) accord better with the principle of hit-and-run entry than the models by CIS and CILS. Contestable markets as modelled by MPR perform somewhat better than monopolists in terms of social welfare, but prices are not stable and correspond with the monopoly price levels quite often. Price instability is not unfamiliar to contestability theory, as stressed by MPR. When the results are compared with those by CIS and CILS, one may conclude that the way in which time is modelled (continuous versus discrete) may not be innocent. When time is continuous instead of discrete, entry is likely to be short-lived and may not be worth undertaking. When time is discrete, entry is associated with demand for a longer time period. This makes entry more profitable. This suggests that menu $\operatorname{costs}^{(3)}$ - or alternatively time lags - are important for the establishment of contestable results. In the experiments outlined below, a discrete time structure is employed. This time structure is favourable to contestability.

There may be many experimental studies on price behaviour, there are not many on both investment and price behaviour. CILS is an example: In CILS, costs need to be sunk in order to acquire a licence. These costs may be interpreted as the investment cost needed for production capacity. Isaac and Reynolds (1992) (hence-

(2) MPR (1990: 585) have three objections against the models employed by CIS and CILS. (1) The players decide on price simultaneously. (2) When players decide on price, they do not observe each others' strategies. (3) Entry and exit are only possible at the beginning or the end of a discrete time period: hit-and-run entry in Baumol et al.'s sense is not possible. In MPR the entrants therefore also have an outside option.

(3) Menu costs are the adjustment costs necessary for changing prices. Examples are price labels, menus and advertising outlays. Note that sunk costs not only are compatible with contestability, they even are necessary to establish it [Van Witteloostuijn (1990)]. 
forth IR) study the behaviour of firms which are or are not under competitive pressure with respect to investment in process $R \& D$ (and price). IR find that competition stimulates investment in R\&D. The demand and cost relations chosen by IR are favourable for studying differences in innovative behaviour. Our model is not contructed for studying these differences, since we are primarily interested in price behaviour. The experiments performed have a game-theoretical structure similar to the ones employed by CILS and IR: Decisions on investment precede those on price. In all three studies the investment decision is associated with the sinking of costs. In this chapter the investment involves an improvement in quality raising the willingness to pay. This study is one of the first on quality improvements. The experiments have a complex game structure, since there are four different types of second-period games. Again, there are as yet not many experimental studies with such an extensive game structure.

The results presented below have a preliminary nature. In order to see whether undergraduate students are able to deal with the price and investment game of Chapter 2, we start with a rather simplified version of this game. We restrict the set of choices to two quality and two price levels. Because of this restriction, cooperation (cartel formation) is not only a profitable, but also a viable (equilibrium) strategy. It is therefore not surprising that there is a strong tendency to cooperate in the first two experiments. In the third experiment the price strategy set is continuous as a consequence of which the price game meets Bertrand conditions. As a result, prices are lower in the third experiment than in the first two, although they remain far from competitive. But what is even more important, price development exhibits a clear downward trend in experiment 3 . This may be partially due to the order in which the games are played. By playing experiment 1 before experiment 3 , the players received an opportunity to reach a tacit cooperative agreement before the 'real' experiment was played. Cooperation in game 3 may be more difficult without prior coordination, since (1) price coordination is difficult to establish when the price strategy set is continuous and (2) the fact that many players start the experiments with low-price strategies indicates that cartel formation is not self-evident from the outset. This argument justifies the expectation to reach more competitive results in future research.

In this chapter we also address some attention to the question what type of persons are likely to behave competitive rather than cooperative. We pay attention to differences in gender and age, and four subjective personality characteristics: Locus of control, self-monitoring, type-A behaviour and sensation-seeking. Some traits favour competitive pricing, while others favour cartel formation. An interesting implication pertains to the impact of personality characteristics of $\mathrm{CEO}^{\circ} \mathrm{s}$ on the degree of competitive behaviour. This in turn may have implications for education, emancipation and labour market policies, and maybe even for competition policy. The analysis is not only interesting from a social point of view. Since personality traits affect profitability, share holders may want to appoint to appoint cooperative CEO's. Alternatively, CEO's may act cooperatively for this reason. Multivariate analysis indicates that a competitive person is likely to have an external locus of control, is not able or willing to monitor himself in social interactions, loves the thrill 
of sensation, is male rather than female and young rather than old. Dyad-level analysis suggests that a heterogenous couple (rivals) may be more cooperative than a homogeneous one. This holds especially for sensation-seeking and gender.

This chapter is constructed as follows. Section 2 gives the set-up of the experiments, and discusses the analytical solutions. Section 3 presents the hypotheses tested, whereas Section 4 goes into the procedures and measures employed. Section 5 presents the results, and Section 6 concludes with a discussion.

The experimental set-up

Three related experiments have been performed. The games are all based on the model set out in Chapter 2. For this reason, we pay attention to the relation between this model and the experiments. This is done in Sub-section 2.1. In the first two experiments, the players have the choice between two quality levels and two price levels. In the first experiment, the players decide on price simultaneously, and in the second they decide sequentially. In the first two experiments, the players receive information on the pay-offs resulting from all possible choices. The pay-offs are precalculated for the players. The pay-offs have the same values in both experiments. Sub-section 2.2 discusses the choices faced by the players in the first two experiments and the theoretical solutions. In the third experiment, the players again have the choice between two quality levels, but now they may choose any price level they want. The information received by the players and the theoretical solution of the third experiment is analyzed in Sub-section 2.3.

\begin{tabular}{||l|l|l||}
\hline \multicolumn{3}{||l||}{ Table 5.1} \\
Structure of the competition game \\
\hline Period & Stage & Enterprises' decisions \\
\hline 1 & 1 & R\&D decisions \\
\hline 2 & 1 & Price decisions \\
\cline { 2 - 4 } & 2 & Market transactions \\
\hline
\end{tabular}

\subsection{The relation with Chapter 2}

The experimental set-up follows Chapter 2 closely. The model outlined in Chapter 2 has a two-period structure. Two firms - firm 1 and firm 2 - compete for the favour of identical consumers in the second period of the game. In the first period the firms decide whether or not to invest in R\&D. When a firm invests, it raises the quality of the product it sells in the second period. In the second period, the firms decide on price. Afterwards transactions take place. The (identical) consumers select the most favourable price-quality offer. The decision structure is given by Table 5.1. In all 
experiments the firms decide on $R \& D$ simultaneously. In all experiments the R\&D decisions are made public before the price decisions are taken. In experiments 1 and 3 , the firms simultaneously decide on price. In experiment 2 prices are decided upon sequentially.

The model employed in Chapter 2 is simplified in order to present clear-cut choices to the players. The simplifications are made with respect to the demand parameters; costs are as before. The two firms compete over one market. In this market, there are $\mathrm{N}$ identical consumers. Fach consumer buys one product, or none. Consumer utility $\mathrm{U}$ is

$\mathrm{U}=\mathrm{Q}-\mathrm{P}$,

where $Q$ denotes quality and $P$ price. The consumers select the most favourable price-quality offer, i.e. the offer maximizing utility. The consumers prefer firm 1 when $Q_{1}-P_{1}>Q_{2}-P_{2}$ where subscripts 1 and 2 refer to firm 1 and firm 2, respectively. In this case, firm 1's demand equals $N$ and firm 2's zero. When $Q_{1}-P_{1}<Q_{2}-P_{2}$, firm l's demand is zero, while firm 2's equals $N$. When $Q_{1}-P_{1}=Q_{2}-P_{2}$, demand is shared equally: Firm 1's and firm 2's demand is N/2.

The cost relations are as in Chapter 2. Average total cost is constant over the relevant range $\{\mathrm{N} / 2, \mathrm{~N}\}$, despite the presence of sunk costs. Total costs TC are made up of variable costs VC and sunk costs SC. Total costs are a linear function of output: $\mathrm{TC}=\phi . \mathrm{S}$. Since sunk costs equal $\mathrm{SC}$, variable costs are $\mathrm{VC}=\phi . S-\mathrm{SC}$ over the relevant range. Marginal costs are $\phi$ as well [Chapter 2]. The cost function thus accords with the flat-bottomed average cost curve used in contestability theory [Baumol (1982)]. When a firm invests in product quality, costs are sunk. For the matter of convenience, the players are assumed to have two opportunities with respect to quality: $\mathrm{A}$ low quality $\mathrm{Q}_{\mathrm{L}}$ or a high quality $\mathrm{Q}_{\mathrm{H}}$. There are no $\mathrm{R} \& \mathrm{D}$ costs required for the low-quality product, but there are for the high-quality product. Total costs differ per quality. For the low-quality product, we have $T_{C}=a_{L} . S$; for the high-quality product, this is $\mathrm{TC}_{\mathrm{H}}=\left(\mathrm{ac}_{\mathrm{H}} \cdot \mathrm{S}-\mathrm{SC}\right)+\mathrm{SC}$ when $\mathrm{S} \geq \mathrm{N} / 2$ and $\mathrm{TC}_{\mathrm{H}}=\mathrm{SC}$ when $S=0$. Of course, $a_{\mathrm{H}}>\mathrm{ac}_{\mathrm{c}}$.

In the experiments performed, the parameters have the following values. The low-quality product has a value equal to 250 Dutch guilders, and the high-quality product a value of 750 guilders. Average total cost is 200 guilders for the low-quality product and 600 guilders for the high-quality product. In the first two experiments, there are 10,000 consumers, and in the third experiment 1,000. R\&D costs are $1,500,000$ guilders in the first two experiments and 150,000 in the third one. ${ }^{(4)}$ The restrictions imposed on the model allow to pre-calculate demand, costs or even net profits. We always pre-calculate as much as is possible in order to simplify the

(4) Experiment 3 was developed in a later stage than experiment 1 and 2. Because the number 10,000 may evoke problems with calculations, as a pilot experiment indicated, we decided to rescale the number of consumers (and R\&D outlays). We do not think that the rescaling causes any interpretation problems. 
choices to be made by the players.

\section{$2.2 \quad$ Experiments 1 and 2}

In the first two experiments, the price decisions of the players are restricted in order to teach the players how to work with a two-staged decision structure. The players have two choices: A low price $\mathrm{P}_{\mathrm{L}}$ and a high price $\mathrm{P}_{\mathrm{H}}$. $\mathrm{P}_{\mathrm{L}}$ is equal to marginal cost, unless it is possible to price above marginal cost while holding the rival firm out of the market. $P_{H}$ equals the monopoly price, in this case the value of the product according to the consumers. The precise price levels depend on the quality choices made. In the first experiment, prices are decided upon simultaneously; in the second experiment, the players decide sequentially upon price. Since each player has the choice between two qualities $\left(\mathrm{Q}_{\mathrm{L}}\right.$ and $\left.\mathrm{Q}_{\mathrm{H}}\right)$, there are four possible pay-off matrices in the price stage. The matrices are given to the players in the instruction they receive. This sub-section justifies the pay-offs chosen and gives the game-theoretical expectations with respect to price and quality strategies. Equilibrium prices are calculated first in accordance with the principle of backward induction. For every possible combination of qualities there is a limited number of price equilibria with belonging pay-offs. By studying the price equilibria first for each combination of qualities, one may find out what pay-offs result from a certain decision on quality.

\subsubsection{The price decision}

Since each player has the choice between two quality levels $\left(Q_{\mathrm{L}}\right.$ and $\left.\mathrm{Q}_{\mathrm{H}}\right)$, there are four second-stage price matrices. When both firms choose for the low-quality product, they face the following pay-off matrix [Table 5.2].

lable 5.2

Pay-off matrix for two low-quality firms

\begin{tabular}{|c|c|c|c|}
\hline \multirow{2}{*}{\multicolumn{2}{|c|}{$\begin{array}{l}\text { FIRM 1: } \mathrm{Q}_{\mathrm{L}} \\
\text { FIRM 2: } \mathrm{Q}_{\mathrm{L}}\end{array}$}} & \multicolumn{2}{|c|}{ FIRM 2} \\
\hline & & \multirow{2}{*}{$\begin{array}{l}P_{\mathrm{l} .} \\
(0 ; 0)\end{array}$} & \multirow{2}{*}{$\begin{array}{l}P_{11} \\
(0 ; 0)\end{array}$} \\
\hline FIRM 1 & $P_{L}$ & & \\
\hline & $\mathrm{P}_{\mathrm{H}}$ & $(0 ; 0)$ & $(250,000 ; 250,000)$ \\
\hline
\end{tabular}

$\mathrm{P}_{\mathrm{L}}$ equals marginal cost (200); $\mathrm{P}_{\mathrm{H}}$ is the product's value (250). The firms share the market (equally) when they both set either $\mathrm{P}_{\mathrm{L}}$ or $\mathrm{P}_{\mathrm{H}}$. Strategy $\mathrm{P}_{\mathrm{H}}$ weakly dominates $P_{L}$, since profits are higher or equal when playing $P_{H}$ instead of $P_{L}$, but not lower. $\left(\mathrm{P}_{\mathrm{H}}, \mathrm{P}_{\mathrm{H}}\right)$ constitutes a Pareto-optimal Nash-equilibrium from the players' points of view. since joint profits are maximized. So, when the players face the above situation, they are likely to play $\mathrm{P}_{\mathrm{H}}$. When both players choose for the low-quality 
product, expected profits are $(250,000 ; 250,000)$.

When both players choose the high-quality product, they face the following price game [Table 5.3].

Table 5.3

Pay-off matrix for two high-quality firms

\begin{tabular}{|l|l|l|l|}
\hline \multicolumn{2}{||l|}{$\begin{array}{l}\text { FIRM 1: } \\
\text { FIRM 2: } Q_{\mathrm{H}}\end{array}$} & \multicolumn{2}{|l|}{ FIRM 2 } \\
\cline { 3 - 4 } & $\mathrm{P}_{\mathrm{L}}$ & $\mathrm{P}_{\mathrm{H}}$ \\
\hline \multirow{2}{*}{ FIRM 1 } & $\mathrm{P}_{\mathrm{L}}$ & $(0 ; 0)$ & $(0 ;-1,500,000)$ \\
\cline { 2 - 4 } & $\mathrm{P}_{\mathrm{H}}$ & $(-1,500,000 ; 0)$ & $(750,000 ; 750,000)$ \\
\hline
\end{tabular}

$\mathrm{P}_{\mathrm{L}}$ equals marginal cost (600); $\mathrm{P}_{\mathrm{H}}$ is the product's value (750). The players only share the market equally when they both set either $P_{L}$ or $P_{H}$. When a firm faces no demand, it does not cover its R\&D outlays and makes a net loss. Both $\left(\mathrm{P}_{\mathrm{L}}, \mathrm{P}_{\mathrm{L}}\right)$ and $\left(\mathrm{P}_{\mathrm{H}}, \mathrm{P}_{\mathrm{H}}\right)$ are Nash-equilibria. When the rival player sets $\mathrm{P}_{\mathrm{L}}\left(\mathrm{P}_{\mathrm{H}}\right), \mathrm{P}_{\mathrm{L}}\left(\mathrm{P}_{\mathrm{H}}\right)$ is the most profitable strategy. $\left(\mathrm{P}_{\mathrm{H}}, \mathrm{P}_{\mathrm{H}}\right)$ is the most likely equilibrium as this is Pareto-optimal from the players' points of view. When the players acknowledge this result and expect their fellow player to behave accordingly, the players are likely to select $P_{H}$. However, when distrust between the players is large, $\left(P_{L}, P_{L}\right)$ may be more likely. Strategy $P_{L}$ guarantees zero profits while strategy $\mathrm{P}_{\mathrm{H}}$ may be associated with (large) negative profits. A player is likely to choose $P_{L}$ when expected profits of playing $P_{H}$ are negative. Firm 1's expected profits when playing $\mathrm{P}_{\mathrm{H}}$ : $\mathrm{E}_{1}\left[\Pi\left(\mathrm{P}_{\mathrm{H}}\right)\right]$ depend on the expectation $E_{1}[p]$ firm 1 attaches to the possibility that firm 2 plays $P_{H}$. Firm 1 's expected profits $E_{l}[\Pi]$ when playing $P_{H}$ are

$\mathrm{E}_{1}\left[\Pi\left(\mathrm{P}_{\mathrm{H}}\right)\right]=\mathrm{E}_{1}\left[\Pi\left(\mathrm{E}_{1}[\mathrm{p}]\right)\right]=-1,500,000 *\left(1-\mathrm{E}_{1}[\mathrm{p}]\right)+750,000 * \Sigma_{1}[\mathrm{p}]$

and vice versa for firm 2 . When $\mathrm{E}_{1}[\mathrm{p}]<(2 / 3)$, firm 1 does better playing $\mathrm{P}_{\mathrm{L}}$; otherwise, it does better playing $\mathrm{P}_{\mathrm{H}} \cdot{ }^{(5)}$ Recall that a player can always guarantee zero profits by selecting $P_{L}$. Expected profits may be denoted by (max $\left[0, E_{1}\left[\Pi\left(E_{1}[p]\right)\right]\right.$; $\left.\max \left[0, E_{2}\left[\Pi\left(E_{2}[p]\right)\right]\right]\right)$. Note that expected profits never are below 0 .

When player 1 chooses the high-quality product and player 2 the low-quality product, the players face the following price game [Table 5.4].

(5) Note that there is no uncertainty with respect to the pay-off of strategy $P_{L}$ while there is with respect to the pay-off of strategy $\mathrm{P}_{\mathrm{H}}$. A risk-averse player will prefer strategy $\mathrm{P}_{\mathrm{L}}$ over strategy $\mathrm{P}_{\mathrm{H}}$, when he expects $\mathrm{E}[\mathrm{p}]$ to be $(2 / 3)$. He will also do so, if he expects $E[p]$ to be somewhat larger than $(2 / 3)$. 


\begin{tabular}{|c|c|c|c|}
\hline \multicolumn{4}{|c|}{$\begin{array}{l}\text { Table } 5.4 \\
\text { Pay-off matrix for one high-quality and one low-quality firm }\end{array}$} \\
\hline \multirow{2}{*}{\multicolumn{2}{|c|}{$\begin{array}{l}\text { FIRM 1: } \mathrm{Q}_{\mathrm{H}} \\
\text { FIRM 2: } \mathrm{Q}_{\mathrm{L}}\end{array}$}} & \multicolumn{2}{|l|}{ FIRM 2} \\
\hline & & $\mathrm{P}_{\mathrm{L}}$ & $\mathrm{P}_{\mathrm{H}}$ \\
\hline \multirow[t]{2}{*}{ FIRM I } & $P_{L}$ & $(1,000,000 ; 0)$ & $(1,000,000 ; 0)$ \\
\hline & $P_{H}$ & $(-1,500,000 ; 0)$ & $(750,000 ; 250,000)$ \\
\hline
\end{tabular}

$P_{H}$ again equals the products' values (250 and 750 , respectively). When both players set $\mathrm{P}_{\mathrm{H} \text { s }}$ they share the market equally. $\mathrm{P}_{\mathrm{L}}$ equals marginal cost $(200)$ for the lowquality player. $P_{L}$ exceeds marginal cost for the high-quality player since he may keep the low-quality player out of the market at a price just below 700 guilders, say 699 guilders. The high-quality player receives all demand when playing $\mathrm{P}_{\mathrm{L}} . \mathrm{P}_{\mathrm{L}}$ is the dominating strategy for the high-quality player as he is better off playing $P_{L}$ no matter what the low-quality player does. Given this fact, the low quality player is indifferent between both strategies. Apart from this consideration, $\mathrm{P}_{\mathrm{H}}$ weakly dominates $P_{L}$ for the low-quality player. Equilibrium profits thus are $(1,000,000 ; 0)$. When player 2 is the high-quality player and firm 1 the low-quality player, equilibrium profits are $(0 ; 1,000,000)$.

\subsubsection{The quality decision}

When the players decide on quality, they may realize that expected profits depend on the above pay-off matrices. If the players acknowledge this, they know that they face the following decision structure when they decide on quality. The instruction received by the players gives the pay-off matrices presented in the previous sub-section. The players do not know the matrix presenting the pay-offs in terms of quality [Table 5.5].

Remember that $F_{i}\left[\Pi\left(E_{i}[p]\right)\right][i \in\{1,2\}]$ is given by equation (2) [page 195]. Expected profits of $\left(Q_{H} ; Q_{H}\right)$ are zero, when the firm concerned plays $P_{L}$ in the second period; they are $E_{i}\left[\Pi\left(E_{i}[p]\right)\right]$ when the firm plays $P_{H}$. In the latter case, expected protits depend on the expectation the firm concerned attaches to the possibility that the rival firm plays $P_{H}$. Since the expected pay-off of $\left(Q_{H} ; Q_{H}\right)$ is larger than or equal to 0 , strategy $\mathrm{Q}_{\mathrm{H}}$ at least weakly dominates strategy $\mathrm{Q}_{\mathrm{L}}$. Profits are higher (or equal) when playing $Q_{H}$ rather than $Q_{L}$, no matter what strategy the rival player chooses. (They are equal when $E_{i}\left[\Pi\left(E_{i}[p]\right)\right]=0$.) In that case, $Q_{H}$ weakly dominates $\mathrm{Q}_{\mathrm{L}}$. In all other cases, $\mathrm{Q}_{\mathrm{H}}$ strictly dominates $\mathrm{Q}_{\mathrm{L}}$.) 
Table 5.5

First period pay-off matrix (Experiments 1 and 2)

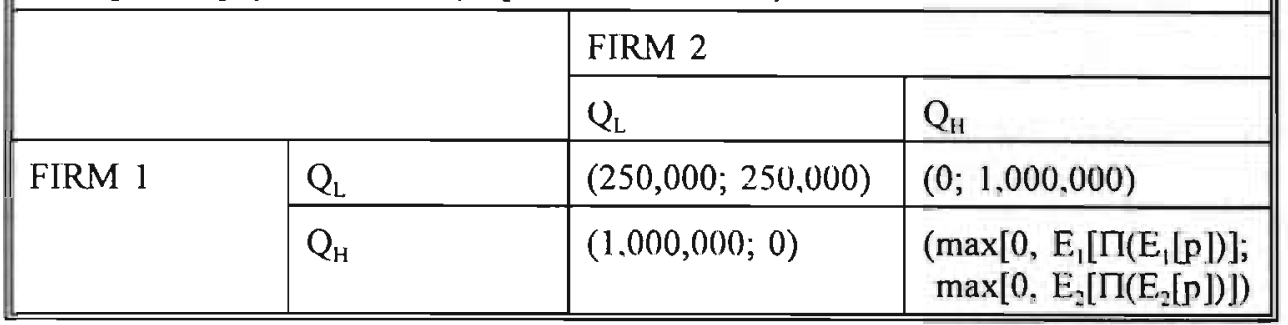

We may summarize the above as follows. There are two equilibria

I $\left(\left(\mathrm{Q}_{\mathrm{H}}, \mathrm{P}_{\mathrm{L}}\right) ;\left(\mathrm{Q}_{\mathrm{H}}, \mathrm{P}_{\mathrm{L}}\right)\right)$ and

II $\left(\left(\mathrm{Q}_{\mathrm{H}}, \mathrm{P}_{\mathrm{H}}\right) ;\left(\mathrm{Q}_{\mathrm{H}}, \mathrm{P}_{\mathrm{H}}\right)\right)$.

Scenario I represents the barrier market scenario [Chapter 1], and scenario II reflects the cooperative solution. Scenario II is likely to arise, when both players realize that it is a Pareto-optimal Nash-equilibrium from their points of view. However, scenario II requires more mutual trust $-E_{i}[p]>(2 / 3)$ - than scenario $I-E_{i}[p]<(2 / 3)$. From a welfare-theoretic point of view, scenario $I$ is to be preferred.

\section{$2.3 \quad$ Experiment 3}

In the third experiment, the players are allowed to set any price they want as long as the price is a real number. The players received the following information before they had to decide on quality and price. There are 1,000 consumers who are willing to pay a maximum of 250 guilders for the low-quality product and a maximum of 750 guilders for the high-quality product. The maximum prices reflect the value of the products to the consumers. The consumers prefer the product which offers the highest surplus (provided the surplus is not negative). Demand is given by the number of consumers $\mathrm{N}$, with $\mathrm{N}=1,000$. Total costs are pre-calculated for the players. They accord with the technological relations provided above [Sub-section 2.1]. Average total and marginal costs are 200 guilders for the low-quality and 600 guilders for the high-quality product. R\&D costs are 150,000 guilders when the high-quality product is chosen, and zero otherwise. Production costs depend on both quality $\mathrm{Q}$ and production $\mathrm{S}$.

Suppose that both firms choose the high-quality product. If the players decide to cooperate, the equilibrium price equals 750 guilders and profits are 75,000 for each firm. However, because the players may set any price they want, player 1 may undercut player 2 by lowering his price with one guilder. When he does so, he attracts all demand and earns a profit equal to 149,000 guilders. This example illustrates that the players face Bertrand competition in the third experiment. Player 2 is likely to acknowledge player I's incentive to lower his price and to act upon it. 
Equivalently, player 2, of course, has an incentive to undercut player 1. Because competition is Bertrand, the Bertrand solution is likely to result. When both firms select the high-quality product, the equilibrium price is 600 guilders (marginal cost). When both players choose the low-quality product, the equilibrium price is 200 guilders. If player 1 goes for the high-quality product and player 2 for the lowquality product (or vice versa), player 1 charges 699 guilders and player 2200 guilders. Player 2 does not want to incur a loss and thus does not price below 200 guilders. With a price equal to 699 guilders, profits are maximized subject to the condition that player 2 needs to be undercut.

Table 5.6

First period pay-off matrix (Experiment 3)

\begin{tabular}{||l|l|l|l||}
\hline \multicolumn{2}{|c|}{} & \multicolumn{2}{|l|}{ FIRM 2 } \\
\cline { 3 - 4 } \multicolumn{2}{c|}{} & $Q_{\mathrm{L}}$ & $\mathrm{Q}_{\mathrm{H}}$ \\
\hline \multirow{2}{*}{ FIRM 1 } & $\mathrm{Q}_{\mathrm{L}}$ & $(0 ; 0)$ & $(0 ; 99,000)$ \\
\cline { 2 - 4 } & $\mathrm{Q}_{\mathrm{H}}$ & $(99,000 ; 0)$ & $(0 ; 0)$ \\
\hline
\end{tabular}

Now the price equilibria have been derived, we may study the choice the players face when deciding on quality. The above outcomes determine the expected pay-offs of quality choices [Table 5.6]. Given this pay-off matrix, strategy $\mathrm{Q}_{\mathrm{H}}$ weakly dominates strategy $Q_{L}$ since $Q_{L}$ produces zero profits while $Q_{H}$ gives either zero or positive profits. The theoretical solution thus comes down to the barrier market scenario: $\left.\left(\left(Q_{\mathrm{H}}, 600\right) ; \mathrm{Q}_{\mathrm{H}}, 600\right)\right)$. In the experiments, however, the players play repeatedly with an unknown time horizon. They thus have an incentive to coordinate with each other. This may induce cooperative instead of contestable results. Furthermore, strategy $\left(Q_{H}, 600\right)$ involves a risk. This may lead to another equilibrium. The players may opt for the low-quality product, since it is less costly to coordinate with low-quality products.

\section{Hypotheses}

\subsection{Experiment specific hypotheses}

Now the experiments are depicted and the theoretical solutions are derived, the hypotheses to be tested may he formulated. The theoretical solutions of the three experiments have been derived in Section 2. On the hasis of the above analysis we may formulate the following hypotheses.

\begin{tabular}{|l|l}
$\mathrm{H} 1$ & In experiment 1 the high-quality product is chosen.
\end{tabular} 
It is optimal to opt for the high-quality product since this is the way to undercut the rival player when the latter chooses the low-quality product. When the rival player selects the high-quality product, the former player is undercut when choosing the low-quality product.

H 2A 1 In experiment 1 price equals marginal cost.

$\mathrm{H} 2 \mathrm{~B}$ In experiment 1 price equals the monopoly price.

There are two price solutions depending on the degree of mutual trust between the players. When the players do not trust each other $-E_{i}[p]>(1 / 3)-$ Hypothesis $2 \mathrm{~A}$ reflects the equilibrium outcome. When they trust each other $-\mathrm{E}_{\mathrm{i}}[\mathrm{p}]<(1 / 3)-$ Hypothesis $2 \mathrm{~B}$ resembles the equilibrium outcome. Hypothesis $2 \mathrm{~B}$ is more likely to be supported by the results, since it constitutes the Pareto-optimal outcome from the firms' points of view, although it is not associated with the larger 'trust' range.

Experiment 2 differs from experiment 1 in that it has a sequential price structure. The player which decides first, is likely to have some fear to be undercut. This is in line with contestability theory. For this reason, player 1 is likely to apply marginal cost pricing more often than in experiment 1. Player 2 applies marginal cost pricing only when his rival does. Player 2 will not undercut player 1 when the latter cooperates. Undercutting is not profitable (when both firms have the same quality), and also endangers the cooperative solution in later rounds. ${ }^{(6)}$ This gives the following two hypotheses.

\begin{tabular}{||l|l|}
\hline \hline H 3A & $\begin{array}{l}\text { The players who decide first on price in experiment } 2 \text { apply more mar- } \\
\text { ginal cost pricing in experiment } 2 \text { than in experiment } 1 . \\
\text { H 3B }\end{array}$ \\
$\begin{array}{l}\text { The players who decide last on price in experiment } 2 \text { apply marginal } \\
\text { cost pricing in experiment } 2 \text { if and only if the rival player applies mar- } \\
\text { ginal cost pricing. }\end{array}$ \\
\hline
\end{tabular}

Since player 1 may be undercut and may loose his R\&D outlays, he invests less often than in experiment 1 . Since player 2 cannot be undercut, he invests more often than in experiment 1 . This enables constructing the following two hypotheses.

\begin{tabular}{|l|l|}
\hline H 4A & $\begin{array}{l}\text { The players who decide first on price in experiment } 2 \text { invest less in } \\
\text { high quality in experiment } 2 \text { than in experiment } 1 .\end{array}$ \\
H 4B & $\begin{array}{l}\text { The players who decide last on price in experiment } 2 \text { invest more in } \\
\text { high quality in experiment } 2 \text { than in experiment } 1 .\end{array}$
\end{tabular}

In the third experiment, prices are continuous. As a consequence of this, the

(6) This line of reasoning could reverse the argument on the behaviour of players deciding on price first. 
players are in the world according to Bertrand. In this world, undercutting is a profitable strategy. Therefore, the Bertrand solution is likely to evolve. Because undercutting may be associated with the loss of R\&D expenses, firms may have an incentive to invests less. The following two hypotheses may thus be formulated. \begin{tabular}{|l|l}
\hline H 5 & $\begin{array}{l}\text { The players apply more marginal cost pricing in experiment } 3 \text { than in } \\
\text { experiment } 1 .\end{array}$
\end{tabular}

H 6 The players invest less often in experiment 3 than in experiment 1 .

In order to have a good overview, the hypotheses are summarized in Table 5.7.

Table 5.7

Experiment-specific hypotheses

H 1 In experiment 1 the high-quality product is chosen.

H $2 \Lambda$ In experiment 1 price equals marginal cost.

H 2B In experiment 1 price equals the monopoly price.

H 3 A The players who decide first on price in experiment 2 apply more marginal cost pricing in experiment 2 than in experiment 1 .

H 3B The players who decide last on price in experiment 2 apply marginal cost pricing in experiment 2 if and only if the rival player applies mar-

$\mathrm{H}$ 4A ginal cost pricing.

The players who decide first on price in experiment 2 invest less in

$\mathrm{H} 4 \mathrm{~B}$ high quality in experiment 2 than in experiment 1.

The players who decide last on price in experiment 2 invest more in

H 5 high quality in experiment 2 than in experiment 1 .

H 6 The players apply more marginal cost pricing in experiment 3 than in experiment 1 .

The players invest less often in experiment 3 than in experiment 1 .

\subsection{Trait hypotheses}

In this sub-section, hypotheses are formulated relating subjective and objective personality characteristics to competitive versus cooperative behaviour. As argued in the introduction, it is important to find out which type of persons behave competitive rather than cooperative. Some traits may favour barrier market results, while others may facilitate cartel formation. In general, it is important to discover which personality characteristics favour socially valuable outcomes, and which do not. The analysis below may have implications pertaining to the impact of the personality 
traits on competitive behaviour. This in turn may have implications for education, emancipation and labour market policies, and maybe even competition policy. As far as competitive behaviour is socially desirable, one may wish to stress the private and social benefits accrueing from competitive behaviour in teaching [Frank et al. (1993)]. Exposure to competitive (or altematively cooperative) behaviour may promote this type of behaviour [Maxwell and Ames (1981) and BBW]. As argued throughout the thesis, competitive behaviour fosters consumer wellbeing and is socially desirable from the perspective of competition policy. It is thus not desirable from this perspective to appoint women with priority at CEO-positions (in case of equal capability), when they indeed act less competitive than men. This would influence both emancipation and labour market policies. This perspective also sheds a different light on the desirability of priority policies with respect to women, as far as these policies are initiated because women cooperate more than men do.

Within economics the influence of individual differences on (non-)cooperative behaviour has not been studied thoroughly, with the exception of gender and educational background. In this chapter, we will pay attention to four personality traits: Locus of control, self-monitoring, type-A behaviour and sensation-seeking, and two objective characteristics: Gender and age. In this chapter we will study (the development of) average behaviour. Studies in organization sciences also pay attention to the variation in behaviour and behaviour with respect to the fellow player. In this subsection we will explain the above mentioned characteristics and formulate hypotheses based on theoretical and empirical literature on the subject. Given the very explorative nature of this type of research - there is neither much theory nor much evidence - hypotheses are just formulated as null bench-marks. Only cumulative research on this issue may produce sound theory and robust evidence. It may well be, for instance, that the trait-behaviour linkages are context-specific, implying the need for developing the context-trait-behaviour nexus in future research.

\section{Locus of control}

The locus of control trait has been extensively studied in the management and psychological literature. The concept has been developed by Rotter (1966) and is based on his social learning theory (1954). Rotter makes a distinction between internal and extcrnal control. People who believe in external control (cxternals) are in the opinion that their well-being depends on the whims of Lady Fortuna. It does not pay off to make any efforts in order to improve one's situation. This makes externals passive. Internals, however, believe that success depends on one's actions. They think that people are able to control their lives by their own actions. This makes internals active. Research on child behaviour shows that internals are more competitive than externals [Cook and Chi (1984) and Cook and Sloane (1985)]. Internal children tend to compete while externals show a passive willingness to follow the fellow player, i.e. to cooperate. In contrast to this result, Lester (1992) and Boone, De Brabander and Van Witteloostuijn (1995) (henceforth BBW) find that internal adults may be more cooperative than their external counterparts. As Lester (1992: 594) comments: 'Students who have scores indicating stronger beliefs in an internal locus of control 
are more motivated to achieve success both by competitive and by cooperative strategies, while students with scores showing stronger beliefs in control by chance or fate are more motivated to avoid success'. As cooperation (cartel formation) is the more profitable strategy in the above experiments we construct the following hypothesis.

\begin{tabular}{|l|l||}
\hline H 7 & Externals are more competitive than internals. \\
\hline
\end{tabular}

\section{Self-monitoring}

Self-monitoring is a well-studied personality trait, too. Individuals observe and control their expressive behaviour and self-presentation in different degrees. Snyder (1974) defines a person high in self-monitoring as someone who is willing and able to present himself favourably in terms of public appearance. These persons are more responsive to the behaviour of other people in their environment. Low self-monitors are either not able to control their expressive behaviour or not motivated to do so. They play in a way which is consistent from their personal point of view, while their counterparts are prone to adjust their behaviour to that of the fellow player. Several studies suggest that high self-monitors indeed show greater social sensibility than low self-monitors: High self-monitors solve more organizational conflicts through collaboration and compromise than their counterparts [Baron (1989)]. This produces the following hypothesis.

\begin{tabular}{|l|l|}
\hline H 8 & Low self-monitors are more competitive than high self-monitors. \\
\hline
\end{tabular}

\section{Type-A behaviour}

Friedman and Rosenman (1974) introduced the notion of type-A behaviour in the 1960s. The concept is defined in various ways, but we will follow Friedman and Rosenman in this respect. They characterize a type-A person as someone who is always in a hurry, hostile, aggressive and impatient, showing a large urge to compete. Persons who do not adhere to the above characteristics, are called type-B persons. Baron (1989) finds that type-A persons start more conflicts than type-B persons do, and accommodate less in order to solve the conflicts. Given this definition, the following hypothesis may be derived.

\begin{tabular}{|l|l||}
\hline H9 & Type-A persons are more competitive than type-B persons. \\
\hline \hline
\end{tabular}

\section{Sensation-seeking}

Individuals differ with respect to the degree of sensation looked for. High sensationseekers have a strong need to experience new (and risky) situations while low 
sensation-scekers tend to adhere to stable and predictable situations in order not to upset their state of mind. BBW (1995: 20) argue that cooperation is risky. Since high sensation-seekers are more likely to take risks, they are more cooperative, when cooperative behaviour is more associated with risk than competitive behaviour. In the above experiments cooperation involves some risk. ${ }^{(7)}$ For this reason we follow $\mathrm{BBW}$ and constructs the following hypothesis.

\begin{tabular}{||l|l||}
\hline H 10 & $\begin{array}{l}\text { Low sensation-seekers are more competitive than high sensation- } \\
\text { seekers. }\end{array}$ \\
\hline
\end{tabular}

Gender and age

Several studies indicate that females are less competitive than males (BBW: 21); some of these studies involve the Prisoner's Dilemma game [Frank, Gilovich and Regan (1993)]. However, Mason, Phillips and Redington (1991) find that the difference between males and females vanishes after 25 play-rounds: Males become more cooperative over time. Contrary to the above results, BBW (1995) find that female students are more competitive than their male counterparts. Females studying economics may be more competitive than other females (self-selection), or become more competitive during their study (adaptation). We will nevertheless hypothesize the following.

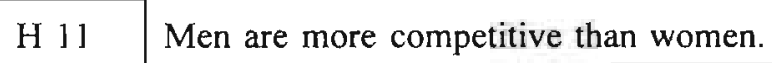

Competitiveness is likely to be decreasing with age [BBW (1995: 22)]. Older people are likely to have a greater ability to behave cooperatively when such a behaviour is appropriate and profitable.

H 12 Competitiveness decreases with age.

The trait hypotheses are summarized in Table 5.8 .

(7) In this chapter, competitive and cooperative behaviour are defined in terms of the results - the prices set. As such they are not related to types of strategic behaviour. Competitive behaviour - average cost pricing - does not involve any risk, since consumer surplus is maximum, and thus demand positive and profits non-negative [Table 5.3]. Cooperative behaviour - monopolistic price setting - involves a risk, since consumer surplus is only maximum if the rival player cooperates as well. Demand then equals zero, and net profits will be negative (loss of R\&D expenses). 


\begin{tabular}{|l|l||}
\hline \multicolumn{2}{||l||}{ Table 5.8} \\
Trait hypotheses \\
\hline H 7 & Externals are more competitive than internals. \\
H 8 & Low self-monitors are more competitive than high self-monitors. \\
H 9 & Type-A persons are more competitive than type-B persons. \\
H 10 & Low sensation-seekers are more competitive than high sensation- \\
H 11 & seekers. \\
H 12 & Men are more competitive than women. \\
\hline
\end{tabular}

\section{Methods}

\subsection{Subjects and procedures}

The experiments were incorporated in three courses for graduate students of economics and business administration at the University of Limburg (Maastricht, Netherlands). Experiments 1 and 2 were incorporated into a two-week skills training course in applied game theory in June 1995. Experiments 1 and 3 were part of a seven-week course in industrial organization and one in experimental economics in December 1995. Students in business administration follow many courses in economics: The undergraduate curriculum, one full year, is identical for both programmes.

The purpose of the course in applied game theory is to learn students to apply and understand formal game theory as laid down by Rasmusen (1990), for instance. The course focused on three topics of game theory: Bidding games, coalitions and Prisoner's Dilemmas. At the beginning of the course the students were asked to fill in a questionnaire in order to measure their subjective and objective characteristics. The students were told that the experiments were constructed to deepen their and our understanding of behaviour in a game-theoretical framework. The students were promised feedback on the main results of the experiments. Strict confidentiality was guaranteed with respect to the information provided by the questionnaires. The experiments in June were attended by 26 students. There were about 40 students who attended the course on applied game theory. Both experiments were carried out in one session of two hours. The experiments are not directly related to the topics studied during the course. The spontaneity of the students is not likely to be influenced by the course.

The course in industrial organization pays attention to the implications of the business strategies for industry structure and social welfare. Particular attention is paid to strategies associated with irreversible investments, i.e. sunk costs. The course integrates elements of traditional industrial economics (SCP-diagram), new industrial economics (game theory) and strategic management. The course in experimental economics studies experimental methods, and presents the major results in this field 
reached so far. At the beginning of both courses, the students were again asked to fill in the questionnaire. The students were told that the experiments were constructed to deepen their insights in business strategy or experimental methods. The students were promised feedback on the main results of the experiments. Strict confidentiality was guaranteed with respect to the information provided by the questionnaires. The experiments in December were attended by eighteen students, four of whom attended the experiments in June as well. Those four students played against each other in both experiments. Their results with respect to experiment 1 are not taken into account. Both experiments were carried out in one session taking two hours. Of the students attending the experiments, thirteen studied industrial organization and five experimental economics. The eighteen students participating in the experiments came from a group of thirty-three students attending either a course in industrial organization, ${ }^{(8)}$ or a course in experimental economics. Students from a related course in industrial organization were also asked to come, but did not turn up.

Both sessions took place in one large room. Each student drew a random number from a box when (s)he entered the room. The number corresponded to a specific seat in the room. The students played the experiments in couples of two against each other. ${ }^{(9)}$ The subjects playing against each other, were seated side-by-side, but were separated by three empty seats. On both occasions one of my supervisors conducted the experiments. He clarified the purpose of the experiments once more, and explained the procedure to be followed during the sessions. The subjects received an instruction before each experiment which was read out loud by the game leader. The instruction presented the decision and pay-off structures (or routines) extensively. The experiments were presented as duopoly investing and pricing problems. Terms as 'compete' and 'cooperate' were avoided in order to guarantee a relatively neutral instruction.

The pace of the experiments was strictly controlled by the game leader. The game leader decided when decisions were to be made and to be exchanged. At the beginning of each experiment, the pace was slow in order to allow everyone to take a full grasp of the games. In order to investigate the subjects' behaviour more closely, the students were asked to motivate the choices made. The subjects played against the same person in both experiments performed during one session. The students played an unknown number of rounds larger than five during each experiment. The subjects received a bunch of paper notes with which the decisions to be made were exchanged. Other communication than exchanging notes was not allowed. Notes were only exchanged after a sign of the game leader. The choices made by a player, his (or her) opponent and the pay-offs were marked on a response sheet. All decisions were made simultaneously except for the price decision in experiment 2 , which was

(8) About half of the students in industrial organization who did not turn up, had other obligations (classes or tutoring).

(9) The subjects played against the same player during one session of two experiments, in order to guarantee orderly conduct during the sessions and to prevent possibilities for explicit (non-tacit) coordination. 
strictly sequential by nature. The order in which the players had to decide on price was determined by the game leader.

The students were not only instructed to maximize profits, but also motivated to do so by financial rewards. At the beginning of the experiments in June, the subjects were told that the top-three players in terms of accumulated pay-off would receive a token worth 40 guilders. ${ }^{(10)}$ Additionally the students knew that the full ranking of the players would be made public after the experiments. At the beginning of the experiments in December, the subjects were told that each student would receive a reward depending on the pay-offs obtained. Expected pay-offs over the two experiments were 20 guilders when the players would cooperate. ${ }^{(11)}$ Maximum pay-offs were 30 guilders.

The order in which the experiments were played, was predetermined in advance. In the previous section, we argued why the mark-up of price over marginal cost is expected to be lower in experiment 2 and 3. However, both experiments were played against the same competitor as in experiment 1 after the latter experiment was played. Fxperiment 1 allowed tacit coordination between the players, and this fact may have facilitated coordination in experiments 2 and 3. Various studies indicate that cooperation is more likely when subjects have contact over a longer time period or have more experience in playing experimental games [Benson and Faminow (1988) and Alger (1987)]. When the experiments would have been played in a different order, the subjects might have been less cooperative than they were in experiments 2 and 3, and experiment 1 . With a larger number of subjects, the experimental design could have been corrected for this order effect by providing different sub-groups with a differently ordered series of experiments. However, given the small number of participating students, we decided to work with the full sample. The order of the experiments probably was not favourable to perfect barrier market outcomes. The infinite horizon applied in all three experiments is also hostile to barrier market results. Both game-theoretical and experimental results strongly suggest that cooperation is fostered by infinite horizons. This is due to the so-called Chain-Store Paradox [Selten (1978)]. However, we chose for an infinite horizon, since we did not want to impose barrier market results straight away by a finite horizon. There is another reason to employ an infinite time horizon. This chapter attempts to test the results of Chapter 2 . In the latter chapter the firms modelled played an infinite number of games as well. We merely assumed the firms employed a short-term time horizon. Recall the discrete time structure employed probably is favourable to barrier market results. In future research we plan to conduct a series of experiments with set-

(10) The players played an unknown number of games per experiment. Quality and pay-offs in any game did not influence quality and pay-offs in future games. As a consequence, the results of each game may be expected to be independent of the results of other games.

(11) Pay-offs were 5 guilders plus the average pay-off over game 1 divided by 100,000 , plus the average pay-off over game 2 divided by 10,000. One guilder is approximately equal to .90 Deutsche mark or .67 U.S. dollar. 
ups that allow for analysing the robustness of the outcomes for these and other rules of the game.

\subsection{Measures}

\subsection{Measuring quality, price and competitive behaviour}

In experiments 1 and 2, the subjects were asked to make a choice between a low and a high quality and price level. The choices were marked using capital ' $\mathrm{L}$ ' or capital ' $H$ '. The pay-offs were pre-calculated for the players. The exact quality and price levels were not known to the players. In experiment 3 , the quality and price levels were made public. In order to compare the results over the three experiments the implied price levels in experiments 1 and 2 are used in the analysis below. Note that the pay-off structure used in experiments 1 and 2 is derived from the demand and cost parameters used in experiment 3. Now, the following parameter values are used for analysing experiments 1 and 2 . The value of the low-quality product is ' 250 ' and $750^{\prime}$ for the high-quality product. The high price level equals the monopoly price, i.e. the value of the product $\left[{ }^{\prime} 250^{\prime}\right.$ or $\left.{ }^{\prime} 750^{\circ}\right]$. The low price equals marginal cost (corrected for the quality differential) ['200', '600' or ' 649 '].

The hypotheses laid down in Sub-section 3.1 refer to quality and price. The latter variable as such is not useful for a statistical analysis since it does not relate to the quality level. The difference in quality is taken into account in two ways. First, the mark-up over marginal cost is employed instead of price sec as this concept does not depend upon the underlying quality level. The mark-up of price over marginal cost is expected to be somewhere between 0 and 25 per cent. ${ }^{(12)}$ Second, we perform the analyses twice. In the first analysis, we pay attention to all price games. In the second analysis, we restrict attention to those price games in which both players have a high-quality product. We will refer to the latter as barrier market games. The other price games do not occur frequently, and are therefore left out of separate consideration.

In Sub-section 3.2 we presented preliminary hypotheses on competilive versus cooperative behaviour and personality characteristics. In Sub-section 5.2 we will test these hypotheses for experiment 1 and 2 . A subject is competitive when he plays a low-price strategy rather than a high-price strategy. A high-price strategy is indicated by ' 1 ', and a low-price strategy by ' 0 '. Competitive versus cooperative bchaviour is measured by the average number of cooperative choices over an experiment. In June 1995 experiment 1 consisted of 13 rounds; in December 1995 it consisted of 11 rounds; experiment 2 - played in June - took 11 rounds. However, there are four possible situations in which to take price decisions, depending on the quality deci-

(12) The maximum possible prices are ' 250 ' (low quality) and ' 750 ' (high quality). In these cases the mark-ups are $(250-200) / 200=(750-600) / 600=25 \%$. A mark-up lower than $0 \%$ is not profitable and thus not likely. 
sions made. It remains true that a high-price strategy may be considered to be cooperative and a low-price strategy to be competitive. In all four situations, the highprice outcome $\left(\mathrm{P}_{\mathrm{H}}, \mathrm{P}_{\mathrm{H}}\right)$ maximizes industry profits while distributing these profits as equally as possible. However, there is no rationale for the high-quality player to choose the cooperative strategy when there is a difference in quality: The high-price strategy is strictly dominated by the low-price strategy. Note that joint profits are also at their maximum when the high-quality firm chooses the low-price option. For this reason, one may want to make a distinction between the quality contexts. In Subsection 5.2, we use two measures for cooperation: The first measure is based on all competition games played: the second one uses only the price games in those situations in which both players have a high-quality product. The other situations do not occur frequently, and are therefore left out of separate consideration.

\subsubsection{Measuring subjective' characteristics}

The locus of control trait was measured using the well-known Rotter scale [Rotter (1966)], translated into Dutch by a colleague from the research program in experimental economics at the University of Limburg [Boone (1992)]. The scale contains 37 closed questions, 23 of which have been designed to measure the locus of control. The other 14 questions were filler items constructed in order to obscure the purpose of the test. The items are statements with an internal and an external alternative. They may run as follows: 'Many times I feel that I have little influence over the things that happen to me' (external alternative) or 'It is impossible for me to believe that chance or luck plays an important role in my life' (internal alternative). The score on the locus of control runs from 0 to 23 . Persons with a low score are internals while those with a high score are externals.

The most widely-used measure of self-monitoring is the Self-Monitoring Scale developed by Snyder (1974). The original scale contained 25 items. Snyder and Gangestadt (1986) improved upon the first version of the scale. The latter version, containing 18 items, has been translated into Dutch by Boone (1992) and used for the present study. The items are statements to which the subjects have to answer with 'true' or 'not true'. An example of such a statement is the following: 'In different situations and with different people, I often act like very different persons' (high selfmonitoring). The score runs from 0 to 18 . High self-monitors reach high scores, and low self-monitors low scores.

Type-A behaviour may be assessed by the Jenkins Activity Survey (JAS) developed by Jenkins, Zyzanski and Rosenman (1979). The survey is translated into Dutch and adapted for the Netherlands by Appels (1985). The advantage of this questionnaire is its convenience in large sample studies. However, from a methodological point of view the structured interview method is preferable since this method allows the investigator to take the behaviour during the interview (speech rate) into account. We chose for convenience, and used the Dutch adaptation of Jenkins' approach. The version used contained 24 questions with three to five answers per item. The response categories indicating type-A behaviour receive score 1 , the others score 0 . 
The total score thus runs from 0 to 24 , where 24 indicates (extreme) type- $\mathrm{A}$ behaviour. An example of the items put forward is: 'Are you hurried when going to work, even when you have enough time?'.

Sensation-seeking was measured using the 'Spanningsbehoeftelijst' (SBL) of Feij and Van Zuijlen (1984). This measure was constructed with the American Sensation Seeking Scale as the base. The SBL contains 67 items, 51 of which are used to measure sensation-seeking. The respondents were asked to indicate their agreement to statements on a five-point scale $(1=$ strongly disagree, $2=$ moderately disagree, $3=$ do not know, $4=$ moderately agree and $5=$ strongly agree). The scores of 15 items are reversed in order to have a high score corresponding with high sensation-seeking. The following statements are examples of the items: 'I would like to learn to fly', 'I like to wander around in a strange city on my own, even if it means getting lost', I usually don't enjoy a movie or play when I can predict what will happen in advance' and 'I like wild, uninhibited parties'.

The questionnaire also provides information on age and gender $(0=$ male and $1=$ female), and also on family, religious and educational background. The latter three pieces of information are not used for the present analysis. The four personality scales have revealed high reliability in a large number of studies over the last two or three decades. Many studies use Cronbach's $\alpha$ as measure of reliability [Cronbach (1951)]. A value exceeding .60 is acceptable [Nunnally (1978)], although a value exceeding .70 is more desirable. The values of Cronbach's $\alpha$ for the four personality traits are well above .70 with the exception of self-monitoring [Table 5.9]. Rotter (1966: 13) finds similar values of Cronbach's $\alpha$ for locus of control (around .70); Snyder and Gangestad (1986: 137) do so for self-monitoring (.70); Appels (1985: 479 ) does so for type-A behaviour (.84) and Feij and Van Zuijlen (1984:11) do so for sensation-seeking ( .54 for men and .55 for women).

Table 5.9

Descriptive statistics

\begin{tabular}{|c|c|c|c|c|c|c|}
\hline $\begin{array}{l}\text { Variables (number of } \\
\text { observations; scale range) }\end{array}$ & Mean & Median & $\begin{array}{l}\text { Std. } \\
\text { dev. }\end{array}$ & Min. & Max. & Cronbach's $\alpha$ \\
\hline $\begin{array}{l}\text { Locus of control } \\
(37 ; 0-23)\end{array}$ & 11.2 & 11 & 4.4 & 4 & 19 & 0.76 \\
\hline $\begin{array}{l}\text { Self-monitoring } \\
(37 ; 0-18)\end{array}$ & 8.2 & 8 & 3.0 & 3 & 15 & 0.66 \\
\hline $\begin{array}{l}\text { Type A-behaviour } \\
(37 ; 0-24)\end{array}$ & 13.1 & 13 & 4.4 & 4 & 22 & 0.77 \\
\hline $\begin{array}{l}\text { Total sensation seeking } \\
(37 ; 4-20)\end{array}$ & 12.4 & 12.5 & 1.9 & 7.9 & 15.7 & 0.76 \\
\hline $\begin{array}{l}\text { Gender } \\
(37: 0-1)\end{array}$ & 0.4 & 0 & 0.5 & 0 & 1 & - \\
\hline $\begin{array}{l}\text { Age } \\
(37)\end{array}$ & 23.0 & 22 & 2.4 & 21 & 34 & - \\
\hline
\end{tabular}




\section{$5 \quad$ Results}

\subsection{Experiment specific results}

Section 2 presents the game-theoretical solutions of the experiments played, and Subsection 3.1 provides more general hypotheses based on this analysis. In this section, we investigate whether the game-theoretical solutions and the more general hypotheses can be shown to hold. Table 5.10 reveals the results of the experiments. The mark-ups within brackets refer to barrier markets games, the mark-ups without brackets to all competition games. Experiments 1 and 2 clearly support the cooperative scenario over the barrier market scenario. Hypothesis 1 and Hypothesis $2 \mathrm{~B}$ are confirmed by the data, Hypo-thesis $2 \mathrm{~A}$ is rejected. The mark-up over price seems to be significantly lower in experiment 3 than in the other two experiments. When prices are made continuous, the mark-up slowly tends to the barrier market solution, although it is still far from zero.

The hypothesis that average quality and average mark-up are equal for experiment 1 as carried out in June 1995 and December 1995, cannot be rejected. The tvalue for quality equals 0.65 with 38 degrees of freedom. The t-value for the markup equals $-0.80(38 \mathrm{df})$ for all price games and $-.50(38 \mathrm{df}$ ) for the barrier market cases. The hypothesis that the variances of quality and mark-up are equal, cannot be rejected. Levene's test for equality of variances obtains F-values equal to $3.384(\mathrm{p}=$ $0.074)$ and $0.864(p=.620)$ for the mark-up in all price games and the barrier market cases, respectively, and a F-value equal to $0.330(p=0.569)$ for quality. This allows one to compare the results for experiments 2 and 3 with the aggregated results of the two versions of experiment 1 .

Table 5.10

General results

$\begin{array}{lllll}\begin{array}{l}\text { Experiment } \\ \text { (number of players) }\end{array} & \begin{array}{l}\text { Hypothesized } \\ \text { quality }\end{array} & \begin{array}{l}\text { Average } \\ \text { quality }\end{array} & \begin{array}{l}\text { Hypothesized } \\ \text { mark-up }\end{array} & \begin{array}{l}\text { Average } \\ \text { mark-up }\end{array} \\ \begin{array}{l}\text { Experiment 1 } \\ \text { June (26) }\end{array} & 750 & 720.4 & 0(25) & 20.9(20.5) \\ \text { December (14) } & 750 & 707.8 & 0(25) & 22.6(21.9) \\ \text { Total (40) } & 750 & 716.0 & 0(25) & 21.4(21.0) \\ \text { Experiment 2A (13) } & 750 & 708.0 & 0(25) & 21.5(19.9) \\ \text { Experiment 2B (13) } & 750 & 736.0 & 0(25) & 20.5(19.1) \\ \text { Experiment 3(18) } & 750 & 708.3 & 0(25) & 13.3(15.1)\end{array}$

Average quality and the average mark-up do not differ significantly between 
experiment 1 and 2 at the .05 level. ${ }^{(13)}$ This holds when the results of all cises are compared, but also when the results of experiment 1 as carried out in June 1995 and the results of experiment 2 are paired [Table 5.11]. Hypotheses $3 \mathrm{~A}, 4 \mathrm{~A}$ and $4 \mathrm{~B}$ thus do not hold. The results do not seem to depend on the question whether prices are decided upon simultaneously or sequentially. However, the data do not convey any information on Hypothesis $3 \mathrm{~B}$. We need to perform a somewhat different analysis for this hypothesis. Consider the price games in which the players have the same quality level. The players taking the last price decision charged low prices in $17.5 \%$ of all cases. In $15.4 \%$ of all cases, both players charged low prices. This implies that the players taking the last price decision 'cheated' upon the players taking the first price decision in $2.1 \%$ of all cases. This difference does not differ significantly from zero. Hypothesis $3 \mathrm{~B}$ thus finds support by the data (paired t-test: 1.39 with 12 degrees of freedom).

Table 5.11

A comparison between experiment 1 and experiment 2

$$
\mathrm{t} \text {-value (unpaired) } \mathrm{t} \text {-value (paired) }
$$

$\begin{array}{lll}\begin{array}{l}\text { Experiment } 2 \mathrm{~A} \\ \text { Quality }\end{array} & 0.35 \text { (df: } 51) & 0.48 \text { (df: } 12) \\ \quad \begin{array}{l}\text { Mark-up } \\ \quad \text { (all games) }\end{array} & -0.03 \text { (df: } 51) & -0.44 \text { (df: } 12) \\ \quad \text { (barrier market games) } & 0.42 \text { (df: } 51) & 0.15 \text { (df: } 12) \\ \begin{array}{l}\text { Experiment 2B } \\ \quad \text { Quality }\end{array} & -1.64 \text { (df: } 42.47)^{(1)} & -0.94 \text { (df: } 12) \\ \quad \begin{array}{ll}\text { Mark-up } \\ \quad \text { (all games) }\end{array} & 0.47 \text { (df: } 51) & 0.28 \text { (df: } 12) \\ \quad \text { (barrier market games) } & 0.70 \text { (df: } 51) & 0.74 \text { (df: } 12)\end{array}$

(1) The degrees of freedom reflect the difference in the sample variance.

Average quality does not differ between experiments 1 and 3. Both unpaired and paired t-tests cannot reject the equality hypothesis [Table 5.12]. However, the average mark-up seems to be strictly lower in experiment 3. Both t-tests, unpaired and paired, indicate that the equality hypothesis may be rejected at the 1 per cent level. Hypothesis 6 does not hold while Hypothesis 5 cannot be rejected. When subjects can freely decide upon price, more competitive solutions seem to be obtained, although they remain rather uncompetitive. The average mark-up is not the only factor of importance; the development in the mark-up is important as well. Figures 5.1 and 5.2 show that in experiment 3 there is a larger tendency for the mark-up to fall than there is in experiment 1 . According to the figures firms charge a mark-up larger than $20 \%$ in

(13) Quality is almost significantly higher at the .05 level for the players taking the last price decision according to the unpaired $t$-test $(p=.054)$. 
experiment 1 after 10 rounds while they charge a mark-up equal to $10 \%$ (all price games) or $15 \%$ (barrier market games) in the last round of experiment 3 .

Table 5.12

$\Lambda$ comparison between experiment 1 and experiment $3^{(1)}$

$$
\mathrm{t} \text {-value (unpaired) t-value (paired) }
$$

\begin{tabular}{|c|c|c|}
\hline \multirow{2}{*}{\multicolumn{3}{|c|}{$\begin{array}{l}\text { Quality } \\
\text { Mark-up }\end{array}$}} \\
\hline & & \\
\hline (all games) & $2.43^{\circ}(\mathrm{df}: 20.56)^{(2)}$ & $2.86^{\circ}(\mathrm{df}: 16)$ \\
\hline (barrier market games) & $2.29^{\circ}(\mathrm{df}: 56)$ & $3.16^{\circ}(\mathrm{df}: 16)$ \\
\hline
\end{tabular}

A simple regression (OLS) confirms this view. The mark-up decreases with $.2 \%$ per round in experiment 1 and even with $.3 \%$ in barrier market games. The latter decrease is significant at the .01 level. The mark-up decreases with $1.1 \%$ per round in experiment $3(p=.012)$ and with $.5 \%$ in barrier market games. However, the latter result does not differ significantly from zero [Table 5.13]. As a result, we must conclude that these data do not allow any definite conclusion with respect to a difference in the convergence levels.

Table 5.13

The mark up as a function of the number of rounds ${ }^{(1)}$

Experiment 1

$$
\text { Constant Round Dummy }{ }^{(2)}
$$

(all games)

$22.24 *(.86)$

$-.20(.10)$

(barrier market games)

$23.40^{\circ}(.94)$

$-.29^{\circ}(.11)$

Experiment 3

(all ganles)

$19.13 *(2.56)$

$-1.05^{\circ}(.41)$

(barrier market games)

$19.37^{*}(1.91)$

$-.47(.32)$

(1) " and " indicate statistical significance at the .05 and .01 level respectively.

(2) The dummy is 0 for the cases in June and 1 for those in December. 
Figure 5.1: Average mark-up

\section{Experiment 1 versus experiment 3}

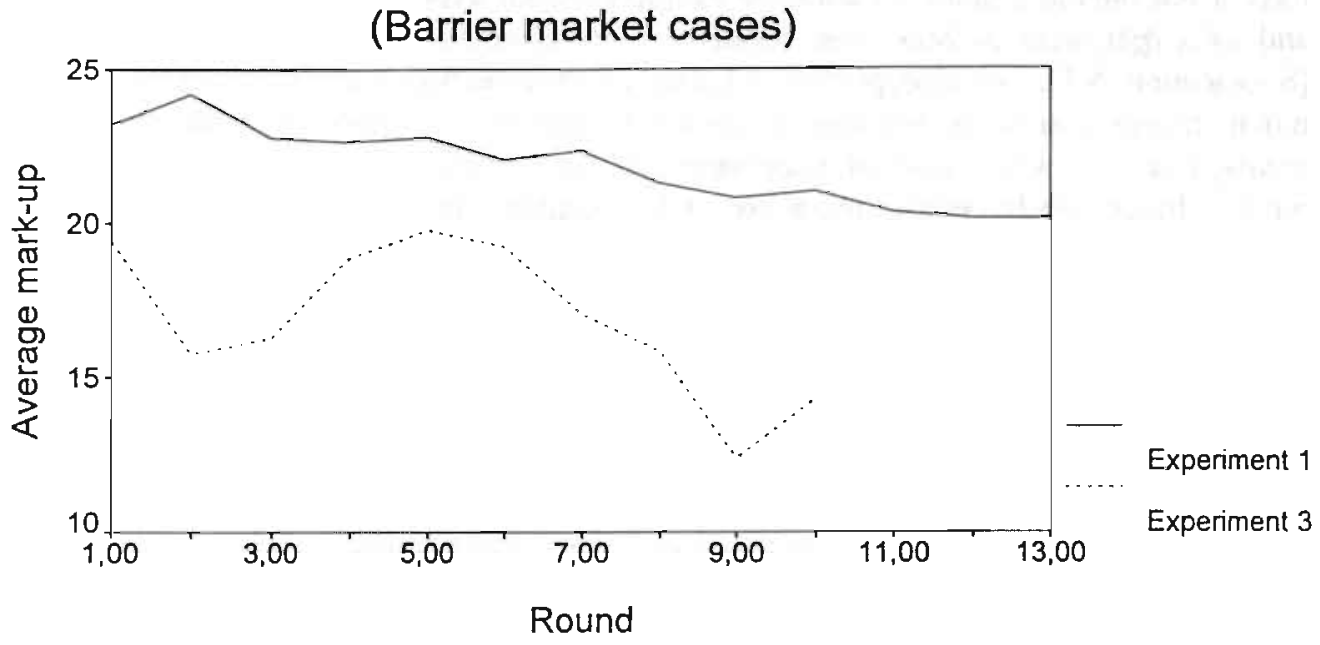

Figure 5.2: Average mark-up

Experiment 1 versus experiment 3

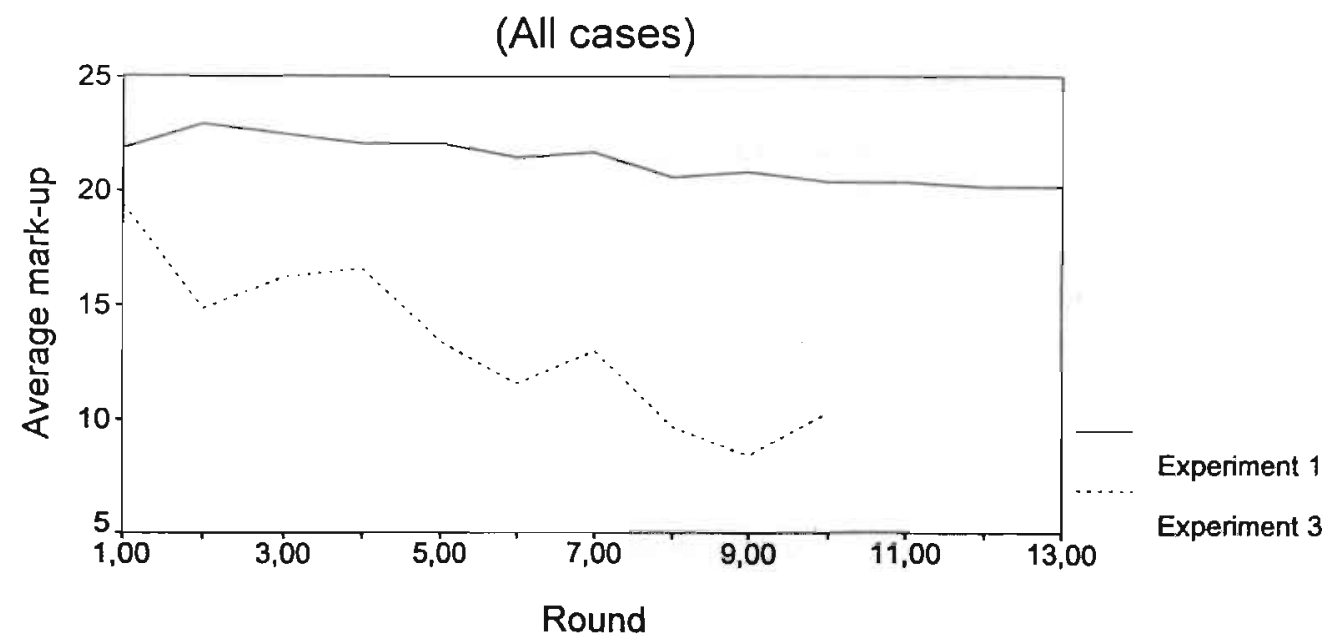




\subsection{Individual differences}

In this sub-section we test the hypotheses relating personality traits to competitive behaviour for experiment 1 separately, and for experiments 1 and 2 together. We analyzed only experiment 1 separately, since it is the only experiment on which we have a reasonable amount of data: 40 subjects played experiment 1,26 experiment 2 and 18 experiment 3 . Since the results for experiments 1 and 2 seem to coincide [Sub-section 5.1], we also pooled the data of these experiments in order to use as much information as is possible. It does not seem wise to pool the data of experiments 1 and 2 with those of experiment 3 , since experiments 1 and 2 involve a binary choice, while choices are more or less continuous in experiment 3 . Table 5.9 and 5.14 give descriptive statistics and rank correlations. Both tables are based on 37 observations. The degree of cooperation is analyzed for all price games and for the barrier market games. In Table 5.14, Al refers to all price games in experiment 1 , Al-2 to all price games in experiments 1 and 2: BMl refers to barrier market games in experiment 1, BM1-2 to those in experiments 1 and 2. Table 5.14 shows that rank correlations in general are not significant. The measures for cooperation are, of course, correlated. But if we neglect these correlations, there is only one significant correlation: Self-monitoring is correlated with sensation-seeking.

\begin{tabular}{|c|c|c|c|c|c|c|c|c|c|}
\hline \multicolumn{10}{|c|}{$\begin{array}{l}\text { Table } 5.14 \\
\text { Descriptive statistics (Rank correlations among variables under study) }{ }^{(1)}\end{array}$} \\
\hline Variables & 1 & 2 & 3 & 4 & 5 & 6 & 7 & 8 & 9 \\
\hline $\begin{array}{l}\text { I.ocus of control } \\
\text { Selt monitoring } \\
\text { Type-A behaviour } \\
\text { Sensation seeking } \\
\text { Age } \\
\text { Cooperation Al } \\
\text { Cooperation A1-2 } \\
\text { Cooperation BMl } \\
\text { Cooperation BM1-2 }\end{array}$ & $\begin{array}{l}- \\
-.13 \\
-.19 \\
-.17 \\
.06 \\
-.01 \\
-.09 \\
-.11 \\
-.01\end{array}$ & $\begin{array}{l}- \\
.24 \\
.35^{\circ} \\
-.06 \\
.03 \\
.01 \\
.03 \\
-.06 \\
\end{array}$ & $\begin{array}{l}- \\
.05 \\
-.02 \\
.09 \\
.04 \\
.11 \\
-.03\end{array}$ & $\begin{array}{l}- \\
.15 \\
-.31 \\
-.22 \\
-.18 \\
-.22 \\
\end{array}$ & $\begin{array}{l}- \\
.05 \\
.14 \\
.19 \\
.16\end{array}$ & $\begin{array}{l}- \\
.92^{*} \\
.80^{\circ} \\
.81^{\circ}\end{array}$ & $\begin{array}{l}- \\
.74^{\circ *} \\
90^{\circ}\end{array}$ & $81^{-}$ & - \\
\hline $\begin{array}{l}\text { Gender }{ }^{(2)} \\
\text { Males (21) } \\
\text { Females (16) } \\
\text { Mann-Whitney }\end{array}$ & $\begin{array}{l}10.1 \\
12.5\end{array}$ & $\begin{array}{l}9.48 \\
6.50 \\
* *\end{array}$ & $\begin{array}{l}14.0 \\
11.9\end{array}$ & $\begin{array}{l}13.2 \\
11.2 \\
* *\end{array}$ & $\begin{array}{l}23.0 \\
23.1\end{array}$ & $\begin{array}{l}.77 \\
.87\end{array}$ & $\begin{array}{l}.76 \\
.90\end{array}$ & $\begin{array}{l}.79 \\
.88\end{array}$ & $\begin{array}{l}.76 \\
.90\end{array}$ \\
\hline $\begin{array}{l}\text { (1) and " indicate } \\
\text { tailed). } \\
\text { (2) Averages are rep }\end{array}$ & tist & 8 & nc & ales. & 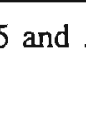 & 1 & & 1 & \\
\hline
\end{tabular}

BBW (1995: 32) report a correlation between locus of control, self-monitoring and sensation-seeking. BBW (1995: 33) expect self-monitoring and sensation-seeking to be correlated because both characteristics may be expected to be related to the 
locus of control. It is noteworthy that according to Table 5.14 both traits are not correlated with locus of control, but nevertheless with each other. Let us regress BBW's argumentation first. It is not surprising that locus of control and self-monitoring are correlated. Locus of control measures whether individuals expect to be able to control their achievements, while self-monitoring refers to their willingness and ability to control social interaction through expressive behaviour. Locus of control is correlated with sensation-seeking for the following three reasons: (1) High sensationseekers tend to decide autonomously, which is a characteristic of internals; (2) internals are likely to take more risks since they think that they can create their own success; and (3) differences in locus of control and sensation-seeking are likely to be due to the same physiological processes. As said above, BBW suggest that the correlation between self-monitoring and sensation-seeking is due to the correlation of both variables with locus of control. Table 5.14, however, suggests that there is no such correlation.

Table 5.14 also suggests that type-A behaviour is not correlated with other personality traits. This finding corresponds with the results given by $\mathrm{BBW}$, and suggests that type-A behaviour is a distinct individual trait. The data also indicate that there are some differences between man and women. Males score higher on selfmonitoring and sensation-seeking. The Jatter result is common [BBW: 34] and may be due to differences in behaviour as well as role expectations. BBW report differences between man and women with respect to locus of control and type-A behaviour. Differences with respect to these variables are not important while differences with respect to (again) self-monitoring are.

\begin{tabular}{|c|c|c|c|c|}
\hline \multirow[t]{2}{*}{ Variables } & \multicolumn{2}{|c|}{$\begin{array}{l}\text { Cooperative behaviour } \\
\text { experiment } 1\end{array}$} & \multicolumn{2}{|c|}{$\begin{array}{l}\text { Cooperative behaviour } \\
\text { experiment } I \text { and } 2\end{array}$} \\
\hline & All games & $\begin{array}{l}\text { Barrier } \\
\text { market } \\
\text { games }\end{array}$ & All games & $\begin{array}{l}\text { Barrier } \\
\text { market } \\
\text { games }\end{array}$ \\
\hline $\begin{array}{l}\text { Locus of control } \\
\text { Self-monitoring } \\
\text { Type-A behaviour } \\
\text { Sensation seeking } \\
\text { Age }\end{array}$ & $\begin{array}{l}-.01 \\
.03 \\
.09 \\
-.31 \\
.05\end{array}$ & $\begin{array}{l}-.11 \\
.03 \\
.11 \\
-.18 \\
.19\end{array}$ & $\begin{array}{l}-.09 \\
.01 \\
.04 \\
-.22 \\
.14\end{array}$ & $\begin{array}{l}-.01 \\
-.06 \\
-.03 \\
-.22 \\
.16\end{array}$ \\
\hline
\end{tabular}

Table 5.15 relates cooperative behaviour and personality traits using bivariate analyses. The rank correlation for sensation-seeking is significant, but only when all price games in experiment $l$ are taken as measure of cooperation. Moreover, the sign 
found does not accord with Hypothesis 8. Note that the coefficient for self-monitoring has the wrong sign, when the cooperation measure is based on all barrier market games in experiments 1 and 2 . For this measure the coefficient for type-A behaviour has the right sign, for the other measures it does not. The Mann-Whitney U-test indicates that the differences between males and females are not significant, although the signs are correct [Table 5.14].

Tables 5.16 and 5.17 give the results of multivariate analyses. Since the dependent variable is binary, we applied logistic regression analysis. The linear regressions (A) reported in the tables give information on the probability with which a subject cooperates. For Table 5.16 this probability equals

$\operatorname{Prob}($ cooperation $)=\mathrm{e}^{\mathrm{A}} /\left(1+\mathrm{e}^{\mathrm{A}}\right)$,

where $\mathrm{A}=\alpha_{0}+\alpha_{1}{ }^{*}$ Dummy december $+\alpha_{2}{ }^{*}$ Round $+\ldots+\alpha_{8}{ }^{*}$ Age.

The probability that a male with median scores on the personality traits [Table 5.9] is cooperative in the first round of any price game in experiment 1 as played in June is Prob $(\mathrm{A}=2.46)=0.92$. In the thirteenth round, this probability would be Prob $(\mathrm{A}=$ $2.22)=0.90$. When the subject would be female instead of male, the probability would be Prob $(A=3.12)=0.96$.

\begin{tabular}{|c|c|c|}
\hline \multicolumn{3}{|c|}{$\begin{array}{l}\text { Table } 5.16 \\
\text { Parameter estimates from ordered logistic models (Experiment } 1)^{(1)}\end{array}$} \\
\hline Variable & All games & Barrier market games \\
\hline $\begin{array}{l}\text { Constant } \\
\text { Dummy December } \\
\text { Round } \\
\text { Locus of control } \\
\text { Self-monitoring } \\
\text { Type-A } \\
\text { Sensation-seeking } \\
\text { Gender } \\
\text { Age }\end{array}$ & $\begin{array}{l}.57(2.02) \\
.51(.32) \\
-.02(.03) \\
-.07^{\circ}(.03) \\
.11^{\circ}(.05) \\
.00(.03) \\
-.12(.13) \\
.66^{\circ}(.34) \\
.15^{\circ}(.07)\end{array}$ & $\begin{array}{l}-3.40(2.78) \\
.94^{\circ}(.43) \\
-.12^{* *}(.04) \\
-.08^{*}(.04) \\
.14^{\circ}(.06) \\
.00(.04) \\
.21(.17) \\
.67^{\dagger}(.40) \\
.30^{\circ *}(.11)\end{array}$ \\
\hline $\begin{array}{l}\text { Number of cases } \\
-2 \text { Log Likelihood } \\
\text { Model Chi-Square }\end{array}$ & $\begin{array}{l}457 \\
410.89 \\
28.16^{\cdots}\end{array}$ & $\begin{array}{l}399 \\
280.69 \\
31.92^{\cdots}\end{array}$ \\
\hline \multicolumn{3}{|c|}{$\begin{array}{l}\text { (1) The data denote the coefficient and the standard error, respectively; }{ }^{\dagger}, \\
\text { and } \cdots \text { indicate significance at the } .1, .05, .01 \text { and } .001 \text { level, respect- } \\
\text { ively. }\end{array}$} \\
\hline
\end{tabular}

For experiment 1, the coefficients for locus of control, self-monitoring, gender and age are significant at the .05 level and have the right sign, when all price games 
are considered. When attention is restricted to barrier market games, age and round are significant at the .01 level, the dummy for December, locus of control and selfmonitoring are significant at the .05 level and gender at the .1 level. The signs are as expected. Sensation-seeking is no longer significant [Table 5.14] and even has the 'right' sign for barrier market games. For experiments 1 and 2, the results are more pronounced [Table 5.17]. When all games are considered, locus of control, selfmonitoring, gender and age are significant at the .001 level, sensation-seeking - with the 'wrong' sign - at the .05 level and the dummy for December at the .1 level. For barrier market games, the significance of locus of control is somewhat lower, the significance of the dummy for December somewhat higher.

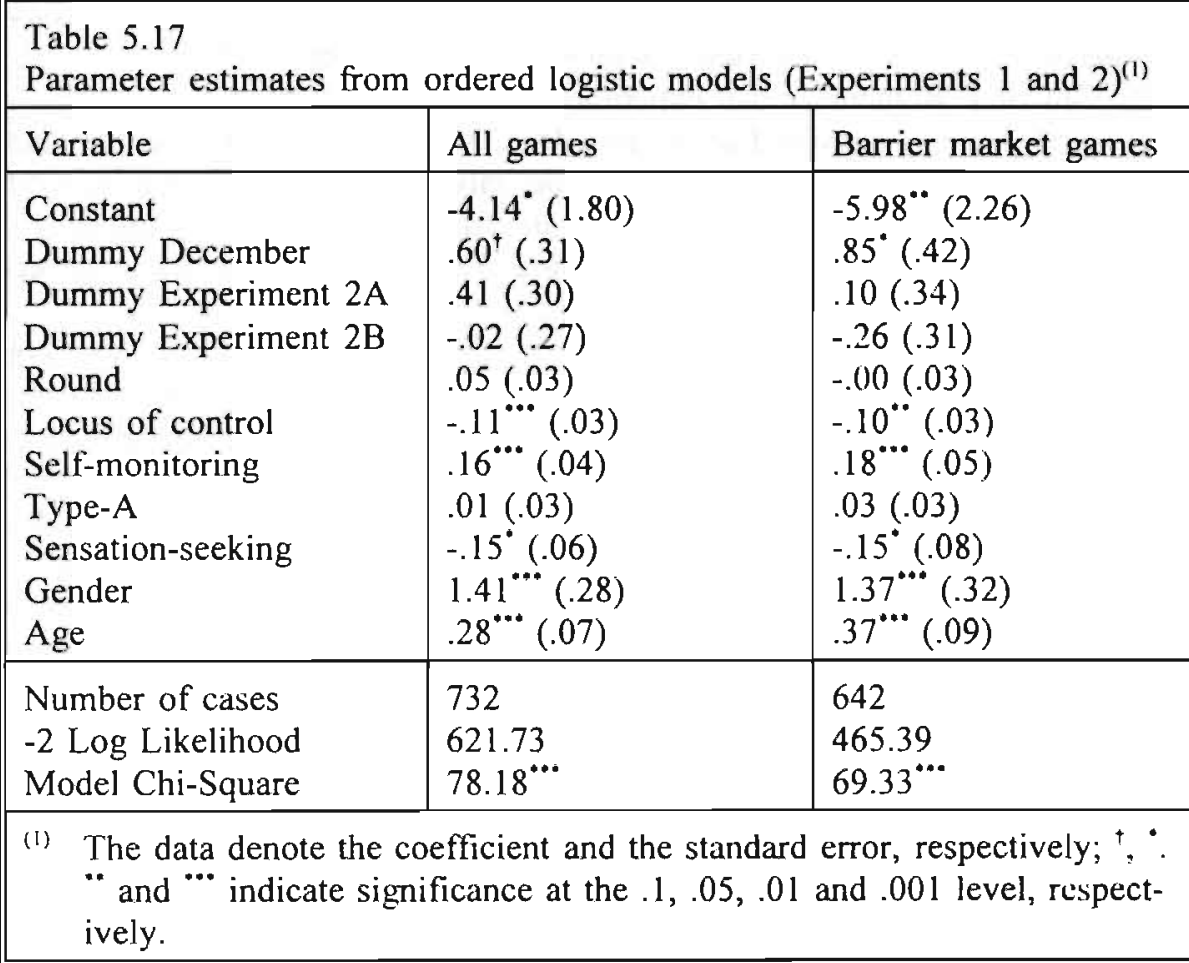

Before we turn to an analysis at the dyad level, we compare the above results with the findings obtained up until now in the literature. Table 5.17 indicates that internals cooperate more than externals do. This result accords with results obtained by BBW (1995) and Lester (1992). Multivariate analysis also indicates that low selfmonitors are more competitive than high-self-monitors. BBW (1995) report the same finding. However, contrary to BBW (1995), we do not find a significant relation for type-A behaviour and a significant, negative relation for sensation-seeking [Table 5.17]. The latter difference may be due to the fact that BBW, in general, obtain competitive results while we acquire cooperative results. When high sensation-seekers vary their behaviour more than low sensation-seekers do, it is not surprising that they 
cooperate more in an experiment based on the Prisoner's Dilemma games and compete more in an experiment based on the game set out in Sub-section 2.2. The relations between cooperative behaviour on the one hand and gender and age on the other correspond with previous results [with respect to gender, see Frank, Gilovich and Regan (1993); with respect to age, see BBW (1995)].

Figures 5.3 to 5.6 give the most pregnant results of dyad-level analyses for the barrier market cases. At the dyad level one counts the average number of cooperative choices for three groups: (1) Both players score low on the trait under consideration: (2) both players score high on the trait under consideration; (3) one player scores low whereas the other scores high. ${ }^{(14)}$ For locus of control this gives: (1) Two internal subjects; (2) two external subjects; (3) one internal and one extemal subject. Figures 5.3 to 5.6 refer to experiments 1 and 2. For the 12 dyads from June 1995 we have data on experiments 1 and 2. For the 5 dyads from December 1995 we only have data on experiment 1. Remember that experiment 1 took 13 rounds in June and 11 in December. Experiment 2 consisted of 11 rounds as well. This implies that the data for round 12 and 13 refer to experiment 1 in June only. The numbers in the legendae refer to the dyads in experiment 1 plus those in experiment 2. For example, with respect to Figure 5.3, I-I $(5+4)$ says that there are five dyads of internals in experiment 1 , four of which played experiment 2 as well.

The data may be studied using statistical techniques. such as multiple range tests - Schefiès, for instance - or even log-linear models. However, due to data limitations we restricted attention to graphical expositions. Scheffé's multiple range test does not produce any significant relationship for the data. The figures merely indicate tendencies. Figure 5.3 shows that external couples are more competitive than internal and mixed couples. Moreover, competitiveness decreases through time for internal couples while it is stable for the other two type of couples. This accords with the results obtained by BBW. Type-B dyads are more competitive than type-A or mixed dyads [Figure 5.4]. As expected, type-A couples show a large variability in their pricing behaviour, but tend to become less competitive through time. Figure 5.5 suggests that both low and high sensation couples are more competitive than mixed ones. Figure 5.6 also indicates that male and female couples compete more vigorously than mixed couples. Male couples become somewhat less competitive through time; female couples, however, become more competitive. So, clear-cut competitive behaviour is exhibited by external persons of type-B. The figures suggest that there is more competition in homogeneous groups than in mixed groups; this holds particularly for type-A behaviour, sensation-seeking and gender. In Sub-section 5.2, we argued that cooperation is the most likely strategy, unless the subjects do not trust each other or are risk-averse. Low sensation-seekers are more likely to be risk-averse and thus to be 'more competitive'. High sensation-seekers may cooperate somewhat less than mixed couples, since they may vary their behaviour somewhat more. Male and female subjects may have a larger incentive to compete with subjects of the same sex

(14) Players score low on a trait when their score is below the median; they score high on a trait otherwise. 
Figure 5.3: Average cooperation

Internals versus externals

(Barrier market cases)

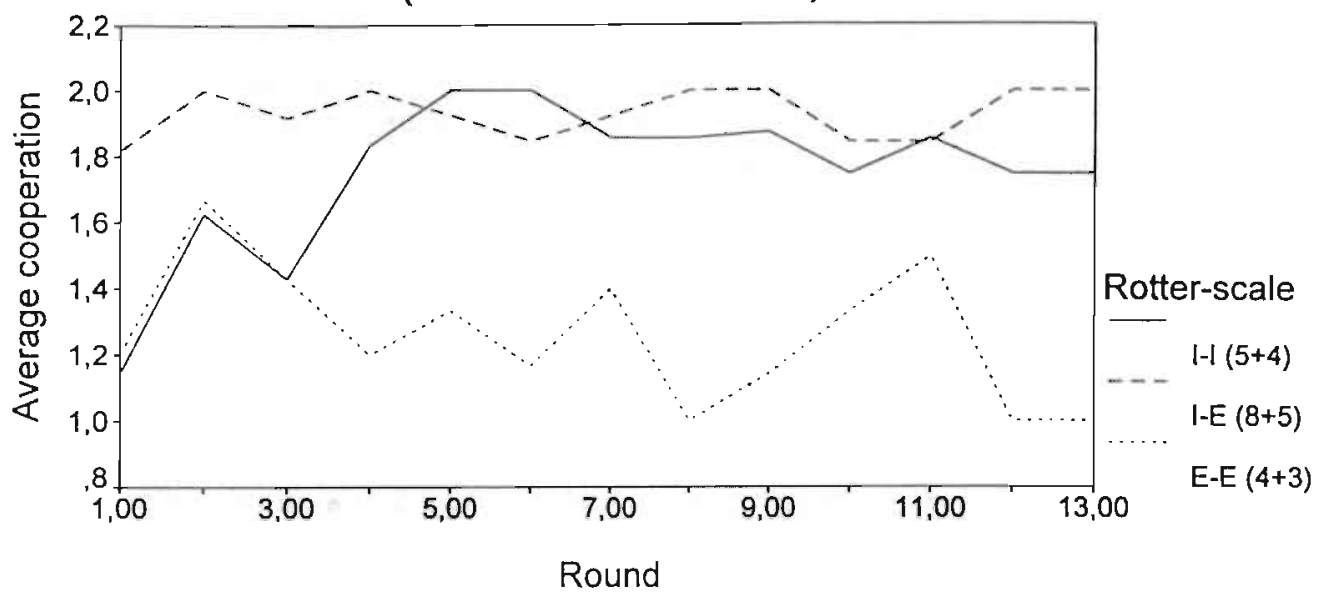

Figure 5.4: Average cooperation

Type-A versus type-B

(Barrier market cases)

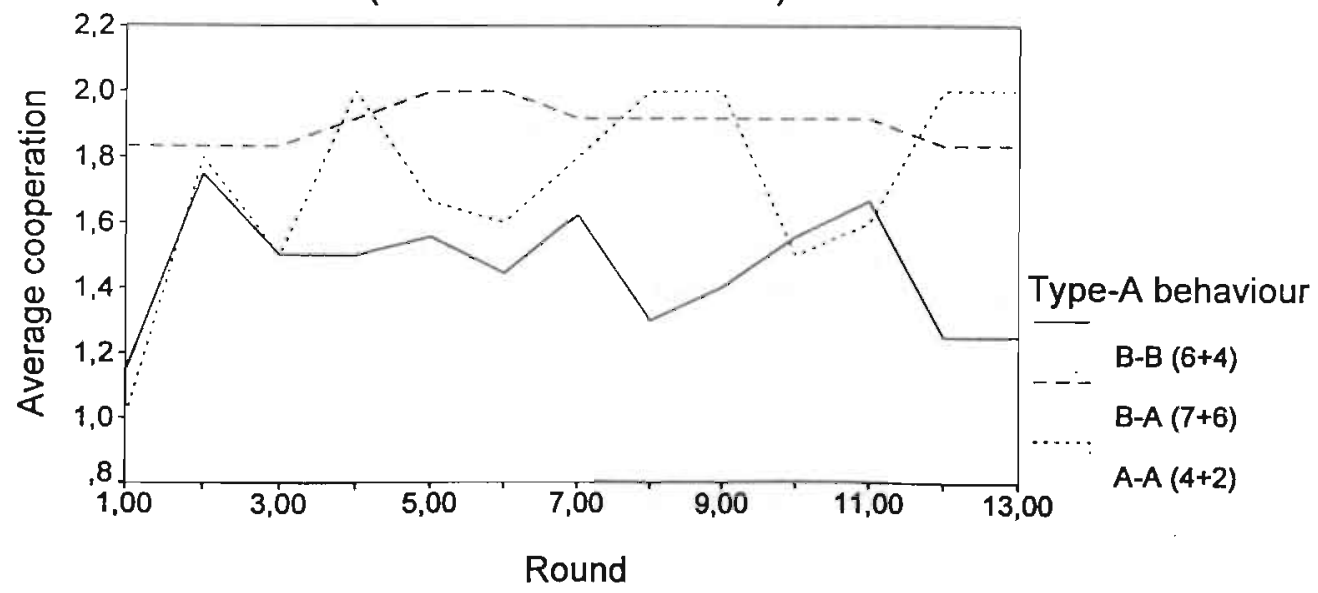


Figure 5.5: Average cooperation

Low versus high sensation-seekers

(Barrier market cases)

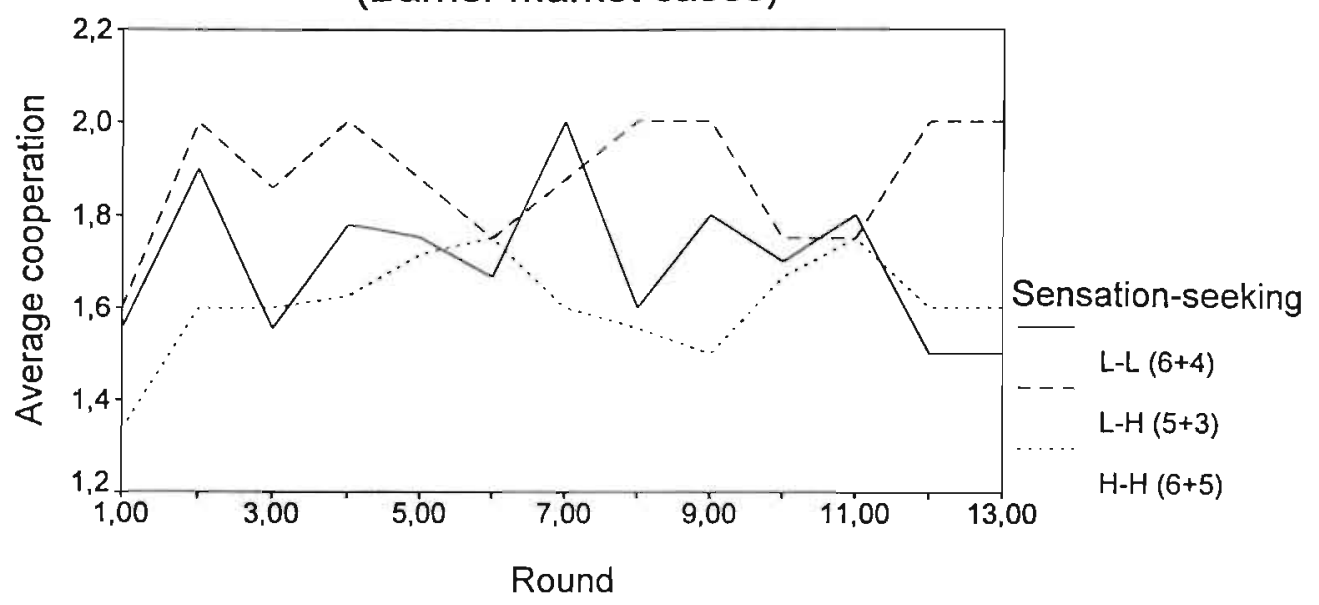

Figure 5.6: Average cooperation by gender

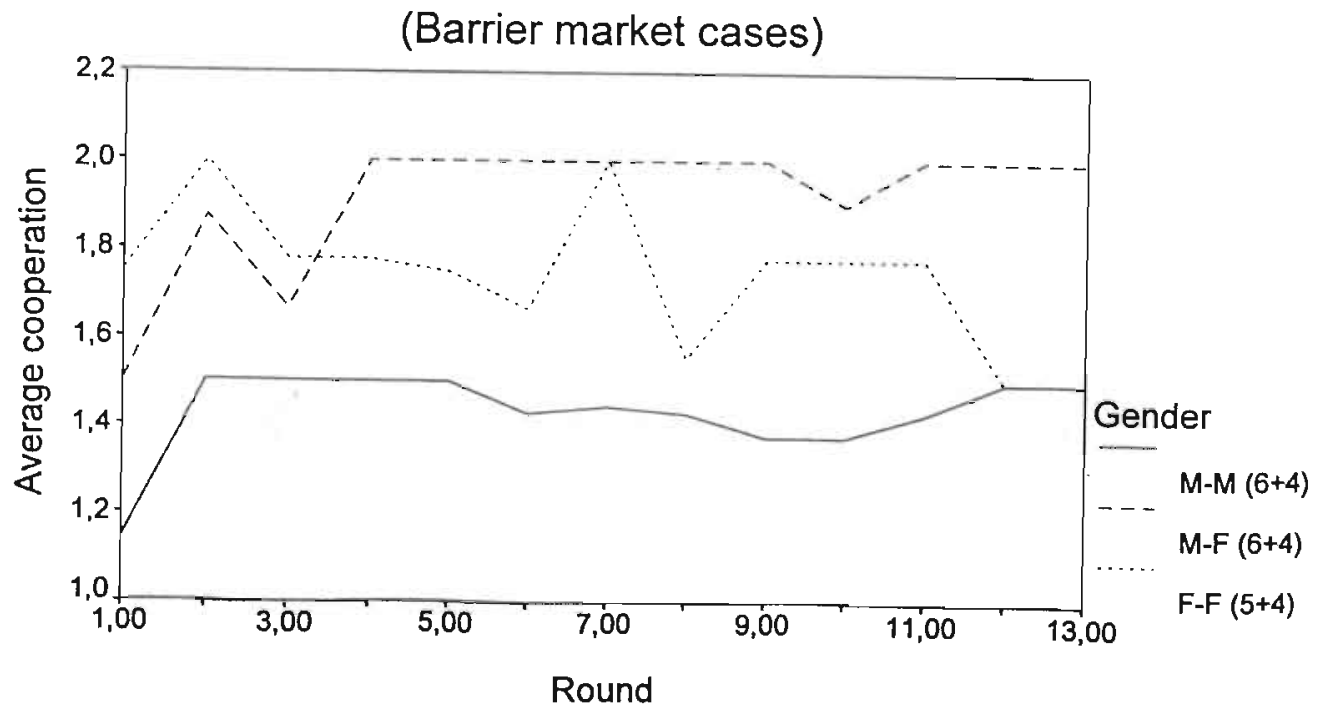


than with those of the opposite sex. The latter result shows that one should be careful before analysing the extremes only. This result contrasts with BBW (1995). According to their results based on 18 dyads and three experiments, mixed couples never are either more or less competitive than both extremes.

\section{Discussion}

This chapter gives some preliminary results of experimental research involving barrier market games. Students in economics and business administration played the developed experiments in couples of two persons. Barrier market results are obtained when both players invest in the high-quality good and apply marginal cost pricing. Experiments 1 and 2 are primarily developed in order to see whether students are able to get a full grasp of the two-periods competition game set out in Chapter 2 . Our experience and the above results indicate that this goal has been achieved. The price strategy set in experiments 1 and 2 is rather restricted: The players have the choice between two prices only. This restriction violates the Bertrand nature of price competition and makes cooperation a viable equilibrium strategy. As a consequence, cooperative results are reached in the first two experiments. In the third experiment, the price strategy set is continuous. Price competition meets the Bertrand conditions again. Consequently, it is not surprising that the mark-up in experiment 3 is substantially lower than in experiments 1 and 2 . Price development also is more favourable in experiment 3: Prices exhibit a clear downward trend. However, prices remain far from competitive in experiment 3 . This may be due to the order in which the experiments are played. Experiment 1 was played before experiment 3 . It is possible that coordination in experiment 3 is facilitated by the coordination developed in game 1 . It is quite likely that more competitive results are obtained when the subjects start with experiment 3 instead of experiment 1, for the following two reasons: (1) Coordination is more difficult to establish in experiment 3 than in experiment 1 , because the price strategy set is continuous in the former experiment while it is not in the latter; and (2) the fact that players tend to start with low-price strategies indicates that coordination - cartel formation - is not self-evident. Cartel formation is also facilitated by the infinite horizon of the sequence of competition games, while the discrete time structure of the competition games probably is favourable for barrier market outcomes. Summarizing, we find that the preliminary results do not accord with the barrier market hypothesis, but because of the preliminary nature this finding does not suffice to diminish our expectation that barrier market results are likely to be obtained in future research.

The chapter also addresses some attention to the question what type of persons are likely to behave competitive rather than cooperative. Attention is paid to differences in gender and age, and four subjective personality characteristics: Locus of control, self-monitoring, type-A behaviour and sensation-seeking. Multivariate analysis indicates that a competitive person is likely to have an external locus of control, is not able or willing to monitor himself in social interactions, loves the thrill of sensation, is male rather than female and young rather than old. Dyad-level analysis 
suggests that a heterogenous couple (rivals) may be more cooperative than a homogeneous one. This holds especially for sensation-seeking and gender. Future research has to reveal whether these patterns are stable and whether the above findings have implications for education, emancipation and labour market policies, and maybe even competition policy.

As far as competitive behaviour is socially desirable, one may wish to stress the private and social benefits accrueing from competitive behaviour in teaching [Frank et al. (1993)]. Exposure to competitive (or alternatively cooperative) behaviour may promote this type of behaviour [Marwell and Ames (1981) and BBW]. As argued throughout the thesis, competitive behaviour fosters consumer wellbeing and is socially desirable from the perspective of competition policy. It is thus not desirable from this perspective to appoint women with priority at CEO-positions (in case of equal capability), when they indeed act less competitive than men. This would influence both emancipation and labour market policies. This perspective also sheds a different light on the desirability of priority policies with respect to women, as far as these policies are initiated because women cooperate more than men do. It is similarly desirable from the above perspective to have young rather than old persons at CEO-positions, when young people indeed compete more than old people do. In this case, it would be desirable to promote job opportunities and career perspectives of young individuals more than those of their old counterparts. This policy recommendation is very relevant for current Western economies, since the demographic structure of the labour markets is not favourable to the career development of young individuals.

The above argument refers to a social perspective. One may also consider private points of view. Since personality traits affect profitability, share holders may want to appoint cooperative CEO's. Alternatively, CEO's may act cooperatively for this reason. It this respect, it is interesting to observe that Gillette in its competition with Bic on products like razor blades and lighters was hindered by its shareholders' desire to obtain large and stable dividends [Hatten and Hatten (1988)]. 


\section{Chapter}

6

\section{Discussion}

The thesis extends the set of scenarios obtaining or approaching barrier market results with three models exhibiting product R\&D competition. All three scenarios illustrate that the Bertrand paradox does not necessarily hold: average (and marginal) cost pricing may be reconciled with investments in product R\&D. Note that the thesis extends the set of barrier market scenarios in a new direction: aspects of product differentiation and innovation are hardly studied up until now [Van Witte-loostuijn (1990) is an exception]. For this reason the above scenarios add an extra element to the robustness of barrier market theory. Table 6.1 comprises the major results once more.

In all three models prices approach average (and marginal) costs. Chapter 2 discusses Bertrand competition in homogeneous goods industries with geographically separated markets. Average total costs are constant over the relevant range of output and capacity constraints do not matter. Because of Bertrand competition, firms are not able to charge a mark-up exceeding entry costs. When entry costs fall, price approaches average and marginal costs. In Chapter 3 consumers exhibit a desire for variety. This desire enables firms to charge a mark-up over marginal cost. The markup approaches zero when the desire for variety goes down. Part of the mark-up is employed to cover R\&D expenses. Net profits approach zero when the desire for variety and gross profits fall. Chapter 4 illustrates that the market power of firms is limited when knowledge is general rather than product-specific. The mark-up is inversely related to the general nature of knowledge - interproduct spillovers - at least when excess capacity is high enough for the entry threat to be credible. The chapter hereby demonstrates the importance of excess capacity for competitive results.

So, in all three scenarios average (and marginal) cost pricing is obtained as a limit result [Schwartz (1986)]. This makes competitive pricing robust ${ }^{(1)}$ with respect to entry costs [Chapter 2], the desire for variety [Chapter 3] and the spillover rate ${ }^{(2)}$ [Chapter 4]. The introduction of a (small) sunk cost does not inhibit competitive pricing in all three chapters. In Chapter 2, sunk costs do not conflict with marginal and average cost pricing, since marginal and average costs are constant over the relevant range. In Chapter 3, a rise in sunk costs only diminishes net profits. Sunk costs are borne by the gross profit margin allowed for by the con-sumers" desire for

(1) A theory is robust with respect to a particular assumption if a minor change in this assumption leads to a minor change in the results [Schwartz (1986: 43)].

(2) This limit result is one-sided. 
variety. In Chapter 4, average cost pricing is obtained for a somewhat lower spillover rate when sunk costs rise slightly.

Table 6.1

A comparison of Chapters 2 to 4
Analytical
Model features
Results
techniques

2 Game theory

Average total costs constant

Prices approach marginal Simulations

Representative consumer No capacity constraints Geographically separated markets cost when entry costs fall Optimal investment in R\&D Duplications of efforts Industries are monopolized when entry costs are low

3 MicroAverage variable costs constant economics Differentiated consumers Game theory No capacity constraints One (segmented) market

Prices approach marginal cost when there is less desire for variety Underinvestment in R\&D All surplus from innovations accrues to consumers Product differentiation is optimal in case of hit-and-run entry; otherwise it is not

4 Game theory

Average variable costs constant Representative consumer Capacity constraints Two markets with substitutes in production
Prices approach marginal cost when spillovers and capacity rise Firms do not invest in R\&D when spillovers are high

Private investments in product $R \& D$, however, are not always optimal. In Chapter 2 investments in process and product $R \& D$ are optimal, but this result is due to the technical relationships defined. Moreover, duplication of $R \& D$ expenses is not prevented. Simulation analysis, however, indicates that preservation of the entry threat and the static efficiency induced are far more important than the loss of resources due to duplication of $R \& D$ expenses. But when entry costs are low, the .entry threat is not necessarily preserved. The industry may be (gradually) monopolized through either bankruptcies or quality and cost leadership. Monopolization arises from the uncertainty surrounding the R\&D process and the fierce nature of price competition, and depends on the height of the entry cost. Since monopolization is detrimental to consumer surplus, it is important that the entry threat is preserved. For this reason, entry bin........ is be sufficiently high. The simulation results also suggest that interfirm spillovers generate large quality increases and cost decreases through time. Moreover, the spillovers following from independent R\&D processes 
seem far more important than the duplication of efforts caused. Since spillovers are favourable for the development of social welfare, patent policies must be eschewed.

In the horizontal differentiation framework outlined in Chapter 3 the duopolists invest too little in product $\mathrm{R} \& \mathrm{D}$. This result is due to the fact that quality improvements may lead to changes in market share, but not to changes in market demand Notwithstanding this result, price competition has the salient feature that all surplus created in the R\&D phase is passed through to the consumers. In this sense competition turns out to be efficient after all. Chapter 3 shows that the tendency to underinvest may be overcome by a subsidy policy, or alternatively a favourable tax regime. Private agreements, such as research joint ventures, do not mend the incentive to underinvestment, unless price agreements are allowed for as well. But the latter is detrimental to consumer well-being. So, we have a trade-off between static and dynamic efficiency. From the consumers' points of view price competition needs to be preferred. This result indicates why the European Commission should only grant exemptions for cooperative R\&D agreements on basis of article 85(3) of the Rome Treaty, if consumers are expected to benefit from the innovations through price competition.

Chapter 3 also indicates that products are not differentiated when price competition is soft [Hotelling scenario]. The resulting lack of product variety does not satisfy the consumer preferences with respect to variety. Moreover, since both firms perform product $R \& D$ for an identical variety, there is duplication in product $R \& I$ ) as well. When price competition is fierce [limit price scenario], product varicty is optimal and there is no duplication of resources. These results suggest that policy makers may promote a lack of product variety by fostering price competition.

An asymmetry in initial qualities strengthens the leading firm's strategic advantage through the decisions on product $R \& D$. The leading firm invests more than in the symmetric Nash-equilibrium, the lagging firm less. As a consequence, the asymmetry widens through time: There is a tendency towards monopolization. On the other hand, quality rises faster in the asymmetric oligopoly while price competition remains fierce. Consumer surplus and industry profits grow, when the asymmetry becomes larger. This result suggests that dominant positions should not be subjected to competition policy right away, since they favour consumer well-being, as long as fringe firms are able to exert competitive pressure. Fringe firms are able to do so, when there are market niches to be exploited by differentiating one's variety from the dominant firms' variety.

The asymmetry in quality may not widen through time, when there is uncertainty with respect to $R \& D$ costs. The leading firm (incumbent) faces less uncertainty than the lagging firm (entrant), since it performed more R\&D in the past. The lagging firm may leapfrog the leading firm, because the laggard tends to underestimate R\&D costs and to overinvest in product R\&D. The laggard's over-investment hurts the leading firm's profitability more than its own profits: The lagging firm makes higher profits than the leading firm. Because of this, the lagging firm is more likely to survive the competition process. This result illustrates the potency of related entry since firms from related industries are probable candidates for 'small laggard' positions. The result also suggests that leapfrogging is likely, because lagging firms tend 
(1) be more optimistic with respect to $R \& D$ costs. Both interpretations accord with the idea behind creative destruction. These conclusions indicate that firms from related industries and lagging firms are able to exert more competitive pressure than suggested in the previous paragraph. This again implies that dominant positions should not be subjected to competition policy right away and stresses the importance of unhindered entry opportunities.

In Chapter 4's model the duopolists have the choice between investing or not investing. Limit price outcomes only result when both firms invest in $R \& D$. Both firms invest when gross profits cover $R \& D$ expenses; they do not when $R \& D$ costs exceed the monopoly level of gross profits. If investment is only profitable when the rival firm does not invest, the firms face a dilemma. As a result, the limit price outcome may arise or it may not. The investment dilemma may be overcome by exchanging technologies. They may be exchanged in such a way that the quality differences between the firms are widened and gross profits rise. The latter may enable both firms to invest. Consumers only acquire surplus if both firms invest, since this creates competitive pressure on prices. This pressure originates from the ability to deliver a product with a similar quality. Firms may also invest in turns. However, this would lead to monopoly-profits and does not deserve recommendation from the consumers' point of view. From a policy perspective, exchanging technologies seems to be a valuable commercial practice, while investing-in-turn does not. In Chapter 4, spillovers are referred to as being intrafirm. However, they may be interpreted as being interfirm as well. If, in general, gross profits are too low to cover R\&D expenses, policies reducing interfirm spillovers - patent life extension - are to be recommendated. If gross profits are too high, these policies need to be sharpened.

Chapter 5 indicates how the hypotheses derived in Chapters 2 to 4 may be tested using experimental techniques. Chapter 5 translates Chapter 2's model into an experimental design and discusses the preliminary results. The results suggest that players invest, but that prices are far from competitive, although they become more competitive through time. The first result may be due to the design of the first two experiments. These games are primarily constructed in order to investigate whether students are able to deal with the complex two periods structure of the competition game. The first two experiments do not fully justice the Bertrand nature of price competition modelled in Chapter 2. It is thus not surprising that prices are high in both experiments. This fact may have facilitated cooperation in the third experiment because of the order in which the experiments were played: the third experiment was played after the first. The unknown time horizon is also unfavourable to barrier market results. Given the incentives to cooperate, the process towards competitive prices in the third experiment is remarkable. In future research we would like to investigate the importance of the order in which experiments are played.

Chapter 5 also indicates that there may be important differences in competitive behaviour between types of persons. Some types of persons may exhibit socially desirable - competitive - behaviour while others do not. The results of this type of analysis may thus have important implications for future education, emancipation, labour market and competition policies. Logistic regressions indicate that externals are more competitive than internals, low self-monitors more than high self-monitors, 
males more than females and young people more than old people. Analysis of couples indicates that externals and type-B persons are more competitive. It also suggests that male and female couples are more competitive than mixed couples. Male couples become less competitive through time while female couples become more competitive. With respect to sensation-seeking mixed couples also seem to be more cooperative. In general one should stress that mixed couples may be more (or less) cooperative than homogeneous couples.

As argued throughout the thesis, competitive behaviour fosters consumer wellbeing and is socially desirable from the perspective of competition policy. One may thus wish to stress the private and social benefits accruing from competitive behaviour in teaching. Exposure to competitive behaviour may promote this type of behaviour. It is not desirable from this perspective to appoint women with priority at CEOpositions (in case of equal capability), when they indeed act less competitive than men. This would influence both emancipation and labour market policies. This perspective also sheds a different light on the desirability of priority policies with respect to women, as far as these policies are initiated because women cooperate more than men do. It is similarly desirable from the above perspective to have young rather than old persons at CEO-positions, when young people indeed compete more than old people do. In this case, it would be desirable to promote job opportunities and career perspectives of young individuals more than those of their old counterparts. This policy recommendation is very relevant for current Western economies, since the demographic structure of the labour markets is not favourable to the career development of young individuals. The above argument refers to a social perspective. One may also consider private points of view. Since personality traits affect profitability, share holders may want to appoint cooperative CEO's. Alternatively, CEO's may act cooperatively for this reason.

The above summary again shows that there are more plausible scenarios obtaining or approaching barrier market results than one might think at first sight with the Bertrand paradox in one's mind. However, some modesty remains appropriate, since the above chapters do not contain more than three theories in Industrial Organization (IO). Theories in IO may have a lot in common, but this does not refer to the results generated. The results obtained by any theory in IO are very sensitive with respects to aspects like firm strategy and the timing of actions [Shapiro (1989)]. However, the models set out above do indicate conditions under which average (and marginal) cost pricing may be combined with product innovations. Notice that investments in product $R \& D$ are suboptimal from a social point of view in Chapter 3 . Whether firms invest efficiently, is not really investigated in Chapters 2 and 4 . The optimality of the investments in Chapter 2 follows directly from the technical relations postulated. In Chapter 4 the firms could chose between two options only: investment or no investment. Future research must indicate whether firms invest optimally in related models. Chapter 3 discusses the implications of asymmetries in starting positions for the innovation rate and social welfare. In future research we may find out whether these (or similar) results also hold for models with quadratic transport costs. It would also be interesting to investigate whether the results in Chapter 4 are robust for asymmetries in starting positions (spillover rate or capacity). This may also give 
some scope for endogenizing Stackelberg-leadership. Chapter 5 indicates that there is a large set of opportunities for experimental testing. This certainly holds when this set is extended with hypotheses concerning personal characteristics. 


\section{References}

- Alger D. (1987), Laboratory tests of equilibrium predictions with disequilibrium data, Review of Economic Studies 54, 105-145.

- Anderson S.P. (1988), Equilibrium existence in the linear model of spatial existence, Economica 55, 479-491.

- Anderson S.P. and R.D. Fischer (1989), Multi-market oligopoly with production before sales, Journal of Industrial Economics 38, 167-182.

- Anderson S.P., A. de Palma and J.-F. Thisse (1989), Demand for differentiated products, discrete choice models, and the characteristics approach, Review of Economic Studies 56, 21-35.

- Appels A. (1985), Jenkins Activity Survey, Lisse: Swets \& Zeitlinger.

- Appels A., P. Mulder and J. van Houtem (1985), De validiteit van de Jenkins Activity Survey, een vragenlijst ter meting van het type A gedrag, Nederlands Tijdschrift voor de Psychologie 40, 474-487.

- D'Aspremont C., J.J. Gabszewicz and J.F. Thisse (1979), On Hotelling's stability in competition, Econometrica 47, 1145-1151.

- D'Aspremont C. and A. Jaquemin (1988), Cooperative and noncooperative R\&D in duopoly with spillovers, American Economic Review 78, 1133-1137.

- Aumann R.J. and R.B. Myerson (1988), Endogenous formation of links between players and of coalitions: An application of the Shapley value, in: A.E. Roth, ed., The Shapley value, Essays in honor of Lloyd A. Shapley, Cambridge: Cambridge University Press, 175-191.

- Bael I. van and J.-F. Bellis (1987), Competition law of the EC, Bicester: CCH Editions (2nd edition: 1990).

- Bagwell K. (1993), A model of competitive limit pricing, Journal of Economics \& Management Strategy, 585-906.

- Bagwell K. and G. Ramey (1988), Advertising and limit pricing, RAND Joumal of Economics 19, 59-71.

- Bailey E.E., D.P. Kaplan and D.S. Sibley (1983), On the contestability of airline markets: Some further evidence, in: J. Finsinger, ed., Economic analysis of regulated markets, London: MacMillan, 48-64.

- Bain J.S. (1949), A note on pricing in monopoly and oligopoly, American Economic Review 39, 448-464.

- Bain J.S. (1956), Barriers to new competition, Cambridge MA: Harvard University Press.

- Barney J. (1991). Firm resources and sustained competitive advantage, Journal of Management 17, 99-120.

- Baron R.A. (1989), Personality and organizational conflict: Effects of the type A behaviour pattern and self-monitoring, Organizational Behavior and Human Decision 
Processes 44, 281-296.

- Barzel Y. (1970), Excess capacity in monopolistic competition, Journal of Political Economy 78, 1142-1149.

- Basu K. and N. Singh (1990), Entry deterrence in Stackelberg perfect equilibria, International Economic Review 31, 61-71.

- Baumol W.J. (1982), Contestable markets: An uprising in the theory of industry structure, American Economic Review 72, 1-15.

- Baumol W.J., J.C. Panzar and R.D. Willig (1982), Contestable markets and the theory of industry structure, New York NY: Harcourt Brace Jovanovich.

- Baumol W.J., J.C. Panzar and R.D. Willig (1983), Contestable markets: An uprising in the theory of industry structure: A reply, American Economic Review 73, 491496.

- Baye M.R., D. Kovenock and C. de Vries (1994), Heads, Tullock was right: The incidence of overdissipation in rent-seeking contests, mimeo.

- Beath J. and Y. Katsoulacos (1992), The economic theory of product differentiation, Cambridge: Cambridge University Press.

- Beath J., Y. Katsaloucos and D. Ulph (1987), Sequential product innovation and industry evolution, Economic Journal 97, 32-43.

- Beath J., Y. Katsoulacos and D. Ulph (1989), The game-theoretic analysis of innovation: A survey, Bulletin of Economic Research 41, 163-184.

- Beckman M.J. and J.-F. Thisse (1986), The location of production activities, in: P. Nijkamp, ed., Handbook of Regional and Urban Economics, Amsterdam: Elsevier.

- Benson B.L. and M.D. Faminow (1988), The impact of experience on prices and profits in experimental duopoly markets, Journal of Economic Behavior and Organization 9, 345-365.

- Bergson A. (1938), A reformulation of certain aspects of welfare economics, Quarterly Journal of Economics 52, 310-334.

- Bertrand J. (1883), review of 'Théorie mathématique de la richesse sociale' and 'Recher-ches sur les principes mathématiques de la théorie des richesses, Journal des Savants 67, 499-508.

- Besanko D., M.K. Perry and R.H. Spade (1990). The logit model of monopolistic competition: Brand diversity, Journal of Industrial Economics 38, 397-415.

- Bester H. (1988), Bargaining, search costs and equilibrium price distributions, Review of Economic Studies 55, 201-214.

- Bhatt S. (1987), Strategic product choice in differentiated markets, Journal of Industrial Economics 36, 207-216.

- Boiteux M. (1956), Sur la gestion des monopoles publics astreints a l'equilibre budgetaire, Econometrica 24, 22-40.

- Bondt R. de and R. Veugelers (1991), Strategic investment with spillovers, European Journal of Political Economy 7, 345-366.

- Boone C. (1992), Onderzoek naar het verband tussen de perceptie van controle van bedrijfsleiders en de strategie en de resultaten van ondernemingen in de meubelindustrie, Antwerpen: Universiteit van Antwerpen.

- Boone C., B. de Brabander and A. van Witteloostuijn (1995), The effects of individual differences on competitive and cooperative choices in five Prisoner's Dilemma 
games, Maastricht-Antwerpen: mimeo.

- Bouckaert J. and H. Degryse (1995), Phonebanking, European Economic Review 39, 229-244.

- Brock W.A. (1983), Contestable markets and the theory of industry structure: A review article, Journal of Political Economy 91, 1055-1066.

- Bulow J.I., J.D. Geanakoplos and P.D. Klemperer (1985), Multimarket oligopoly: Strategic substitutes and complements, Journal of Political Economy 93, 488-511.

- Bunte F.H.J. (1995), Variety and quality competition in a horizontal differentiation framework: A Welfare analysis, St Andrews: CRIEFF Discussion Paper 9509.

- Cairns R.D. and D. Mahabir (1988), Contestability: A revisionist view, Economica 55, 269-276.

- Calem P.S. (1988), Entry and entry deterrence in penetrable markets, Economica 55, 171-183.

- Carlton D.W. (1986), The rigidity of prices, American Economic Review 76, 637658.

- Carlton D.W. and J.M. Perloff (1994), Modern industrial organization, New York NY: Harper Collins (2nd edition).

- Chamberlin E.H. (1933), The theory of monopolistic competition, Cambridge MA: Harvard University Press (5th edition: 1946).

- Chamberlin E.H. (1951), Monopolistic competition revisited, Economica 18, 343362.

- Clark J.M. (1940), Towards a concept of workable competition, American Economic Review 30, 241-256.

- Cook H. and C. Chi (1984), Cooperative behavior and locus of control among American and Chinese-American boys, Journal of Psychology 118, 169-177.

- Cook H. and J. Sloane (1985), Locus of control and cooperative behavior in 10year old children, Journal of Social Psychology 125, 619-630.

- Cournot A.A. (1838), Recherches sur les principes mathématiques de la théorie des richesses, Paris: Librairie Philosophique J. Vrin (printed in 1980).

- Coursey D., R.M. Isaac, M. Luke and V.L. Smith (1984), Market contestability in the presence of sunk (entry) costs, RAND Journal of Economics 15, 69-84.

- Coursey D., R.M. Isaac and V.L. Smith (1984), Natural monopoly and contested markets: Some experimental results, Journal of Law and Economics 27, 91-113.

- Cox T.H., S.A. Lobel and P.L. McLeod (1991), Effects of ethnic group cultural differences on cooperative and competitive behavior on a group task, Academy of Management Journal 34, 827-847.

- Cronbach L.J. (1951), Coefficient $\alpha$ and the internal structure of tests, Psychometrika $16,297-335$.

- Dasgupta P. (1986), The theory of technological competition, in: J.E. Stiglitz and G.F. Mathewson, eds., New developments in the analysis of market structure, Cambridge MA: MIT Press.

- Dasgupta P. and E. Maskin (1986), The existence of equilibrium in discontinuous economic games, 1: Theory, Review of Economic Studies 53, 1-26.

- Dasgupta P. and J.E. Stiglitz (1988), Learning-by-doing, market structure and industrial and trade policies, Oxford Economic Papers 40, 246-268. 
- Davies S. and B. Lyons (1991), Introduction, in: S. Davies, B. Lyons, H. Dixon and P. Geroski, eds., Economics of industrial organization, London: Longman.

- Davis D.D. and C.A. Holt (1993), Experimental economics, Princeton NJ: Princeton University Press.

- Dei F. (1990), A note on multinational corporations in a model of reciprocal dumping, Journal of International Economics 29, 161-171.

- Demsetz H. (1959), The nature of monopolistic competition, Journal of Political Economy 67, 21-30.

- Demsetz H. (1972), The inconsistencies in monopolistic competition, Journal of Political Economy 80, 592-597.

- Demsetz H. (1982), Barriers to entry, American Economic Review 72, 47-57.

- Deneckere R. and M. Rothschild (1992), Monopolistic competition and preference for diversity, Review of Economic Studies 59, 361-373.

- Dixit A. (1979), A model of duopoly suggesting a theory of entry barriers, Bell Journal of Economics 10, 20-32.

- Dixit A. (1980), The role of investment in entry-deterrence, Economic Journal 90, 95-106.

- Dixit A.K. and V. Norman (1978), Advertising and welfare, Bell Journal of Economics 9, 1-17.

- Dixit A.K. and J.E. Stiglitz (1977), Monopolistic competition and optimum product diversity, American Economic Review 67, 297-308.

- Dixit A.K. and J.E. Stiglitz (1993), Monopolistic competition and optimum product diversity: Reply, American Economic Review 83, 302-305.

- Dixon S. (1994), Limit pricing and multi-market entry, Maastricht, mimeo.

- Dodgson J.S., C.K. Newton and Y. Katsaloucos (1992), A modelling framework for the empirical analysis of predatory behaviour in the bus-service industry, Regional Science and Urban Economics 22, 51-70.

- Dosi G. (1988), Sources, procedures, and microeconomic effects of innovation, Journal of Economic Literature 26, 1120-1171.

- Eaton B.C. (1972), Spatial competition revisited, Canadian Journal of Economics 2, 268-278.

- Eaton B.C. and R.G. Lipsey (1980), Exit barriers are entry barriers: The durability of capital as a barrier to entry, Bell Journal of Economics 11, 721-729.

- Economides N. (1989), Quality differentiation and maximal variety differentiation, Regional Science and Urban Economics 19, 21-29.

- Encaoua D., P. Geroski and A. Jaquemin (1986), in: J.E. Stiglitz and G.F. Mathewson, eds., New developments in the analysis of market structure, Cambridge MA: MIT Press.

- European Commission (1995), XXIVe Verslag over het mededingingsbeleid, Brussel-Luxemburg.

- Evans L.B. and J.J. Siegfried (1992), Entry and exit in United States manufacturing industries from 1977 to 1982, in: D.B. Audretsch and J.J. Siegfried, eds., Empirical studies in industrial organization: Essays in honor of Leonard W. Weiss, Dordrecht: Kluwer, 253-273.

- Evans W.N. and I.N. Kessides (1994), Living by the "golden rule": Multimarket 
contact in the U.S. airline industry, Quarterly Joumal of Economics 108, 341-366.

- Feenstra R.C. and J.A. Levinsohn (1995), Estimating markups and market conduct with multidimensional product attributes, Review of Economic studies 62, 19-52.

- Feij J.A. and R.W. van Zuijlen (1984), SBL: Spanningsbehoeftelijst, Lisse: Swets \& Zeitlinger.

- Frank R.H., T. Gilovich and D.T. Regan (1993), Does studying economics inhibit cooperation?, Journal of Economic Perspectives 7, 159-171.

- Friedman J.W. (1979), Oligopoly and the theory of games, Amsterdam: NorthHolland Publishing Company.

- Friedman J.W. (1983), Oligopoly theory, Cambridge MA: Cambridge University Press.

- Friedman M. and R.H. Rosenman (1974), Type A behaviour and your heart, Greenwich CO: Fawcett.

- Fudenberg D., R. Gilbert, J. Stiglitz and J. Tirole (1983), Preemption, leapfrogging and competition in patent races, European Economic Review 22, 3-31.

- Fudenberg D. and J. Tirole (1987), Understanding rent dissipation: On the use of game theory in industrial organization, American Economic Review 77: Papers en Proceedings, 176-183.

- Fudenberg D. and J. Tirole (1991), Game theory, Cambridge MA: MIT Press, (third reprint: 1993).

- Gabszewicz J.J. and J.-F. Thisse (1986a), Spatial competition and the location of firms, in: J.J. Gabszewicz, J.-F. Thisse, M. Fujita and U. Schweizer, Location theory, Chur: Harwood.

- Gabszewics J.J. and J.-F. Thisse (1986b), On the nature of competition with differentiated products, Economic Journal 96, 160-172.

- Gabszewics J.J. and J.F. Thisse (1992), Location, in: R.J. Aumann and S. Hart, eds., Handbook of game theory, Amsterdam: North-Holland.

- Galbraith J.K. (1958), The affluent society, Harmondsworth: Penguin (reprint: 1965).

- Gaskins D.W. (1971), Dynamic limit pricing: Optimal pricing under threat of entry, Journal of Economic Theory 2, 306-322.

- Geroski P.A. (1991), Market dynamics and entry, Oxford: Blackwell.

- Gilbert R.J. (1989), Mobility barriers and the value of incumbency, in: R. Schmalensee and R.D. Willig, eds., Handbook of Industrial Organization, Amsterdam: Elsevier.

- Gilbert R.J. and D.M.G. Newbery (1982), Preemptive patenting and the persistence of monopoly, American Economic Review 72, 514-526.

- Grant R.M. (1991), The resource-based theory of competitive advantage: Implications for strategy formulation, California Management Review 33, 114-135.

- Guesnerie R. (1980), Second best pricing rules in the Boiteux tradition, Journal of Public Economics 13, 51-80.

- Hamilton J.H. and S.M. Slutsky (1990), Endogenous timing in duopoly games: Stack-elberg or Cournot equilibria, Games and Economic Behavior 2, 29-46.

- Harris C. and J. Vickers (1985), Perfect equilibrium in a model of a race, Review of Economic Studies 52, 193-209. 
- Hart O.D. (1985), Monopolistic competition in the spirit of Chamberlin: A general model, Review of Economic Studies 52, 529-546.

- Hartwick J.M. (1991), Patent races optimal with respect to entry, International Joumal of Industrial Organization 9, 197-207.

- Hatten K.J. and M.L. Hatten (1988), Effective strategic management: Analysis and action, Englewood Cliffs NJ: Prentice Hall.

- Hay J.D. (1976), Sequential entry and entry-deterring strategies in spatial competition, Oxford Economic Papers 28, 240-257.

- Heywood J.S. and D. Pal (1993), Contestability and two-part pricing, Review of Industrial Organization 8, 557-565.

- Hines H.H. (1957), Effectiveness of entry by already established firms, Quarterly Journal of Economics 71, 132-150.

- Horstmann I.J. and J.R. Markusen (1992), Endogenous market structures in international trade (natura facit saltum), Journal of International Economics 32, 109-129.

- Hotelling H. (1929), Stability in competition, Economic Journal 37, 41-57.

- Irmen A. and J.F. Thisse (1995), Competition in multi-characteristic spaces: Hotelling was almost right, EEA paper.

- Isaac R.M. and S.S. Reynolds (1992), Schumpeterian competition in experimental markets, Journal of Economic Behavior and Organization 17, 59-100.

- Jenkins C.D., S.J. Zyzanski and R.H. Rosenman (1979), Jenkins Activity Survey, New York: Psychological Corporation.

- Johnston J. (1960), Statistical cost analysis, New York: McGraw-Hill.

- Jong E. de (1988), Expectation formation: Criteria and an assessment, De Economist $136,435-467$.

- Jong H.W. de (1995), European capitalism: Between freedom and social justice, Review of Industrial Organization 10, 399-419.

- Judd K.L. (1985), Credible spatial preemption, RAND Journal of Economics 16, 153-166.

- Kamien M.I., E. Muller and I. Zang (1992), Research joint ventures and R\&D cartels, American Economic Review 82, 1293-1306.

- Kamien M.I. and N.L. Schwartz (1982), Market structure and innovation, Cambridge: Cambridge University Press (reprint: 1985).

- Katz M.L. (1986), An analysis of cooperative research and development, RAND Journal of Economics 17, 527-543.

- Kelly D. and T.L. Amburgey (1991), Organizational inertia and momentum: A dynamic model of strategic change, Academy of Management Journal 34, 591-612.

- Kirman A. and N. Schüller (1990), Price leadership and discrimination in the European car market, Journal of Industrial Economics 39, 69-91.

- Kleijweg A. and M. Lever (1995), Toe- en uittreding in de industrie, Economisch Statistische Berichten, 958-960.

- Kreps D.M. and J.A. Scheinkman (1983), Quantity precommitment and Bertrand competition yield Cournot outcomes, Bell Journal of Economics 14, 326-337.

- Krouse C.G. (1990). Theory of industrial economics, Cambridge MA: Basil Blackwell.

- LeBlanc G. (1992), Signalling strength: Limit pricing and predatory pricing, RAND 
Journal of Economics 23, 493-506.

- Lee T. and L.L. Wilde (1980), Market structure and innovation: A reformulation, Quarterly Journal of Economics 94, 429-436.

- Leininger W. (1991), Patent competition, rent dissipation, and the persistence of monopoly: The role of research budgets, Journal of Economic Theory 53, 146-172.

- Lerner A.P. and H.W. Singer (1937), Some notes on duopoly and spatial competition, Journal of Political Economy 45, 145-186.

- Lester D. (1992), Cooperative/competitive strategies and locus of control, Psychological Reports 71, 594.

- Lindsey R., B. von Hohenbalken and D.S. West (1991), Spatial price equilibrium with product variety, chain stores, and integer pricing: An empirical analysis, Canadian Journal of Economics 24, 900-922.

- Lipsey R.G. and K. Lancaster (1956), The general theory of second best, Review of Economic Studies 24, 11-32.

- Loury G.C. (1979), Market structure and innovation, Quarterly Journal of Economics $93,395-410$.

- Lyons B. (1991), Barriers to entry, in: S. Davies, B. Lyons, H. Dixon and P. Geroski, eds., Economics of industrial organization, London: Longman.

- Maks J.A.H. (1986), On the compatibility of the welfare state and the market economy, in: W. Albeda, ed., The future of the welfare state, Maastricht.

- Mansfield E. (1985), How rapidly does new industrial technology leak out?, Joumal of Industrial Economics 34, 217-223.

- Mansfield E., J. Rapoport, J. Schnee, S. Wagner and M. Hamburger (1971), Research and innovation in the modern corporation, New York: Norton.

- Markham J.W. (1951), The nature and significance of price leadership, American Economic Review 41, 891-905.

- Martin S. (1995), Oligopoly limit pricing: Strategic substitutes, strategic complements, International Journal of Industrial Organization 13, 41-65.

- Marwell G. and R.E. Ames (1981), Economists free ride, does anyone else?, Journal of Public Economics 15, 295-310.

- Maskin E. and J. Tirole (1988), A theory of dynamic oligopoly I: Overview and quantity competition with large fixed costs, Econometrica 56, 549-569.

- Mason C.F., O.R. Phillips and D.B. Redington (1991), The role of gender in a noncooperative game, Journal of Economic Behavior and Organization 15, 215-235.

- Milgrom P. and J. Roberts (1982), Predation, reputation, and entry deterrence, Joumal of Economic Theory 27, 280-312.

- Milgrom P. and J. Roberts (1986), Price and advertising signals of product quality, Journal of Political Economy 94, 796-821.

- Miller C.C. and L.B. Cardinal (1994), Strategic planning and firm performance: A synthesis of more than two decades of research, Academy of Management Journal 37, 1649-1655.

- Millner E.L., M.D. Pratt and R.J. Reilly (1990), Contestability in real-time experimental flow markets, RAND Journal of Economics 21, 584-599.

- Mills D.E. (1988), Preemptive investment timing, RAND Journal of Economics 19, 114-122. 
- Mishan E.J. (1981), Economic efficiency and social welfare, London: Allen \& Unwin.

- Modigliani F. (1958), New developments on the oligopoly front, Journal of Political Economy 66, 215-232.

- Mood A.M., F.A. Graybill and D.C. Boes (1974), Introduction to the theory of statistics, Singapore: McGraw-Hill.

- Morrison C.J. (1990), Market power, economic profitability and productivity growth measurement: An integrated structural approach, NBER working paper 3355.

- Nelson R.R. and S.G. Winter (1982), An evolutionary theory of economic change, Cambridge MA: Belknap Press.

- Neven D. and J.-F. Thisse (1989), Choix des produits: Concurrence en qualité et en variété, Annales d'Economie et de Statistique 15/16, 85-112.

- Ng Y.-K. (1983), Welfare Economics, London: MacMillan.

- Nordhaus W.D. (1969), Invention, growth, and welfare: A theoretical treatment of technological change, Cambridge MA: MIT Press.

- Novshek W. (1980), Equilibrium in simple spatial (or differentiated product) models, Journal of Economic Theory 22, 313-326.

- Nunnally J.C. (1978), Psychometric theory, New York NY: McGraw-Hill.

- Pascoa M.R. (1993), Noncooperative equilibrium and Chamberlinian monopolistic competition, Journal of Economic Theory 60, 335-353.

- Peteraf M.A. (1993), The comerstone of competitive advantage: A resource-based view, Strategic Management Journal 14, 171-191.

- Peteraf M.A. (1995), Sunk costs, contestability and airline monopoly power, Review of Industrial Organization 10, 289-306.

- Poddar S. (1995), Product differentiation, entry and undercut-proof equilibrium, Louvain-la-Neuve: CORE, Discussion Paper 9523.

- Posner R.A. (1975), The social costs of monopoly and regulation, Journal of Political Economy 83, 807-827.

- Prescott E.C. and M. Visscher (1977), Sequential location among firms with foresight, Bell Journal of Economics 8, 378-393.

- Ramsey F. (1929), A contribution to the theory of taxation, Economic Journal 37, 47-61.

- Rasmusen E. (1989), Games and information, Cambridge MA: Basil Blackwell (2nd edition: 1994; reprint: 1995).

- Reid G. (1987), Theories of industrial organization, Oxford: Basil Blackwell (reprint: 1989).

- Reinganum J.F. (1985), Innovation and industry evolution, Quarterly Journal of Economics 99, 81-99.

- Reinganum J.F. (1989). The timing of innovation: Research, development, and diffusion, in: R. Schmalensee and R.D. Willig, eds., Handbook of Industrial Organization, Amsterdam: Elsevier.

- Robinson J. (1933), The economics of imperfect competition, London: MacMillan (reprint: 1948).

- Rotter J.B. (1954), Social learning and clinical psychology, Englewood Cliffs NJ: Pren-tice Hall. 
- Rotter J.B. (1966), General expectancies for internal versus external control of reinforcement, Psychological Monographs 80, 1-28.

- Salonen H. (1994), Entry deterrence and limit pricing under asymmetric information about common costs, Games and Economic Behavior 6, 312-327.

- Saloner G. (1991), Modelling, game theory, and strategic management, Strategic Management Journal 12, 119-136.

- Salop S. (1979), Monopolistic competition with outside goods, Bell Journal of Fconomics 10, 141-156.

- Schelling T. (1960), The strategy of conflict, Cambridge MA: Harvard University Press (6th reprint: 1979).

- Scherer F.M. (1965), Firm size, market structure, opportunity, and the output of patented inventions, American Economic Review 55, 1097-1125.

- Scherer F.M. and D. Ross (1990), Industry market structure and economic performance, Boston MA: Houghton Mifflin (3rd edition).

- Schmalensee R. (1978), Entry deterrence in the ready-to-eat breakfast cereal industry, Bell Journal of Economics 9, 305-327.

- Schmalensee R. (1986), Advertising and market structure, in: Stiglit/ J.E. and (i.F. Mathewson, eds., New developments in the analysis of market structure, Houndmills: MacMillan.

- Schneider S.C. and A. de Meyer (1991), Interpreting and responding to strategic issues: The impact of national culture, Strategic Management Journal 12, 307-320.

- Schumpeter (1943), Capitalism, socialism and democracy, New York NY: Harper (3rd edition: 1950; reprint: 1962).

- Schwartz M. (1986), The nature and scope of contestability theory, Oxford Economic Papers S38, 37-57.

- Schwartz M. and R.J. Reynolds (1983), Contestable markets: An uprising in the theory of industry structure: Comment, American Economic Review 73, 488-490.

- Selten R. (1978), The chain-store paradox, Theory and Decision 9, 127-159.

- Siegfried J.J. and L.B. Evans (1994), Empirical studies of entry and exit: A survey of the evidence, Review of Industrial Organization 9, 121-155.

- Sinclair R.A. (1995), An empirical model of entry and exit in airline markets, Review of Industrial Organization 10, 541-557.

- Shepherd W.G. (1984), "Contestability" vs. competititon, American Economic Review 74, 572-587.

- Smith A. (1776), An inquiry into the nature and causes of the wealth of nations, edited by R.H. Campbell and A.S. Skinner (1976), Oxford: Clarendon Press (reprint: 1979).

- Snyder M. (1974), Self-monitoring of expressive behaviour, Journal of Personality and Social Psychology 30, 526-537.

- Snyder M. and S. Gangestad (1986), On the nature of self-monitoring: Matters of assessment, matters of validity, Journal of Personality and Social Psychology 51, 125-139.

- Sorenson T.I. (1995), Product improvement and leadership in differentiated markets, Review of Industrial Organization 10, 373-388.

- Sosnick S.H. (1958), A critique on concepts of workable competition, Quarterly 
Journal of Economics 72, 380-423.

- Spence A.M. (1977), Entry, Capacity, Investment and oligopolistic pricing, Bell Journal of Economics 8, 534-544.

- Spence A.M. (1979), Investment strategy and growth in a new market, Bell Journal of Economics 10, 1-19.

- Spence A.M. (1983), Contestable markets and the theory of industry structure: A review article, Journal of Economic Literature 21, 981-989.

- Srinivasan K. (1991), Multiple market entry, cost signalling and entry deterrence, Management Science 37, 1539-1555.

- Stackelberg H. von (1943), Grundlagen der theoretischen Volkswirtschaftslehre, edited by V.F. Wagner, Bern: Francke, Tübingen: Mohr (2nd edition: 1951).

- Stahl D.O. (1988), Bertrand competition for inputs and Walrasian outcomes, American Fconomic Review 78, 189-201.

- Stigler G. (1968), The organization of industry, Homewood IL: Irwin.

- Stiglitz J.E. (1987), Technological change, sunk costs, and competition, Brookings Papers on Economic Activity 3, 883-947.

- Stiglitz J.E. (1989), Imperfect information in the product market, in: R. Schmalensee and R.D. Willig, eds., Handbook of industrial organization, Amsterdam: Elsevier.

- Sullivan M. (1990), Measuring image spillovers in umbrella-branded products, Journal of Business 63, 309-329.

- Sutcliffe K.M. (1994), What executives notice: Accurate perceptions in top management teams, Academy of Management Journal 37, 1360-1378.

- Sutton J. (1991), Sunk costs and market structure: Price competition, advertising, and the evolution of concentration, Cambridge MA: MIT Press.

- Suzumura K. (1992), Cooperative and noncooperative R\&D in an oligopoly with spillovers, American Economic Review 82, 1307-1320.

- Sylos Labini P. (1957), Oligopoly and technical progress, Cambridge MA: Harvard University Press (English edition: 1969).

- Teece D.J. (1980), Economies of scope and the scope of the enterprise, Journal of Economic Behavior and Organization 1, 223-247.

- Thomas J.B., S.M. Clark and D.A. Gioia (1993), Strategic sensemaking and organizational performance: Linkages among scanning, interpretation, action and outcomes, Academy of Management Journal 36, 239-270.

- Tirole J. (1988), The theory of industrial organization, Cambridge MA: MIT Press (reprint: 1989).

- Venables (1990), International capacity choice and national market games, Journal of International Economics 29, 23-42.

- Vickers J. (1986), The evolution of market structure when there is a sequence of innovations, Journal of Industrial Economics 35, 1-12.

- Waller M.J., G.P. Huber and W.H. Glick (1995), Functional background as a determinant of executives' selective perception, Academy of Management Journal 38, 943-974.

- Walras L. (1874), Eléments d'économie politique pure ou théorie de la richesse sociale, Lausanne and Paris: Pichon (edition: 1900; reprint: 1952).

- Walters A.A. (1963), Production and costs functions: An econometric survey, 
Econome-trica 31, 1-66.

- Wegberg M. van (1993), Multi-market competition theory, Maastricht: Datawyse.

- Wegberg M. van and A. van Witteloostuijn (1992), Credible entry threats into contestable markets: A symmetric multimarket model of contestability, Economica $59,437-452$.

- Weiszäcker C.C. von (1980), A welfare analysis of barriers to entry, Bell Joumal of Economics 11, 399-420.

- Wenders J.T. (1987), On perfect rent dissipation, American Economic Review 77, 456-459.

- Wernerfelt B. (1988), Umbrella branding as a signal of new product quality: An example of signalling by posting a bond. RAND Journal of Economics 19, 458-466.

- Witteloostuijn A. van (1990), Rationality, competition and evolution: Entry (deterrence) in dynamic barrier market theory, Maastricht: Datawyse.

- Witteloostuijn A. van (1992), Theories of competition and market performance: Multi-market competition and the source of potential entry, De Economist 140, 109 139.

- Witteloostuijn A. van (1996), Bridging behavorial and economic theories of decline: Organizational inertia, strategic competition and chronic failure, Maastricht: mimeo.

- Witteloostuijn A. van and J.A.H. Maks (1987), Concurrentie en mededingingsbeleid, Maandschrift Economie 51, 448-461.

- Witteloostuijn A. van and J.A.H. Maks (1988). Workable competition and the barrier market, European Journal of Political Economy 4, 117-135.

- Wright B.D. (1983), The economics of invention incentives: Patents, prizes, and research contracts, American Economic Review 73, 691-707.

- Yang X. and B.J. Heijdra (1993), Monopolistic competition and optimum product diversity: Comment, American Economic Review 83, 295-301.

- Zappe C. and I. Horowitz (1993), Quasi-Coumot behavior in a multimarket. multiplant setting, Managerial and Decision Economics 14, 75-81.

- Zhang Z.J. (1995), Price-matching policy and the principle of minimum differentiation, Journal of Industrial Economics 43, 287-299. 


\section{Samenvatting}

Het proefschrift beschrijft drie sçenario's waarin barrière markt resultaten behaald dan wel benaderd worden. Het toont hiermee aan dat de Bertrand-paradox niet noodzakelijkerwijs een verzoening van prijszetting tegen gemiddelde (en marginale) kosten en investeren in R\&D in de weg staat. In al de scenario's staan elementen van produktinnovatie en -differentiatie centraal. Het proefschrift breidt zodoende de verzameling barrière markt scenario's uit in een nieuwe richting. Beide elementen zijn namelijk tot nu toe nauwelijks bestudeerd [Van Witteloostuijn (1990) is een uitzondering]. De drie scenario's verhogen de robuustheid van het barrière markt concept. Tabel 1 vat de resultaten van de drie theoretische hoofdstukken samen. De drie theoretische hoofdstukken worden aangevuld met een exploratief experimenteel onderzoek [Hoofdstuk 5].

Tabel 1

Een vergelijking van de Hoofdstukken 2, 3 en 4
Analytische
Model-eigenschappen
Resultaten
methodes

2 Speltheorie

Gemiddelde totale kosten constant

Representatieve consument

Geen capaciteitsbeperkingen

Geografisch gescheiden markten

Prijzen benaderen marginale kosten kosten als toetredingskosten dalen Optimale investeringen in R\&D Duplicatie van R\&D inspanningen Markten worden gemonopoliseerd als toetredingskosten laag zijn

3 Micro-economie

Gemiddelde variabele kosten constant

Prijzen benaderen marginale kosten Speltheorie

Horizontaal gedifferentieerde consumenten als Geen capaciteitsbeperkingen Eén (gesegmenteerde) markt

als behoefte aan variêteit daalt

Onderinvestering in R\&D

Alle surplus komt consumenten toe Produkt-differentiatie is optimaal in het limiet-prijs scenario; in het Hotelling scenario ontbreekt zij

4 Speltheorie

Gemiddelde variabele kosten constant

Prijzen benaderen marginale kosten Representatieve consument als spillovers en capaciteit toenemen

In Hoofdstuk 2 is de evenwichtsprijs in de limiet gelijk aan zowel de gemiddelde als de marginale kostprijs. Dit resultaat vloeit voort uit de wijze waarop de kustenstructuur gemodelleerd is. Uit empirisch onderzoek [Scherer en Ross (199())] blijkt dat de gemiddelde totale kosten (van homogene goederen) constant zijn op het relevante interval. ondanks het bestaan van verzonken kosten. Deze observatie is als 
uitgangspunt genomen voor de totale kostenfunctie. De totale kosten TC zijn een lineaire functie van de produktie $\mathrm{S}: \mathrm{TC}=$ ac. $\mathrm{S}$ waar ac de gemiddelde totale kosten voorstelt. De totale kosten TC kunnen onderverdeeld worden in verzonken kosten SC en variabele kosten $\mathrm{VC}=$ ac.S-SC. De marginale kosten zijn dientengevolge op het relevante interval gelijk aan ac, de gemiddelde totale kosten. Aangezien de bedrijven in Hoofdstuk 2 op de prijs concurreren over een homogeen produkt en geen capaciteitsbeperkingen kennen, is de evenwichtsprijs gelijk aan zowel de gemiddelde als de marginale kosten. Hoofdstuk 2 laat zien dat het mogelijk is verzonken kosten te verzoenen met prijzen tegen gemiddelde en marginale kosten.

De verzonken kosten in Hoofdstuk 2 bestaan uit R\&D kosten. De bedrijven doen zowel aan produkt als proces $R \& D$. De prestaties van bedrijven in termen van produkt- en procesinnovaties kunnen om een tweetal redenen verschillen. (1) De uitkomsten van het $R \& D$-proces kunnen van geluk afhankelijk zijn. (2) Bedrijven kunnen verschillen in hun verwachtingen ten aanzien van de innovatie-mogelijkheden. Beide factoren verklaren waarom één bedrijf een ongunstige kwaliteit-kosten-verhouding kan hebben ten opzichte van één of meerdere andere bedrijven. Indien dit het geval is, wordt het ecrstgenoemde bedrijf van zijn thuismarkt verdreven en maakt het zijn R\&D-kosten niet goed, tenzij de toetredingskosten voldoende hoog zijn. De simulaties laten dan ook zien dat bedrijven failliet gaan, indien de toetredingskosten niet hoog genoeg zijn. Zij laten tevens zien dat bedrijuen met een grote achterstand in kwaliteit of gemiddelde kosten niet langer in $R \& D$ investeren, omdat zij verwachten de achterstand niet goed te kunnen maken. Als dit gebeurt. wordt het verschil in de kwaliteit-kosten-verhoudingen steeds groter.

De simulaties laten dus zien dat een bedrijf op een tweetal wijzen een monopoliepositie kan verwerven: (1) Al zijn concurrenten gaan failliet; of (2) het bedrijf verwerft langzamerhand een superieure kwaliteit-kosten-verhouding. Monopolie-vorming vloeit voort uit de onzekerheid rondom het $R \& D$ proces en is afhankelijk van de hoogte van de toetredingskosten. Aangezien monopolie-vorming het consumentensurplus aantast, is het van belang dat een effectieve toetredingsdreiging blijft bestaan. Hiertoe dienen de bedrijven over voldoende hoge toetredingsbelemmeringen te beschikken. De simulaties laten ook zien dat spillovers tussen bedrijven de kwaliteitsen de kostenontwikkeling en dus de maatschappelijke welvaart positief beïnvloeden. Het is van belang onafhankelijke R\&D-processen en spillovers tussen deze processen te bevorderen. Er dient dan ook enige terughoudendheid betracht te worden ten aanzien van beleid dat grenzen stelt aan (gratis) spillovers, zoals patent- en octrooibeleid en wellicht merkenrecht.

Hoofdstuk 3 beschouwt consumenten met verschillende voorkeuren voor produktvariëteit. Dit verschil biedt ruimte voor produkt-differentiatie. Dit laatste biedt een tweede mogelijkheid om de Bertrand-paradox te doorbreken. De veronderstelling van constante gemiddelde totale kosten is dus niet langer nodig. Om deze reden wordt deze veronderstelling vervangen door de (voor heterogene goederen) meer gebruikelijke aanname van constante gemiddelde variabele kosten. Hoofdstuk 3 is gebaseerd op Hotelling's originele model van horizontale differentiatie. Zoals bekend, bestaat er geen eenduidig prijs-evenwicht in dit model [D'Aspremont, Gabszwewicz en Thisse (1979)]. Om dit gebrek te ondervangen, onderscheiden wij twee plausibele uitkom- 
sten en baseren op elke uitkomst een scenario. Het eerste scenario is gebaseerd op Hotelling's originele uitkomst. Dit evenwicht ligt voor de hand, indien de duopolisten elkaars wederzijdse afhankelijkheid onderkennen en het nalaten om de concurrent geheel van de markt te verdrijven. In het tweede scenario doen bedrijven wel pogingen om de concurrent van de markt te verdrijven. Om dit te voorkomen worden limiet-prijzen gezet.

In het Hotelling-scenario is sprake van zwakke prijsconcurrentie, omdat geen pogingen ondernomen worden de concurrent van de markt te verdrijven. Dit geef bedrijven een prikkel om marktaandeel te verwerven door zich in het centrum van de markt te vestigen. Omdat deze prikkel voor beide bedrijven bestaat, worden de produkten niet gedifferentieerd: In het evenwicht is de produkt-differentiatie minimaal. In het limiet prijs-scenario is sprake van scherpe prijsconcurrentie, omdat wel pogingen ondernomen worden de concurrent van de markt te verdrijven. De prijsdruk is sterker naar mate de produkt-variëteiten meer met elkaar overeen komen. Om de prijsdruk te verminderen, passen bedrijven dus enige mate van produkt-differentiatie toe: In het evenwicht is de produkt-differentiatie minimaal noch maximaal. De mate van differentiatie blijkt zelfs optimaal te zijn. Produkt-variëteit kan dus bevorderd worden door prijsconcurrentie te stimuleren.

In beide scenario's worden te weinig middelen in kwaliteitsverbetering gestoken. Dit resultaat is te wijten aan het feit dat kwaliteitsverbeteringen niet lijden tot prijsstijgingen. De bedrijven zijn niet in staat ook maar enig surplus van de innovaties te verwerven. De prijsconcurrentie is hiervoor te scherp. Er wordt dus weliswaar te weinig geïnnoveerd, maar daar staat tegenover dat alle surplus aan de consumenten doorgegeven wordt. In deze zin blijkt concurrentie efficiënt te zijn. Innovaties kunnen enkel gestimuleerd worden door subsidies te verlenen dan wel door een gunstig belasting-regime in te stellen. Private overeenkomsten, zoals Research Joint Ventures (RJVs), bevorderen innovaties alleen, indien prijsovereenkomsten eveneens tot de mogelijkheden behoren. Dit laatste is echter zeer nadelig voor consumenten. De overheid wordt dus voor een klassieke afweging geplaatst: Lage prijzen en weinig produkt-verbeteringen - statische efficiëntie - of hoge prijzen en veel produkt-verbeteringen - dynamische efficiëntie. Indien het belang van de consument vooropgesteld wordt, dient de voorkeur aan prijsconcurrentie gegeven te worden met lage prijzen en weinig innovaties als gevolg. Dit resultaat suggereert dat enige voorzichtigheid betracht dient te worden bij het verlenen van vrijstellingen voor private R\&D-overeenkomsten op basis van artikel 85(3) van het Verdrag van Rome.

De prijzen die in het evenwicht gezet worden, zijn in beide scenario's afhankelijk van de behoefte van consumenten aan produkt-variëteit. De evenwichtsprijzen en innovaties zijn in het limiet prijs-scenario gelijk aan die in het Hotelling-scenario. Qua uitkomsten verschillen beide modellen alleen in termen van produkt-differentiatie. De produkten worden zodanig gedifferentieerd dat de Hotelling-prijzen en innovaties bestand zijn tegen pogingen de markt te monopoliseren. De evenwichtsprijzen wijken meer van de marginale kosten af naar mate de behoefte aan produktvariëteit groter is. Dit betekent dat naar mate produkten meer met elkaar overeenkomen in de ogen van consumenten, de prijs dichter bij de marginale kosten ligt. De bruto- en de netto-winsten van de duopolisten nemen af, indien de behoefte van 
consumenten aan produkt-variëteit afneemt. In de limiet worden dus barrière markt resultaten benaderd.

In hoofdstuk 3 worden ook nog twee vormen van asymmetrie bestudeerd. De eerste asymmetrie betreft een verschil in de initiële kwaliteiten. De voorsprong stelt de leider in staat een groter marktaandeel te verwerven ten koste van de volger, ceteris paribus. De R\&D-kosten per consument zijn voor de leider dientengevolge lager dan voor de volger. De leider investeert dientengevolge meer dan in het symmetrische evenwicht, de volger minder. Het kwaliteitsverschil wordt groter door de tijd: Er bestaat een natuurlijke tendens tot monopolisering. In het asymmetrische duopolie stijgt de kwaliteit sneller dan in het symmetrische duopolie, terwijl de prijsconcurrentie sterk blijft. Consumenten-surplus en bedrijfstak-winsten worden groter, naar mate de asymmetrie stijgt. Dominante posities zijn voordelig voor het welzijn van consumenten, zolang er prijsdruk blijft bestaan. Volgers zijn in staat prijsdruk te blijven uitoefenen, indien er markt-niches zijn die benut kunnen worden door middel van produkt-differentiatie.

De tweede bron van asymmetrie betreft een verschil in informatie over het R\&Dproces. Zittende, dominante ondernemingen hebben in het verleden meer R\&D ondernomen dan kleine ondernemingen - toetreders of bedrijven met een kwaliteitsachterstand - in zijn dus in staat de R\&D-kosten beter in te schatten. Omdat de R\&D-kosten convex verlopen, schatten kleine bedrijven de R\&D-kosten optimistisch in. Dit heeft tot gevolg dat kleine bedrijven overinvesteren ten opzichte van zittende, dominante ondernemingen. Indien de overinvesteringen klein van omvang zijn, hebben zij nauwelijks invloed op de netto-winst van kleine bedrijven vanwege de eerste orde-voorwaarde. Zij hebben echter een sterke negatieve invloed op de netto winst van zittende, dominante ondernemingen. Kleine bedrijven maken dus door de bank genomen meer winst. Zij hebben dus een grotere kans het concurrentie-proces te overleven. Door de overinvestering kunnen de kleine bedrijven zittende, dominante ondernemingen zelfs voorbijstreven [leapfrogging]. Deze resultaten tonen het belang van aanverwante markten aan voor een effectieve toetredingsdreiging. Bedrijven uit aanverwante markten zijn de meest waarschijnlijke kandidaten voor kleine achterstandsposities. De resultaten stroken met de gedachte van creatieve vernietiging.

De toetredingsdreiging in de Hoofdstukken 2 en 3 wordt niet belemmerd door het bestaan van capaciteitsbeperkingen. In Hoofdstuk 4 worden de implicaties van deze veronderstelling nader bestudeerd door capaciteitsbeperkingen te introduceren. De kostenstructuur in hoofdstuk 4 komt overeen met die in hoofdstuk 3. De Bertrandparadox wordt in hoofdstuk 4 doorbroken door het bestaan van kwaliteitsverschillen. De concurrentie gaat in Hoofdstuk 4 uit van bedrijven in aanverwante markten. Deze bedrijven kunnen een soortgelijke kwaliteit aanbieden als de zittende onderneming. Het kwaliteitsverschil verschaft zittende ondernemingen de mogelijkheid bruto-winsten te maken waaruit de R\&D-uitgaven bekostigd kunnen worden. De bruto-marge in Hoofdstuk 3 vloeide niet voort uit kwaliteitsverschillen, maar uit de behoefte (en het bestaan van) aan produkt-variëteit. Aangezien consumenten-heterogeniteit geen rol behoeft in Hoofdstuk 4, wordt wederom van een representatieve consument uitgegaan.

Hoofdstuk 4 beschrijft twee technisch verwante markten. De goederen die op 
beide markten verkocht worden, zijn geen substituten in consumptie. Beide markten worden elk bezet door één zittende onderneming. De ondernemingen beschikken over een grotere capaciteit dan nodig om de thuismarkt te bedienen; de capaciteit is echter niet noodzakelijkerwijs voldoende om beide markten tegelijkertijd te voorzien. De capaciteit kan benut worden om produkten op beide markten af te zetten. De ondernemingen kunnen beide in de kwaliteit van het produkt op de thuismarkt investeren. Indien zij dit doen, zijn zij tevens in staat op de anverwante markt een produkt met een hogere kwaliteit aan te bieden. De kwaliteitsverbetering op de markt van de concurrent is niet groter dan die van de concurrent. De kwaliteitsverbetering op de aanverwante markt vloeit voort uit een spillover binnen het bedrijf. Dit laatste geeft het belang aan van het bestaan van meerdere aanwendingsmogelijkheden van technologische kennis.

In Hoofdstuk 4 wordt de aandacht geconcentreerd op de vraag onder welke voorwaarden bedrijven beide limietprijzen zetten. Een bedrijf ziet af van een limietprijs-strategie, indien de monopolie-winst op de residuele vraag die resulteert na toetreding, groter is. Bedrijven zetten limietprijzen, indien de spillovers laag zijn en de reserve-capaciteit groot. Als de spillovers laag zijn, is het kwaliteitsverschil groot en de bruto marge hoog. Indien de reserve-capaciteit groot is, zijn residuele vraag en bruto-winst in geval van toetreding laag. In dat geval wordt de voorkeur aan de limietprijs-strategie gegeven. Indien de spillovers hoog zijn en de reserve-capaciteit klein, is de monopolie-winst over de residuele vraag groter dan de winst uit limietprijzen. Beide bedrijven hebben een prikkel om de limietprijs-strategie te laten varen. Omdat beide bedrijven hun volledige capaciteit willen benutten, willen zij beide hun concurrent onderprijzen. Zij hebben er echter ook belang bij onderprijzing door de concurrent te voorkomen: Er bestaan alleen asymmetrische Nash-evenwichten waarin beide bedrijven prijzen zetten die de limietprijs te boven gaan. De bedrijven hebben dus een coördinatieprobleem. In geval van prijsleiderschap wordt dit probleem ondervangen.

De bedrijven besluiten als volgt over investeringen in produkt $R \& D$, indien het winstgevend is limietprijzen te zetten, als beide bedrijven geïnvesteerd hebben in $R \& D$. Beide bedrijven investeren, indien de R\&D-kosten lager zijn dan de te behalen bruto-winst. Beide bedrijven zien van investeringen af, indien de R\&D-kosten de bruto-winst van een monopolist te boven gaat. Indien investering alleen voordelig is voor één bedrijf, staan de bedrijven voor een dilemma. Investeren is alleen voordelig, indien de concurrent dit nalaat. Dit dilemma kan voorkomen worden door technologieën te ruilen. Deze kunnen zo geruild worden dat de kwaliteitsverschillen en de bruto-winsten toenemen. Dit stelt beide bedrijven mogelijkerwijs in staat te investeren. Dit laatste is van belang voor consumenten vanwege de prijsdruk die ontstaat, indien bedrijven soortgelijke produkten op de markt kunnen brengen. Er is dus wederom een afruil tussen statische en dynamische efficiëntie. Hoge spillovers veroorzaken lage bruto-marges. Dit is voordelig voor consumenten, indien beide bedrijven in R\&D investeren. Lage spillovers stellen bedrijven in staat de R\&D-kosten terug te verdienen. Dit prikkelt beide bedrijven tot investeren. Consumenten zijn met dit laatste gebaat. aangezien zij alleen surplus verwerven, indien beide bedrijven investeren. Bedrijven kunnen ook om toerbeurt investeren. Dit laatste resulteert in 
monopolie-winsten en verdient vanuit het oogpunt van consumenten dus geen aanbeveling.

De spillovers betreffen effecten binnen het bedrijf, maar kunnen eveneens geinterpreteerd worden als zijnde effecten tussen bedrijven. Indien bruto-winsten in het algemeen te laag zijn om de R\&D-uitgaven te dekken. verdient beleid dat spillovers tussen bedrijven verlaagt, aanbeveling. Hierbij valt te denken aan patent- en octrooibeleid en wellicht merkenrecht. Indien bruto-winsten te hoog zijn, verdient dergelijk beleid aanscherping.

Hoofdstuk 5 test de uitkomsten van Hoofdstuk 2 met behulp van een drietal experimenten. In al deze experimenten spelen de subjecten een reeks twee-perioden concurrentie-spelen. In de eerste periode van deze spelen nemen de spelers een beslissing over de kwaliteit van het produkt. Zij hebben hierbij twee keuzes: Een lage kwaliteit of een hoge kwaliteit. De keuze voor de hoge kwaliteit gaat gepaard met R\&D kosten, de keuze voor de lage kwaliteit niet. De kwaliteitsbeslissing is in alle spelen gelijktijdig genomen. Deze beslissingen worden bekend gemaakt, voordat de prijzen bepaald dienen te worden. In de experimenten 1 en 2 hebben de subjecten eveneens twee keuzes ten aanzien van de prijzen: Een lage prijs of een hoge prijs. In het eerste experiment wordt hierover simultaan beslist, in het tweede experiment sequentieel. In het derde experiment worden de spelers (geheel) vrij gelaten in hun prijsgedrag. De prijzen worden in dit experiment gelijktijdig bepaald. E hoge kwaliteit is in alle drie de spelen de evenwichtsstrategie. In de experimenten 1 en 2 zijn beide prijsstrategieën - laag en hoog - evenwichtsstrategieën. In het derde experiment is de kostprijs de evenwichtsstrategie.

In alle drie de experimenten kiezen de spelers inderdaad voor het produkt met de hoge kwaliteit. In de experimenten 1 en 2 worden monopolie-prijzen gezet. In experiment 3 is een benedenwaartse trend voor de prijs waar te nemen. Het resultaat voor de experimenten 1 en 2 valt te wijten aan de opzet van deze experimenten. Deze spelen zijn met name opgezet om te onderzoeken of studenten in staat zijn om te gaan met de complexe twee perioden structuur van de spelen. De experimenten 1 en 2 doen dan ook niet geheel recht aan het Bertrand karakter van prijsconcurrentie in Hoofdstuk 2. Het is niet geheel verbazingwekkend dat de prijzen hoog zijn in beide experimenten, aangezien de beperking van de keuze-mogelijkheden samenwerking kartelvorming - bevordert. Dit feit heeft tevens de samenwerking in het derde experiment vergemakkelijkt vanwege de volgorde waarin de experimenten gespeeld zijn: Het derde experiment is gespeeld na het eerste experiment. De onbekende tijdshorizon is eveneens niet voordelig voor barrière markt resultaten. Gegeven de prikkels om kartels te vormen, is de tendentie naar competitieve prijzen in het derde spel opmerkclijk. In toekomstig onderzoek dient het belang van het volgorde-effect nader bestudeerd te worden.

Hoofdstuk 5 geeft ook aan dat er belangrijke verschillen in competitief gedrag zijn tussen typen personen. Sommige type personen vertonen sociaal wenselijk competitief - gedrag, anderen niet. De resultaten van dit type analyses hebben mogelijkerwijs gevolgen voor toekomstig onderwijs-, emancipatie-, arbeidsmarkt- en concurrentic-beleid. Logistische regressies tonen aan dat externe individuen competitiever zijn dan interne individuen, lage zelf-beheersers meer dan hoge zelf-beheer- 
sers, mannen meer dan vrouwen en jongeren meer dan ouderen. Koppel-analyses geven aan dat externe individuen en type-B personen zich competitiever gedragen. Zij laten ook zien dat gemengde koppels coöperatiever zijn dan koppels mannen of vrouwen. Koppels mannen worden minder competitief door de tijd heen, koppels vrouwen daarentegen competitiever. Met betrekking tot sensatie-zucht geldt eveneens dat gemengde koppels coöperatiever zijn. In het algemeen dient benadrukt te worden dat gemengde koppels (minder) coöperatief kunnen zijn dan homogene koppels.

De samenvatting geeft aan dat barrière markt resultaten vaker behaald of benaderd worden dan wellicht gedacht wordt met het oog op de Bertrand paradox. Enige bescheidenheid blijft echter op zijn plaats, aangezien het proefschrift niet meer bevat dan drie (specifieke) theorieën op het gebied van de Industriële Organisatie. Theorieën op dit terrein mogen veel gemeen hebben; dit heeft echter geen betrekking op de behaalde resultaten. Resultaten op dit terrein zijn in het algemeen zeer gevoelig voor aspecten als ondernemingsstrategie en tijdsstructuur [Shapiro (1989)]. In Hoofdstuk 6 wordt echter aangetoond dat de modellen in dit proefschrift enige robuustheid genieten. De oproep tot voorzichtigheid neemt ook niet weg dat de modellen voorwaarden aangeven waaronder prijszetting tegen gemiddelde (en marginale) kosten gecombineerd kan worden met investeringen in produktinnovaties. 



\section{Curriculum vitae}

Frank Bunte is op 26 juli 1968 geboren te Tegelen. In 1986 behaalde hij het diploma Gymnasium- $\alpha$ aan het Collegium Marianum te Venlo. Van september 1986 tot en met september 1991 studeerde hij Economische Wetenschappen aan de Universiteit van Maastricht (UM) - destijds Rijksuniversiteit Limburg geheten. Na zijn studie is hij 10 maanden lang als Toegevoegd Docent werkzaam geweest aan dezelfde instelling. In die periode schreef hij een rapport over de lokale - Maastrichtse arbeidsmarkt. In maart 1995 heeft hij als Onderzoeker hier nog een rapport aan toegevoegd. In juli 1992 trad Frank in dienst als Assistent in Opleiding, eveneens aan de UM. In de periode tot en met juli 1996 schreef hij het onderliggende proefschrift. In de zomer van 1995 verbleef hij twee maanden aan de Universiteit van St Andrews waar hij onder begeleiding van John Beath en Gavin Reid nader vorm gaf aan zijn promotie-onderzoek. In september en oktober 1996 was Frank deeltijds als docent aan de UM verbonden. Sinds 1 november 1996 is hij in dienst bij het Landbouw Economische Instituut (LEI) te Den Haag. 